
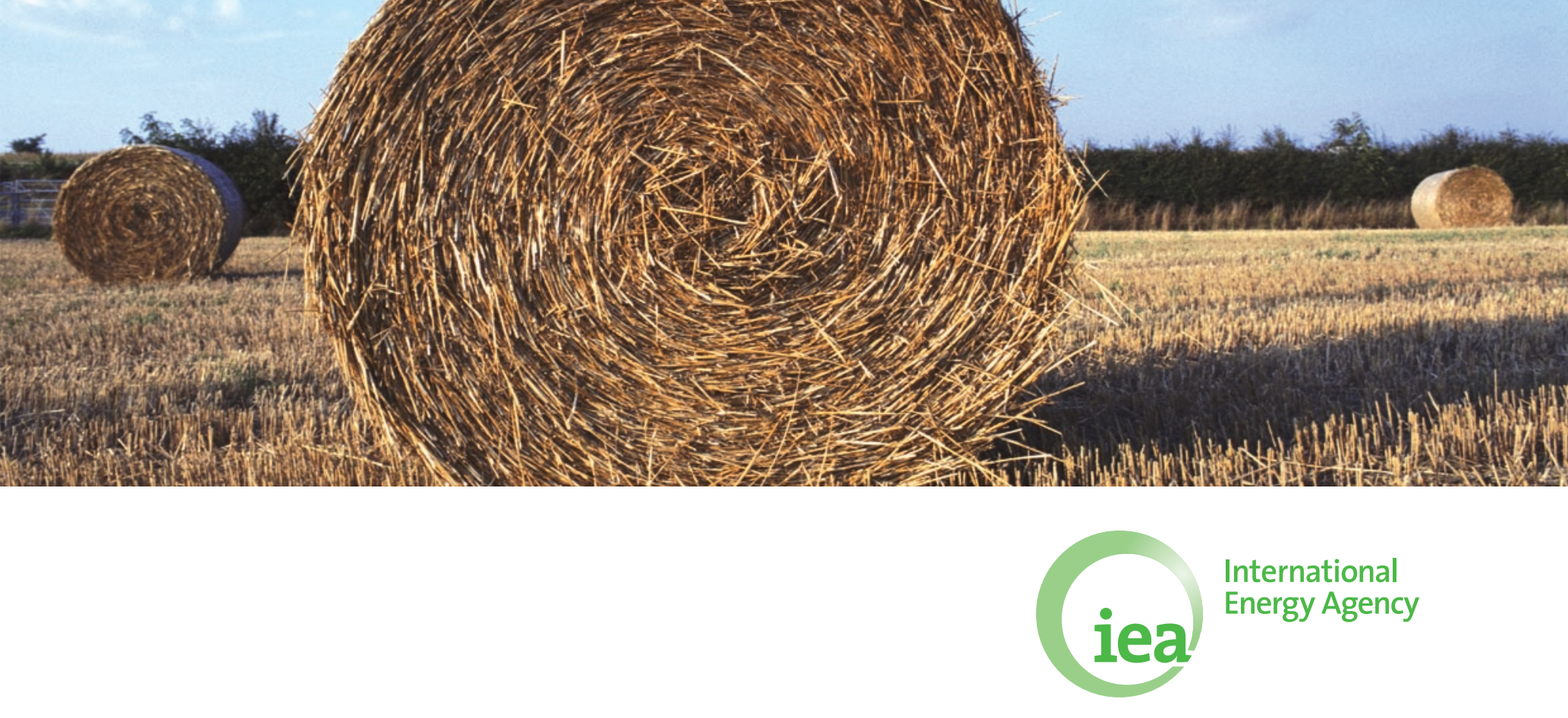

\title{
SUSTAINABLE PRODUCTION OF SECOND-GENERATION BIOFUELS
}

Potential and perspectives in major economies and developing countries

INFORMATION PAPER 
The International Energy Agency (IEA), an autonomous agency, was established in November 1974. Its mandate is two-fold: to promote energy security amongst its member countries through collective response to physical disruptions in oil supply and to advise member countries on sound energy policy.

The IEA carries out a comprehensive programme of energy co-operation among 28 advanced economies, each of which is obliged to hold oil stocks equivalent to 90 days of its net imports. The Agency aims to:

- Secure member countries' access to reliable and ample supplies of all forms of energy; in particular, through maintaining effective emergency response capabilities in case of oil supply disruptions.

- Promote sustainable energy policies that spur economic growth and environmental protection in a global context - particularly in terms of reducing greenhouse-gas emissions that contribute to climate change.

- Improve transparency of international markets through collection and analysis of energy data.

- Support global collaboration on energy technology to secure future energy supplies and mitigate their environmental impact, including through improved energy

efficiency and development and deployment of low-carbon technologies.

- Find solutions to global energy challenges through engagement and dialogue with non-member countries, industry, international organisations and other stakeholders.

IEA member countries:

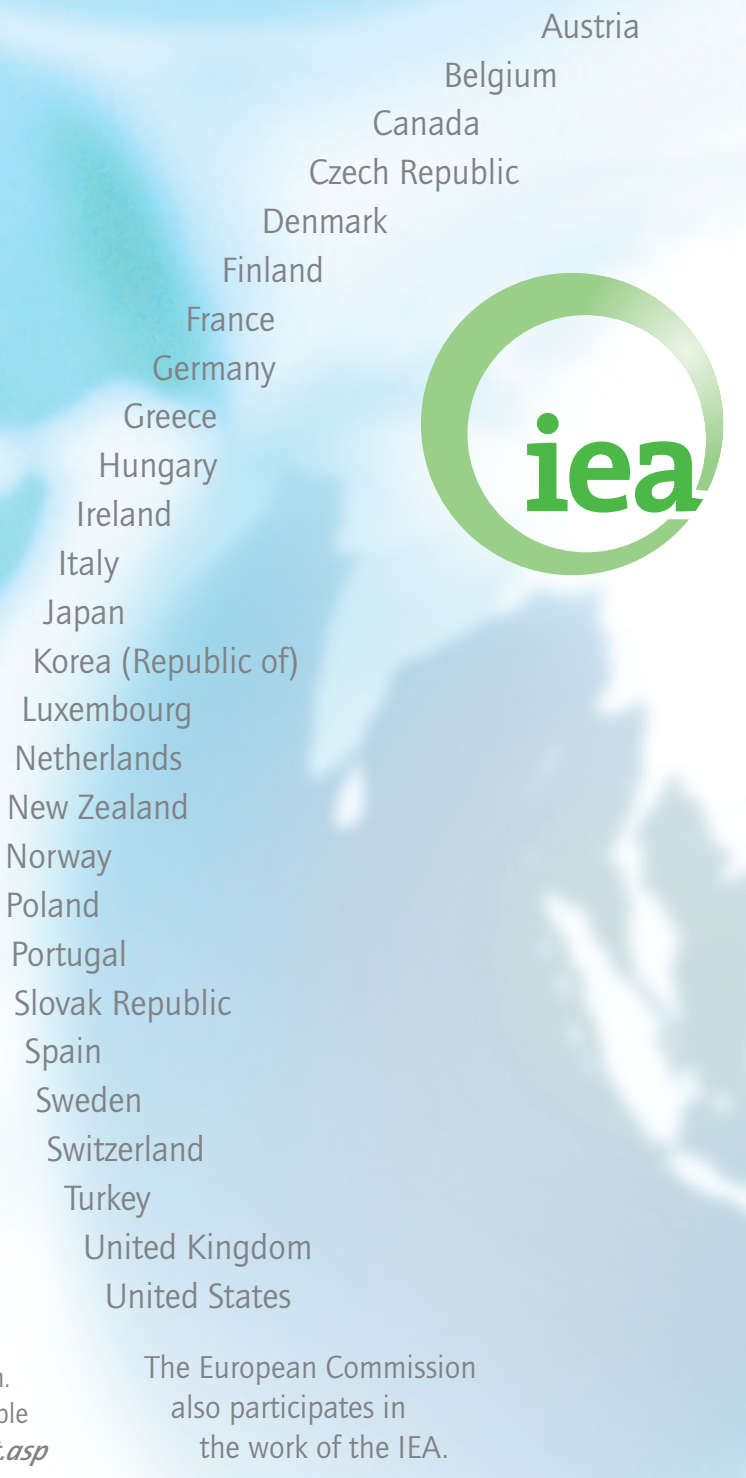

\section{(c) OECD/IEA, 2010 \\ International Energy Agency \\ 9 rue de la Fédération \\ 75739 Paris Cedex 15, France}

Please note that this publication is subject to specific restrictions that limit its use and distribution. The terms and conditions are available online at www.iea.org/about/copyright.asp
International Energy Agency

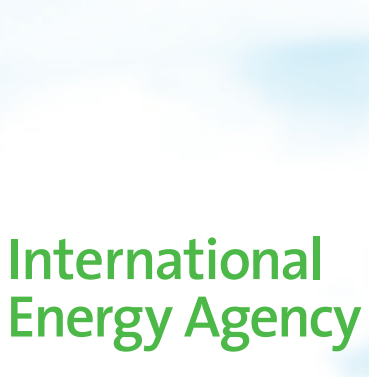




\title{
SUSTAINABLE PRODUCTION OF SECOND-GENERATION BIOFUELS
}

\author{
Potential and perspectives in major economies \\ and developing countries
}

This paper was drafted by the IEA Renewable Energy Division. This paper reflects the views of the IEA Secretariat and may not necessarily reflect the views of the individual IEA member countries. For further information on this document, please contact Anselm Eisentraut, Renewable Energy Division at: anselm.eisentraut@iea.org 



\section{Acknowledgements}

The lead author and co-ordinator of this report is Anselm Eisentraut, Biofuels Researcher with the Renewable Energy Division of the International Energy Agency (IEA). The study also draws on contributions of Franziska Mueller-Langer, Jens Giersdorf and Anastasios Perimenis of the German Biomass Research Centre (DBFZ), who provided parts of the sustainability chapter and four country profiles commissioned by the Deutsche Gesellschaft für Technische Zusammenarbeit (GTZ). Dr. Antonio Pflüger, former head of the IEA Energy Technology Collaboration Division as well as Dr. Paolo Frankl, head of the Renewable Energy Division, and Dr. Mike Enskat, Senior Programme Manager for Energy at GTZ, provided guidance and input. Several IEA colleagues also provided useful data and comments on the draft, in particular Ralph Sims, Lew Fulton, Michael Waldron, Pierpaolo Cazzola, Francois Cuenot, Timur Gül, Ghislaine Kieffer and Yasmina Abdeliah.

This publication was carried out in close cooperation between IEA and GTZ and has been funded by GTZ on behalf of the German Federal Ministry for Economic Cooperation and Development (BMZ). Raya Kühne, Thomas Breuer and Thorben Kruse coordinated the GTZ contribution.

A number of consultants contributed to the country profiles in Annex A of this study, including Suani T. Coelho, Patricia Guardabassi and Beatriz A. Lora (Biomass Useres Network do Brazil, Brazil); Luis Antonio Carrillo (Delegation Provinciale MINFOF/MINEP, Cameroon); Zhao Lixin, Yishui Tian and Meng Haibo (Institute of Energy and Environmental Protection, China); Rajeev K. Sukumaran and Ashok Pandey (National Institute for Interdisciplinary Science and Technology, India); Manuela Prehn and Enrique Riegelhaupt (Red Mexicana de Bioenergia, Mexico); Graham P. von Maltitz and Martina R. van der Merwe (Council for Scientific and Industrial Research, South Africa); G.R. John and C.F. Mhilu (College of Engineering and Technology of the University of Dar-es-Salaam, Tanzania); and Werner Siemers (Joint Graduate School of Energy and Environment (JGSEE) at King Mongkut's University of Technology Thonburi, Thailand).

A number of experts participated in the project workshop held on February 9-10, 2009 in Paris and several reviewers provided valuable feedback and input to this publication:

Amphol Aworn, National Innovation Agency, Thailand; Jacques Beaudry-Losique, US Department of Energy, United States; Rick Belt, Ministry of Resources, Energy and Tourism, Australia; Luis Carillo, MINFOF/MINEP, Cameroon; Chatchawan Chaichana, Chang Mai University, Thailand; Annette Cowie, University of New England, Australia; Ricardo de Gusmao Dornelles, Ministry of Mines and Energy, Brazil; Annie Dufey, Fundacion Chile, Chile; André Faaij, Copernicus Institute, The Netherlands; Luis Pérez Fernández, IDAE, Spain; Willem van der Heul, Ministry of Economic Affairs, The Netherlands; Dunja Hoffmann, GTZ, Germany; Martin von Lampe, OECD, France; Manoel Regis Lima Verde Leal, CTBE, Brazil; Carlos Fernández López, IDAE, Spain; Thembakazi Mali, SANERI, South Africa; Terry McIntyre, Environment Canada, Canada; Hendrik Meller, GTZ, Germany; John Neeft, Senter Novem, The Netherlands; David Newman, Endelevu Energy, Kenya; Martina Otto, UNEP, France; Ashok Pandey, NIIST, India; Jayne Redrup, Department of Energy and Climate Change, United Kingdom; Jonathan Reeves, GBEP, Italy; Boris Reutov, FASI, Russia; Jack Saddler, University of British Columbia, Canada; Angela Seeney, Shell International, UK; Joseph Spitzer, Joanneum Research, Austria; Pradeep Tharakan, Asian Development Bank, Phillippines; Brian Titus, Natural Resources Canada, Canada; John Tustin, IEA Bioenergy, New Zealand.

For questions and comments please contact:

\section{Anselm Eisentraut}

Renewable Energy Division

International Energy Agency

Tel. +33 (0)1 40576767 anselm.eisentraut@iea.org 



\section{Table of Contents}

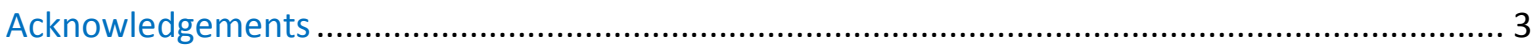

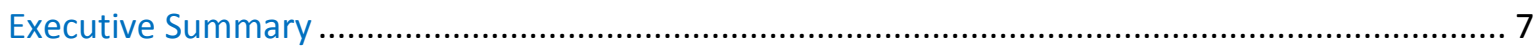

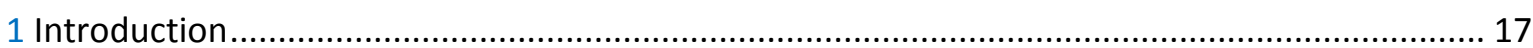

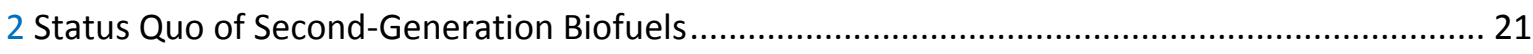

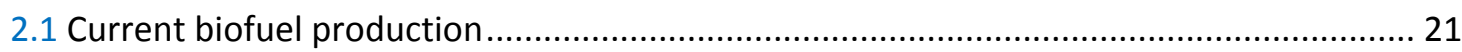

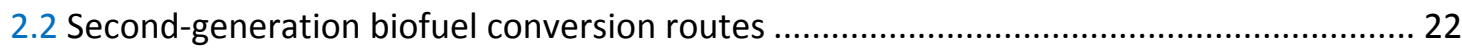

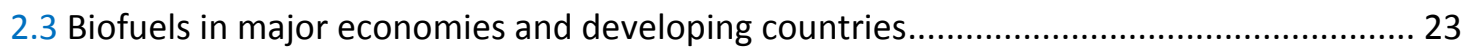

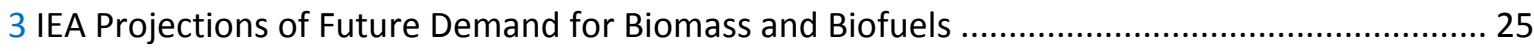

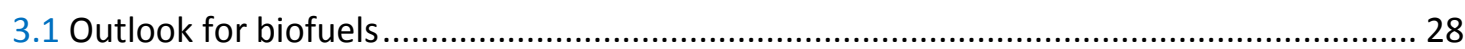

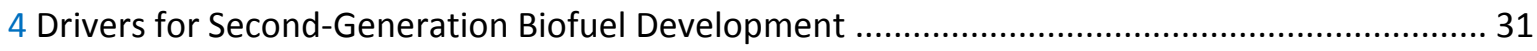

4.1 Biofuel support policies for second-generation biofuels ................................................. 32

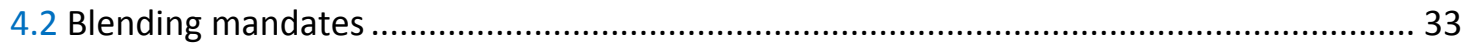

4.3 Implications on global biofuel demand and trade opportunities for developing countries . 34

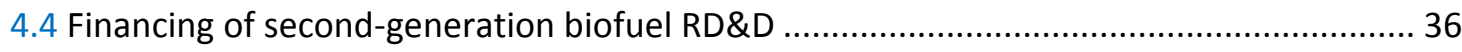

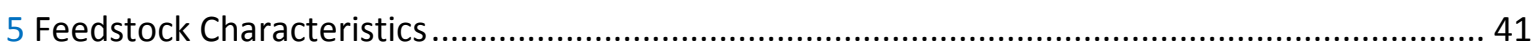

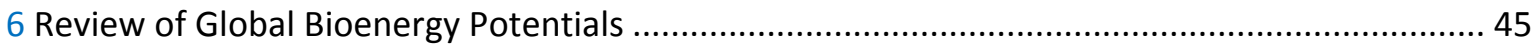

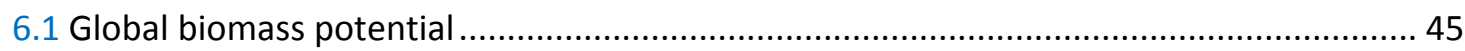

6.2 Potential for dedicated energy crops from surplus land .................................................. 47

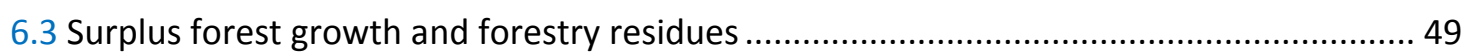

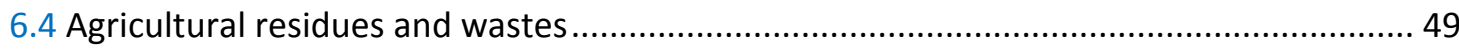

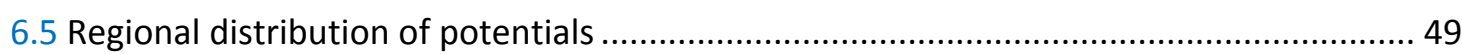

6.6 Discussion of results based on the current situation in selected countries ........................ 53

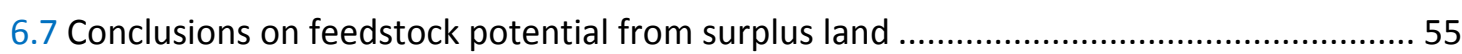

7 Potential Second-Generation Biofuel Production from Agricultural and Forestry Residues ........ 57

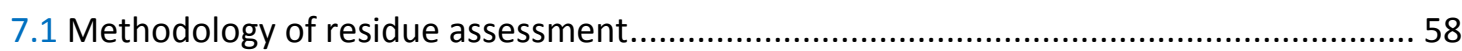

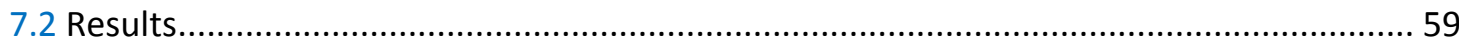

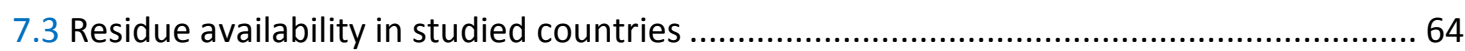

8 Sustainability of Second-Generation Biofuel Production in Developing Countries .......................67

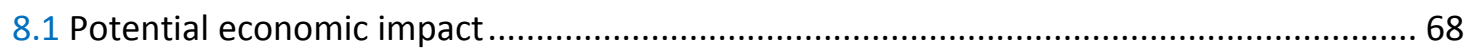

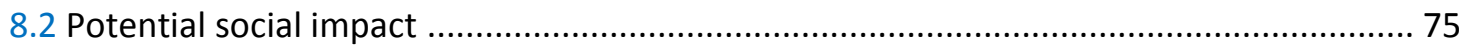

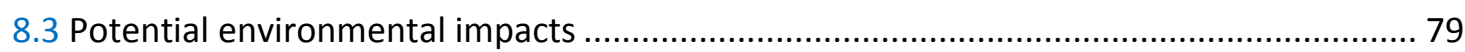

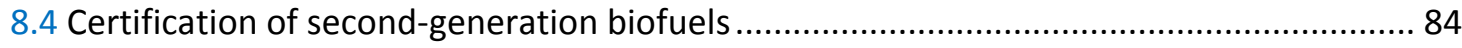

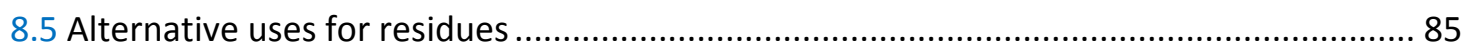

8.6 Recommendations to ensure sustainability of second-generation biofuels ...................... 87

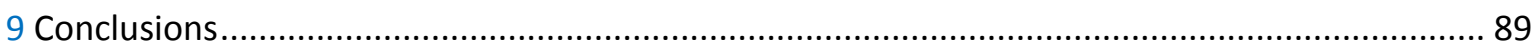




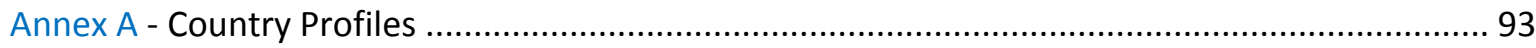

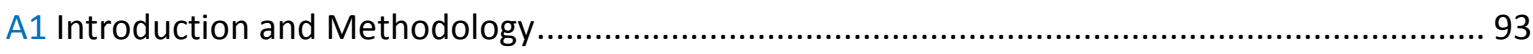

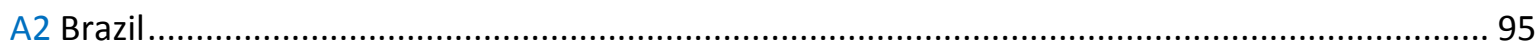

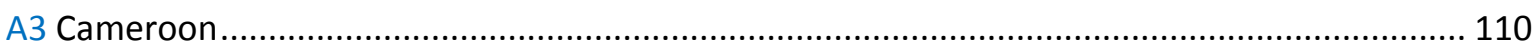

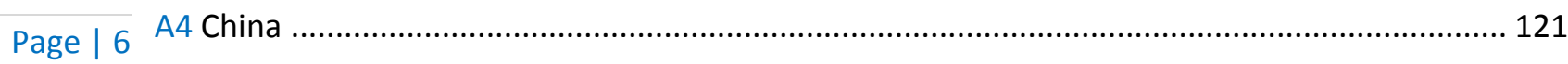

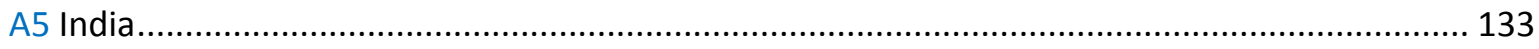

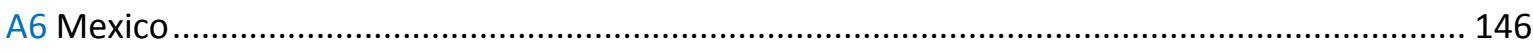

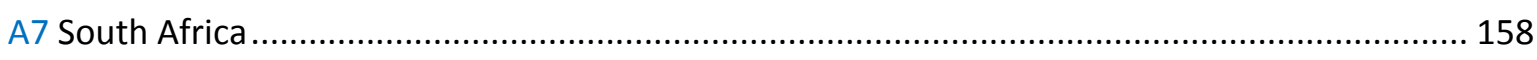

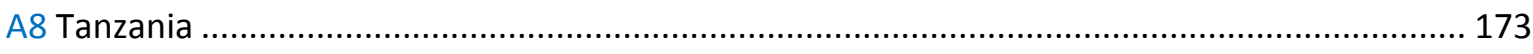

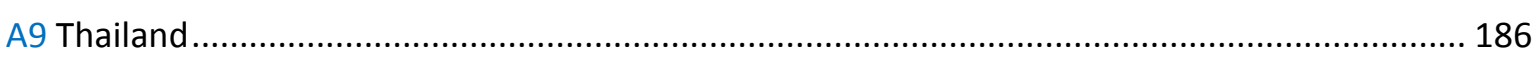

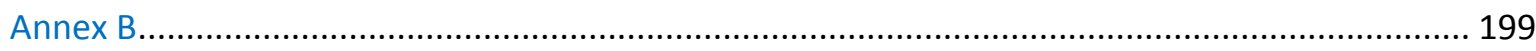

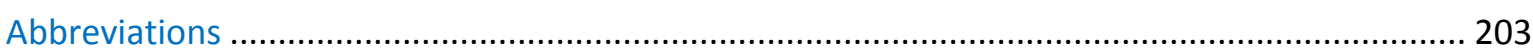

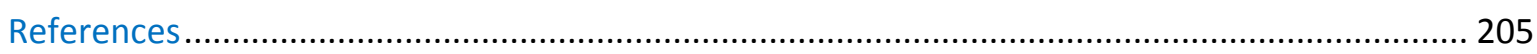




\section{Executive Summary}

\section{Context}

Global biofuel production has been increasing rapidly over the last decade, but the expanding biofuel industry has recently raised important concerns. In particular, the sustainability of many first-generation biofuels - which are produced primarily from food crops such as grains, sugar cane and vegetable oils - has been increasingly questioned over concerns such as reported displacement of food-crops, effects on the environment and climate change.

In general, there is growing consensus that if significant emission reductions in the transport sector are to be achieved, biofuel technologies must become more efficient in terms of net lifecycle greenhouse gas (GHG) emission reductions while at the same time be socially and environmentally sustainable. It is increasingly understood that most first-generation biofuels, with the exception of sugar cane ethanol, will likely have a limited role in the future transport fuel mix.

The increasing criticism of the sustainability of many first-generation biofuels has raised attention to the potential of so-called second-generation biofuels. Depending on the feedstock choice and the cultivation technique, second-generation biofuel production has the potential to provide benefits such as consuming waste residues and making use of abandoned land. In this way, the new fuels could offer considerable potential to promote rural development and improve economic conditions in emerging and developing regions. However, while second-generation biofuel crops and production technologies are more efficient, their production could become unsustainable if they compete with food crops for available land. Thus, their sustainability will depend on whether producers comply with criteria like minimum lifecycle GHG reductions, including land use change, and social standards.

Research-and-development activities on second-generation biofuels so far have been undertaken only in a number of developed countries and in some large emerging economies like Brazil, China and India. The aim of this study is, therefore, to identify opportunities and constraints related to the potential future production of second-generation biofuels and assess the framework for a successful implementation of a second-generation biofuel industry under different economic and geographic conditions. Therefore, eight countries have been analysed in detail: Mexico, four major non-OECD economies (Brazil, China, India and South Africa), and three developing countries in Africa and South-east Asia (Cameroon, Tanzania and Thailand). The study further assesses the potential of agricultural and forestry residues as potential feedstock for second-generation biofuels. The results of this study help answer what contribution second-generation biofuels from residues could make to the future biofuel demand projected in IEA scenarios, and under which conditions major economies and developing countries could profit from their production.

\section{Second-generation biofuels: potential and perspectives}

Second-generation biofuels are not yet produced commercially, but a considerable number of pilot and demonstration plants have been announced or set up in recent years, with research activities taking place mainly in North America, Europe and a few emerging countries (e.g. Brazil, China, India and Thailand). Current IEA projections see a rapid increase in biofuel demand, in particular for second-generation biofuels, in an energy sector that aims on stabilising atmospheric $\mathrm{CO}_{2}$ concentration at 450 parts per million (ppm). 
The World Energy Outlook 2009 (IEA, 2009a) 450 Scenario $^{1}$ projects biofuels to provide 9\% (11.7 EJ) of the total transport fuel demand (126 EJ) in 2030. In the Blue Map Scenario ${ }^{2}$ of Energy Technology Perspectives 2008 (IEA, 2008b) that extends analysis until 2050, biofuels provide 26\% (29 EJ) of total transportation fuel (112 EJ) in 2050, with second-generation biofuels accounting for roughly $90 \%$ of all biofuel. More than half of the second-generation biofuel production in the Blue Map Scenario is

Page 18 projected to occur in non-OECD countries, with China and India accounting for $19 \%$ of the total production.

\section{Drivers for second-generation biofuel development}

Ambitious biofuel support policies have recently been adopted in both the United States (with 60 billion litres of second-generation biofuel by 2022) and the European Union (with $10 \%$ renewable energy in the transport sector by 2020). Due to the size of the two markets and their considerable biofuel imports, the US and EU mandates could become an important driver for the global development of second-generation biofuels, since current IEA analysis sees a shortfall in domestic production in both the US and EU that would need to be met with imports (IEA, 2009b). Regarding second-generation biofuels, this shortfall could be particularly favourable for Brazil and China, where pilot plants are already operating and infrastructure allows for biofuel exports. In other countries, like Cameroon and Tanzania, the lack of R\&D activities combined with poor infrastructure and shortage of skilled labour form considerable obstacles to being able to profit from second-generation biofuel demand in the EU and US in the near future.

Feedstock trade, however, could be an option for these countries to profit from a growing biomass market for second-generation biofuels outside their own borders, since requirements for financing and skilled labour are smaller. Biomass production could also attract foreign investment, and obtained profits could be invested into the rural sector, thereby helping develop feedstock cultivation and handling skills. However, constraints like infrastructure and smallholder interests might make domestic use of lignocellulosic feedstocks (e.g. for electricity production) more beneficial than their export.

\section{Review of global bioenergy potentials and perspectives for second- generation biofuel production}

To produce second-generation, considerable amounts of biomass have to be provided, which will require an analysis of existing and potential biomass sources well before the start-up of large-scale production. In recent studies, bioenergy potentials differ considerably among different regions; the main factor for large biomass potentials is the availability of surplus agricultural land, which could be made available through more intensive agriculture.

Expert assessments in the reviewed studies varied greatly, from $33 \mathrm{EJ} / \mathrm{yr}$ in 2050 (Hoogwijk et al., 2003) assuming that mainly agricultural and forestry residues are available for bioenergy production. In the most ambitious scenario (Smeets et al., 2007), the bioenergy potential reaches

\footnotetext{
${ }^{1}$ This scenario models future energy demand in light of a global long-term $\mathrm{CO}_{2}$ concentration in the atmosphere of

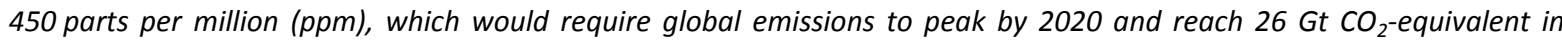
2030, 10\% less than 2007 levels. The total global primary energy demand would then reach $14389 \mathrm{Mtoe}$ (604 EJ) in 2030.

${ }^{2}$ This scenario models future energy demand until 2050, under the same target as the WEO 450-Scenario (i.e. a long-term concentration of 450ppm $\mathrm{CO}_{2}$ in the atmosphere). Global primary energy demand in this scenario reaches 18025 Mtoe. (750 EJ) in 2050.
} 
roughly $1500 \mathrm{EJ} / \mathrm{yr}$ in 2050 . The scenario assumes availability of $72 \%$ of current agricultural land for biofuel production, mainly through increased yields and more intensive animal farming.

In the reviewed studies large potentials are often estimated in developing regions like Latin America or Sub-Saharan Africa, where agricultural productivity is currently low. Compared to the current situation in the eight countries in the project, some of the expert scenarios reviewed appear very ambitious. Brazil currently seems to be the only country with considerable potential to sustainably produce energy crops for second-generation biofuel production, mainly on underutilised pasture land. In many of the other countries (e.g. Cameroon, India, Tanzania, Thailand) significant investments in technological improvement, new infrastructure and capacity building are needed to increase the productivity and sustainability of the agricultural sector. This could allow dedicate agricultural land to second-generation feedstock production in the future.

\section{Potential contribution of lignocellulosic residues for production of second-generation biofuels}

The constraints related to the availability of additional land suggest that second-generation biofuel industries should focus on currently available feedstock sources in the initial phase of the industry's development. Agricultural and forestry residues form a readily available source of biomass and can provide feedstock from current harvesting activities without need for additional land cultivation.

To assess the potential for lignocellulosic-residues, this study presents two scenarios in which $10 \%$ and $25 \%$ of global forestry and agricultural residues, respectively, are assumed to be available for biofuel production. The remaining residues could still be used for other uses, including fodder, organic fertiliser or domestic cooking fuel. The amount of residues is calculated on the basis of annual production data as indicated in the FAOStat database (FAOStat, 2009), using ratios of residue to main product (RPR) as indicated by Fischer et al. (2007). To assess available residues in 2030 , increases in agricultural production $(1.3 \% / \mathrm{yr})$ and roundwood consumption $(1.1 \% / \mathrm{yr})$ were adopted from the FAO (2003).

Results of IEA assessment ${ }^{3}$ show that considerable amounts of second-generation biofuels could be produced using agricultural and forestry residues:

- $10 \%$ of global forestry and agricultural residues in 2007 could yield around 120 billion lge (4.0 EJ) of BTL-diesel or lignocellulosic-ethanol and up to 172 billion Ige (5.7 EJ) of bio-SNG. This means that second-generation biofuels could provide $4.2-6.0 \%$ of current transport fuel demand.

- $\mathbf{2 5 \%}$ of global residues in the agricultural and forestry sector could even produce around 300 billion Ige (10.0 EJ) of BTL-diesel or lignocellulosic-ethanol, equal to $10.5 \%$ of current transport fuel demand. Bio-SNG could contribute an even greater share: $14.9 \%$ or 429 billion lge (14.4 EJ) globally if a sound distribution infrastructure and vehicle fleet were made available (Figure 1).

\footnotetext{
${ }^{3}$ Average biofuel yields (based on IEA, 2008a) applied are: 214 lge/ton dry matter ( $\left.t_{D M}\right)$ for cellulosic-ethanol and
} 217 Ige/t $t_{D M}$ for biomass-to-liquid (BTL) diesel, 307 Ige/t $t_{D M}$ for bio-synthetic natural gas (bio-SNG). 
Figure 1. Theoretical second-generation biofuel production from residues in 2007

Page | 10

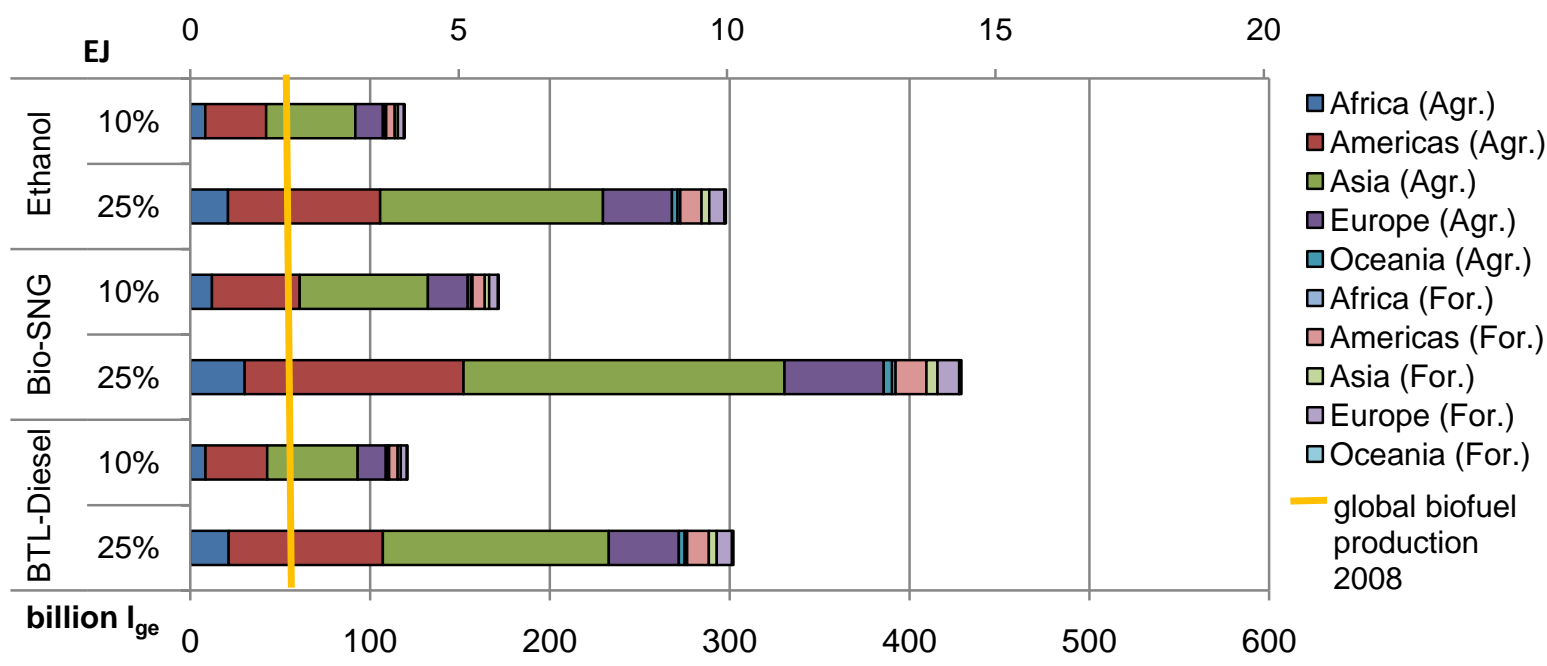

Amounts cannot be summed up. Each bar indicates biofuel yields using all available residues. "25\%" and "10\%" assume respective shares of agricultural and forestry residues to be available for biofuel production.

Assumed conversion factors: BTL-Diesel - 217 lge/ $\mathrm{t}_{\mathrm{DM}}$, Ethanol - 214 lge/ $\mathrm{t}_{\mathrm{DM}}, \mathrm{Bio}-\mathrm{SNG}-307$ lge/ $\mathrm{t}_{\mathrm{DM}}$

In 2030 , compared to 2007 , residue production increases by roughly $28 \%$ for crop sources and by $50 \%$ for roundwood:

- $10 \%$ of global residues could then yield around 155 billion Ige (5.2 EJ) BTL-diesel or lignocellulosic-ethanol, or roughly $4.1 \%$ of the projected transport fuel demand in 2030 . The conversion to bio-SNG could even produce 222 billion lge (7.4 EJ), or around $5.8 \%$ of total transport fuel. This means that second-generation biofuels using $10 \%$ of global residues could be sufficient in meeting $45-63 \%$ of total projected biofuel demand ( 349 bn lge) in the WEO 2009450 Scenario.

- $\mathbf{2 5 \%}$ of global residues converted to either LC-Ethanol, BTL-diesel or Bio-SNG could contribute 385-554 billion Ige (13.0-23.3 EJ) globally (Figure 2). These amounts of secondgeneration biofuels are equal to a share of $10.3-14.8 \%$ of the projected transport fuel demand in 2030, and could fully cover the entire biofuel demand projected in the WEO 2009450 Scenario.

Considering that roughly two-thirds of the potential is located in developing countries in Asia, Latin America and Africa, including these countries in the development of new technologies will be especially important.

However, since the agricultural sector in many developing countries differs significantly from that in the OECD, a better understanding of material flows is a key aspect to ensure the sustainability of second-generation biofuel production. More detailed country and residue-specific studies are still needed to assess the economic feasibility of collecting and pre-processing agricultural and forestry residues. 
Figure 2. Theoretical second-generation biofuel production from residues in 2030

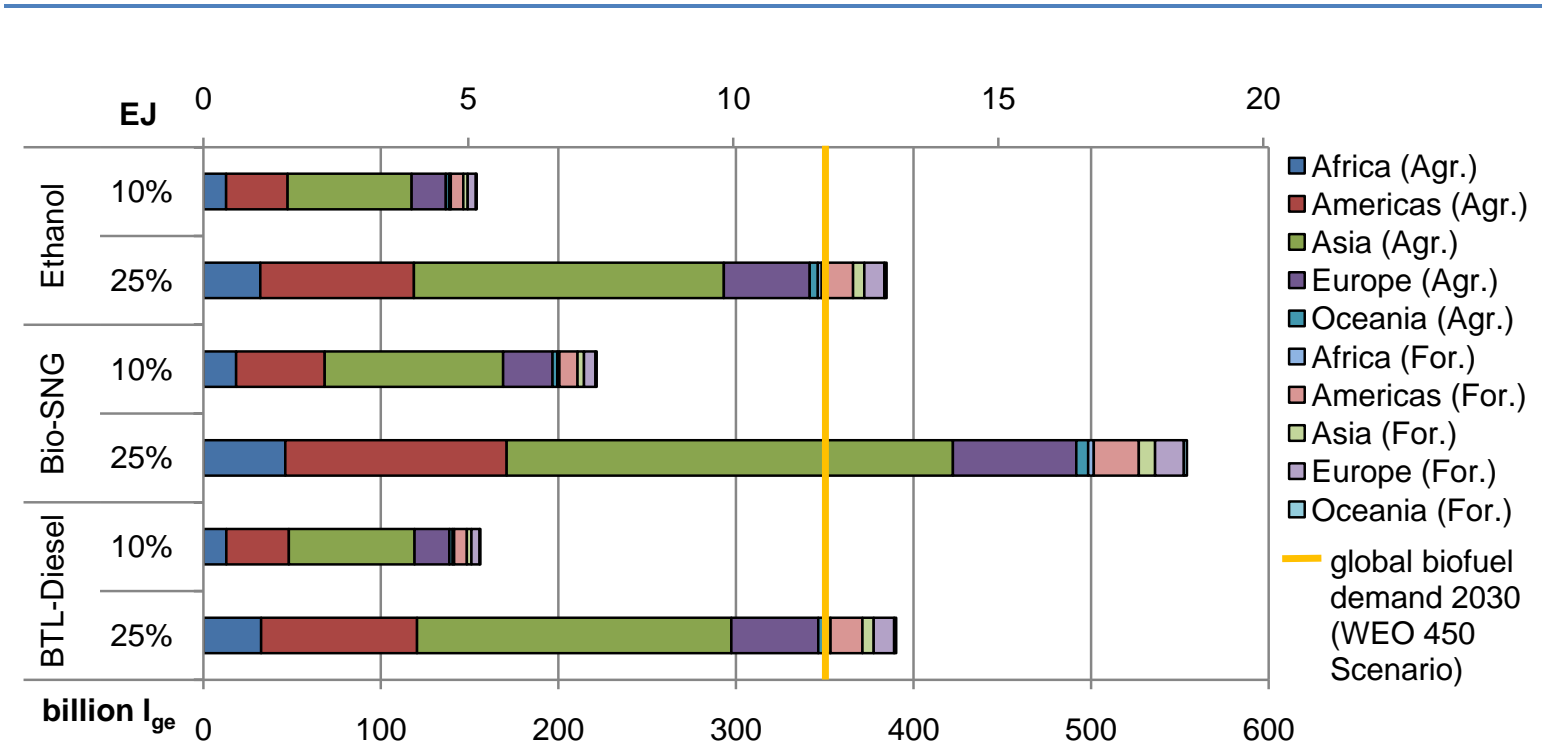

Amounts cannot be summed up. Each bar indicates biofuel yields using all available residues. "25\%" and "10\%" assume respective shares of agricultural and forestry residues to be available for biofuel production.

Assumed conversion factors: BTL-Diesel - 217 Ige/ $t_{D M}$, Ethanol - 214 lge/ $t_{D M}, B i o-S N G-307$ Ige/ $t_{D M}$

\section{Sustainability of second-generation biofuel production}

So far, no experience with commercial production of second-generation biofuels yet exists. In particular, in developing countries it will be a challenge to balance large-scale industrial development with small-scale local value chains, which would be required to ensure environmental, economical and social sustainability.

\section{Potential economic impacts}

Financing of commercial second-generation biofuel plants (USD 125-250 million) should not be a problem in most of the studied countries (Brazil, China, India, South Africa, Mexico and Thailand), since foreign direct investment could be received in addition to domestic funding. However, for less developed countries like Cameroon and Tanzania, the required investment costs could be a bottleneck, since domestic funding possibilities are limited and significant administrative and governance problems may considerably reduce the willingness of foreign companies to undertake large investments in these countries.

The large biomass demand (up to $600000 \mathrm{t} / \mathrm{yr}$ ) for a commercial second-generation biofuel plant requires complex logistics systems and good infrastructure to provide biomass at economically competitive costs. This is a particular challenge in the rural areas of the studied countries where poor infrastructure, as well as complex land property structure and the predominance of small land holdings increase the complexity of feedstock logistics (e.g. in Cameroon, India, South Africa and Tanzania).

The assessment of opportunity costs for residues from the agricultural and forestry sector is difficult due to the absence of established markets for these material flows. Data accuracy on costs is generally better when residues are used commercially (e.g. bagsse that is burned for heat and 
electricity production) than if they are used in the informal sector (e.g. as domestic cooking fuel, organic fertiliser or animal fodder). In cases where feedstock costs were indicated by local experts in the studied countries, they were often reasonably small compared to dedicated energy crops. Thus, residues are an economically attractive feedstock for second-generation biofuel production.

Comparably low feedstock prices, in the range of USD 1-8/GJ, were indicated for Brazil, China, India,

Page 12 Mexico, South Africa and Thailand. Using the latest IEA production cost analysis, theoretical production costs for second-generation biofuels from straw or stalks are currently in the range of USD 0.60-0.79/Ige in South Africa and up to USD 0.86/Ige in India and China (Table 1). This is still high compared to the reference gasoline price of USD 0.43/lge (i.e. oil at USD 60/bbl), but in the long term, technology improvement, higher conversion efficiencies and better transport logistics could bring costs close to the gasoline reference, if costs for feedstocks would remain stable.

Table 1. Theoretical production price for second-generation biofuels in selected countries

\begin{tabular}{|l|l|c|c|c|}
\hline \multirow{2}{*}{\multicolumn{2}{|l|}{ oil price: USD 60/bbl }} & Feedstock price* & \multicolumn{2}{|c|}{ USD/Ige } \\
\cline { 3 - 5 } $\begin{array}{l}\text { Woody energy } \\
\text { crops }\end{array}$ & global (IEA analysis) & USD/GJ & Btl-diesel & Ic-Ethanol \\
\hline \multirow{5}{*}{ Straw/stalks } & China & $1.9-3.7$ & $0.66-0.79$ & $0.68-0.85$ \\
\cline { 2 - 5 } & India & $1.2-4.3$ & $0.62-0.80$ & $0.63-0.86$ \\
\cline { 2 - 5 } & Mexico & 3.1 & 0.74 & 0.79 \\
\cline { 2 - 5 } & South Africa & $0.8-3.1$ & $0.6-0.74$ & $0.6-0.79$ \\
\cline { 2 - 5 } & Thailand & $2.0-2.8$ & $0.67-0.72$ & $0.67-0.77$ \\
\hline
\end{tabular}

*Note that feedstock prices reflect assumptions by local experts and might vary regionally

Assumed cost factors are: capital costs: $50 \%$ of the total production costs; feedstock is $35 \%$; operation and maintenance (O\&M), energy supply for the plant and others between 1-4\% each.

Source: Based on IEA analysis presented in Transport, Energy and $\mathrm{CO}_{2}$ (IEA, 2009c)

Overall, production of second-generation biofuels based on agricultural residues could be beneficial to farmers, since it would add value to these by-products. This could reduce the necessity to support farmers and smallholders in countries where the agricultural sector is struggling and investment is urgently needed, such as in Tanzania and Cameroon. However, these are the countries in which limited financing possibilities, poor infrastructure and a lack of skilled labour are currently constraining establishment of a second-generation biofuel industry.

\section{Potential social impact}

Job creation and regional growth will probably be the most important drivers for the implementation of second-generation biofuel projects in major economies and developing countries. The potential for creation of jobs along the value-chain varies depending on the feedstock choice. Use of dedicated energy crops will create jobs in the cultivation of the feedstock, whereas the use of residues will have limited potential to create jobs since existing farm labour could be used. The following conclusions regarding labour were found for the countries included in this study: 
- Sufficient labour for feedstock cultivation and transport could be provided in all of the studied countries.

- Highly skilled engineers for the biofuel conversion are only abundant in Mexico and in the large emerging countries with experience in other energy industries or first-generation biofuel production (i.e. Brazil, China, India, South Africa).

- Significant capacity building would be required in Cameroon, Tanzania, and to a certain extent in Thailand, to successfully adopt second-generation biofuel technologies.

A large constraint regarding the social impact of feedstock production is the occupation of arable land for energy crop cultivation and thus competition with current agricultural production. Except for Brazil (see section on environmental impact), data on land use in the studied countries is often poor and land use management strategies rarely exist. Displacement of smallholders might thus occur if large-scale land acquisition is not planned carefully. This is a concern particularly in Africa (e.g. Cameroon and Tanzania), where land ownership is often not secured. An assessment of actual available land will be required to avoid that second-generation biofuel production from dedicated energy crops would cause the same negative social impact as some first-generation biofuel projects.

These concerns are comparably small for the utilisation of agricultural and forestry residues as second-generation biofuel feedstock. The use of residues could provide an additional source of income in the agricultural and forestry sector with positive impact on local economies and rural development. However, constraints exist that increasing opportunity costs could affect farmers or rural population that is depending on residues as animal fodder or domestic fuel. Therefore, more research on regional markets has to be undertaken to evaluate the potential social impacts of increased competition for agricultural and forestry residues.

The use of second-generation biofuels to provide energy access in rural areas seems currently unlikely due to high production costs and the need for large-scale production facilities. Other bioenergy options like electricity production are technically less demanding and require less capital investment, and could thus be more effective in promoting rural development, as has been successfully demonstrated for instance in China, India, Tanzania and Cameroon.

\section{Potential environmental impacts and GHG balances}

The environmental impact of second-generation biofuel production varies considerably depending on the conversion route as well as the feedstock and site-specific conditions (climate, soil type, crop management, etc.).

An important driver for biofuel promotion is the potential to reduce lifecycle $\mathrm{CO}_{2}$ emissions by replacing fossil fuels. Currently available values indicate a high GHG mitigation potential of 60$120 \%^{4}$, similar to the $70-110 \%$ mitigation level of sugarcane ethanol (IEA, 2008c) and better than most current biofuels. However, these values do not include the impact of land use change (LUC) $)^{5}$ that can have considerable negative impact on the lifecycle emissions of second-generation biofuels and also negatively impact biodiversity.

To ensure sustainable production of second-generation biofuels, it is therefore important to assess and minimise potential iLUC caused by the cultivation of dedicated energy crops. This deserves a careful mapping and planning of land use, in order to identify which areas (if any) can be potentially

\footnotetext{
${ }^{4}$ An improvement higher than $100 \%$ is possible because of the benefits of co-products (notably power and heat).

${ }^{5}$ Two types of land use change exist: direct LUC occurs when biofuel feedstocks replace native forest for example; indirect LUC (iLUC) occurs when biofuel feedstocks replace other crops that are then grown on land with high carbon stocks.
} 
used for bioenergy crops. The following land-use issues and insights were found for the countries included in this study:

- Brazil is the only of the studied countries that has initiated a programme (ZAE Cana) to direct available land to the production of biofuel feedstock in order to stop deforestation and indirect land use change. The programme currently focuses on sugarcane, but it could also be applied to other biofuel feedstocks.

- In particular in India and Thailand, pressure on cropland is already so high that biofuel expansion requires careful planning.

- In South Africa, complex land ownership and the current insecurity about the government's land reform are the main constraints for the utilisation of some $3 \mathrm{Mha}$ of land that have been identified as potentially available.

If residues are used as feedstock, the issue of iLUC is of less importance, since no additional land needs to be cultivated. This is also reflected in recent policies like the California Low Carbon Fuel Standard. The use of residues for biofuel production could only cause iLUC when current use (e.g. as fodder or fuel wood) is replaced by crops that are grown on additional land.

\section{Impact on soil, water and biodiversity}

Feedstock plantations for second-generation biofuels are usually perennial tree or grass species, the cultivation of which can have a number of positive impacts:

- The year-round cover provided by perennial tree or grass species can increase the water retention capacity of the soil.

- Perennial plantations can also considerably reduce the impact of erosion through wind and water, which is a considerable benefit compared to annual feedstocks. This would be particularly advantageous on vulnerable soils like the loess plateau in China, or tropical soils in Thailand.

- Soil carbon stock can be increased through both roots and leaf litter.

However, there are drawbacks to using perennial tree or grass species:

- Little research on indigenous lignocellulosic crops has been undertaken in Asia or Africa. Therefore, constraints exist to prevent potentially invasive crop species from being introduced to these regions when biomass demand for second-generation biofuel production increases.

- Experiences in South Africa and other countries show that non-native species can become a severe threat for local biodiversity.

The use of residues is bound by different constraints, since biomass is taken away from the site rather than added. Using secondary residues as feedstock is expected to have only little negative impact on the environment, since these residues are usually not returned to the field. The use of primary residues, however, could lead to nutrient extraction that has to be balanced with synthetic fertilisers to avoid decreasing productivity.

The access to freshwater is a growing concern in many of the studied countries (e.g. China, India, South Africa). Therefore, feedstock sources like agricultural and forestry residues that do not require irrigation should be given priority in these countries, and water requirements during the biofuel production process (e.g. $4-8 \mathrm{I}_{\text {water }} / \mathrm{l}_{\text {ethanol }}$ for cellulosic ethanol) need to be considered carefully. 


\section{Conclusions}

\section{Key messages from this study}

- There is a considerable potential for the production of second-generation biofuels. Even if only $10 \%$ of the global agricultural and forestry residues were available in 2030 , about half of the forecasted biofuel demand in the World Energy Outlook 2009450 Scenario could be covered - equal to around $5 \%$ of the projected total transport fuel demand by that time.

- To ensure a successful deployment of second-generation biofuels technologies requires intensive RD\&D efforts over the next 10-15 years.

- The technical development will mainly take place in OECD countries and emerging economies with sufficient RD\&D capacities like Brazil, China and India.

- In many developing countries, the framework conditions needed to set up a second-generation biofuel industry are not currently sufficient. The main obstacles that need to be overcome include poor infrastructure, lack of skilled labour and limited financing possibilities.

- Investments in agricultural production and infrastructure improvements would promote rural development and can significantly improve the framework for a second-generation biofuel industry. This will allow developing countries to enter second-generation biofuel production once technical and costs barriers have been reduced or eliminated.

- The suitability of second-generation biofuels for countries' respective needs has to be evaluated against other bioenergy options. This should be part of an integrated land use and rural development strategy, to achieve the best possible social and economic benefits.

- Capacities should then be built slowly but continuously in order to avoid bottlenecks when the new technologies become technically available and economically feasible. To ensure technology access and transfer, co-operation on RD\&D between industrialised and developing countries as well as among developing countries should be enhanced.

- Agricultural and forestry residues should be the feedstock of choice in the initial stage of the production, since they are readily available and do not require additional land cultivation.

- More detailed research is still needed to ensure that second-generation biofuels will provide economic benefits for developing countries. This research includes a global road map for technology development, an impact assessment of commercial second-generation biofuel production, and improved data on available land. Additionally, more case studies could enable further analyses of local agricultural markets, material flows, and specific social, economical and environmental benefits and risks in developing countries.

\section{Research gaps and next steps}

It is still too early to fully assess the potential social, economic and environmental impacts of largescale second-generation biofuel production in practice. The following research steps are suggested to understand better the potential and impact of second-generation biofuels in developing countries and emerging economies:

- Creation of a global road map for second-generation biofuels, to enable governments and industry to identify steps needed and to implement measures to accelerate the required technology development and uptake. 
- Set-up of pilot and demonstration plants outside the OECD in order to develop supply chain concepts, assess feedstock characteristics, and analyse production costs in different parts of the world.

- Collection of field data from commercial second-generation biofuel production from residues to better understand impacts on agricultural markets and the overall economic situation in developing countries.

- Improved data accuracy on sustainably available land in developing countries to determine the potential for dedicated energy crops. 


\section{Introduction}

Biomass is the oldest source of energy and currently accounts for roughly $10 \%$ of total primary energy consumption. While traditional biomass in form of fuel wood still is the main source of bioenergy, liquid biofuel production has shown rapid growth during the last decade. Considering the important role of biomass for energy production and its increasing importance in the transport sector, the IEA in 2007 established an informal Bioenergy Workplan of Action to undertake detailed studies on biomass utilisation and the production of bioenergy and biofuels. In November 2008, the first part of this workplan was accomplished through the study From $1^{\text {st }}$ - to $2^{\text {nd }}$-Generation Biofuel Technologies (IEA, 2008a; http://www.iea.org/textbase/papers/2008/2nd_Biofuel_Gen.pdf). That study provides an overview of the current industry, including research, development and demonstration activities, and described the state of the art of second-generation biofuel technologies. The present study forms the second step of the above-mentioned workplan and focuses on the potential for the sustainable production of second-generation biofuels in major economies and developing regions.

In 2008, global biofuel production reached about 83 billion litres, a more than fourfold increase compared to 2000 production volumes. This amount currently contributes about $1.5 \%$ of global transport fuel consumption, with demand projected to rise steadily over the coming decades (IEA, 2009a). While the United States and the European Union are amongst the largest producers of biofuel, emerging and developing countries increased their share to about $40 \%$ of total production. Brazil, China and Thailand are currently the largest producers outside the OECD region.

During recent years, the production of many first-generation biofuels has faced heavy criticism regarding its sustainability. On the one hand, rises in agricultural commodity prices have spurred discussions as to which extent first-generation biofuels can be produced without endangering food production. On the other hand, the release of GHG associated with land use changes led to controversial discussions on the effectiveness of first-generation biofuels to reduce global carbon emissions. Despite the fact that some of the currently produced biofuels are performing well in terms of economic and environmental sustainability, ongoing debates shifted focus onto secondgeneration biofuels, which are based on non-edible biomass and promise to avoid the sustainability concerns related to current biofuel production.

Virtually all currently produced biofuel can be classified as first-generation, whereas secondgeneration biofuel production is in the demonstration stage with the first commercial plants expected to start production within a few years. So far, RD\&D activities are mainly taking place in industrialised countries; thus, questions arise when and to what extent will developing regions be able to adopt the new technologies, and whether sustainable production of second-generation biofuels is feasible in these countries. Currently, production of high-quality second-generation biofuels is not seen as priority in most developing countries, where the access to basic energy supply, like electricity and clean cooking fuels (in particular in rural areas), is more urgent than the supply of clean transport fuels. However, biofuels are associated with considerable benefits, including the potential to reduce import dependency for oil and diversify energy supply. Using lignocellulosic-biomass as feedstock, second-generation biofuels could avoid competition with food production and at the same time increase income opportunities, especially in the agricultural sector. In this way, the new fuels could offer considerable potential to promote rural development and increase the overall economic situation in emerging and developing regions.

While first-generation biofuel options for developing countries have already been discussed in previous studies (e.g. UNEP, 2009), the IEA in co-operation with the GTZ, decided to assess 
opportunities and risks related to the production of second-generation biofuels. Following up on a review study of first- and second-generation biofuel technologies undertaken jointly by the IEA Secretariat and IEA Bioenergy Task 39 in 2008, this report aims to evaluate the framework for a sustainable production of second-generation biofuels in major economies and developing countries. The aim of this publication is to highlight what role second-generation biofuels could play to

Page | 18 promote rural development in these regions, point out needs for further research on this topic, and to provide recommendations to national and international policy makers. For this reason, eight countries have been selected to study the framework for an implementation of second-generation biofuels under different economic and geographical conditions. The chosen countries include Mexico, four large emerging economies (Brazil, China, India and South Africa), as well as developing countries in Africa and south-east Asia (Cameroon, Tanzania, Thailand); detailed profiles of these countries are presented in Annex A.

This study first discusses the global status quo of second-generation biofuels and their potential role in the future energy supply. Next, the study identifies global drivers for the development of this new industry and their impact on developing and emerging countries. The potential impact of biofuel mandates in the European Union and the United States on second-generation biofuel development in developing and emerging countries is analysed, as is the access to funding for second-generation R\&D in these countries. This report then reviews recent studies on bioenergy potentials to point out key factors that impact the potential production of biomass for use as bioenergy. The scenarios and the assumptions made are compared to the current situation in the eight studied countries in order to evaluate how realistic the scenarios might be and what key barriers exist to mobilise large amounts of biomass for the production of second-generation biofuels.

Based on the expectation that agricultural and forestry residues could be the most sustainable feedstock for second-generation biofuels, an availability assessment is undertaken to explore what role this feedstock could play in global transport fuel supply. Using crop and roundwood production data from the FAO, the production of residues and technically feasible second-generation biofuel yields are assessed for 2007 and 2030. Amounts of biofuels are calculated under two assumptions: one, that $25 \%$ of all residues are available, as indicated in previous studies; the other, that only $10 \%$ of residues could be used sustainably, as has been indicated in some of the studied countries. The results are then discussed in light of the country profiles to assess the economic, social and environmental impacts of second-generation biofuel production in major economies and developing countries.

The country profiles presented in Annex A of this study assess the current state of the art of biofuel production and perspectives on second-generation biofuels. This includes the assessment of agricultural and forestry residues and their availability for second-generation biofuel production. The political framework for such a new industry is also discussed, as are sustainability aspects related to a future production of the new fuels. The country profiles were conducted in close collaboration with local consultants to ensure access to the best available data. Due to the scale of the project, analyses undertaken in the country profiles are based on existing data; no primary research has been undertaken.

The overall objectives of this study are to:

- Describe the current situation of second-generation biofuel technologies in major economies and developing countries.

- Identify global drivers for the development of these new technologies and their impact on emerging economies. 
- Point out some key factors and main barriers for large-scale production of biomass in developing countries based on a literature review.

- Assess the potential that agricultural and forestry residues could have for the production of second-generation biofuels and what contribution they could make to the future biofuel demand projected in IEA scenarios.

- Analyse whether second-generation biofuel production can help major economies and Page | 19 developing countries to create additional income opportunities and drive rural development in a sustainable way.

- Provide suitable information for use by international policy makers and stakeholders in the selected countries. 



\section{Status Quo of Second-Generation Biofuels}

\section{Key messages}

- Biofuel production in 2008 reached around 83 billion litres, of which 68 billion litres were ethanol and 15 billion litres biodiesel. This was virtually all first-generation biofuel based mostly on sugarcane and corn, and to a lesser extent on canola, sunflowers and other agricultural feedstocks.

- Investments in R\&D of second-generation biofuels are significant in the US, EU, and other OECD countries, and some companies have announced they will start commercial production within the next years.

- Only a few emerging economies like Brazil, China and India have started to invest in second-generation biofuels and set up pilot plants. However, other emerging and most developing countries are not currently developing a second-generation biofuel industry.

\subsection{Current biofuel production}

Currently the transportation sector produces about $25 \%$ of global energy-related $\mathrm{CO}_{2}$ emissions and accounts for roughly $50 \%$ of global oil consumption (IEA, 2008b). Biofuels are seen as one of the most feasible options for reducing carbon emissions in the transport sector, along with improvements in fuel efficiency and electrification of the light vehicle fleet. For heavy-duty vehicles, marine vessels and airplanes in particular, biofuels will play an increasing role to reduce $\mathrm{CO}_{2}$ emissions since electric vehicles and fuel cells are not feasible for these transport modes.

Over the last decade, global biofuel production increased rapidly; in 2008, about 68 billion litres of bioethanol and 15 billion litres of biodiesel were produced globally (Figure 3) - almost all of which was first-generation biofuel (mainly in the form of ethanol from sugar cane and corn) (IEA, 2009b). The United States is currently the largest biofuel producer, followed by Brazil and the European Union. While corn-based ethanol is dominating domestic production in the United States, Brazil produces ethanol mainly from sugar cane. In the European Union, biodiesel accounts for the major share of total biofuel production and is mainly derived from oil crops (canola and sunflower) as feedstock.

While the production of first-generation biofuels is in an advanced state regarding both processing and infrastructure, second-generation technologies are mainly in a pilot or demonstration stage and are not yet operating commercially. The main obstacle for second-generation biofuels is high initial investment costs as well as higher costs for the end-product compared to fossil fuels or many firstgeneration biofuels.

Though investments in R\&D are significant in certain OECD countries (see Chapter 3), it remains uncertain when second-generation biofuels will become commercially competitive. Some companies have reported they will start commercial production of second-generation biofuels within the coming years (CHOREN, 2008; POET, 2009), but they will still depend on subsidies to be economically viable for some years to come. The WEO 2009450 Scenario therefore projects that second-generation biofuels will not penetrate the market on a fully commercial scale earlier than 2015 (IEA, 2009a). 
Figure 3. Global biofuel production $2000-2008$

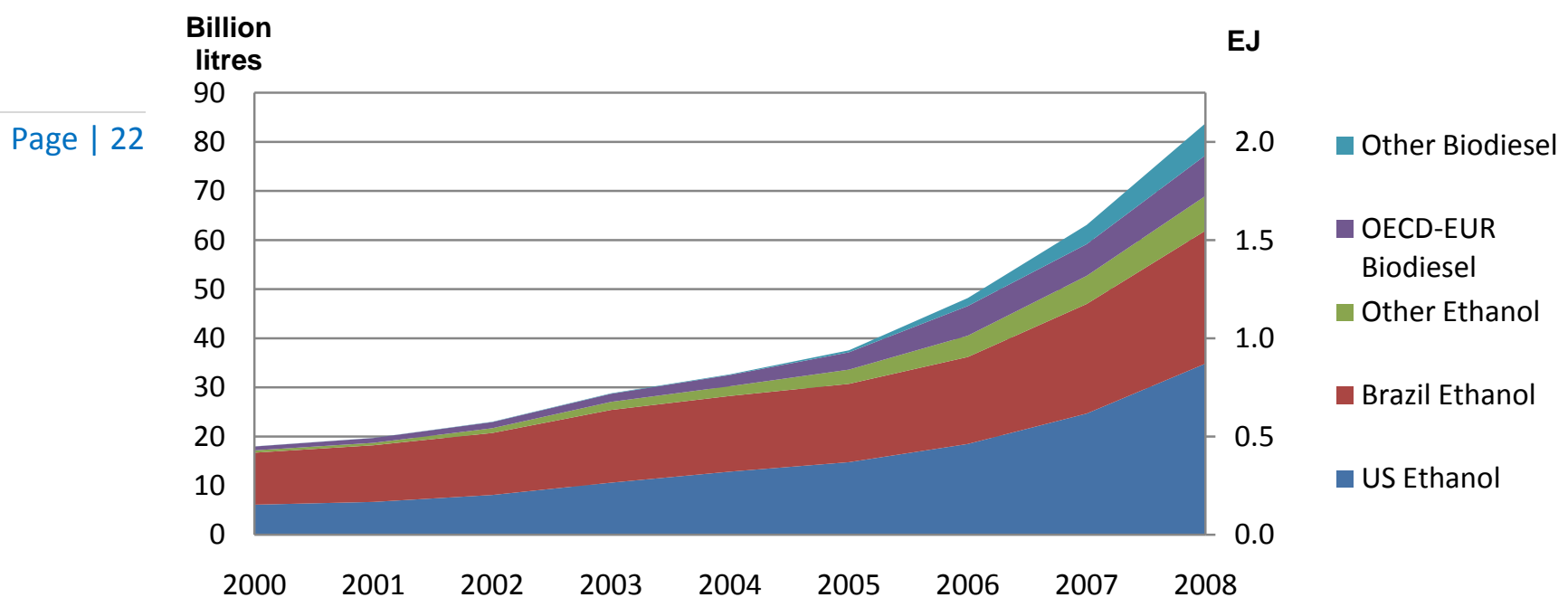

Source: IEA, 2009b

\section{Box 1. Definition of $1^{\text {st }}$ - and $2^{\text {nd }}$-generation biofuels \\ First $\left(1^{\text {st }}\right)$-generation biofuels \\ First generation biofuels are biofuels which are on the market in considerable amounts today. Typical $1^{\text {st }}$-generation biofuels are sugarcane ethanol, starch-based or 'corn' ethanol, biodiesel and Pure Plant Oil (PPO). The feedstock for producing $1^{\text {st }}$ generation biofuels either consists of sugar, starch and oil bearing crops or animal fats that in most cases can also be used as food and feed or consists of food residues. [...] \\ Second $\left(2^{\text {nd }}\right)$-generation biofuels \\ Second generation biofuels are those biofuels produced from cellulose, hemicellulose or lignin. $2^{\text {nd }}$-generation biofuel can either be blended with petroleum-based fuels combusted in existing internal combustion engines, and distributed through existing infrastructure or is dedicated for the use in slightly adapted vehicles with internal combustion engines (e.g. vehicles for DME). Examples of $2^{\text {nd }}$-generation biofuels are cellulosic ethanol and Fischer-Tropsch fuels.}

Source: IEA Bioenergy Task 39, 2009

\subsection{Second-generation biofuel conversion routes}

$R \& D$ efforts have been undertaken for different conversion routes, and so far there is no clear trend showing which technology will be the most promising future option. The two main conversion routes are:

1) Bio-chemical route: This process is based on enzymatic-hydrolysis of the lignocellulosic material through a variety of enzymes that break the cellulosic material into sugars. In the second step of the process, these sugars are fermented into alcohol which is then distilled into ethanol.

2) Thermo-chemical route: The first step in the process is the gasification of the feedstock under high temperature into a synthesis gas. This gas can then be transformed into different types of liquid or gaseous fuel, so-called "synthetic fuels" (e.g. BTL-diesel, bio-SNG). 
An overview of the different conversion routes and the producible biofuels is given in Table 2; more-detailed information can be found in the recent IEA publication From $1^{\text {st }}$-to $2^{\text {nd }}$-Generation Biofuel Technologies (IEA, 2008a).

Table 2. Classification of second-generation biofuels from lignocellulosic feedstocks

\begin{tabular}{|c|l|l|}
\hline Biofuel group & \multicolumn{1}{|c|}{ Specific biofuel } & \multicolumn{1}{c|}{ Production process } \\
\hline Bioethanol & Cellulosic ethanol & $\begin{array}{l}\text { Advanced enzymatic hydrolysis } \\
\text { and fermentation* }\end{array}$ \\
\hline $\begin{array}{c}\text { Synthetic } \\
\text { biofuels }\end{array}$ & $\begin{array}{l}\text { Biomass-to-liquids (BTL) } \\
\text { Fischer-Tropsch (FT) diesel synthetic diesel } \\
\text { Biomethanol } \\
\text { Heavier alcohols (butanol and mixed) } \\
\text { Dimethyl ether (DME) }\end{array}$ & Gasification and synthesis** \\
\hline Methane & Bio-synthetic natural gas (SNG) & Gasification and synthesis** \\
\hline Bio-hydrogen & Hydrogen & $\begin{array}{l}\text { Gasification and synthesis** or } \\
\text { biological* processes. }\end{array}$ \\
\hline
\end{tabular}

*Bio-chemical route; ${ }^{* *}$ Thermo-chemical route

Source: Based on IEA, 2008a

BTL-diesel and lignocellulosic ethanol are the most discussed second-generation biofuel options. Both fuels can be blended with conventional diesel and gasoline, or used pure. Another promising second-generation biofuel is bio-SNG, a synthetic gas similar to natural gas. The gas can be produced from a wide variety of biomass feedstocks and can be compressed or liquefied for use as transport fuel in modified vehicles. The biofuel yields in terms of fuel equivalent are higher in this conversion route compared to lignocellulosic ethanol and BTL-diesel.

\subsection{Biofuels in major economies and developing countries}

Despite the widespread use of biomass for energy production, many emerging and developing countries strongly rely on oil imports to meet their energy demand and are thus vulnerable to increasing and volatile oil prices. The establishment of a sustainable biofuel industry is, therefore, a feasible way for these countries to decrease dependency on fossil fuel imports, improve their economic situation, and create new employment opportunities, especially in the agricultural sector (UN Energy, 2007).

Some emerging and developing countries have already successfully developed a first-generation biofuel industry. Brazil, China, Thailand, India and others have started production of first-generation biofuels during recent years. In Brazil and Thailand, biofuels have been produced for several decades, resulting in significant production capacities and infrastructure (e.g. flex-fuel vehicles, fuel-stations). In most of the other countries listed above, the biofuel industry is still relatively small and immature.

So far, only a few developing and emerging countries are undertaking RD\&D in second-generation biofuels. In Brazil, a pilot plant has been set up and demonstration-scale production is expected to begin in 2010. In China, two pilot plants are operating, and in Thailand research is currently underway in several universities. In most other countries that have been studied, second-generation biofuel production is yet years away. More details on RD\&D efforts, policy support and financing possibilities are discussed in Chapter 4. 



\section{IEA Projections of Future Demand for Biomass and Biofuels}

\section{Key messages}

- In IEA scenarios, biomass is expected to play an increasingly important role in the energy sector, in particular in a world that aims to curb the atmospheric concentration of $\mathrm{CO}_{2}$ to $450 \mathrm{ppm}$. In this scenario, biomass is projected to provide 13.6\% of TPES in 2030 (WEO 2009450 Scenario). In 2050, the IEA Energy Technologies Perspectives 2008 Blue Map Scenario predicts an even bigger share of $20 \%$ in the global TPES.

- In the transport sector, biofuels, together with electric-vehicles, are seen as an important technology to reduce $\mathrm{CO}_{2}$-emissions. The most important contributor to emission reductions, however, will be improvements in end use efficiency.

- In the WEO 2009450 Scenario their share increases to more than $9.3 \%$ of total transportation fuel, and second-generation biofuels will play an important role after 2020. In 2050 the IEA Blue Map Scenario projects a share of $26 \%$ biofuels in the transport sector of which the major share is expected to be second-generation biofuels.

- Land requirements to produce the required volumes of biofuels in 2050 are assumed to be around $160 \mathrm{Mha}$, if second-generation biofuels are produced from dedicated energy crops. The use of agricultural and forestry residues could considerably reduce the amount of land required for second-generation biofuel production.

Biomass accounted for roughly $10 \%$ (about $50 \mathrm{EJ} / \mathrm{yr}$ ) of global primary energy consumption in 2007, making it the largest primary source of renewable energy. However, the exact consumption of traditional biomass is difficult to assess, and uncertainties regarding global primary biomass usage remain the region of $10 \mathrm{EJ}$. The main share of biomass, about $30 \mathrm{EJ} / \mathrm{yr}$, is currently consumed in non-OECD countries for cooking and direct heating. Modern biomass, including biofuels, on-site heat, electricity and district heat, accounts for roughly 19 EJ (462 Mtoe) globally (IEA, 2008d).

Figure 4 shows the steady increase of global primary biomass consumption, indicating an almost twofold increase in biomass consumption between 1970 and 2006. While solid biomass consumption is steadily increasing outside the OECD, it grew only about $1.3 \%$ annually between 1991 and 2006 in OECD countries. On the other hand, the supply of liquid biomass (i.e. biofuels) increased about $17.3 \%$ per year over the same period, reflecting the fast-growing demand in the OECD during recent years.

In several countries, in particular outside the OECD, biomass is still the main primary energy source. Of the countries studied for this project, those with the highest share of biomass in their TPES are Tanzania (89\%) and Cameroon (64\%), followed by Brazil (31\%). Other major economies like China and South Africa are more dependent on coal, natural gas and oil for their primary energy supply, with biomass playing only a minor role to date (Figure 5). 
Figure 4. Global primary biomass consumption 1971-2007

Page | 26

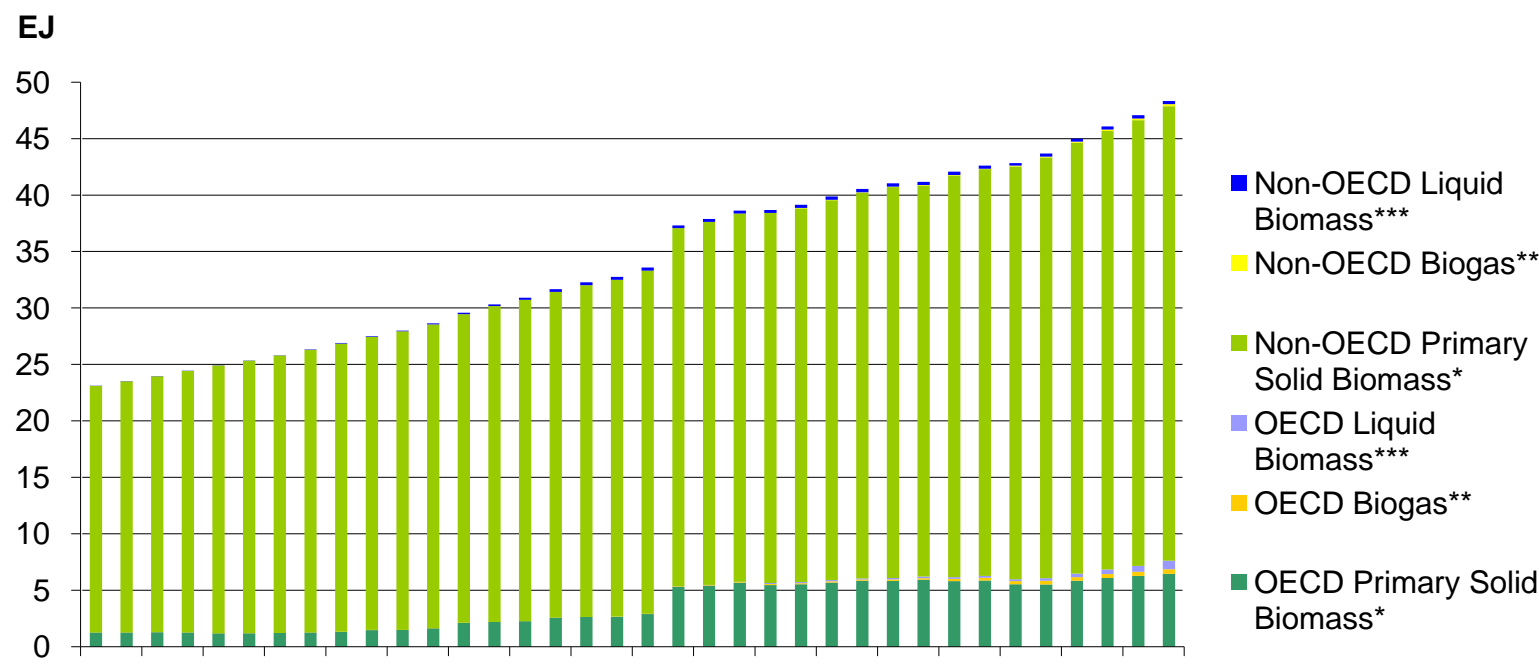

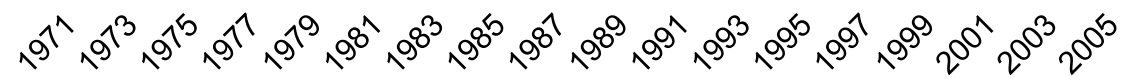

* Primary solid biomass includes wood, wood wastes, black liquor, other (straw, bagasse, etc.); ** biogas includes landfill-, sludge-, and other biogas; ${ }^{* * *}$ liquid biomass includes bioethanol, biodiesel and other biofuels.

Source: IEA Statistics, 2009

Figure 5. Biomass in total primary energy supply 2007 in selected countries

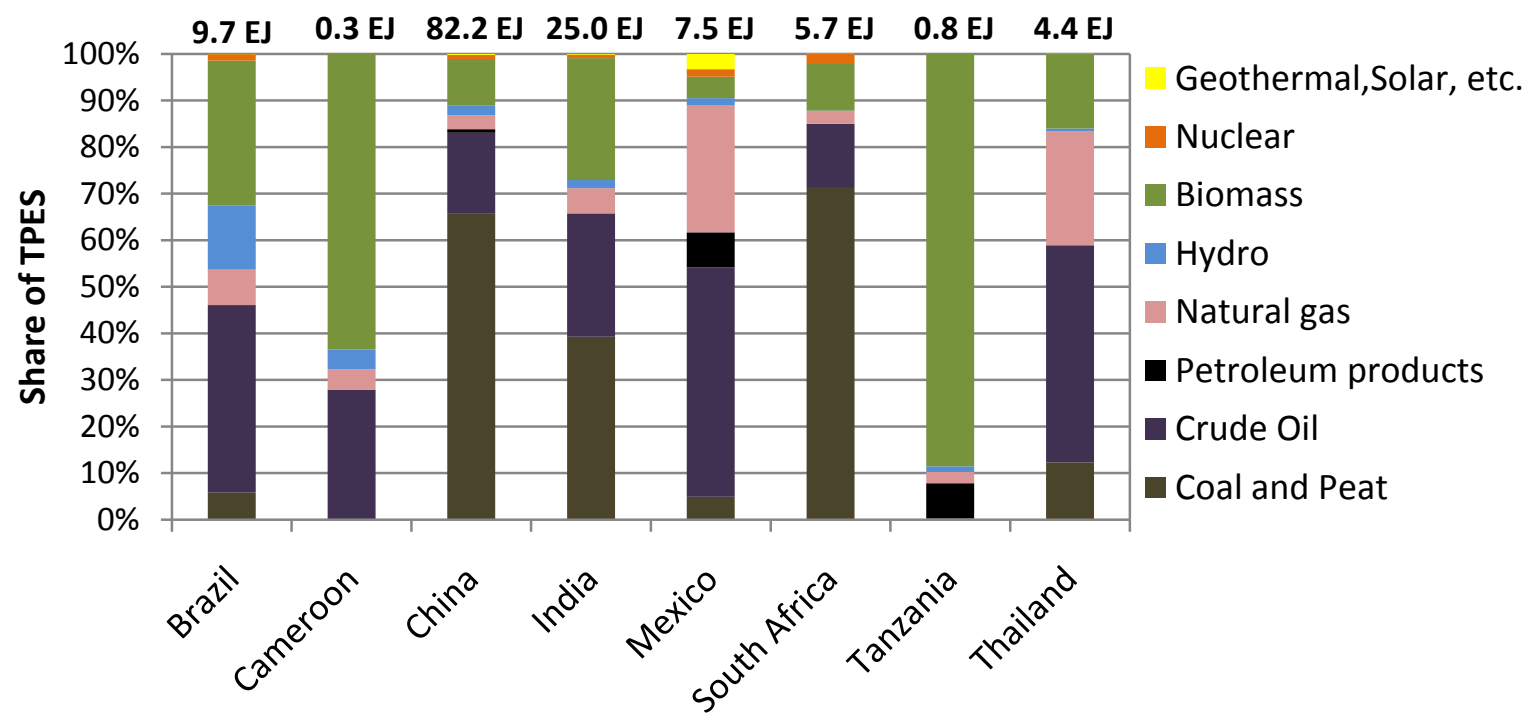

Source: IEA Statistics, 2009

To model future energy demand, the IEA provides different scenarios, based on different assumptions and time spans. The World Energy Outlook 2009 projects global energy consumption through the year 2030. Projections are based on a Reference Scenario that models how global energy markets evolve if governments make no changes to their existing policies and measures. The total primary energy supply in this scenario reaches 16790 Mtoe (705.2 EJ) in 2030 (Table 3), an 
increase of roughly $40 \%$ compared to 2007 levels. Global $\mathrm{CO}_{2}$ emissions are expected to increase by $1.5 \%$ annually, reaching $40.2 \mathrm{Gt}$ by 2030 . The increase in emissions is caused solely by non-OECD countries - mainly China (55\%), India (18\%), and the Middle East (9\%).

The WEO 2009 further includes a 450 Scenario, which depicts a world in which collective policy action is taken to limit the long-term concentration of greenhouse gases in the atmosphere to $450 \mathrm{ppm}$ of $\mathrm{CO}_{2}$-equivalent. This ambitious target has been seriously considered by $\mathrm{G} 8$ leaders at the 2007 Heiligendamm summit. To reach the target will require the adoption of a structured framework of effective international policy mechanisms and their implementation. In this scenario, global energy demand in 2030 reaches 14389 Mtoe (605 EJ), about 14\% less than in the Reference Scenario (Table 3).

Global $\mathrm{CO}_{2}$ emissions are projected to peak in 2020 and decline quickly thereafter, reaching $26.4 \mathrm{Gt}$ in 2030 , or $10 \%$ less than 2007 emission levels. Renewable energy accounts for $23 \%$ of the projected emission savings, making it the most important sector, second only to energy efficieny improvements (IEA, 2009a).

Table 3. Biomass and biofuels consumption in 2030 in WEO 2009 scenarios

\begin{tabular}{|l|c|c|}
\hline & \multicolumn{2}{|c|}{ World Energy Outlook 2009} \\
& Reference Scenario for 2030 & 450 Scenario for 2030 \\
\hline World primary energy demand & 16790 Mtoe (705.2 EJ) & 14389 Mtoe (604.3 EJ) \\
\hline Primary biomass demand & 1604 Mtoe (67.4 EJ) & 1952 Mtoe (82.0 EJ) \\
\hline $\begin{array}{l}\text { Share of total primary energy } \\
\text { demand }\end{array}$ & $9.6 \%$ & $13.6 \%$ \\
\hline $\begin{array}{l}\text { Total final biomass consumption } \\
\text { Share of total }\end{array}$ & 1270 Mtoe (53.3 EJ) & 1446 Mtoe (60.7 EJ) \\
\hline $\begin{array}{l}\text { Industry sector } \\
\text { Share of total }\end{array}$ & $11.1 \%$ & $14.2 \%$ \\
\hline $\begin{array}{l}\text { Biofuels } \\
\text { Share of total transport fuel }\end{array}$ & 167 bn Ige (5.6 EJ) & 349 bn lge (11.7 EJ) \\
\hline Other sectors & $4.0 \%$ & $9.3 \%$ \\
\hline Share of total & 845 Mtoe (35.5 EJ) & 817 Mtoe (34.3 EJ) \\
\hline
\end{tabular}

Source: IEA, 2009a

Another set of scenarios for long-term projections of global energy demand until 2050 is in the IEA publication Energy Technology Perspectives 2008 (ETP 2008), which includes a Baseline Scenario that models a business-as-usual development of global energy demand based on the assumptions in the WEO Reference Scenario. It projects that, in the absence of sound policies and technology deployment, global primay energy demand reaches 23268 Mtoe (977 EJ) in 2050 (Table 4). This would cause a rise in $\mathrm{CO}_{2}$ emissions to $62 \mathrm{Gt}$ in 2050 and could result in an increase in global temperature of $6^{\circ} \mathrm{C}$ by the end of the century. 
The most ambitious of the ETP 2008 scenarios is the Blue Map Scenario, which projects required technology development in order to achieve a global emission reduction target of $50 \%$ by 2050 compared to current levels. This is consistent with the target in the WEO 2009450 Scenario to stabilise the atmospheric concentration of $\mathrm{CO}_{2}$ at $450 \mathrm{ppm}$. Such significant emission reductions require rapid clean-energy technology deployment to meet the emission reductions targets, which involves marginal costs of up to USD $200 / \mathrm{t} \mathrm{CO}_{2}$ saved. Total primary energy demand in this scenario would reach 18025 Mtoe (750 EJ), 23\% less than in the Baseline Scenario (Table 4). The global emissions level would remain around $14 \mathrm{Gt}$ by $2050,36 \%$ of which is achieved through end-use efficiency and $21 \%$ through renewables (IEA, 2008b).

Table 4. Biomass and biofuels consumption in ETP 2008 Blue Map Scenario

\begin{tabular}{|l|c|c|}
\hline & \multicolumn{2}{|c|}{ Energy Technology Perspectives 2008 } \\
& Baseline Scenario for 2050 & Blue Map Scenario for 2050 \\
\hline World primary energy demand & 23268 Mtoe (977 EJ) & 18025 Mtoe (750 EJ) \\
\hline Primary biomass demand & 2142 Mtoe (90.0 EJ) & 3605 Mtoe (150 EJ) \\
\hline $\begin{array}{l}\text { Share of total primary energy } \\
\text { demand }\end{array}$ & $9.2 \%$ & $20.0 \%$ \\
\hline $\begin{array}{l}\text { Total final biomass consumption } \\
\text { Share of total }\end{array}$ & 1282 Mtoe (53.8 EJ) & $2003(84.1 \mathrm{EJ})$ \\
\hline $\begin{array}{l}\text { Industry sector } \\
\text { Share of total }\end{array}$ & $8.1 \%$ & $19.0 \%$ \\
\hline Biofuels & $6.7 \%$ & 822 Mtoe (34.5 EJ) \\
Share of total transport fuel & 133 bn Ige (4.5 EJ) & 870 bn Ige (29.1 EJ) \\
\hline Other sectors & $2.2 \%$ & $26.0 \%$ \\
\hline Share of total & 816 Mtoe (34.3 EJ) & 488 Mtoe (20.5 EJ) \\
\hline
\end{tabular}

Source: IEA, 2008b

Projections for global biomass demand in the scenarios differ significantly. In the WEO 2009 Reference Scenario, about $9.6 \%$ of the total primary energy demand is derived by biomass in 2030, reflecting an increase of $19 \mathrm{EJ}$ compared to 2007 consumption. In the 450 Scenario, this share rises to about $13.6 \%$ of global primary energy demand, or $82 \mathrm{EJ}$, in 2030 (Table 3). For 2050 the Blue Map Scenario projects a share of biomass of $20 \%$ (150 EJ) in global primary energy demand (Table 4), which would require an area of 375-750 Mha for biomass cultivation.

\subsection{Outlook for biofuels}

Though biofuel production has been increasing steadily over the last years, future growth remains uncertain. In the WEO 2009 Reference Scenario, biofuel demand is projected to grow to 167 billion litres gasoline equivalent (Ige) in 2030, reaching a share of about $4 \%$ of total transport fuel demand. 
About $55 \%$ of this is consumed within the OECD region, whereas non-OECD countries account for roughly $45 \%$ of total biofuel consumption in 2030 .

In the 450 Scenario, global biofuel demand more than doubles compared to the Reference Scenario and reaches 349 bn Ige in 2030, a share of $9.3 \%$ of total transport fuel ${ }^{6}$. It assumes a rapid increase in the production of second-generation biofuels, accounting for all of the biofuel growth between 2020 and 2030. One-third of the total increase in biofuel demand until 2030 is projected to take place in the United States, followed by the European Union, Brazil and China (IEA, 2009a).

In the ETP 2008 Baseline Scenario, biofuels are projected to play only a minor role, providing around $2.2 \%$ of total transport fuel in 2050. Pursuing the ambitious target to reduce global $\mathrm{CO}_{2}$ emissions by $50 \%$ by 2050 , global biofuel demand in the Blue Map Scenario is projected to increase significantly to about 880 billion lge in 2050 , a share of about $26 \%$ of total road transportation fuel. This makes biofuels, together with electrification of the vehicle fleet, the second largest contributor to $\mathrm{CO}_{2}$ reductions (17\%) in the transportation sector, right after end use efficiency (52\%).

To reach this share requires full commercialisation of and thus a considerable increase in the production of second-generation biofuels, which would then meet the main share (roughly 90\%) of projected biofuel demand in 2050 . To produce these amounts, the scenario projects that around 160 Mha land would be required (Figure 6). The use of agricultural and forestry residues would be a viable option to significantly reduce the required amounts of land indicated in the Blue Map Scenario and thus reduce competition with land for agriculture or nature conservation. (The extent to which agricultural and forestry residues could contribute to the production of second-generation biofuels will be discussed in Chapter 7.)

Figure 6. Demand for biofuels and land requirements in 2050 in the IEA Blue Map scenario

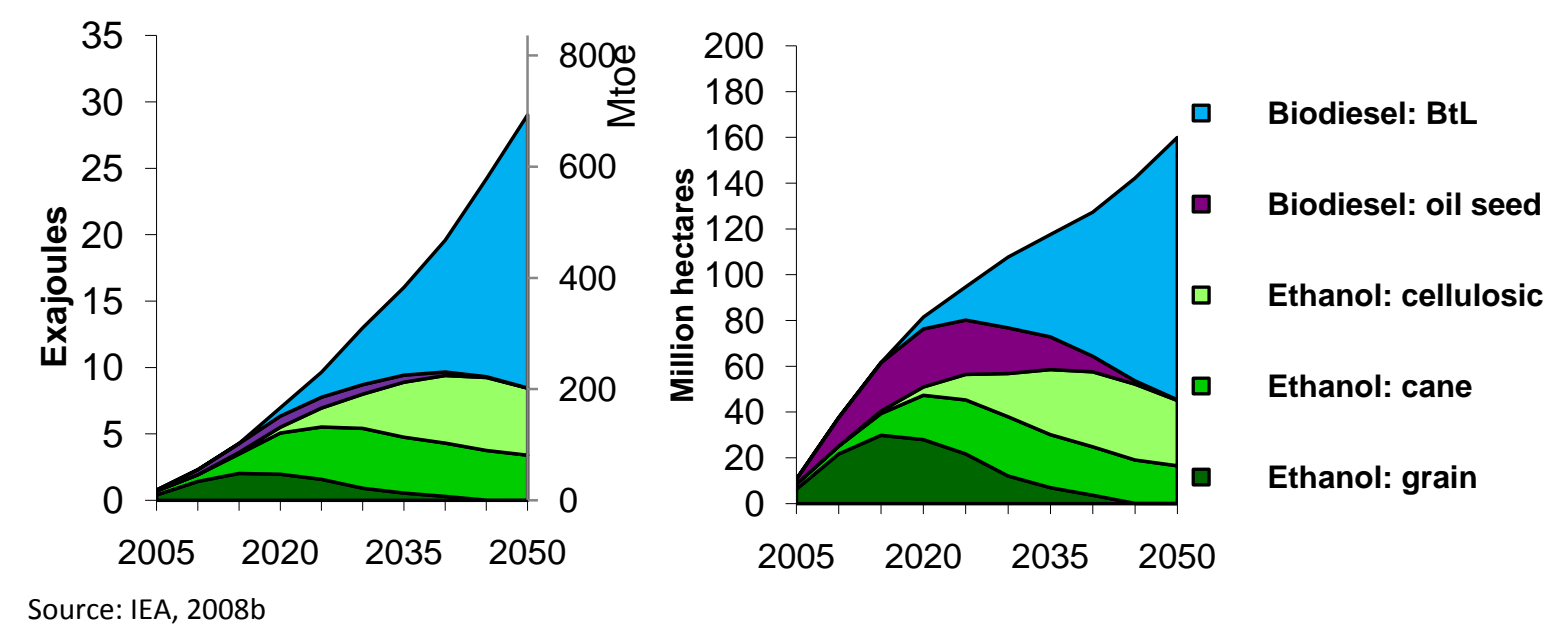

Source: IEA, 2008b

\footnotetext{
${ }^{6}$ Total transport fuel demand in 2030 is 125.7 EJ (2 994 Mtoe), provided by Oil: 105.4 EJ (2 510 Mtoe); Biofuels: 11.7 EJ (278 Mote); Electricity: 5.1 EJ (122 Mtoe), Gas: 3.4 EJ (82 Mtoe) and other 0.1 EJ (3 Mtoe).
} 



\section{Drivers for Second-Generation Biofuel Development}

\section{Key messages}

- Biofuel support policies are a key driver for the promotion of biofuels and have been adopted in several OECD countries, as well as developing and emerging countries. Of the countries studied, Brazil, China, India, South Africa and Thailand have adopted respective policies and blending quotas for biofuels. However, these countries are not yet directly addressing second-generation biofuels in their policies.

- $R \& D$ activities in OECD countries are supported by governmental funding (e.g. more than USD 1 billion in the US, USD 430 million in Canada and USD 12 million in Australia), whereas financing possibilities in developing countries are more limited and often depend on foreign investment. This is one of the reasons why only a few second-generation biofuel projects have yet been set up outside the OECD (e.g. in Brazil, China, India and Thailand).

- One of the main drivers for second-generation biofuel production in the next years will be the US Renewable Fuels Standard (RFS), due to its steadily increasing blending mandate for cellulosic ethanol. The EU Renewable Energy Directive (RED) does not set a specific quota for second-generation biofuels. It fosters their use only indirectly by counting their contribution twice toward mitigation targets; hence, its impact on the development of this industry is less certain compared to that of the US RFS.

- For emerging countries, trade opportunities of second-generation biofuels with the EU and the US are likely to grow, since production in these regions is expected to fall short of domestic demand. In particular, countries like Brazil and China that are already developing second-generation biofuels and can provide good export infrastructure and skilled labour are likely able to profit from the growing demand for second-generation biofuels.

- Feedstock trade could be an option for countries that currently cannot provide suitable framework conditions for a domestic second-generation biofuel industry. This might only bring limited economic benefits, but could be a possibility for less-developed countries to profit from the growing demand for second-generation biofuels globally.

New energy technologies often depend upon support measures to promote research and development (R\&D) and subsequent large-scale demonstration and market deployment. This is particularly true for second-generation biofuel technologies, which are currently only in initial stages of development. Governments' incentives to support second-generation biofuel production and consumption depend on countries' specific conditions and hence vary widely. General drivers include the desire for increased energy-security, support for the agricultural and forestry sectors, economic benefits, and better environmental performance compared to many first-generation biofuels. 
As mentioned earlier, no commercial production of second-generation biofuels yet exists, though a considerable number of demonstration and pilot plants are in place, are planned or are under construction, mainly in the United States and the European Union. Further RD\&D efforts are therefore needed to ensure successful deployment of this new technology in the future. In this section, global drivers for the development of second-generation biofuels are discussed along with

Page $\mid 32$ their impact on the development of this industry in emerging and developing countries.

\subsection{Biofuel support policies for second-generation biofuels}

The rapid development of global biofuel production over the last decade has in many cases been the result of ambitious support policies. State support is often needed to successfully promote biofuel production since biofuels are often not competitive alternatives to fossil fuels. A considerable number of states and countries have adopted biofuel support policies, including some of the countries in this study, like Brazil, China, India, Mexico, Thailand, and South Africa (Table 5). However, to date, these policies focus mainly on first-generation biofuels. (For more details, see country profiles in Annex A and the IEA database at $h t t p: / / r e n e w a b l e s . i e a . o r g$.

Table 5. Biofuel support policies in the studied countries

\begin{tabular}{|c|c|c|}
\hline & Current biofuel production & Policy targets \\
\hline \multirow[b]{2}{*}{ Brazil } & 27 bn litres sugar cane bioethanol & $20-25 \%$ mandatory blending \\
\hline & 1.1 bn litres biodiesel (mainly soy) & $\begin{array}{l}\text { B4 (2009); B5 mandatory blending through } \\
\text { 2013; social fuel stamp to integrate } \\
\text { smallholders }\end{array}$ \\
\hline Cameroon & No commercial production & No biomass/biofuel policy \\
\hline \multirow{2}{*}{ China } & 1.5 bn litres grain bioethanol & E10 for 2020 (12.7 bn litres ethanol) \\
\hline & 0.4 bn litres biodiesel & 2.3 bn litres biodiesel consumption in 2020 \\
\hline \multirow{2}{*}{ India } & $\begin{array}{l}1.08 \text { bn litres of } \text { molasses } \\
\text { bioethanol }\end{array}$ & $\begin{array}{l}\text { B5 mandatory in } 10 \text { states; } 10 \% \text { target } \\
\text { proposed for } 2011 / 12\end{array}$ \\
\hline & 0.24 bn litres of biodiesel & $\begin{array}{l}\text { Biodiesel currently not sold, but } 20 \% \\
\text { biodiesel target proposed for } 2011 / 12\end{array}$ \\
\hline Mexico & No commercial production & General framework, but no specific policies \\
\hline South Africa & $\begin{array}{l}\text { Small trials; corn based ethanol } \\
\text { projects put on hold due to } \\
\text { discussion on food vs. fuel }\end{array}$ & $\begin{array}{l}2 \% \text { target for the next five years, but no } \\
\text { mandatory blending; sugar cane/ sweet } \\
\text { sorghum bioethanol production probable }\end{array}$ \\
\hline Tanzania & No commercial production & No biofuel targets established \\
\hline \multirow[b]{2}{*}{ Thailand } & $320 \mathrm{mn}$ litres sugar cane ethanol & $\begin{array}{l}\text { Investments subsidies for ethanol plants; } \\
\text { subsidies for E10, E20, E85 }\end{array}$ \\
\hline & $450 \mathrm{mn}$ litres palm biodiesel & $\begin{array}{l}\text { B2 mandatory blending; B5 mandatory } \\
\text { from 2011; R\&D on LC-ethanol and BTL- } \\
\text { diesel }\end{array}$ \\
\hline
\end{tabular}

Source: Country analysis presented in Annex A 
In the United States and the European Union, ambitious support policies have recently been adopted that include explicit measures to promote second-generation biofuels. Due to the market position of these economic areas, their policies are expected to significantly drive secondgeneration biofuel development and will therefore be examined as well.

\subsection{Blending mandates}

Amongst various policy instruments, blending mandates are a common measure to ensure a certain amount of biofuel is consumed regardless of the current market situation, thereby offering more market certainty to the producer side. The United States is the only country so far to have adopted a blending mandate for second-generation biofuels - the Renewable Fuels Standard (RFS) - which is part of the Energy Independence and Security Act of 2007 (EISA). It defines the volume of different biofuels that have to be blended with conventional fuel between 2006 and 2022.

Currently the major share of biofuel in the United States is ethanol produced from corn, which has been strongly favoured by the existing support policies. With the adoption of the RFS, however, the blending of second-generation biofuels based on lignocellulosic feedstock is mandated from 2010 onwards. The total volume of biofuels mandated in the Renewable Fuels Standard increases from 15 billion litres in 2006 to 136 billion litres in 2022 (Figure 7). The RFS requires an increase in consumption of lignocellulosic ethanol from virtually zero at present to 60.6 billion litres per year in 2022 (Figure 7). Furthermore, the act calls for minimum GHG savings for advanced (i.e. non-grain based) biofuels of $50-60 \%$ compared to fossil fuel to make biofuel production more sustainable. These requirements favour the development of highly efficient biofuel technologies, including second-generation biofuels. The total effect on emission savings is estimated to be around 100 million tons of $\mathrm{CO}_{2}$ per year in 2022 (UCSUSA, 2008).

Figure 7. Biofuel Mandate in the United States Renewable Fuels Standard

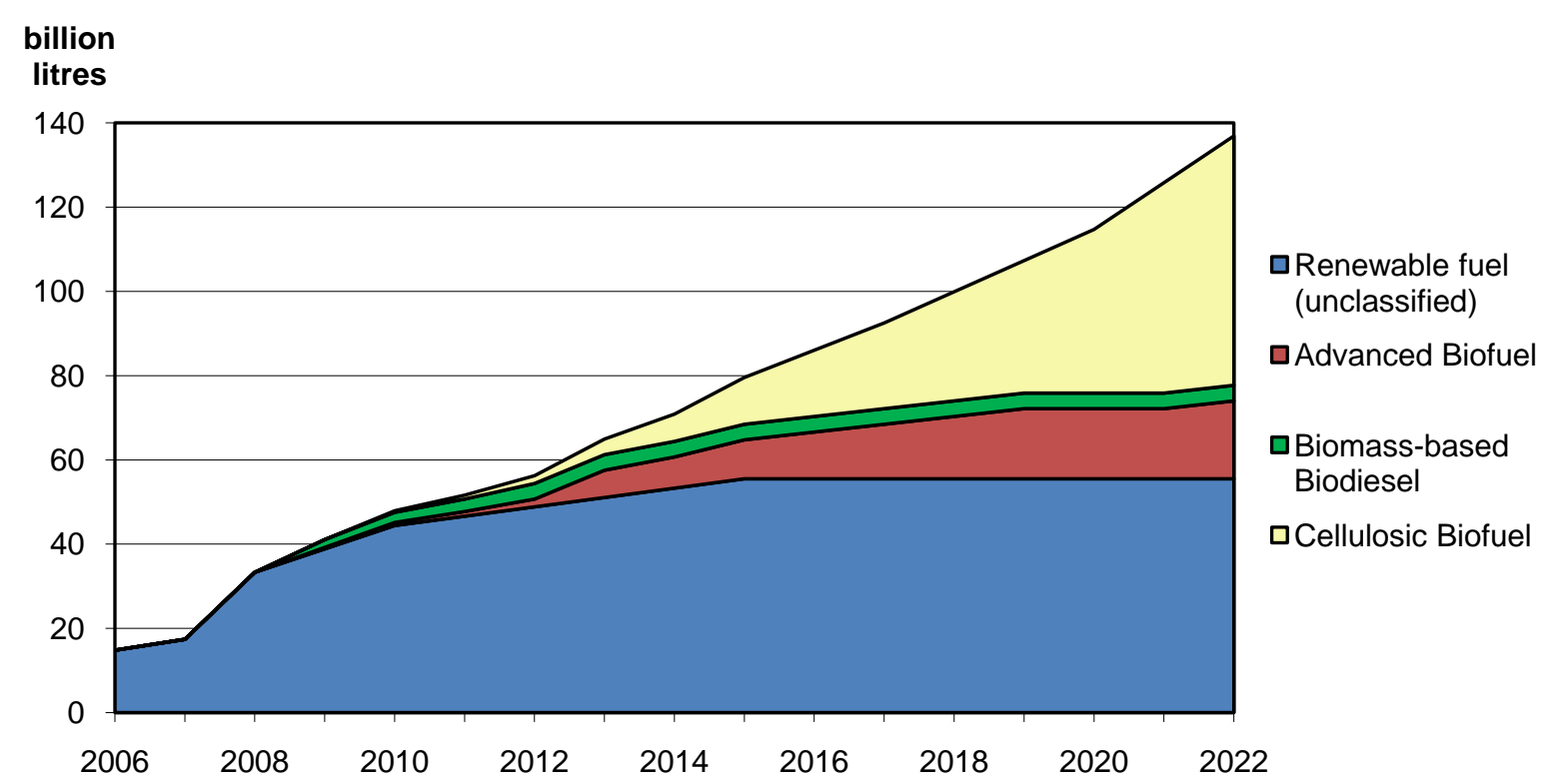

Renewable fuel: includes all types of biofuel; Advanced Biofuel: biofuels other than corn-based ethanol with GHG savings $>50 \%$; Biomass-based Biodiesel: biodiesel with GHG savings >50\%; Cellulosic Biofuel: lignocellulosic biofuel with GHG saving $>60 \%$.

Source: U.S. Renewable Fuels Standard 
Europe is currently the leading producer of biodiesel with a production of roughly 8.5 billion litres in 2008 and a global market share of 50\%. Additionally, around 3.5 billion litres of ethanol were produced in 2008 (IEA, 2009b). Increasing concerns over the European Union's energy security and increasing GHG emissions have been the main drivers for the implementation of laws aiming to promote the production and consumption of renewable energy, and furthermore have led to the

Page | 34 adoption of Directive 2003/30/EC in 2003 that defined non-binding blending targets of $2 \%$ in 2005 and 5.75\% in 2010. In April 2009, the European Parliament adopted Directive 2009/28/EC on the promotion of the use of energy from renewable sources (Renewable Energy Directive). It aims for emission savings of 600-900 $\mathrm{Mt} \mathrm{CO}_{2}$ per year and a reduction in fossil fuel consumption of 200-300 Mt per year in the European Union (EC, 2008). The directive sets mandatory targets for EU member states to ensure a share of $20 \%$ renewable energy in total energy consumption. For the transport sector a mandatory share of $10 \%$ renewable energy is required in 2020 , which is expected to be met mainly with biofuels.

Unlike the United States, the European Union does not set a quota for the use of second-generation biofuels in its Renewable Energy Directive (RED), but the new technology could profit from obligatory sustainability standards for biofuels that are defined in the RED. The criteria include minimum GHG savings for biofuels of at least 35\% compared to fossil fuels from 2013 onwards, rising to $50 \%$ in 2017 and $60 \%$ in 2018. Furthermore, the directive determines that biofuel feedstock must not be grown on environmentally sensitive land, including protected areas and land with high biodiversity value or high carbon stock. It also addresses issues like social sustainability and indirect land use change, the latter by promoting higher agricultural productivity and the use of degraded land for biofuel production.

Since second-generation biofuels are expected to have significantly higher GHG mitigation potential than many first-generation biofuels (see chapter 8 ), sustainability standards in the RED are expected to promote their production. In addition, the RED states that the contribution of second-generation biofuels will count twice toward mitigation targets compared to first-generation biofuel. Though it sets no mandatory quota for lignocellulosic biofuels as the RFS does, production of secondgeneration biofuels is explicitly favoured by the definition of minimum GHG savings and the doublecounting of lignocellulosic biofuels. However, the impact of the RED on global second-generation biofuel production is less certain than in the RFS since mandatory quota are not defined.

Other countries have also recently updated their support policies to include sustainability criteria and/or minimum lifecycle emission savings for biofuels (e.g. China, India and South Africa). These criteria could generally favour the production of second-generation biofuels if the general framework in those countries allows for production and overall biofuel demand grows.

\subsection{Implications on global biofuel demand and trade opportunities for developing countries}

Biofuel support policies have a strong impact on global biofuel markets affecting both production and demand. However, the biofuel sector's dependency on state support measures shows strong regional differences, depending on production costs and fossil fuel prices. For most emerging and developing countries, biofuel subsidies are only a limited option to promote domestic biofuel production since financing possibilities are constrained. However, tax-exemptions, and other measures are applied in some countries (e.g. Thailand). Biofuel production in emerging and developing countries is, furthermore, affected by biofuel policies in OECD countries, whose ambitious biofuel mandates can hardly be met solely from domestic sources. 
For the United States for instance, the IEA sees a shortage in domestic biofuel supply compared to the blending requirements in the Renewable Fuels Standard. It expects that both first-generation biofuel and cellulosic ethanol blending quotas will not be met by domestic production in 2012, suggesting the necessity of imports from other countries, primarily Brazil (IEA, 2009b). The United States Department of Energy (USDOE) projects that in the long term (2020) 37.9 billion litres of biofuels will be traded globally, 30.2 billion litres of which will be produced in Central and South America. The European Union and the United States would account for the major share of biofuel imports; the US alone is projected to import 15.1 billion litres in 2020 to meet RFS mandates (USDOE, 2008a).

The shortage in cellulosic ethanol production within the United States might thus drive production of second-generation biofuels outside the country if domestic production capacity develops as currently expected. A number of countries that would most likely become biofuel or feedstock suppliers to the United States have already been identified in a recent study. Among them are many major economies and developing countries, including Argentina, Brazil, China, Colombia, India, Mexico, and the Caribbean Basin Initiative (CBI) (Kline et al., 2008).

The IEA's Medium Term Oil Market Report 2009 expects that domestic biofuel production in the European Union will meet only $3 \%$ of its 2010 transport fuel demand, a shortfall of $2.75 \%$ compared to the target (IEA, 2009b). Since the target is non-binding, imports from countries outside the European Union will not necessarily be increasing through the expected shortfall. In the long term, however, export demand is likely to increase due to the madatory share of $10 \%$ renewable energy in the transport sector in 2020 as defined in the RED. This is also reflected in the directive, which states, "While it would technically be possible for the Community to meet its target ... solely from domestic production, it is both likely and desirable that the target will in fact be met through a combination of domestic production and imports."

It is yet too early, to project the extent to which the 2020 mandate can be met by domestic sources in the European Union and what role second-generation biofuels are going to play to meet the mandate. The price of fossil fuels and biofuel feedstocks, plus potential technological breakthroughs in second-generation biofuel production, amongst others, will influence the amount of biofuels that can be produced within the European Union and thus determine the import demand for biofuels.

\section{Access for developing countries to biofuel markets in the European Union and the United States}

Both the United States and the European Union are dependent on biofuel imports to meet their blending mandates as discussed earlier. Nonetheless, they have adopted measures to protect their domestic biofuel markets against imports. Tariffs on biofuel imports, for instance, reduce the costcompetitiveness of imported biofuels compared to domestic biofuels. Quality standards related to the production and fuel characteristics of biofuels also reduce export possibilities for some countries. These measures often prevent emerging and developing countries from exporting biofuels to industrialised regions.

Some developing countries, however, profit from preferential trade opportunities. In the European Union, certain less-developed countries are favoured through the Generalised System of Preferences (GSP) and get duty-free access to the EU's market for ethanol and bio-diesel exports. In the United States, the import of biofuels is more restricted; ethanol imports for instance currently face an added duty of USD 0.14/I. Only certain Caribbean Basin Initiative countries are allowed to 
export ethanol to the U.S. market duty free up to a certain volume, which was set at a maximum of 1.7 billion litres in 2008 (ACE, 2009).

Export possibilities for emerging and developing countries are furthermore affected by the currently debated sustainability criteria in the European Union's RED, the RFS and the California Low-Carbon Fuel Standard (CLCFS). The RED defines minimum GHG savings for biofuels as well as additional

Page | 36 environmental criteria and social standards for the sustainable production of biofuels and feedstocks. Scientific discussion of the proper methodologies to measure GHG savings and the environmental sustainability of biofuel production is yet ongoing, with the final criteria to be adopted in 2010. The US Environmental Protection Agency is also currently debating the inclusion of default GHG emission values for different biofuels in the RFS II but has postponed its adoption for five years in order to agree on a standard methodology.

Since the policy discussion on default emission values for certain biofuels is still in progress, uncertainty exists on the producer side as to whether current biofuel production will meet those sustainability requirements and criteria. Producing countries that aim for export to these regions, therefore, have the challenge to evaluate which biofuel option might best meet these criteria in the long term. Based on the default lifecycle emission values as defined in the California Low Carbon Fuel Standard and other available lifecycle assessments for biofuels (see chapter 8), secondgeneration biofuels appear to be a technology that will meet the above mentioned sustainability requirements, in particular when residues are used as feedstock. The new biofuel sustainability criteria in the US and the EU could thus drive the development of second-generation biofuel production in the long-term. However, they do not currently provide sufficient certainty to producers in order to invest into second-generation biofuel production.

Though market access to both the European Union and the United States is less restricted for certain developing countries, many suffer from being less competitive than more developed countries due to low production efficiency, infrastructure constraints and other issues. This is particularly true when it comes to second-generation biofuels, which require more advanced feedstock logistics and highly skilled labour. Social standards for the feedstock and biofuel production will impact the competitivness even more, since the legal framework to ensure working standards is often less stringent in developing countries.

\subsection{Financing of second-generation biofuel RD\&D}

\section{Governmental funding}

Some countries provide direct funding for second-generation biofuel RD\&D projects. The US Food, Conservation, and Energy Act of 2008 for instance, provides a total volume of more than USD 1 billion for biofuel and bioenergy related projects, including specific provisions to develop second-generation biofuel production. It includes tax credits of USD $0.27 /$ liter for cellulosic biofuel, loan guarantees for biofuel plants and funding for the establishment of lignocellulosic biomass crops. In December 2008, the US Department of Energy announced that it would provide an additional USD 200 million for pilot- and demonstration-scale biorefinery projects (USDOE, 2008b).

The Canadian government also provides around USD 430 million for RD\&D of next-generation biofuels through the NextGen Biofuels Fund in order to promote the development of the new technologies (SDTC, 2008). The Australian government has set up an R\&D funding program of USD 12 million for second-generation biofuels, as well (Department of Resources, Energy and Tourism, 2009). 
Within the European Union, USD 2.5 billion in funding for second-generation RD\&D is available through the Seventh Research Framework Programme of the European Commission (FP7). Secondgeneration biofuels form only a small part of the overall programme; around 10 second-generation related projects are financed through the FP7 (http://cordis.europa.eu). The only biofuel project within the FP7 that affects non-OECD countries is co-operation between a large Danish enzyme company and the Brazilian Centro de Tecnologia Canavieira (CTC) with the aim to develop a costcompetitive enzyme mix for production of lignocellulosic ethanol.

Table 6. Overview on second-generation biofuel projects in emerging and developing countries

\begin{tabular}{|c|c|c|c|c|c|}
\hline Country & Company & Capacity & Feedstock & Status & Scale \\
\hline Brazil & $\begin{array}{l}\text { Petrobras, using } \\
\text { enzymatic hydrolysis } \\
\text { process }\end{array}$ & $800 \mathrm{t} / \mathrm{yr}$ & Bagasse & Operating & $\begin{array}{l}\text { Pilot plant; } \\
\text { demonstration- } \\
\text { scale } \\
\text { production } \\
\text { planned for } \\
2010\end{array}$ \\
\hline Brazil & $\begin{array}{l}\text { Centro de } \\
\text { Technologica } \\
\text { Canaviera and } \\
\text { Novozymes }\end{array}$ & n.a. & Bagasse & Operating & $\begin{array}{l}\text { R\&D project to } \\
\text { develop cost- } \\
\text { competitive } \\
\text { enzymes }\end{array}$ \\
\hline China/US & $\begin{array}{l}\text { Cofco Bio-Energy } \\
\text { with auto-hydrolysis } \\
\text { and steam explosion } \\
\text { unit supplied by } \\
\text { SunOpta BioProcess }\end{array}$ & $1.2 \mathrm{t} / \mathrm{yr}$ & Corn stover & $\begin{array}{l}\text { Operating } \\
\text { since } 2006\end{array}$ & \\
\hline China & $\begin{array}{l}\text { Novozymes in } \\
\text { cooperation with } \\
\text { China National } \\
\text { Cereals, Oil and } \\
\text { Foodstuff } \\
\text { Corporation (COFCO), } \\
\text { Sinopec }\end{array}$ & $500 \mathrm{t} / \mathrm{yr}$ & Corn stover & Operating & $\begin{array}{l}\text { Pilot plant with } \\
\text { target to be } \\
\text { commercially } \\
\text { viable by } 2010 \text {. }\end{array}$ \\
\hline $\begin{array}{l}\text { Argentina/ } \\
\text { Canada }\end{array}$ & $\begin{array}{l}\text { Dynamotive fast } \\
\text { pyrolysis to produce } \\
\text { bio-crude }\end{array}$ & $\begin{array}{l}250,000 \mathrm{t} / \mathrm{yr} \\
\text { feedstock }\end{array}$ & $\begin{array}{l}\text { Dry sawdust, } \\
\text { forest } \\
\text { residues and } \\
\text { municipal } \\
\text { solid waste } \\
\text { (MSW) } \\
\text { biomass }\end{array}$ & $\begin{array}{l}\text { Site } \\
\text { negotiations }\end{array}$ & $\begin{array}{l}\text { Bio-crude (bio- } \\
\text { oil) can be } \\
\text { refined and } \\
\text { converted to a } \\
\text { range of vehicle } \\
\text { fuels and } \\
\text { chemicals. }\end{array}$ \\
\hline India/US & $\begin{array}{l}\text { Indian Oil Company } \\
\text { (IOC) in collaboration } \\
\text { with US National } \\
\text { Renewable Energy } \\
\text { Laboratory (NREL) }\end{array}$ & & $\begin{array}{l}\text { Agricultural } \\
\text { residues }\end{array}$ & $\begin{array}{l}\text { Planning } \\
\text { phase }\end{array}$ & $\begin{array}{l}\text { Pilot plant for } \\
\text { cellulosic } \\
\text { ethanol; IOC } \\
\text { will provide USD } \\
4 \text { million core } \\
\text { budget }\end{array}$ \\
\hline
\end{tabular}




\begin{tabular}{|c|c|c|c|c|c|}
\hline Country & Company & Capacity & Feedstock & Status & Scale \\
\hline India & $\begin{array}{l}\text { Praj Industries. Acid } \\
\text { and enzyme } \\
\text { hydrolysis with } \\
\text { thermal treatment of } \\
\text { cellulose to produce } \\
\text { a gas processed into } \\
\text { liquid fuels. }\end{array}$ & & Mixed & $\begin{array}{l}\text { R\&D with a } \\
\text { claimed } \\
\text { breakthrough }\end{array}$ & $\begin{array}{l}\text { Company with } \\
\text { ethanol and } \\
\text { biodiesel plant } \\
\text { design services. } \\
\text { Market interest } \\
\text { in Colombia, } \\
\text { Ghana and } \\
\text { Madagascar }\end{array}$ \\
\hline Thailand & $\begin{array}{l}\text { Collaboration on BTL } \\
\text { R\&D between } \\
\text { National Innovation } \\
\text { Agency, King } \\
\text { Mongkut's } \\
\text { University, } \\
\text { Chulalongkorn } \\
\text { University, National } \\
\text { Metal and Materials } \\
\text { Technology Centre }\end{array}$ & & $\begin{array}{l}\text { Diverse } \\
\text { biomass }\end{array}$ & $\begin{array}{l}\text { Some } \\
\text { operating, } \\
\text { others under } \\
\text { construction }\end{array}$ & $\begin{array}{l}\text { Different } \\
\text { gasification and } \\
\text { FT projects } \\
\text { including a } \\
100 \mathrm{kWe} \\
\text { gasification } \\
\text { pilot-plant }\end{array}$ \\
\hline
\end{tabular}

Source: Based on IEA, 2008a; NIA, 2009

While governmental support for second-generation projects in developed countries reaches several billion US dollars. Given the limited financing possibilities and the competing priority to improve basic energy supply (e.g. clean cooking fuels, rural electrification), most developing countries (e.g. Cameroon and Tanzania) cannot provide sufficient domestic funding and policy support for secondgeneration biofuel RD\&D. As a result, investment in second-generation biofuel RD\&D is taking place mainly in OECD countries.

\section{Foreign investment in second-generation biofuels}

Some of the studied countries presented in Annex A have recognised the potential for secondgeneration biofuel production and mention the technology in their biofuel policies (e.g. China, Brazil, South Africa and Thailand). China, Brazil, Thailand and India have already set up secondgeneration biofuel projects and are undertaking several research projects to further develop the new technologies (Table 6). The large emerging markets are of particular interest to foreign investors due to favourable economic conditions and the availability of both infrastructure and skilled labour.

One possible option to attract foreign investment is the Clean Development Mechanism (CDM), which is one of the flexible mechanisms under the Kyoto Protocol. It allows industrialised countries to invest in emissions-reducing projects in developing countries in order to fulfil their own emission reduction targets. The switch from carbon-intensive fuels to biofuels is one of the eligible technologies under the CDM. Therefore, second-generation biofuels that replace fossil fuels could be promoted through the scheme. However, to date no biofuel project has been created under the CDM (UNFCCC, 2009). The lack of a standardised life cycle assessment (LCA) methodology, the noneligibility of biofuels exported to Annex A countries (i.e. developed countries), and the existence of less-capital-intensive projects (that generate more carbon credits per invested dollar) form considerable barriers for investment into second-generation biofuels under the CDM. 


\section{Feedstock trade}

The production and trade of feedstock for second-generation biofuels could be another option for emerging and developing countries to profit in cases where second-generation biofuel production takes place outside the country. The lower financial risks and reduced need for highly skilled labour make the production of biomass feedstock considerably more feasible compared to biofuel production. There are several examples of international biomass trade between emerging or developing countries and industrialised regions. South Africa, for instance, exports around $5.8 \mathrm{Mm}^{3}$ roundwood equivalent of wood chips and particles, while and Chile exports $4.7 \mathrm{Mm}^{3}$ (Bradley et al., 2009). Another example is a power plant in Geertruidenburg, the Netherlands, which is fired with coffee shells imported from Brazil (Essent, 2008).

Since certain second-generation feedstocks could be traded internationally, biofuel mandates could not only impact biofuel production in certain countries but also lead to creation of export markets for biomass feedstocks. In the end, the possibility of feedstock trade and the benefits to exporting countries will depend on feedstock costs and the overall market situation. Some potential feedstocks (e.g. straw, rice husks) might not be suitable for long-distance trading since their energy density (i.e. $\mathrm{GJ} / \mathrm{m}^{3}$ ) is too low to allow for economically competitive transportation.

Feedstock trade might also be driven by foreign land acquisitions for the cultivation of biofuel feedstocks. Examples of such investment during recent years include Tanzania (see country profile in Annex A), Democratic Republic of Congo ${ }^{7}$, Mozambique ${ }^{8}$ and Zambia $^{9}$ (IFPRI, 2009). In general, such foreign investment can have a positive impact on domestic economies and can lead to increasing employment opportunities and infrastructure improvement in rural areas. Foreign investment in feedstock production could enable countries to profit from non-domestic secondgeneration biofuel development, especially in developing countries where domestic financing possibilities are limited and skilled-labour for biofuel production is not available.

Recent development of large-scale land acquisitions through foreign investors, however, has raised concerns as to what extent land-providing countries can profit from these projects. Constraints include the competition for fertile land, land-tenure rights and the exclusion of smallholders. Furthermore, environmental aspects, like the increased usage of water and pesticides, are critical issues (discussed in further detail in Chapter 8). Therefore, opportunities and risks of such projects have to be evaluated carefully to ensure that local economies can benefit and that rural development is promoted.

Feedstock production may only bring limited economic benefits to producing countries, but it could be a possibility for less-developed countries to profit from the production of second-generation biofuels in the near future. Moreover, feedstock production has considerable potential to prepare countries to produce second-generation biofuels if infrastructure, feedstock cultivation and handling skills are developed. Once second-generation biofuels become commercially viable, a domestic industry can be built upon existing infrastructure and feedstock sources, thus significantly reducing overall investment costs. Even without a perspective to producing second-generation biofuels, the acquired skills and improved infrastructure would allow for other domestic bioenergy options to become feasible and would help to promote overall development.

\footnotetext{
${ }^{7} 2.8$ Mha secured by China (ZTE International) for biofuel palm oil plantation.

${ }^{8} 100000$ ha secured by Skebab (Sweden) for biofuel crops; land secured by Sun Biofuels (UK) for jatropha.

${ }^{9} 2$ Mha requested by China for jatropha plantation for biodiesel production.
} 
Although all of the studied countries have access to the sea, and are thus in a favourable position to participate in international feedstock trade, the inland infrastructure is fairly poor in some countries, in particular in rural areas. The poorest infrastructure is found in Cameroon, Tanzania and Thailand, as well as in certain parts of India. This forms a considerable barrier to feedstock transportation and trade in these countries.

Page | 40

\section{Scientific cooperation on RD\&D}

Besides commercial investment, there is also academic co-operation on second-generation biofuels in the studied countries. Both Thailand and China have signed memoranda of understanding with Forschungszentrum Karlsruhe (FZK) to cooperate on its bioliq ${ }^{\circledR}$ process in order to build capacities and to set up a BTL-plant in each country. In India, the Indian Oil Company is working together with the US National Renewable Energy Laboratory to establish a pilot plant for lignocellulosic ethanol.

If developing countries are not able to actively engage in the development of second-generation biofuel technologies, intellectual property rights will become a major barrier to implement production in these countries. Initiatives for cooperation on technology development should, therefore, be increased to enable developing countries to build capacity and profit from the new technology when it reaches a commercial stage. 


\section{Feedstock Characteristics}

Second-generation biofuels are based on lignocellulosic material, i.e. biomass, which is abundant virtually everywhere around the globe. Biomass can be derived from natural ecosystems (like forests, grassland or aquatic ecosystems), or can also be produced by cultivating bioenergy crops like perennial grasses or wood species. Furthermore, any kind of lignocellulosic waste like straw or sawdust can be used.

Table 7. Overview on potential lignocellulosic feedstocks for second- generation biofuels

\begin{tabular}{|c|c|c|c|c|c|}
\hline & $\begin{array}{l}\text { Second-Generation } \\
\text { Biofuel Feedstock }\end{array}$ & $\begin{array}{l}\text { Technical requirements } \\
\text { for } \\
\text { harvesting/collection }\end{array}$ & Potential advantages & Constraints & Availability \\
\hline \multicolumn{6}{|c|}{ Dedicated Energy Crops } \\
\hline $\begin{array}{l}\text { Short-rotation } \\
\text { coppice }\end{array}$ & $\begin{array}{l}\text { Poplar (Populus } \\
\text { spec.), willow (Salix } \\
\text { spec.), eucalyptus } \\
\text { (Eucalyptus spec.), } \\
\text { locust (Robinia spec.) }\end{array}$ & $\begin{array}{l}\text { Manual harvest possible } \\
\text { but labour intensive; } \\
\text { specialist machines } \\
\text { needed to harvest } \\
\text { efficiently (e.g. modified } \\
\text { forage harvester) }\end{array}$ & $\begin{array}{l}\text { Relatively fast growing; can } \\
\text { reduce soil erosion; can } \\
\text { increase soil carbon and } \\
\text { soil fertility in poor soils }\end{array}$ & $\begin{array}{l}\text { Potentially invasive; } \\
\text { usually planted on } \\
\text { arable land; relatively } \\
\text { low energy density } \\
\text { means not suitable for } \\
\text { long transportation }\end{array}$ & $\begin{array}{l}\text { All year round, } \\
\text { though } \\
\text { harvest for } \\
\text { deciduous } \\
\text { trees is best } \\
\text { done in winter }\end{array}$ \\
\hline $\begin{array}{l}\text { Perennial } \\
\text { cultivation }\end{array}$ & $\begin{array}{l}\text { Miscanthus } \\
\text { (Miscanthus } \\
\text { sinensis), } \\
\text { switchgrass } \\
\text { (Panicum virgatum), } \\
\text { reed canary grass } \\
\text { (Phalaris } \\
\text { arundinacea), other } \\
\text { Grasses }\end{array}$ & $\begin{array}{l}\text { Existing pasture } \\
\text { machinery (mower, } \\
\text { baler) }\end{array}$ & $\begin{array}{l}\text { Can be grown on degraded } \\
\text { land; can mitigate soil } \\
\text { erosion; can increase soil } \\
\text { carbon and soil fertility in } \\
\text { poor soils }\end{array}$ & $\begin{array}{l}\text { Potentially invasive; } \\
\text { usually planted on } \\
\text { arable land; relatively } \\
\text { low energy density } \\
\text { means not suitable for } \\
\text { long transportation }\end{array}$ & $\begin{array}{l}\text { Harvest during } \\
\text { autumn and } \\
\text { winter }\end{array}$ \\
\hline \multicolumn{6}{|c|}{ Primary Residues } \\
\hline Agriculture & Straw, stover & $\begin{array}{l}\text { Existing pasture } \\
\text { machinery (e.g. baler) }\end{array}$ & $\begin{array}{l}\text { No competition with food; } \\
\text { no additional land } \\
\text { required; collection can } \\
\text { prevent pests }\end{array}$ & $\begin{array}{l}\text { Other uses: nutrient } \\
\text { cycling, animal feed, } \\
\text { heating; low energy } \\
\text { density means not } \\
\text { suitable for long } \\
\text { transportation } \\
\text { distances }\end{array}$ & $\begin{array}{l}\text { During crop } \\
\text { harvesting } \\
\text { season }\end{array}$ \\
\hline $\begin{array}{c}\text { Forestry \& } \\
\text { logging }\end{array}$ & $\begin{array}{l}\text { Treetops, branches, } \\
\text { stumps }\end{array}$ & $\begin{array}{l}\text { Specialist machines to } \\
\text { collect residues } \\
\text { efficiently }\end{array}$ & $\begin{array}{l}\text { Relatively cheap; no } \\
\text { additional land required; } \\
\text { removal can help to } \\
\text { prevent forest-fires }\end{array}$ & $\begin{array}{l}\text { Other uses: fuel wood } \\
\text { demand, heat/ } \\
\text { electricity production; } \\
\text { removal can cause loss } \\
\text { of organic matter, soil } \\
\text { carbon and reductions } \\
\text { in habitat for } \\
\text { biodiversity; not } \\
\text { suitable for long } \\
\text { transportation } \\
\text { distances }\end{array}$ & $\begin{array}{l}\text { Year-round (if } \\
\text { residue mat is } \\
\text { not needed to } \\
\text { protect soils } \\
\text { during rainy } \\
\text { season) }\end{array}$ \\
\hline
\end{tabular}




\begin{tabular}{|c|c|c|c|c|c|c|}
\hline & & $\begin{array}{l}\text { Second-Generation } \\
\text { Biofuel Feedstock }\end{array}$ & $\begin{array}{l}\text { Technical requirements } \\
\text { for } \\
\text { harvesting/collection }\end{array}$ & Potential advantages & Constraints & Availability \\
\hline & \multicolumn{6}{|c|}{ Secondary Residues } \\
\hline \multirow[t]{6}{*}{ Page | 42} & Crop processing & $\begin{array}{l}\text { Coffee, rice, corn, } \\
\text { cacao (shells, husks, } \\
\text { cob) }\end{array}$ & $\begin{array}{l}\text { No additional technical } \\
\text { equipment; no } \\
\text { additional infrastructure }\end{array}$ & $\begin{array}{l}\text { By-product - no food } \\
\text { competition; no additional } \\
\text { land required; } \\
\text { concentrated at processing } \\
\text { site; avoids disposal costs }\end{array}$ & $\begin{array}{l}\text { Competition with heat } \\
\text { and electricity } \\
\text { generation }\end{array}$ & Year-round \\
\hline & $\begin{array}{l}\text { Sugar and first- } \\
\text { generation } \\
\text { bioethanol } \\
\text { Production }\end{array}$ & $\begin{array}{l}\text { Sugar cane, sweet } \\
\text { sorghum, sugar beet } \\
\text { (bagasse, pulp) }\end{array}$ & $\begin{array}{l}\text { No additional technical } \\
\text { equipment; no } \\
\text { additional infrastructure }\end{array}$ & $\begin{array}{l}\text { No food competition; } \\
\text { concentrated at ethanol- } \\
\text { plant; no additional land } \\
\text { required; avoids disposal } \\
\text { costs }\end{array}$ & $\begin{array}{l}\text { Competition with heat } \\
\text { and electricity } \\
\text { generation; animal feed }\end{array}$ & $\begin{array}{l}\text { During } \\
\text { feedstock } \\
\text { harvesting } \\
\text { season }\end{array}$ \\
\hline & $\begin{array}{l}\text { Vegetable oil } \\
\text { production }\end{array}$ & $\begin{array}{l}\text { Canola, oil palm, } \\
\text { jatropha (presscake, } \\
\text { shells, fruit bunch) }\end{array}$ & $\begin{array}{l}\text { No additional technical } \\
\text { equipment; no } \\
\text { additional infrastructure }\end{array}$ & $\begin{array}{l}\text { Concentrated at oil mills; } \\
\text { currently very cheap; no } \\
\text { additional land required; } \\
\text { avoids disposal costs }\end{array}$ & $\begin{array}{l}\text { Competition with heat } \\
\text { and electricity } \\
\text { generation. Press cake } \\
\text { provides a valuable } \\
\text { animal fodder. }\end{array}$ & $\begin{array}{l}\text { During crop } \\
\text { harvesting } \\
\text { season }\end{array}$ \\
\hline & $\begin{array}{c}\text { Forestry } \\
\text { processing }\end{array}$ & Sawdust, bark & $\begin{array}{l}\text { No additional technical } \\
\text { requirements }\end{array}$ & $\begin{array}{l}\text { Concentrated at saw and } \\
\text { paper mills; no additional } \\
\text { land required; avoids } \\
\text { disposal costs }\end{array}$ & $\begin{array}{l}\text { Competition with heat } \\
\text { and electricity } \\
\text { generation }\end{array}$ & Year-round \\
\hline & \multicolumn{6}{|c|}{ Tertiary Residues } \\
\hline & $\begin{array}{l}\text { Municipal solid } \\
\text { waste }\end{array}$ & $\begin{array}{l}\text { Palettes, furniture, } \\
\text { demolition timber }\end{array}$ & $\begin{array}{l}\text { Separation from other } \\
\text { waste might be required }\end{array}$ & $\begin{array}{l}\text { Concentrated at landfill } \\
\text { site; no additional land } \\
\text { required; avoids disposal } \\
\text { costs }\end{array}$ & $\begin{array}{l}\text { Competition with heat } \\
\text { and electricity } \\
\text { generation }\end{array}$ & Year-round \\
\hline
\end{tabular}

Sources: based on IEA, 2007a; Rosillo-Calle et al., 2006; Faaij et al., 1997; Bassam, 1998

Table 7 gives an overview of potential feedstocks for second-generation biofuels and their sources. It includes technical requirements for harvesting or collecting the different feedstocks and gives an overview of the possible advantages and constraints related to their use. However, it does not cover the entire range of lignocellulosic crops and residues that can potentially be used for the production of second-generation biofuels. For emerging and developing regions, little data is available on the suitability of different indigenous feedstocks for second-generation biofuels. (A more detailed discussion on advantages and constraints for the utilisation of different feedstock types can be found in Chapter 8.)

Feedstocks for lignocellulosic biofuels can be divided into two main categories: dedicated energy crops and residues. Dedicated energy crops include fast-growing woody plant species like willow (Salix spec.), poplar (Populus spec.), eucalyptus (Eucalyptus spec.) and others, as well as herbaceous plant species like miscanthus (Miscanthus spec.), switchgrass (Panicum virgatum), Johnson grass (Sorghum halepense) and others. Both types of energy crops are cultivated in perennial plantations with typical rotation periods of three to seven years for woody plants and one year for herbaceous plant species (Rosillo-Calle et al., 2006). The management of herbaceous species is less intensive than that of annual crops; moreover, harvesting herbaceous plants does not require any special equipment, provided that common pasture machinery (e.g. mowers, hay balers) is available. For short-rotation tree species, harvesting is more challenging and can be done either by using special machinery (e.g. modified forage harvesters, feller bunchers) or manual labour. 
The possible positive effects of perennial cultivation of both woody and herbaceous species include the potential to mitigate erosion through year-round soil cover as well as the increase of soil carbon stock and soil fertility over time (IEA, 2006). However, effects depend on the type of soil as well as the tree species, and there is the possibility of negative impacts on water resources (see Chapter 8 for more details). Another constraint is the invasiveness of certain non-indigenous tree or grass species. If introduced to another country, these species might spread outside the cultivation area and displace native species. In South Africa, this has already led to the ban of certain energy crops.

Residues can be divided into primary, secondary and tertiary residues. Primary residues are produced when harvesting crops or timber. They comprise agricultural residues like straw and stover, as well as forestry residues like treetops, branches, and stumps. Secondary residues are accumulated during the processing of crops into food products or the production of other biomass based materials. Feedstocks in this category include nutshells, bagasse, presscake, and fruit bunches, as well as sawdust, bark and scrap wood. Tertiary residues include post consumer residues that are derived after consumption of biomass based products, e.g. municipal solid waste.

Since residues are by-products, their production does not require any additional land and thus does not compete with production of food and fodder crops. For other residues, disposal costs have to be paid; these costs can be avoided - with a positive effect on overall production costs - if the residues are used for biofuel production. Furthermore, the collection of primary residues can help control forest fires and pests, such as the European corn borer (Ostrinia nubialis) that overwinters in corn stalks.

However, constraints exists if residues are used as animal feed, biofuel production would then directly affect the production of food. Other constraints include nutrient extraction and the competition with other uses of residues. Heat and power generation, biomaterials and conventional fuel wood are often based on biomass residues and would hence compete with the production of second generation biofuels.

Since secondary and tertiary residues are concentrated at processing sites, their collection is less costly and does not require specialised machinery. On the contrary, primary residues need to be collected in the field and hence require specialised machinery. Using primary residues might therefore be less profitable than using secondary residues. (For more details on feedstock supply, see Chapter 8.) 



\section{Review of global bioenergy potentials}

\section{Key messages}

- Recent studies on biomass potentials show that expert assessments vary broadly. The indicated global potentials range from a potential of $33 \mathrm{EJ} / \mathrm{yr}$ (Hoogwijk et al., 2003) up to $1500 \mathrm{EJ} / \mathrm{yr}$ in 2050 in the most ambitious scenario (Smeets et al., 2007).

- The key factor that influences the potentials is the availability of surplus agricultural land for cultivation of dedicated energy crops. The amount of surplus agricultural land depends on the level of intensification in the agricultural sector, in particular the intensity of animal farming.

- In the reviewed studies, large potentials for biomass production are projected in emerging regions like Sub-Saharan Africa, the Caribbean and Latin America, as well as the $\mathrm{CIS}$ and the Baltics. This is due to the currently low-productive agriculture which is assumed to significantly improve over time, thus making agricultural land available for biofuel production.

- Of the eight countries studied for this project, Brazil currently seems to be the only country with considerable potential to produce energy crops on underutilised pasture. Other countries (e.g. Cameroon, India, Tanzania, Thailand) have limited land reserves and would have to increase their agricultural productivity significantly to free large amounts of land for second-generation biofuel crops.

- In order to better identify the potential for dedicated energy crops, improvements in accuracy of land use data are required. In particular, in countries where traditional land use through smallholders is prevailing (e.g. Cameroon and Tanzania), better regional data is needed.

- In many developing countries technological improvement, new infrastructure, including roads and energy supply, and capacity building in the agricultural sector are needed. These investments will help to revitalise rural economies and could allow for sustainable feedstock production with additional income opportunities in the long term.

\subsection{Global biomass potential}

The IEA scenarios mentioned earlier underline the important role that biomass is expected to play in future energy supply. In these scenarios, biofuel consumption is projected to increase considerably during the next decades. This is particularly the case under $\mathrm{CO}_{2}$-constrained conditions as assumed in the BLUE Map Scenario, where almost $90 \%$ of all biofuels are expected to be secondgeneration fuels by 2050 . To assess the potential for second-generation biofuels production, 
existing and potential biomass resources have to be identified. Since second-generation biofuels can be produced from virtually any type of biomass, a review of studies evaluating the potential for biomass production has been undertaken to analyse potential resources in developing regions. The aim of the following literature review is to illustrate the range of estimates for different world regions. The aim is furthermore to point out key factors that determine biomass potentials in the Page $\mid 46$ reviewed studies and the perspectives for major economies and developing countries, based on findings from the eight country profiles in Annex A of this study.

The number of studies that are discussed in this chapter is limited, but since they are based on the results of several previous publications (e.g. IEA, 2006; Smeets et al., 2007), they reflect the conclusions on bioenergy potentials of a broad number of authors.

Different types of potentials have been defined (e.g. in Hoogwijk, 2004; Antilla et al., 2009), according to their possible mobilisation for bioenergy production:

- The theoretical potential refers to the theoretical amount of biomass that is produced according to total primary production regardless of current land use.

- The geographic potential describes the theoretical potential in areas that are considered available and suitable for biomass production. Losses, for example during harvest, are not taken into consideration.

- The technical potential is the amount of biomass that could be harvested from available and suitable land. It includes losses during the harvesting process.

- The economic potential includes biomass that is technically acquirable and can be derived at costs competitive with alternative energy applications.

- The ecological potential takes ecological criteria into account, like the loss of biodiversity and soil erosion.

A differentiation of the potentials is crucial to understand existing estimates of global bioenergy assessments. Most of the potentials discussed here are focussing on geographic and technical potentials and do not take economic aspects into consideration - thus indicating higher amounts than could, in practice, be produced cost-competitively.

The total bioenergy potential covers the various sources of biomass (including dedicated energy crops, as well as forestry and agricultural residues and waste) that were taken into consideration in the respective country studies. Results vary widely, ranging from a low estimate ${ }^{10}$ of $33 \mathrm{EJ}$ (Hoogwijk et al., 2003) up to a maximum potential ${ }^{11}$ of more than 1500 EJ in 2050 (Smeets et al., 2007) (Figure 8). The high potential indicated by Smeets et al. is based on a scenario with highly advanced and intensive agriculture that would allow for a big share of current agricultural land to be available for biomass cultivation.

Considering that total primary energy demand in 2007 was about 505 EJ (IEA, 2009a), the potentially available biomass could cover between $6 \%$ and $300 \%$ of the current energy consumption. Compared to projected total primary energy demand in the Blue Map Scenario (750 EJ), bioenergy potentials could contribute $4.5 \%$ in the lowest assumption (Hoogwijk et al., 2003) and up to $200 \%$ in the most optimistic scenario, presented by Smeets et al. (2007). None of the studies reviewed for this paper makes assumptions on how the potentially available biomass will most likely be converted into bioenergy. Therefore it is not possible to conclude from the review how much biomass exactly would be dedicated to the production of second-generation

\footnotetext{
${ }^{10}$ Geographical potential, assuming higher heating value (HHV) of $15 \mathrm{GJ} / \mathrm{t}_{D M}$.

${ }^{11}$ Technical potential, assuming $H H V$ of $19 \mathrm{GJ} / t_{D M}$.
} 
biofuels in the long term. The demand for certain types of bioenergy and the economics of each conversion route will determine how available biomass resources will be used in practice.

The studies discussed above, however, do not take economical aspects into consideration. In one study Faaij (2007) estimated that about $100 \mathrm{EJ} / \mathrm{yr}$ of agricultural residues and wastes could be supplied at costs of around USD 2-3/GJ (approximately USD 30-45/ $\mathrm{t}_{D M}$ ) by 2050 . The price of dedicated energy crops from plantations was estimated in the range of USD 3-5/GJ (approximately USD $45-75 / t_{\mathrm{DM}}$ ). For second-generation biofuel production, these indicated prices could result in costs of USD $0.67-0.94 / \mathrm{Ige}_{\text {ge }}$ with an oil price of USD 60/bbl. In the long term, with oil at USD 120/bbl, prices for BTL-diesel and lignocellulosic ethanol could drop to USD $0.46-0.71 / \mathrm{I}_{\mathrm{ge}}$ (based on IEA Mobility Model, 2009; see Chapter 8 for more details).

Figure 8. Literature review of global bioenergy potentials for 2050

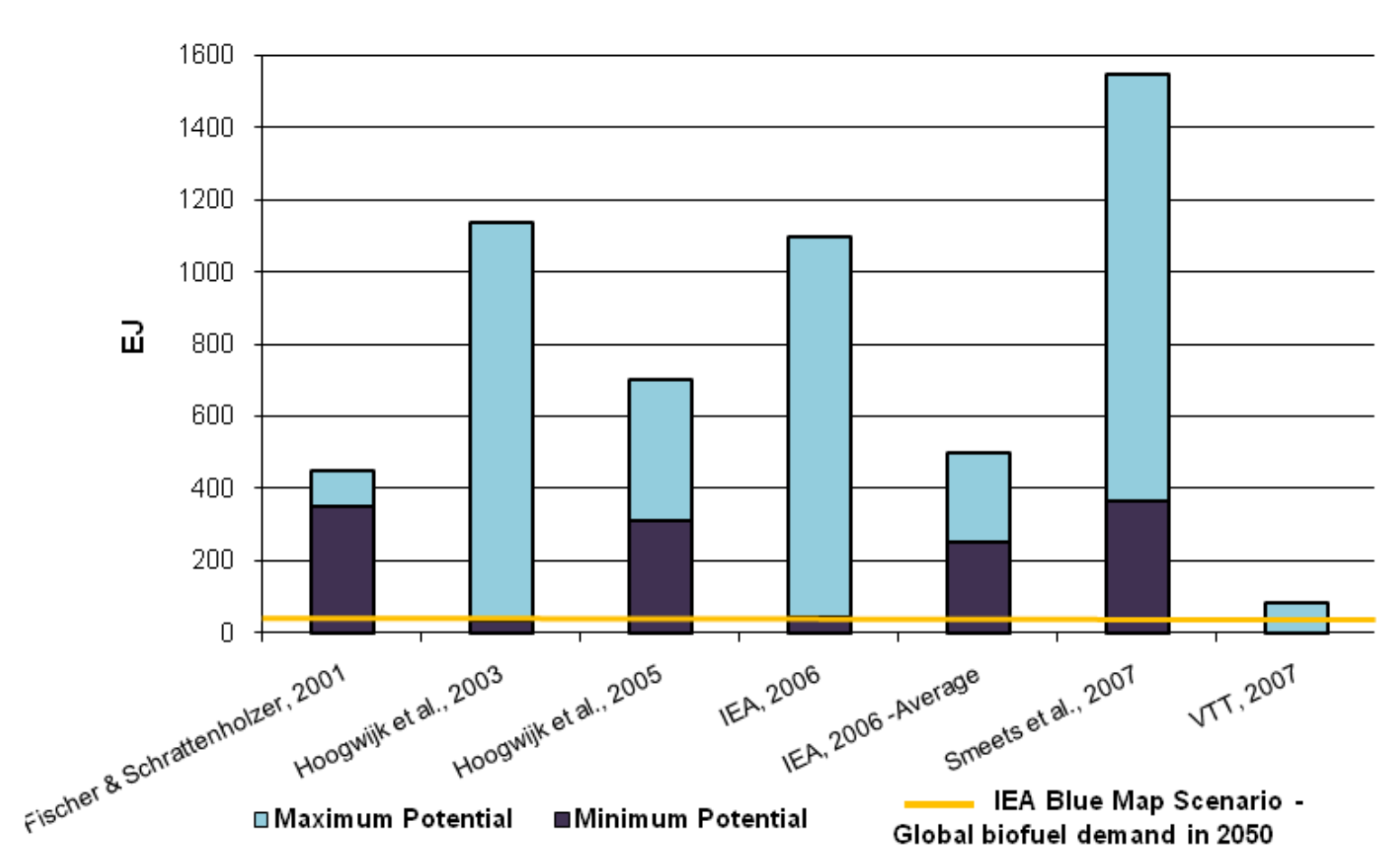

Hoogwijk et al. describe the geographic potential; IEA, Smeets et al. and VTT describe the technical potential; and Fischer \& Schrattenholzer describe the economical potential.

\subsection{Potential for dedicated energy crops from surplus land}

One of the major factors that influcences the future biomass potential in the reviewed studies is the availability of suitable land for biomass cultivation. As mentioned earlier, a variety of dedicated energy crops can be cultivated as feedstock for second-generation biofuels (Chapter 5), with highest yields resulting when cultivation takes place on fertile cropland.

In the reviewed studies, significant improvements in the agricultural system are assumed to free vast amounts of agricultural land, in particular pasture areas. This would require significant changes to the status quo, especially in developing countries where those improvements might not be feasible in the near future. This means that in the short term unused land reserves would be the only basis for the planning of bioenergy plantations in order to avoid competition with food production. Figure 9 shows the currently unused cropland in different world regions that has been 
identified by the FAO. Since parts of this potential cropland is actually under forest cover, wetlands, or other valuable and protected habitats, only about 250-800 Mha are assumed to be available in practice (FAO, 2008a). Similar estimates on land availability are presented by the International Institute for Applied System Analysis (IIASA), which suggests that about 790 Mha of extensive pastures could theoretically be available for production of biofuels or bioenergy. A comparison to

Page | 48 other landcover databases, however, showed variations of up to $50 \%$, reflecting high uncertainties in the identification of unused land (Kraxner, 2008).

Figure 9. Potential area for cropland expansion

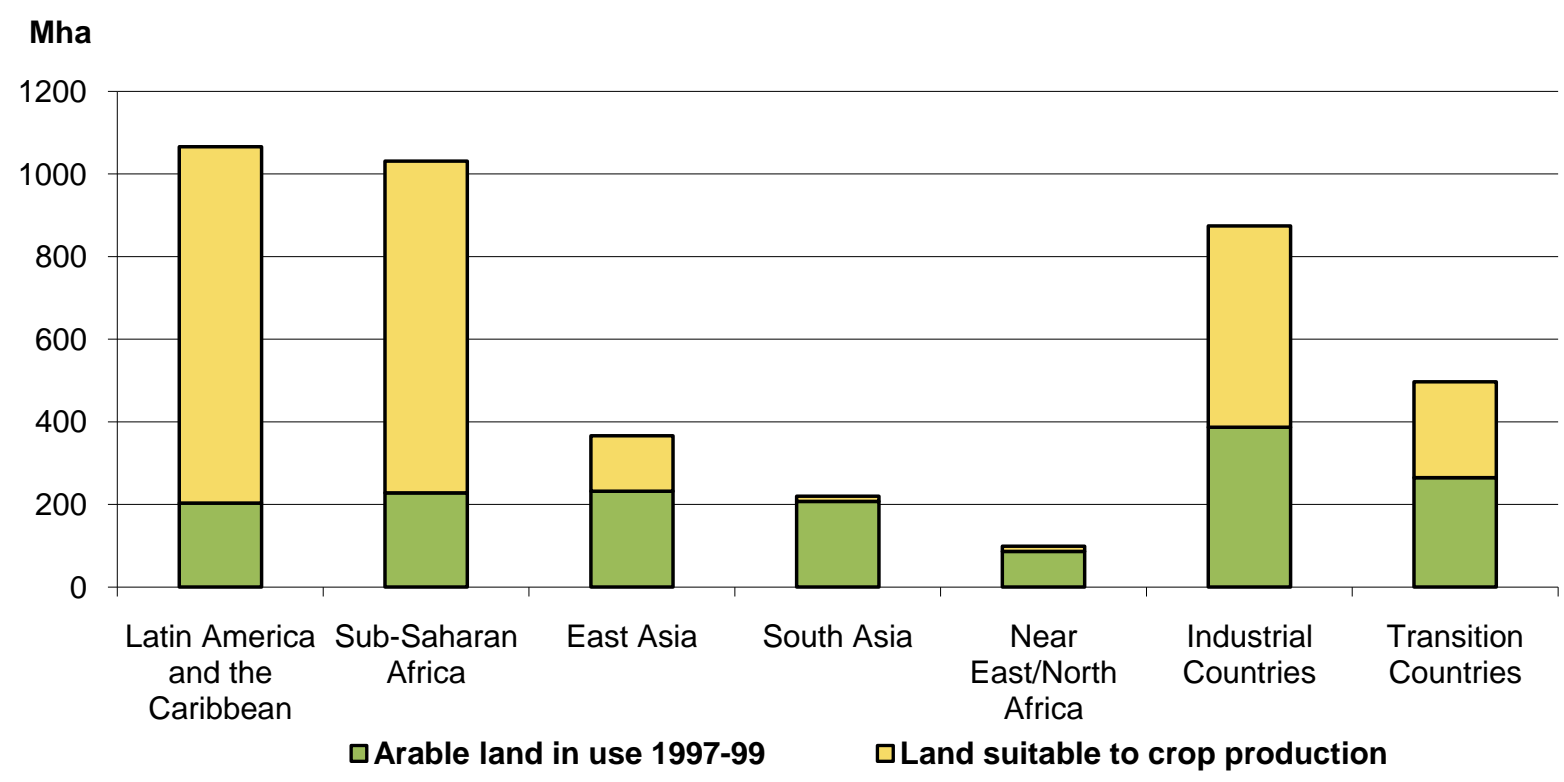

Source: FAO, 2003

Global food demand in 2050 is considered in all scenarios in the reviewed studies, so that the indicated potentials for bioenergy would be produced on surplus land that is not needed for food production. Many of the assumptions on future land availability appear very ambitious. The most optimistic estimate was found in the WEO 2006 where the maximum available land area was suggested to be around $5.7 \mathrm{Gha}$, assuming an availability of $4 \mathrm{Gha}$ of agricultural land and $1.7 \mathrm{Gha}$ of marginal land. To avoid competition with food production, this would require the adoption of intensive agriculture with increased yields and intensive animal farming, on a large scale. The average value indicated in the WEO 2006 is between 1 Gha and 3.7 Gha in 2050, which is more or less consistent with the 0.7-3.6 Gha estimated by Smeets et al. (2007) and the 0-3.7 Gha estimated by Hoogwijk et al. (2003).

In the lowest scenario presented in Hoogwijk et al. (2003), no additional agricultural land is projected to be available and there is, hence, limited potential for dedicated energy crops. Dedicated energy crops could therefore only be grown on marginal land, yielding a projected bioenergy supply of only $8 \mathrm{EJ}$ in 2050. In the highest scenario in this study, however, dedicated energy crops could produce up to $1098 \mathrm{EJ}$, with $90 \%$ coming from surplus agricultural land. This comes close to the highest assumption given by Smeets et al. (2007), who found that technically about $1300 \mathrm{EJ} / \mathrm{yr}$ of bioenergy could technically be produced in 2050, assuming that 72\% of current agricultural land could be made available for cultivation of energy crops. This includes, both fertile cropland as well as a large share of pasture land which is not suitable for production of conventional 
agricultural crops. Using current second-generation biofuel technology, $10 \%$ of this biomass would be sufficient to produce the projected biofuel demand in the Blue Map Scenario. Around $70 \%$ of this potential is situated in emerging and developing regions, where the agricultural sector to date often shows low efficiency.

\subsection{Surplus forest growth and forestry residues}

The forestry sector is another source of biomass that could contribute considerably to the projected total bioenergy potential in the reviewed studies. This potential depends on various factors, including the sustainability of the forestry sector, the consideration of protected forests and the expected future demand of wood fuel and industrial roundwood, amongst others. The total potential for forest-derived biomass was estimated to be 10-16 EJ (Hoogwijk et al., 2003) and 30-150 EJ (IEA, 2006) under different scenarios. In the higher scenarios, all technically available forest biomass and forestry residues were assumed available, whereas in the lower scenario sustainable forest management is assumed. The estimates given by VTT (2007) are more moderate -around 23 EJ - well below the estimate in Smeets and Faaij (2007), which suggests that $92 \mathrm{EJ}$ of forest biomass could be available in 2050. In this study, about 6 EJ would be derived from logging residues, $11 \mathrm{EJ}$ from processing residues and about $11 \mathrm{EJ}$ from wood waste. However, the economic potential is estimated around $43 \mathrm{EJ}$, due to the assumption that only $15 \mathrm{EJ}$ of surplus forest growth could be made available in a profitable way.

\subsection{Agricultural residues and wastes}

Agricultural residues and wastes can be derived from different sources, as discussed in Chapter 5. In the studies reviewed for this paper, both primary and secondary agricultural residues are included in the overall bioenergy potential for 2050. The lowest assumption is given by Hoogwijk et al. (2003) who estimate between $10 \mathrm{EJ}$ and $32 \mathrm{EJ}$ of agricultural residues to be available by 2050 . The higher estimate in this study is similar to the projection of VTT (2007), which indicates a potential of $32 \mathrm{EJ}$ in 2050. In the WEO 2006, the potential is indicated in a range of 15-70 EJ; Smeets et al. (2007) indicate the potential for agricultural residues of 46-66 EJ in 2050, also within the range of the WEO 2006 figures. Chapter 7 provides an overview of the potential for agricultural and forestry residues for the production of second-generation biofuels, as assessed in this study.

\subsection{Regional distribution of potentials}

The above biomass potentials are not evenly distributed around the globe, and high amounts are concentrated in areas with favourable climatic conditions and vast land reserves. Some of the studies have a global view and distinguish between different regions (e.g. Smeets et al., 2007; Fischer and Schrattenholzer, 2001; Hoogwijk et al., 2005), while other studies focus only on certain regions or countries (e.g. Fischer et al., 2007), allowing for a more detailed analysis of the regional potentials for bioenergy.

\section{Europe}

For Europe, biomass potentials on a country level are available (e.g. Fischer et al., 2007), but only aggregated results for the whole region will be discussed here. The assessment of biomass resources in Europe, in particular in the European Union, has gained significant attention due to ambitious mandates for the use of renewable energy defined in Renewable Energy Directive, which mandates a share of $20 \%$ renewable energy in total energy supply and $10 \%$ in the transport sector 
by 2020. Biomass will be an important source to meet those targets and, therefore, of considerable interest to EU member countries. With ambitious support policies and promising technology development in place for second-generation biofuels, the production of these fuels will play an increasing role in the next decade or so.

Fischer et al. (2007) assessed bioenergy potentials for the EU27 countries and Ukraine. The

Page $\mid 50$ potentially available land area for cultivation of energy crops in the EU27 was indicated to be 47.8 Mha in 2030, 5.1 Mha of which could be made available from current pasture areas. For Ukraine, up to 22.4 Mha in 2030 were estimated to be available for biomass cultivation. If all potentially available land were cultivated with first-generation biofuel feedstock, about $6 \mathrm{EJ} / \mathrm{year}$ of biofuel could be produced, while with second-generation technology up to $13.5 \mathrm{EJ}$ of biofuel could be produced. Regarding the potential for bioenergy from agricultural residues, the study estimated that 2.3 EJ of biofuel could be available in 2000, decreasing to $1.7 \mathrm{EJ}$ biofuel equivalent in 2030 .

Smeets et al. (2007) estimated the technical bioenergy potential in 2050 in Europe to lie between $100 \mathrm{EJ}$ and $303 \mathrm{EJ}$, mainly provided by dedicated energy crops grown on the expected $129-$ 592 Mha available surplus agricultural land. In the lowest scenario, these crops could provide 53 EJ whereas in a scenario with very intensive agriculture, up to $255 \mathrm{EJ}$ would technically be available. Forestry and agricultural residues are calculated to provide between $11 \mathrm{EJ}$ and 13 EJ whereas surplus forest growth could provide around $35 \mathrm{EJ}$ of biomass. In particular the former Soviet Union countries have a vast potential of surplus agricultural land, according to the analysis.

\section{North America}

North America is currently the world's leading biofuel producing region with a market share of roughly $46 \%$ in 2008 (IEA, 2009b), consisting almost entirely of first-generation biofuel. Though RD\&D efforts on second-generation biofuel production in the United States and Canada are remarkable, no commercial production yet exists. According to the ambitious biofuel mandate in the Renewable Fuels Standard, the United States will need to increase its biofuel production significantly within the next 15 years, in particular that of cellulosic ethanol. Therefore, it is important to assess existing biomass potentials that could provide feedstock for biofuel production. With a high level of development and strong expertise in first-generation biofuel production, the conditions for the use of lignocellulosic feedstocks for second-generation biofuels are favourable in both the United States and Canada.

For North America, Smeets et al. (2007) suggest between 54 Mha and 348 Mha of surplus agricultural land will be available for bioenergy production by 2050 , depending on the scenario. The total technical potential for bioenergy could reach between $39 \mathrm{EJ}$ and $204 \mathrm{EJ}$ in 2050. The estimates of 39-71 EJ given by Hoogwijk et al. (2005) are within the range indicated by Smeets et al.

The total bioenergy potential in 2050 includes 6-11 EJ of agricultural residues and 6 EJ of forestry residues in the different scenarios. Surplus forest growth is estimated to provide roughly $5 \mathrm{EJ}$ in 2050. The biggest share of the projected bioenergy potential is derived by dedicated energy crops that could provide 20-174 EJ of biomass (Smeets et al., 2007).

\section{Latin America}

Latin America is the second largest biofuel producing region, with a total output of 29 billion litres in 2008. Biofuel production is mainly taking place in Brazil (96\%), and to a lesser extent in Colombia 
(1.4\%) (IEA, 2009b). Studies suggest the region has great potential to produce bioenergy due to favourable climatic conditions and vast areas suitable for agriculture that are currently not cultivated or used as extensive pasture (Smeets et al., 2007). Historically, agricultural yield improvements have been less important in Latin America and Sub-Saharan Africa (as compared to Asia, for example) and therefore could play an increasing role in the future (FAO, 2008a). Brazil for instance plans to expand its sugar cane production from currently 4.4 Mha (2008 data) to about 8 Mha in 2017, assuming a share of $50 \%$ for biofuel production mainly by reducing current extensive pasture area (MME, 2009). (For more details, see the country profile on Brazil in Annex A). The same could be feasible for other bioenergy crops and other countries, including feedstocks for second-generation biofuels.

The geographic bioenergy potential for Latin America indicated by Hoogwijk et al. (2005) is between $31 \mathrm{EJ}$ and $103 \mathrm{EJ}$ in 2050 under different land-use scenarios. This takes only the potential from dedicated energy crops on different land categories into consideration and excludes forest and agricultural residues.

The projections of Smeets et al. (2007) for the bioenergy potential in 2050 lies between $89 \mathrm{EJ}$ and $281 \mathrm{EJ}$ in the different scenarios, most of which would be provided by dedicated energy crops (47-221 EJ). Surplus forest growth could also provide a considerable potential of roughly $22 \mathrm{EJ}$ and another $1 \mathrm{EJ}$ could be derived from forestry residues. This is considerably less than the potential of agricultural residues, which could provide between $10 \mathrm{EJ}$ and $11 \mathrm{EJ}$ of bioenergy.

Currently second-generation biofuel RD\&D in Brazil focuses mainly on the production of cellulosic ethanol from sugar cane bagasse. Therefore, it is uncertain if the new technology could become a driver to increase agricultural productivity to free land for feedstock production. The economic situation of first-generation biofuels in the region suggests that available land will instead be dedicated to feedstocks like sugar cane or oil palm, whereas second-generation biofuels would use the residues of such production processes. However, major technological breakthroughs could change the economic situation and lead to favourable conditions for the production of secondgeneration biofuels in the long term.

\section{Africa}

The share of biomass in the primary energy supply is relatively high in Africa, since many households rely on traditional biomass to meet their energy needs. Regarding production of biofuels, however, Africa currently plays only a minor role with a total output of about 100 million litres in 2008 , or about $0.1 \%$ of global biofuel production (IEA, 2009b). Studies on global bioenergy potentials suggest that in the long term considerable possibilities exist, in particular in sub-Saharan Africa, for the production of bioenergy and biofuels.

Both Smeets et al. (2007) and Hoogwijk et al. (2005) suggest that relatively large biomass potentials on surplus land exist for sub-Saharan Africa in 2050, compared to arid northern Africa and the Middle East. This is mainly due to currently low crop yields, the improvement of which would free vast amounts of agricultural production for the cultivation of energy crops. If such improvements were to occur, both Hoogwijk et al. (2005) and Smeets et al. (2007) indicate the availability of vast land areas for cultivation and production of biomass. Smeets et al. (2007) suggest that 104-717 Mha of surplus agricultural land could be made available in sub-Saharan Africa if the efficiency of the agricultural sector was significantly improved. The biomass that could be produced in the region, including forestry and agricultural residues, is between $3 \mathrm{Gt}_{\mathrm{DM}}(49 \mathrm{EJ})$ and about $347 \mathrm{EJ}$ in 2050 in the different scenarios. Between $16 \mathrm{EJ}$ and $21 \mathrm{EJ}$ of agricultural and forestry residues could be 
available in 2050. The major share of this would come from agricultural residues, with only 2 EJ from surplus forest growth in 2050. Dedicated energy crops are estimated to provide between $31 \mathrm{EJ}$ and $317 \mathrm{EJ}$ in the different scenarios.

Considering that current biomass consumption in the region is roughly $640 \mathrm{Mt} / \mathrm{year}$ (12 EJ), the

Page 52 of biomass to the production of second-generation biofuel when the technology becomes available and the required infrastructure is built.

\section{Asia}

The potential for biomass production in Asia is highly regional. While a high potential has been indicated for East Asia, potential in South Asia is projected to be considerably smaller. Current biofuel production in Asia is led by China as major producer, with a share of $53 \%$, followed by Thailand with $22 \%$ (IEA, 2009b). South Asia currently has a relatively high level of poverty and undernourishment, with only a limited potential for expansion of cropland (FAO, 2003). As a result, the potential for biomass production in the region is comparably smaller than in East Asia. Hoogwijk et al. (2005) assess South Asia to have production levels between $14 \mathrm{EJ}$ and $46 \mathrm{EJ}$ in 2050, which is similar to the estimate of Smeets et al. (2007) that indicates the availability of $23 \mathrm{EJ}$ to $37 \mathrm{EJ}$. Around $10 \mathrm{EJ}$ of agricultural and forestry residues are projected to be available in 2050, whereas the major share of the total potential (15-25 EJ) is derived from woody energy crops on surplus agricultural land.

For East Asia, Hoogwijk et al. (2005) find considerably larger bioenergy potentials, reaching between 24 EJ and 102 EJ in 2050 under different land-use scenarios. This is again similar to the results of Smeets et al. (2007), who indicate potentials from 23 EJ to 194 EJ in 2050. With a bioenergy potential from forestry and agricultural residues of roughly $10 \mathrm{EJ}$, the main share of the projected biomass would come from dedicated energy crops. The high potential in the most ambitious scenario reflects the possibility of an expanded agricultural sector and the subsequent availability of land for biomass cultivation.

\section{Oceania}

Biofuel production in Oceania contributes very little to global production, with a share of roughly $0.5 \%$ in 2008 (IEA, 2009b). However, projections for bioenergy potential in 2050 suggest that substantial amounts of biomass could be produced in the region, which would possibly allow for the production of second-generation biofuels as well. Main improvements that need to be undertaken to increase biomass production include increased irrigation and the shift from pasture land to cropland. Technologically improving yields in the agricultural sector, however, is expected to play only a minor role (Hoogwijk et al., 2005). Overall, they suggest Oceania offers significant potential for low-cost feedstock production, making it a relevant region for the production of secondgeneration biofuels.

Biomass potentials for 2050 indicated by Hoogwijk et al. (2005) are within the range of Smeets et al. (2007), latter vary between $40 \mathrm{EJ}$ and $114 \mathrm{EJ}$ for the different scenarios, with the major share derived by dedicated energy crops. Forestry residues as well as residues from the agricultural sector are estimated to play only a minor role, former could contribute around 0.6 EJ and the latter between 2 EJ and 5 EJ. Compared with current biomass consumption the indicated amounts of biomass could provide more than threefold the current demand at the lower end of the estimates. 
Given this fact and considering the governmental funding for second-generation biofuel R\&D in Australia, the region has considerable potential to become a producer of second-generation biofuels in the future.

\subsection{Discussion of results based on the current situation in selected countries}

\section{Land availability}

Rough estimates on availability of land that could be available for the cultivation of biomass for energy are discussed in the country profiles in Annex A of this study. Amongst the studied countries, there are significant differences as to what extent additional land reserves exist. In densely populated India for instance, $51 \%$ of total land is already under agricultural cultivation, so the expansion potential is fairly limited. About $40 \mathrm{Mha}$ (13.5\% of total land area) are classified as cultivable waste land, but these areas are often already under conservation or used by subsistence farmers and the rural poor. With a steadily growing population, it is likely that available cropland would be used for food production rather than for cultivation of energy crops in the future. Since water shortages are currently decreasing, agricultural productivity in some regions - and the future availability of suitable land for cultivation of second-generation biofuel feedstocks - appears highly uncertain.

In Thailand, the situation is similar to the one in India. Due to the high pressure on agricultural land in many regions, only limited potential exists to free surplus land without jeopardising food security. Therefore, only 352000 hectares ( $0.6 \%$ of total land area) are potentially suitable for cultivation of energy crops. The growing land demand for both food and first-generation biofuel production limits the possibilities to cultivate this idle land with second-generation biofuels feedstocks.

Similar to Thailand and India, China has experienced an increasing population and rapid economic growth over recent decades, resulting in domestic food demand that continues to increase. With a cultivated area of roughly $150 \mathrm{Mha}$, agriculture occupies most of the available arable land; there are only an estimated $7 \mathrm{Mha}(0.1 \%$ of total land area) of reserve arable land resources, most of it in the western region (Chinability, 2009). Though suitable for production of energy crops, growing demand for crop production and built-up land suggests that very little of this area could be used to produce feedstock for second-generation biofuels. Furthermore, the lack of infrastructure might hamper biomass supply at reasonable costs. However, data on land use in China are often old and need to be updated in order to identify whether additional land resources exist that might be suitable for production of second-generation biofuel feedstock.

In South Africa, there are roughly $18 \mathrm{Mha}$ in area suitable for crop production, about $6.5 \mathrm{Mha}$ of which are already either under forest cover or used for crop production. The availability of the remaining 11.5 Mha of potential cropland is limited due to complex land tenure and the fact that most of this land is currently under protection or used for wildlife and cattle herding; thus, only about 3 Mha (2.5\% of total land area) of potential cropland are estimated to be available for crop or biomass cultivation. Currently this land is not cultivated due to complex land holding structure and uncertainties caused by the government's land-reform. If these obstacles could be overcome, production of second-generation biofuel feedstock would be feasible. The use of indigenous grasslands could also be an option to harvest biomass in the short-term, but low yields and poor infrastructure do not currently allow for an economically feasible use of this feedstock source. 
Of all countries studied for this project, Brazil probably has the largest land reserves. Vast areas of underutilised pasture exist, which account for roughly 20\% (197 Mha) of the total land area. Partly suitable to grow energy crops, they could be made available with comparably small risk through increasing cattle densities. At the moment, these pasture areas are mainly considered for sugar cane expansion. However, if second-generation biofuels reach the commercial stage, cultivation of

Page | 54 lignocellulosic feedstock become feasible, especially in regions less suitable for sugar cane production.

To ensure the sustainability of this expansion, the Brazilian government has developed a unique system to identify areas for sustainable cultivation of sugar cane based on environmental, economic and social criteria. The National Agro-Ecological Zoning for Sugar Cane (ZAE Cana), the largest crop survey in Brazilian history, regulates the expansion of sugar cane production in light of the growing demand for food and biofuels. To preserve Brazil's indigenous lands, biodiversity and natural resources, it prohibits the construction or expansion of sugar cane farms in areas like the Amazon, Pantal (Brazilian wetlands) or the Upper Paraguay River Basin. Coupled with the areas not suitable for sugar cane farming, the bill would effectively prohibit the cultivation of sugar cane on $92.5 \%$ of Brazil's land area. Therefore, only 64 Mha will be eligible for sugar cane farming, considerably less than the 197 Mha of underutilised pasture area mentioned above.

\section{Yield improvement}

In the studies discussed above, yield improvement is seen as another key aspect to shift agricultural lands used for cultivating food crops to energy crop cultivation. In fact, many developing countries currently achieve yields that are below the agro-ecologically attainable maxima. Thus, there remains considerable potential to raise agricultural production. In Tanzania, for instance, average wheat yields could theoretically amount to $3 \mathrm{t} / \mathrm{ha}$ according to prevailing agro-ecological conditions, while currently an average of only $1.6 \mathrm{t} / \mathrm{ha}$ is achieved. A similar situation occurs in Brazil, where an average of $3.3 \mathrm{t} / \mathrm{ha}$ of wheat could be produced instead of current levels of $1.8 \mathrm{t} / \mathrm{ha}$. In India, the potential for yield improvement exists as well, since current rice yields account for only $63 \%$ of the agro-ecological attainable yield (FAO, 2003). More efficient management (e.g. integrated pest management, no-till/conservation agriculture) and better allocation of crop areas could, therefore, lead to considerably higher crop yields. This could on the one hand be beneficial to produce sufficient amounts of food for the growing population, and on the other hand might enable land area to be dedicated to the production of biofuels without threatening food security.

In order to considerably improve yields and increase the overall productivity in less developed countries, improved cultivation and agricultural management skills are needed, as well as improved infrastructure, synthetic fertiliser and modern equipment (e.g. tractors and forage harvesters). This is currently a challenge in several of the countries studied for this project, where small-scale farms are prevalent and are usually poorly equipped and without extensive financial resources. Small land holdings (an average of $0.5-5$ ha across different regions in India) and limited profits restrict access to modern technical equipment. Moreover, constrained finances in many emerging and developing countries do not allow for efficient agricultural subsidies that could support smallholders. Considering these economical factors, the potential for yield improvement can be considerably below the agro-ecological maxima indicated above. Improved crop yields can thus only be achieved if it is economically profitable for the farmer to acquire certain required inputs (e.g. fertiliser). In this regard, second-generation biofuel production could favour crop yield development, since farmers could increase there income through selling residues to the plant. This creates two income streams thus may make yield increases more achievable. 
In the near future, however, significant improvement in agricultural productivity with the subsequent availability of cropland for biofuel production will be limited in most developing countries and will depend mainly upon improved infrastructure and agricultural management. Only in some emerging regions, where large-scale agriculture is widespread and agricultural management is more advanced, will yield improvements be easier to achieve (e.g. in Brazil).

\subsection{Conclusions on feedstock potential from surplus land}

The potential to produce second-generation biofuel feedstock on additional land varies on the regional resources available. Land in developing countries that has been identified as potentially available is subject to several constraints regarding its utilisation for feedstock production. In contrast to many developed countries, infrastructure in these regions, especially in rural areas, is in poor condition, thus reducing the possibility of transporting feedstock or end-product.

The findings from the eight studied countries underline that the potential availability of surplus land for cultivation of second-generation biofuel feedstock differs considerably across regions. While many bioenergy potential studies assume significant improvement in the agricultural sector in order to produce vast amounts of biomass, this development cannot be seen in most of the countries studied for this project. As a number of constraints exist that currently reduce the amount of land that could be allocated to the cultivation of biofuel feedstocks, the following points should be considered:

- In many major economies and developing countries, the population is steadily growing and thus demand for agricultural land for food production is increasing (e.g. in China, India, Thailand), thereby limiting the potential for sustainable production of dedicated energy crops.

- Complex land tenure complicates the identification and mobilisation of suitable land in some countries (e.g. in South Africa, Tanzania and Cameroon).

- Water shortages are a growing concern for instance in China, India, Tanzania and South Africa, and require careful planning of feedstock cultivation.

- Improvements in accuracy of land use data are required to identify areas for sustainable feedstock production; in particular, in countries where traditional land use through smallholders is prevailing (e.g. Cameroon and Tanzania) better regional data is needed.

- The Brazilian Sugar Cane Zoning (ZAE Cana) could become a model for sustainable land use management for biofuels in other countries as well.

Considering the uncertainties regarding land availability and the lack of research on indigenous energy crops, it is suggested that the second-generation biofuel industry in emerging and developing countries should focus on available feedstock sources like agricultural and forestry residues in the short term. This will help to promote sustainable development and to avoid a delay in start of production due to insufficient feedstock availability, as long as feedstock resources are used sustainably. In the meantime, land use databases could be built based on the latest scientific knowledge in order to enable the sustainable cultivation of biofuel feedstocks in the long term. 



\section{Potential Second-Generation Biofuel Production from Agricultural and Forestry Residues}

\section{Key messages}

- Currently, around 5.1 billion dry tonnes of agricultural residues are produced globally. The total amount of residues from roundwood production and processing is 500 million tonnes dry matter, most of which is produced in Asia, followed by the Americas and Europe.

- While previous studies often assumed that $25 \%$ of residues could generally be used for bioenergy production, the residue availability indicated by local consultants was considerably smaller in some of the countries studied for this report (e.g. India and South Africa). Therefore, two scenarios were established for the global potential analysis: one assuming availability of $25 \%$ and one based on $10 \%$ availability of residues.

- Assuming the availability of $10 \%$ of these residues for second-generation biofuel production, yields could total 120 bn Ige of BTL-diesel or lignocellulosic ethanol, roughly twice the global biofuel demand in 2008 . If $25 \%$ of the residues were available, around $300 \mathrm{bn}$ Ige of BTL-diesel or lignocellulosic ethanol could be produced globally, or up to $430 \mathrm{bn}$ Ige of bio-SNG.

- In 2030, both agricultural and forestry production is expected to increase, resulting in higher amounts of residues in these sectors. Globally, around $6.8 \mathrm{Gt}_{\mathrm{DM}}$ of agricultural residues and $0.7 \mathrm{Gt}_{\mathrm{DM}}$ of forestry residues would be produced.

- If $10 \%$ of these residues could be mobilised for production of second-generation biofuels, this could yield either around 155 bn Ige of BTL-diesel or Ic-ethanol, or up to 220 bn Ige of bio-SNG. If $25 \%$ of global residues were available, biofuel yields would be much higher, reaching either around 385 bn Ige of BTL-diesel or Ic-ethanol, and up to 554 bn Ige of bioSNG.

- This means that in 2030 , between $45 \%$ and $63 \%$ of the projected biofuel demand in the WEO 450 Scenario could be covered with second-generation biofuels using $10 \%$ of global residues, assuming that necessary technologies are in place. If $25 \%$ of the global residues would be available, between 385-554 billion lge of second-generation biofuels could be produced. This is more than the projected biofuel demand in 2030. Thus, total biofuel production could even increase above the projected level without occupying any additional agricultural or forestry land. 


\subsection{Methodology of residue assessment}

Most authors agree that the major share of the global future bioenergy potential would come from surplus land, a resource whose availability in developing and emerging countries is highly uncertain. Therefore, this study tries to assess the potential contribution of agricultural and forestry residues to the production of second-generation biofuels.

Advantages of this feedstock source are its ready availability and non-reliance on additional land use or the development of specific cultivation techniques. Due to their short term availability, agricultural as well as forestry residues could form an important feedstock in the initial phase of building a second-generation biofuel industry. Furthermore, agricultural residues are produced on every farm and thus offer the opportunity for farmers to profit from biofuel production, which could positively affect rural development, especially in developing countries.

To assess the amount of primary agricultural and forestry residues, data on crop and roundwood production, as well as on the ratio between main products and residues, are required. Data on the global production of different crops and industrial roundwood were obtained from the United Nations Food and Agriculture Organization FAOStat database ${ }^{12}$, the only source for such data with global coverage. To assess the amount of primary and secondary residues for each crop type, residue-to-product ratios (RPR) were adopted from Fischer et al. (2007), OECD (2004) and Koopmans \& Koppejan (1997), who indicated RPR for most agricultural crops (Annex B). The available data for processing residues is generally poor, due to a wide variety of processing techniques which result in different shares of residues. Therefore, only some key crops were taken into consideration (e.g. rice, oil palm, sugar cane, a.o.), the processing of which is relatively standardised.

The ratio between main product and residue can vary depending on a set of factors including crop variety, water and nutrient supply, and the use of chemical growth regulators ${ }^{13}$, amongst others. Therefore, average RPR were chosen in cases where both low and high residue fractions were suggested by Fischer et al. (2007). Calculation of the residue dry mass was done based on moisture content as indicated in the above-mentioned studies.

For residues from forestry, the approach presented in Smeets and Faaij (2007) was adopted. In this study, a residue to product ratio of 0.6 is indicated for primary residues, which is in line with values given by other authors. This means that for every solid cubic meter of industrial roundwood, 0.6 solid cubic meters of logging residues are left behind as residue. Logging residues from fuel wood harvesting are not taken into consideration, since it is assumed that these residues are already used as traditional energy source. For secondary residues, which are produced during wood processing, an RPR of 0.5 was indicated by Smeets and Faaij (2007) and used accordingly in this study. The moisture content of the wood residues is assumed to be $50 \%$ and the weight of $1 \mathrm{~m}^{3}$ solid roundwood is set at $0.5 \mathrm{t}$, based on values available from literature (IEA, 2007). The assessment of available residues is based on average crop and roundwood production of the years 2004-07 to balance possible extremes in annual harvests.

In practice, not all existing residues can be used for bioenergy production due to scattered abundance, technical constraints, ecosystem functions and other uses (e.g. animal fodder, fertiliser, domestic heating and cooking). Therefore, an availability of $25 \%$ has been assumed in several previous studies (Berndes et al., 2003). Compared to the findings from the eight country profiles in Annex A of this study, this estimate seems to be too optimistic in many cases, since existing uses

\footnotetext{
${ }^{12}$ www.faostat.fao.org

${ }^{13}$ Chemical growth regulators limit the growth of crops to ensure better stability and higher grain yields.
} 
often reduce the availability of residues in the studied countries. Therefore, second-generation biofuel yields based on an assumed $10 \%$ availability of agricultural and forestry residues were calculated as well.

Furthermore, future crop production and roundwood consumption for the year 2030 was calculated. Data for the increase in global crop production was adopted from FAO (2003), indicating an average annual growth of $1.3 \%$ over the period, derived from figures in Africa (2.05\%), the Americas (1.3\%), Asia (1.5\%), Europe (0.9\%), and Oceania (0.9\%). The global demand for industrial roundwood in 2030 was adopted from FAO (2003) as well, assuming an equal increase in production in all regions.

The assumptions in this study do not take into consideration possible changes in the human diet since this issue was considered too complex for the approach undertaken here. It is acknowledged, however, that a change of diet could influence the future share of certain crops (e.g. if the share of meat in the diet rises, more feed grain like soy and corn is needed) and thus the availability of certain residues.

For the purpose of this study, there are two scenarios for residue availability (either $10 \%$ or $25 \%$ of the total), and all such available residues are assumed to be converted into second-generation biofuels. In practice, though, not all types of residues are considered suitable for each conversion route; nevertheless, future development might increase the variety of feedstocks that can be used for a specific conversion pathway. Therefore, the biofuel yields in this study are calculated using all of the estimated available residues for each of the indicated conversion routes (lignocellulosic ethanol, bio-SNG and BTL-diesel). Due to higher overall efficiency and lower technical complexity, the bio-SNG pathway has a higher fuel output in terms of gasoline equivalent compared to the BTLdiesel and cellulosic bioethanol conversion routes, which yield similar amounts of secondgeneration biofuel. (Obviously, to use bio-SNG in the transport sector, a distribution infrastructure and vehicle fleet is required.)

Conversion efficiencies of $214 \mathrm{Ige}_{\mathrm{ge}} / \mathrm{t}_{\mathrm{DM}}$ are assumed for the lignocellulosic-ethanol pathway, $217 \mathrm{Ige} / \mathrm{t}_{\mathrm{DM}}$ for the BTL-diesel conversion route, and $307 \mathrm{Ige} / \mathrm{t}_{\mathrm{DM}}$ for the bio-SNG pathway (based on IEA, 2008a; DBFZ, 2008). ${ }^{14}$ The applied conversion efficiencies are average values and were chosen because reliable data on large-scale conversion efficiency does not yet exist. The calculation here focuses only on biofuel output and does not include potential gains from by-products. It has to be noted, though, that the use of by-products and waste-heat raises the total energy output and can increase the profitability of the whole process considerably (IEA, 2008a). For example, lignin, a waste product of lignocellulosic ethanol production, can be used to generate heat and electricity or can be used for pellet production. Wasted process heat has been suggested for use in district heating, thus raising the overall profitability of the production process (Sassner \& Zacchi, 2008). In the bio-SNG conversion, pure $\mathrm{CO}_{2}$ is produced that could be sold to the chemical industry and other users.

However, the marketing possibilities of by-products strongly depend on local circumstances and optimal uses can thus vary significantly between regions. While the biofuel production process requires heat and power that can be produced from by-products, the use of process heat for district heating is not feasible in certain regions, like tropical areas. It is therefore critical to analyse local marketing possibilities in order to achieve the best possible profits from by-products.

\subsection{Results}

Average global crop production in 2004-07 amounted to about $6.8 \mathrm{bn}$ t fresh matter. The cultivated area for production of these crops was about 1.22 Gha, representing around $25 \%$ of global

${ }^{14} I_{g e}=$ liter gasoline equivalent; $t_{D M}=$ tonne dry matter . 
agricultural area, a comparably small share compared to the 3.4 Gha currently under permanent meadows and pastures (FAOStat, 2009). Regions with major crop production are Asia (3.3 bn t fresh matter) and the Americas (1.9 bn t fresh matter) (Figure 10). The average global production of roundwood in the same period was about 1.7 billion solid cubic meters, with the largest share coming from the Americas $\left(786 \mathrm{Mm}^{3}\right.$ ) and Europe (534 $\mathrm{Mm}^{3}$ ) (Figure 10).

Page | 60 Figure 10. Annual global crop and roundwood production (2004-07 average)

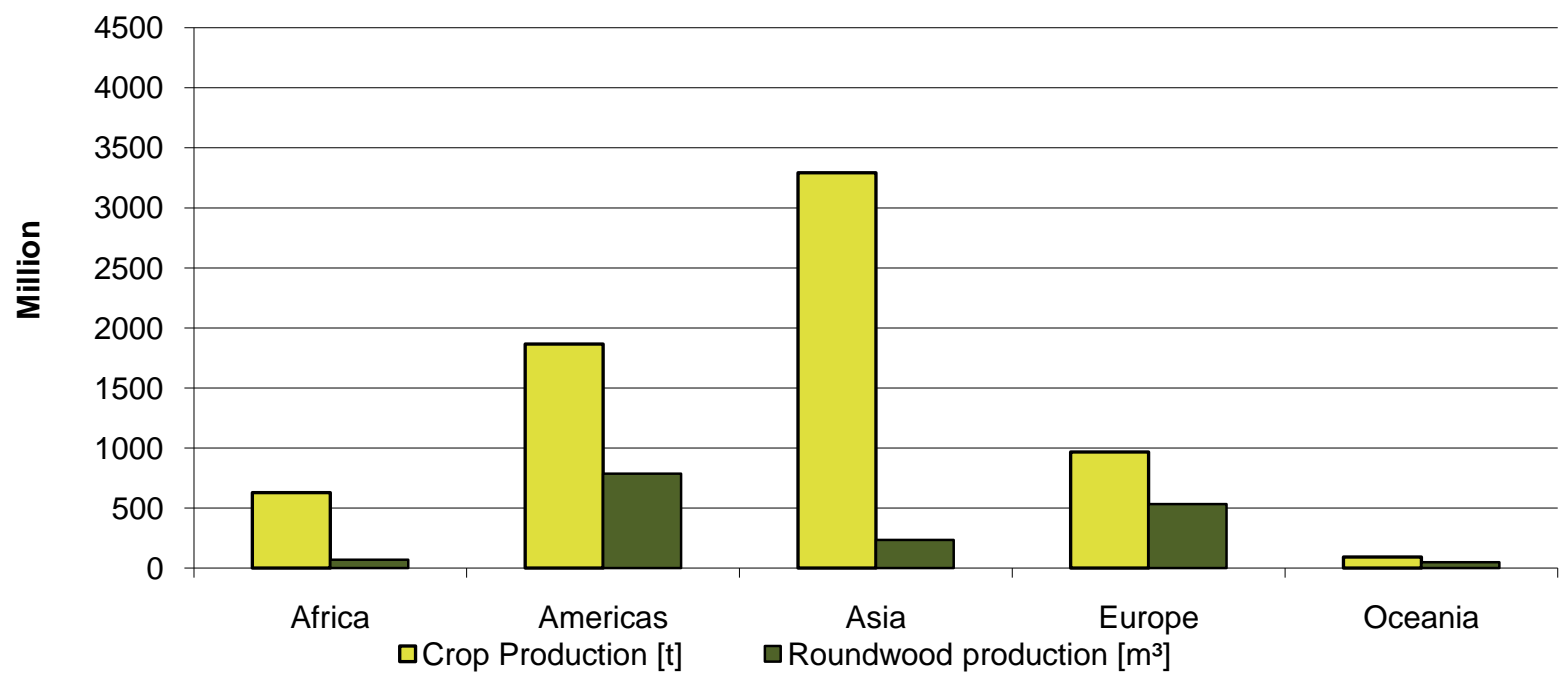

Source: FAOStat, 2009

Based on these current amounts of agricultural crops, it was calculated that around 5.1 billion dry tonnes of agricultural residues were produced globally and that around 501 million dry tonnes of forestry residues were generated. Under the two scenarios whereby $25 \%$ or $10 \%$ of these residues could be used for biofuel production, around $1.3 \mathrm{Gt}_{D M}$ and $0.5 \mathrm{Gt}_{D M}$ of agricultural residues would be available as feedstock, roughly $11 \%$ which would be derived from secondary residues. The forestry sector could provide $0.1 \mathrm{Gt}_{\mathrm{DM}}$ (assuming the $25 \%$ availability scenario) or $0.05 \mathrm{Gt}_{\mathrm{DM}}$ (under the $10 \%$ scenario) as feedstock for biofuel production (Figure 11). The share of primary and secondary residues in this sector is almost equal. The largest amounts of residues based on 2004-07 averages are in Asia $\left(2.4 \mathrm{Gt}_{\mathrm{DM}}\right)$, the Americas $\left(1.8 \mathrm{Gt}_{\mathrm{DM}}\right)$ and Europe $\left(0.7 \mathrm{Gt}_{\mathrm{DM}}\right)$ (Figure 11).

To estimate the energy content of agricultural residues, a higher heating value (HHV) of $15 \mathrm{GJ} / \mathrm{t}_{\mathrm{DM}}$ was assumed, as indicated in the literature (Fischer et al., 2007), although this value can vary between $8 \mathrm{GJ} / \mathrm{t}_{\mathrm{DM}}$ and $19 \mathrm{GJ} / \mathrm{t}_{\mathrm{DM}}$. For forestry residues, $\mathrm{HHV}$ of $19 \mathrm{GJ} / \mathrm{t}_{\mathrm{DM}}$ was assumed, as indicated in IEA (2008a). Agricultural and forestry residues in the $25 \%$ availability scenario have an energy content of $21.4 \mathrm{EJ}$, whereas in the $10 \%$ scenario the residues provide $8.6 \mathrm{EJ}$.

Converting the assessed residues into biofuel (using the above mentioned conversion factors) could theoretically yield either around 302 billion Ige of BTL-diesel, 429 billion Ige of bio-SNG or 298 billion Ige of cellulosic ethanol if $25 \%$ of all residues were converted via one single pathway. In this case, second-generation biofuels could provide between five and seven times the 59 bn Ige of biofuel that is currently consumed, which would be equivalent to $10.5-14.9 \%$ of current transport fuel demand.

In the $10 \%$ residue availability scenario, yields of second-generation biofuel are still significant: 120 billion Ige of either BTL-diesel or lignocellulosic ethanol and 172 billion lge of bio-SNG (Table 8). This could cover between two and three times the current global biofuel demand (Figure 12) or 
roughly $4.2-6.0 \%$ of current road transport fuel demand. This is a considerable contribution considering that only residues would be used for biofuel production.

Figure 11. Global production of agricultural and forestry residues (2004-2007 average)

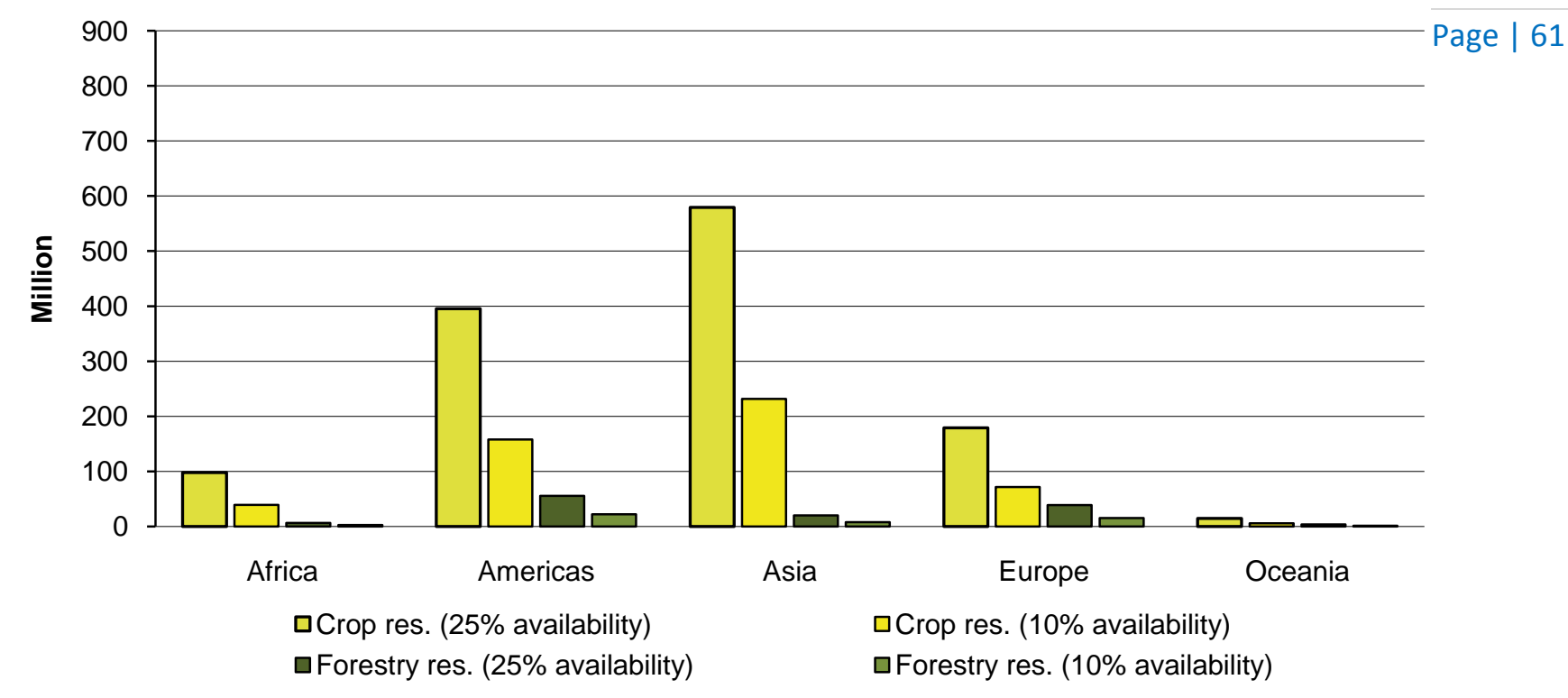

Source: own calculations based on FAOStat, 2009; Fischer et al., 2007 and Smeets \& Faaij, 2007

Figure 12. Theoretical second-generation biofuel potential from lignocellulosic residues in 2007

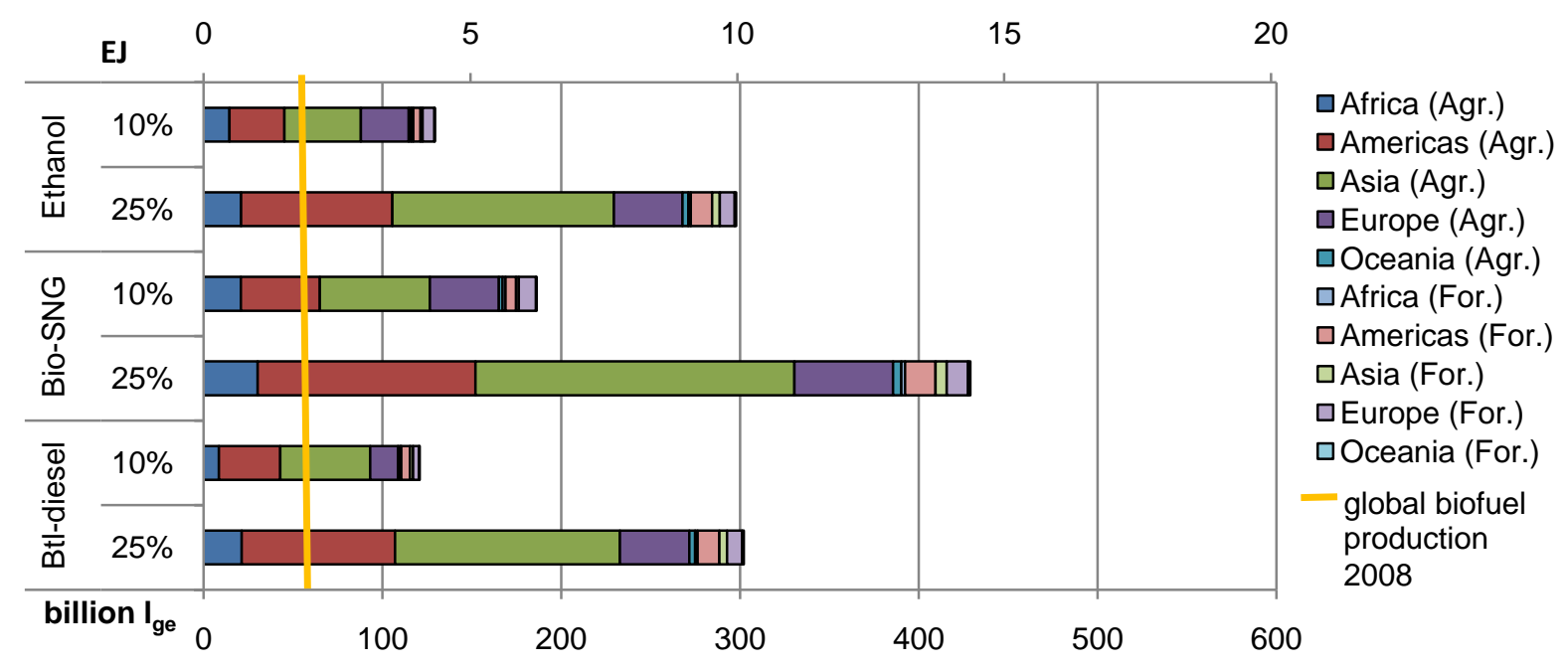

Note: Amounts can not be summed up. Each bar indicates biofuel yields using all available residues. $25 \%$ and $10 \%$ assume respective shares of agricultural and forestry residues to be available for biofuel production.

Assumed conversion factors - BTL-diesel: $217 \mathrm{Ige} / \mathrm{t}_{\mathrm{DM}}$; Ethanol: $214 \mathrm{Ige} / \mathrm{t}_{\mathrm{DM}} ;$ Bio-SNG: $307 \mathrm{Ige} / \mathrm{t}_{\mathrm{DM}}$ 
Table 8. Potential second-generation biofuel production in different regions in 2007

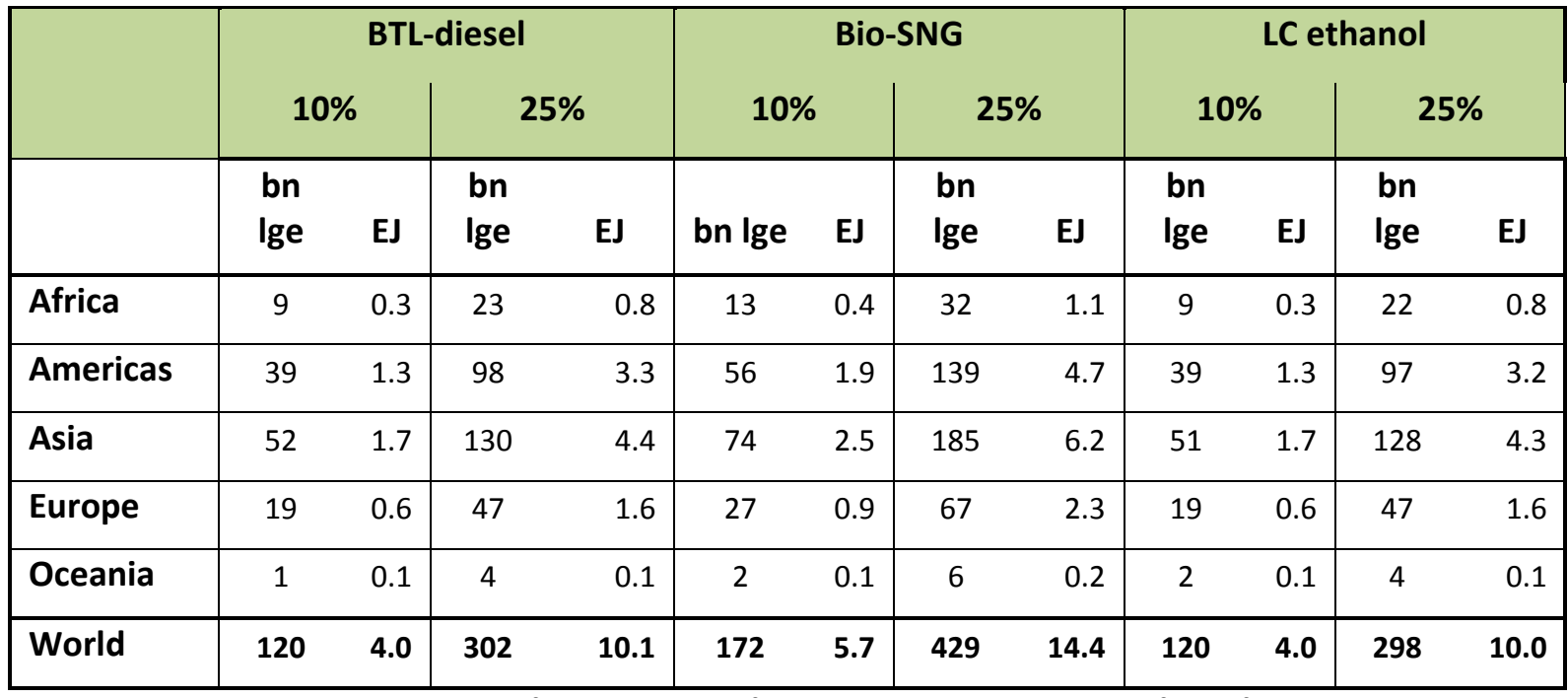

$25 \%$ and $10 \%$ assume respective shares of agricultural and forestry residues to be available for biofuel production.

It was also calculated that global crop production in 2030 will increase roughly $35 \%$ above 2007 levels (FAO, 2003; IFPRI, 2001). This results in a global production of 9.2 billion tonnes fresh matter of agricultural crops (Figure 13). The agricultural area required for this production would be around $1.34 \mathrm{Gha}$, an increase of $9.5 \%$ compared to 2007 . The production of industrial roundwood in 2030 is projected to increase by $50 \%$ to roughly 2400 million $\mathrm{m}^{3}$ (FAO, 2003). Since no regionally specific growth rates in roundwood production were indicated, an equal increase in production quantities in all regions was assumed.

Figure 13. Projected global crop and roundwood production in 2030

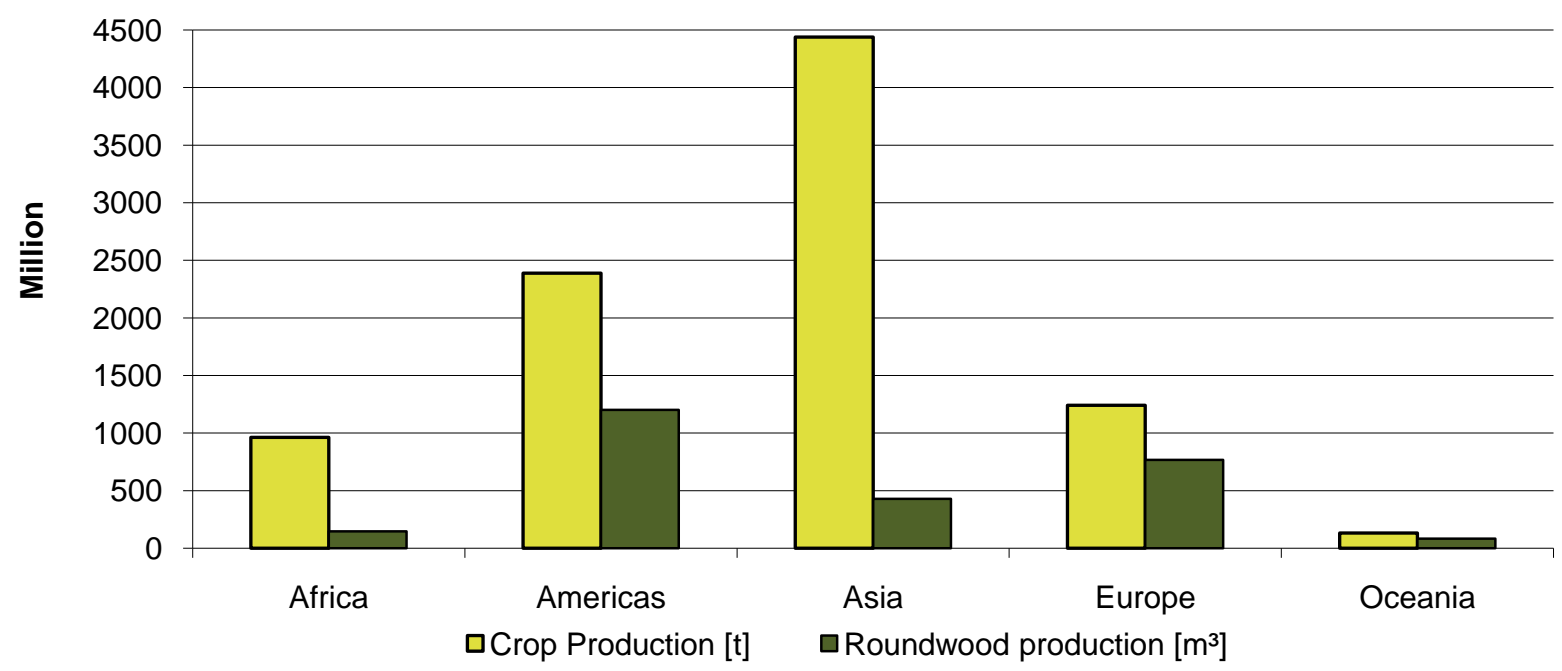

Source: IEA based on FAOStat, 2009; FAO, 2003; IFPRI, 2001

Given these increases in crop and roundwood production, the theoretical amount of residues would reach around 7.5 billion tonnes dry matter in 2030, which yields 1.9 billion dry tonnes of agricultural and forestry residues in the $25 \%$ scenario and 0.8 billion dry tonnes in the $10 \%$ availability scenario. 
Despite a considerable increase in crop production in Africa (53\%) and Oceania (43\%) by 2030, Asia still accounts for the major share of residues (47\%), followed by the Americas $(27 \%)$ and Europe (16\%) (Figure 14).

Figure 14. Global production of agricultural and forestry residues in 2030

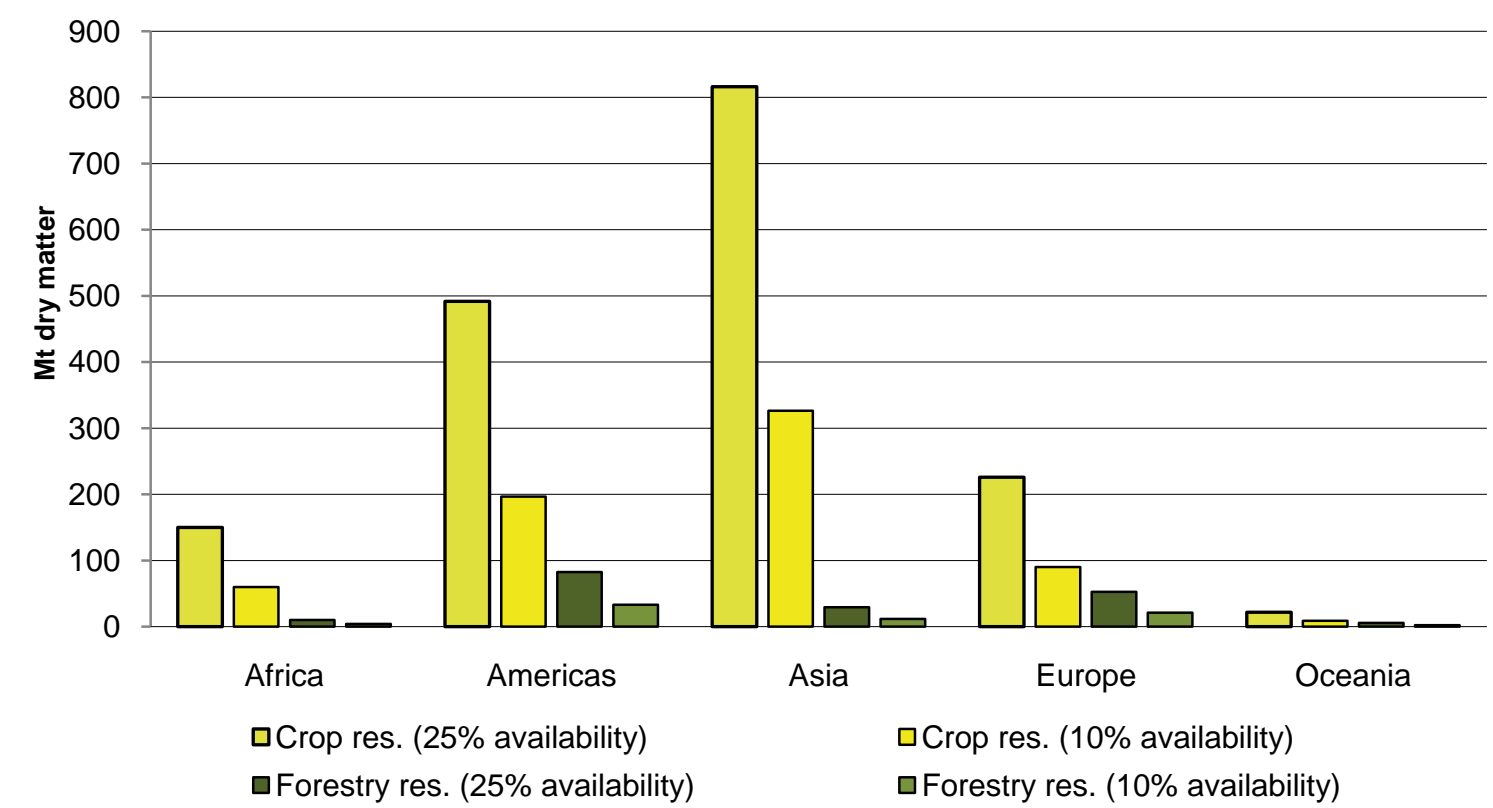

Source: IEA based on FAOStat, 2009; FAO, 2003; IFPRI, 2001

Figure 15. Theoretical second-generation biofuel production from lignocellulosic residues in 2030

EJ 0

\begin{tabular}{|c|c|}
\hline \multirow{2}{*}{ 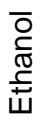 } & $10 \%$ \\
\hline & $25 \%$ \\
\hline$\stackrel{ர}{7}$ & $10 \%$ \\
\hline 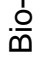 & $25 \%$ \\
\hline $\begin{array}{l}\bar{\Phi} \\
\Phi\end{array}$ & $10 \%$ \\
\hline 产 & $25 \%$ \\
\hline
\end{tabular}

5

$$
\text { billion } I_{\text {ge }} 0
$$
10 15

1

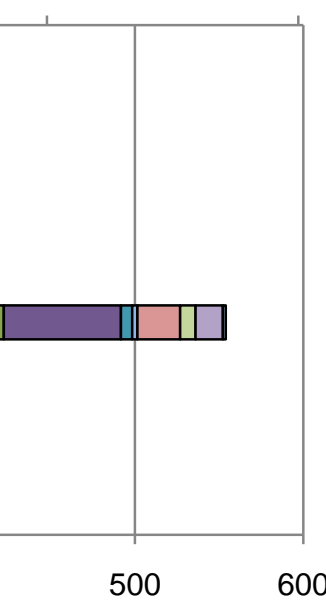

20

$$
\begin{aligned}
& \square \text { Africa (Agr.) } \\
& \square \text { Americas (Agr.) } \\
& \square \text { Asia (Agr.) } \\
& \square \text { Europe (Agr.) } \\
& \square \text { Oceania (Agr.) } \\
& \square \text { Africa (For.) } \\
& \square \text { Americas (For.) } \\
& \square \text { Asia (For.) } \\
& \square \text { Europe (For.) } \\
& \square \text { Oceania (For.) } \\
& \text { global biofuel } \\
& \text { demand 2030 } \\
& \text { (WEO 450 } \\
& \text { Scenario) }
\end{aligned}
$$$$
600
$$

Amounts can not be summed up. Each bar indicates biofuel yields using all available residues. $25 \%$ and $10 \%$ assume respective shares of agricultural and forestry residues to be available for biofuel production. Assumed conversion factors - BTL-diesel: $217 \mathrm{I} \mathrm{I}_{\mathrm{ge}} / \mathrm{t}_{\mathrm{DM}}$; Ethanol: $214 \mathrm{I}_{\mathrm{ge}} / \mathrm{t}_{\mathrm{DM}} ;$ Bio-SNG: $307 \mathrm{Ige} / \mathrm{t}_{\mathrm{DM}}$

Under the $25 \%$ scenario, these residues in 2030 could yield 385 billion Ige of lignocellulosic ethanol, 391 billion Ige of BTL-diesel, or 554 billion Ige of bio-SNG. This equals a share of $10.1-14.6 \%$ of the total transport fuel demand in 2030. The indicated volume is more than the entire biofuel demand 
projected in the WEO 2009450 Scenario (349 billion lge). Since the projected amount still contains a share of first-generation biofuel, total biofuel production could even increase above the projected level without occupying any additional agricultural or forestry land, if the technologies are deployed in time and feedstock sources could be mobilised sustainably. Under the $10 \%$ availability scenario, the residues yield 154 billion lge of lignocellulosic ethanol,
155 billion Ige of BTL-diesel or 221 billion Ige of bio-SNG. This could still cover between $45 \%$ and $63 \%$ of the total biofuel demand in 2030 , which represents a share of $4.1-5.8 \%$ of total transport fuel demand (Figure 15).

Table 9. Theoretical second-generation biofuel production in different regions in 2030

\begin{tabular}{|c|c|c|c|c|c|c|c|c|c|c|c|c|}
\hline \multirow{3}{*}{$\begin{array}{l}\text { Res. } \\
\text { Availability }\end{array}$} & \multicolumn{4}{|c|}{ BTL-diesel } & \multicolumn{4}{|c|}{ Bio-SNG } & \multicolumn{4}{|c|}{ LC ethanol } \\
\hline & \multicolumn{2}{|c|}{$10 \%$} & \multicolumn{2}{|c|}{$25 \%$} & \multicolumn{2}{|c|}{$10 \%$} & \multicolumn{2}{|c|}{$25 \%$} & \multicolumn{2}{|c|}{$10 \%$} & \multicolumn{2}{|c|}{$25 \%$} \\
\hline & bn lge & EJ & bn lge & EJ & bn lge & EJ & bn lge & EJ & bn lge & EJ & bn lge & EJ \\
\hline Africa & 14 & 0.5 & 35 & 1.2 & 20 & 0.7 & 49 & 1.7 & 14 & 0.5 & 34 & 1.1 \\
\hline Americas & 42 & 1.4 & 106 & 3.5 & 60 & 2.0 & 150 & 5.0 & 42 & 1.4 & 104 & 3.5 \\
\hline Asia & 73 & 2.5 & 184 & 6.1 & 104 & 3.5 & 260 & 8.7 & 72 & 2.4 & 181 & 6.1 \\
\hline Europe & 24 & 0.8 & 60 & 2.0 & 34 & 1.1 & 86 & 2.9 & 24 & 0.8 & 60 & 2.0 \\
\hline Oceania & 2 & 0.1 & 6 & 0.2 & 3 & 0.1 & 9 & 0.3 & 2 & 0.1 & 6 & 0.2 \\
\hline World & 155 & 5.2 & 391 & 13.1 & 221 & 7.4 & 554 & 18.6 & 154 & 5.2 & 385 & 12.9 \\
\hline
\end{tabular}

$25 \%$ and $10 \%$ assume respective shares of agricultural and forestry residues to be available for biofuel production.

The assessment undertaken in this study shows that residues derived from the agricultural and forestry sector could make a considerable contribution to meet global transport fuel demand. Even if only $10 \%$ of the currently produced residues would be used for biofuel production, this could provide between $4-6 \%$ of the current transport fuel demand, or two to three times as much as current biofuel production. A residue availability of $25 \%$ could provide roughly between $10 \%$ and $15 \%$ of the projected biofuel demand.

However, the results show that sustainable second-generation biofuel production from residues can only provide a limited share of total transport fuel. This share might increase in the long term, through technology improvement and higher conversion efficiencies. Nonetheless, secondgeneration biofuels represent only one technology to help reduce global transport emissions; increased efficiency will still be the most important way to reduce overall GHG emissions in this sector (for more details see e.g. IEA, 2009c).

\subsection{Residue availability in studied countries}

For this study, availability of residues from forestry and agriculture has also been assessed in eight countries, which are discussed in detail in Annex A. The presented amounts of residues that could be available for second-generation biofuel production are based on estimates from local experts, since residues do usually not appear in official statistics. Therefore, precise data on the share of agricultural residues that remain currently unused could not be obtained for several countries. In particular, in Cameroon and Tanzania it was not possible to estimate the share of unused agricultural residues. In other countries, estimates are available but their accuracy varies due to regional differences within the country, in particular in larger countries like India, China and Brazil. 
In all of the studied countries, both agricultural and forestry residues are at least partially already in use for different applications. Strong variations mainly exist between rural areas dominated by subsistence farmers and areas with large-scale crop production. In underdeveloped rural areas like those in parts of Thailand, Cameroon and Tanzania, residues are almost entirely used for domestic heating and cooking, animal fodder or fertiliser. In areas with more intensive agriculture, a smaller share of residues is utilised for domestic energy needs, but in some cases commercial heat and power generation is based on residues, which reduces the feedstock availability significantly (e.g. in China, Brazil).

In general, the assumption that $25 \%$ of primary agricultural residues could be available for biofuel production globally is helpful to get an indicative value of the globally available amount. However, assuming the availability of $10 \%$ of primary residues might, in particular in developing and emerging countries, be more realistic due to competing uses for both forestry and agricultural residues.

In many cases, less than $25 \%$ of the residues were evaluated to be currently unused in the studied countries. In some cases, as with China, more than $25 \%$ of residues have been identified as unused; in China, around $40 \%$ of corn and cotton stalks, as well as wheat and rice straw, were estimated to be available (Table 10). One feedstock source that is abundant in several of the studied countries is sugar cane tops and leaves, which are often burned in the field.

Table 10. Assumed availability of agricultural and forestry residues in selected countries

\begin{tabular}{|c|c|c|c|c|c|c|c|c|}
\hline & Brazil & Cameroon & China & India & Mexico & Tanzania & Thailand & $\begin{array}{l}\text { South } \\
\text { Africa }\end{array}$ \\
\hline $\begin{array}{ll}\text { Primary } & \text { agric. } \\
\text { residues } & \end{array}$ & $\begin{array}{r}50 \% / \\
\text { n.a. }\end{array}$ & n.a. & $40 \%$ & $10 \%$ & $\begin{array}{r}30- \\
70 \%\end{array}$ & n.a. & $0-100 \%$ & $\begin{array}{r}10 \% / \\
\text { n.a. }\end{array}$ \\
\hline $\begin{array}{l}\text { Secondary agric. } \\
\text { residues }\end{array}$ & $\begin{array}{r}25 \% / \\
\text { n.a. }\end{array}$ & n.a. & $50 \%$ & $10 \%$ & $\begin{array}{r}15- \\
100 \%\end{array}$ & n.a. & $0-100 \%$ & $10-50 \%$ \\
\hline $\begin{array}{l}\text { Primary forestry } \\
\text { residues }\end{array}$ & $50 \%$ & n.a. & $20 \%$ & n.a. & $60 \%$ & n.a. & n.a. & n.a. \\
\hline $\begin{array}{l}\text { Secondary } \\
\text { forestry residues }\end{array}$ & $30 \%$ & n.a. & $30 \%$ & n.a. & $40 \%$ & n.a. & n.a. & $10 \%$ \\
\hline
\end{tabular}

Source: For more details regarding crop-specific information, see country profiles in Annex A.

In some of the studied countries, production of specific crops is concentrated in certain regions; thus, large amounts of homogenous feedstock are available in these areas. Since second-generation biofuel plants are currently designed for specific feedstock types, such regions offer favourable conditions to set up a production unit based on residues. Furthermore, multiple cropping occurs in some countries, as in Thailand and India, where residues are produced two or even three times a year. In these areas, a constant feedstock flow to the biofuel plant can be ensured year-round, thus reducing need for long-term feedstock storage. Areas with large-scale crop production and multiple-cropping can be considered "hotspots" for second-generation biofuel plants if transport infrastructure is sufficient.

In Chapter 5, different types of residues were briefly characterised in terms of their advantages and constraints for the production of second-generation biofuels. While less important on a global basis, secondary and tertiary residues can be a locally important feedstock source. In Cameroon, for 
instance, residues from wood processing are concentrated at sawmills and are often just burnt for disposal (Carillo, 2009a). Since they are concentrated at a sawmill, collection is less complicated and costly, making their use in second-generation biofuel production potentially more attractive. In Brazil, India and Thailand a similar situation occurs for sugar cane bagasse, a waste product from sugar and ethanol production. Since it is considered as waste, the bagasse is burned to produce

Page $\mid 66$ electricity and heat at a low efficiency level that could be raised with comparably little effort. The use of bagasse is particularly favourable for setting up a second-generation biofuel plant since parts of the required infrastructure are already in place.

Prior to planning a second generation biofuel plant, it would be important to conduct field analyses to assess regional material flows, competing uses and year-to-year fluctuations in residue availability to ensure a sufficient feedstock supply and sustainable production of the biofuel. It is crucial to consider that agricultural markets and related material flows in developing regions differ significantly from those in industrialised countries. The possible opportunities and constraints regarding social, economical and environmental aspects of residue utilisation will be discussed in more detail in the following chapter. 


\section{Sustainability of Second-Generation Biofuel Production in Developing Countries}

\section{Key messages}

- Most of the studied countries (Brazil, India, Mexico, South Africa, Thailand) are able to provide domestic financing or attract foreign investments for commercial secondgeneration biofuel plants in the region of USD 125-250 million. For less developed countries like Cameroon and Tanzania, financing will be a challenge.

- Job creation is an important driver in emerging and developing countries to promote second-generation biofuels. New jobs for highly skilled labour would be created in biofuel plants and where dedicated energy crops would be cultivated. The collection of residues, however, would mainly be done with existing farm labour.

- The occupation of additional land for feedstock production is a critical issue in several countries, since land use data are often of poor and land use management strategies rarely exist. Careful planning of feedstock cultivation is thus required to avoid land competition for food production or smallholder displacement.

- Furthermore, feedstock cultivation of surplus land can lead to land use change, causing the release of considerable amounts of GHG and/or the destruction of valuable natural habitats. This would negatively affect the GHG mitigation potential of second-generation biofuels, which currently ranges from $60-120 \%$ of that of fossil fuels.

- For the use of residues these risks are comparably small, since no additional land is required. Negative impacts might occur, however, in the form of nutrient extraction that leads to degradation of the soil with negative impact on its productivity.

- The water use for second-generation biofuel production is a critical issue that needs to be considered, especially in countries with growing water constraints (e.g. India, China and South Africa). Despite the water needed for cultivation of feedstocks, around 4-5 I water/I biofuel are consumed during the production process of cellulosic ethanol.

- To ensure best possible benefits from biomass use, other bioenergy options (e.g. electricity generation) should be evaluated as well. They can be valuable options for emerging countries in order to promote rural development, especially when such bioenergy projects are integrated into food production systems.

- Monitoring of demonstration commercial plants is needed to collect reliable and representative data on the economic, social and environmental impacts of secondgeneration biofuels. In particular in developing countries, country-specific information on biomass supply and conversion costs, on local agricultural markets, and on nutrient cycles is required to draw specific conclusions and recommendations for each country. 
Second-generation biofuels are being promoted with the expectation they will help provide sustainable biofuels to the transport sector. The new technologies represent a growing industry, facing the challenge of balancing large-scale industrial development with small-scale local value chains. Both aspects of the supply chain need to co-exist in a sustainable way to address the interlinked issues of environment, economy and social welfare. Because these new technologies are

Page | 68 not yet available on a large scale, not every possible impact on sustainability can be assessed in detail; nevertheless, the most important issues related to the sustainability of biofuels are discussed in the following sections.

\subsection{Potential economic impact}

\section{Capital investment}

Currently, second-generation biofuel plants are comparably more capital intensive than firstgeneration biofuel refineries. Investment costs for a commercial scale second-generation biofuel plant with a capacity around 50-150 Ml/yr are estimated to be USD 125-250 million (IEA, 2008a), up to ten times more than those for a first-generation biodiesel plant of the same capacity. Especially for countries like Tanzania and Cameroon, financial risks are expected to be one of the bottlenecks for implementing second-generation biofuels at a local level. However, in countries like Brazil, China, India and Thailand, finance risk should not pose difficulties since large bioenergy projects with investments exceeding USD 200 million have already been successfully realised. With regard to economies of scale, specific total capital investment $(\mathrm{TCl})$ typically decreases with increasing plant capacity, but sudden price increases cannot be predicted.

\section{Biomass supply costs}

Costs for biomass supply at biofuel production facilities strongly depend on regionally specific conditions, such as biomass potentials related to the total area of the region, infrastructure with regard to transport network and its utilisation, and the availability of multimodal plant sites that have access to roads, rail and/or harbours.

Since there are not any established markets for most of the primary agricultural residues, there is no reliable data for costs. Price estimates for feedstocks for second-generation biofuels vary significantly between different emerging and developing countries. Price ranges for sugar cane tops

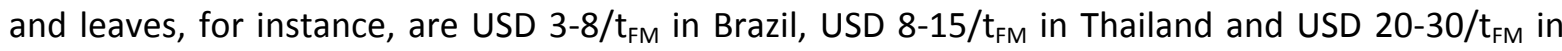
India (CENBIO, 2009; JGSEE, 2009).

Typically, biomass supply costs increase with scaled-up biofuel plant sizes with higher annual biomass demand (around $600000 \mathrm{t} / \mathrm{yr}$ for a large commercial BTL plant). This is due to increasing transport distances and often more complex logistics like higher handling and storage demand. When using agricultural and/or forestry residues like straw and logging chips as feedstock for second-generation biofuels, their lower bulk density $\left(0.1 \mathrm{t}_{\mathrm{DM}} / \mathrm{m}^{3}\right.$ for straw and $0.2-0.3 \mathrm{t}_{\mathrm{DM}} / \mathrm{m}^{3}$ for logging residue chips) compared to current biofuel feedstocks (e.g. oil, sugar, starch crops) will further increase biomass provision costs and/or require adapted transport. Since moisture content of biomass also influences provisions costs, naturally air-dried biomass could reduce transport costs significantly, depending on the supply concept (IEA, 2008a). 
For favourable plant sites, biomass provision costs are approximately $10-25 \%$ of total biomass costs (including production and provision costs), but provision costs can be more than $65 \%$ (thus exceeding production costs) under unfavourable conditions. General infrastructure conditions (e.g. road networks, ports) are fairly good in the developed and urban regions of the selected emerging countries and also to some extent in the selected developing countries which are important to regional and international trade flows. However, infrastructure and road maintenance in rural areas are often precarious in developing countries and thus would make biomass and biofuel provision costs potentially higher in inland locations.

Against this background, overall biomass supply costs are difficult to estimate for emerging and developing countries, especially for second-generation biofuel feedstock. In Brazil, assessments of sugar cane trash provision costs exist, since the growing share of the area harvested mechanically also increases interest in the utilisation of primary agricultural residues for energy. In the Brazilian case, total supply costs for sugar cane residues delivered to the ethanol plant amounted to USD 14-31/t, given the different harvest and transport options for the leaves and tops (Hassuani, 2005). This case study illustrates that the use of primary residues can lead to major changes in biomass cultivation, provision, and conversion (e.g. soil preparation, tillage, opportunity costs, production efficiency), with a strong effect on overall the economic viability. Additionally, provision costs (including transaction costs) for agricultural and forestry residues can also vary according to land property structures (smallholder systems, large-scale plantations, etc.). Thus, it is difficult to estimate biomass supply costs without detailed assessment of the specific case.

Research on biomass supply, in particular from agricultural and forestry residues, lags in many emerging and developing regions. This prevents the development of an economically feasible supply of vast amounts of biomass and could threaten the introduction of second-generation biofuels or other bioenergy options like electricity generation co-firing. Sustainable biomass supply concepts are thus quickly needed to enable large-scale bioenergy and second-generation biofuel projects.

\section{Biofuel production costs}

Cost estimates for second-generation biofuels show significant differences depending on plant complexity and biomass conversion efficiency. Important factors include annual full-load hours of plant operation, feedstock costs and capital requirements. Accordingly, biofuel plants with a higher biomass-to-biofuel production ratio are typically able to accept higher biomass supply costs compared to less efficient plants.

Figure 16 shows current IEA projections for short- and long-term production costs of different biofuels under two oil price scenarios. With oil at USD 60/bbl, production costs for both BTL-diesel and lignocellulosic ethanol are currently in the range of USD 0.84-0.91/Ige and thus are not competitive with fossil fuels and most firstgeneration biofuels. In the long term, however, with increasing plant capacities and improved conversion efficiencies, both BTL-diesel and lignocellulosic ethanol could be produced at significantly reduced costs. In this case, production costs are projected to be around USD 0.62//ge for lignocellulosic ethanol and USD 0.58/Ige for BTL-diesel (IEA, 2009c). The estimated production prices are less than those for rapeseed biodiesel, but still more expensive than gasoline and other first-generation biofuels.

With oil at USD 120/bbl, production costs rise to USD 1.07/lge for BTL-diesel and USD 1.09/Ige for lignocellulosic ethanol. In the long term, prices are projected to fall to USD 0.73/Ige for BTL-diesel and USD 0.72/Ige for lignocellulosic ethanol (Figure 16). Therefore, with reduced overall costs and oil price at USD 120/bbl, second-generation biofuels could be produced at lower costs than gasoline and rapeseed biodiesel and close to the costs of corn ethanol (IEA, 2009c). 
Figure 16. Comparison of biofuel cost stimates in the short and long term

Page | 70

USD 120/bbl

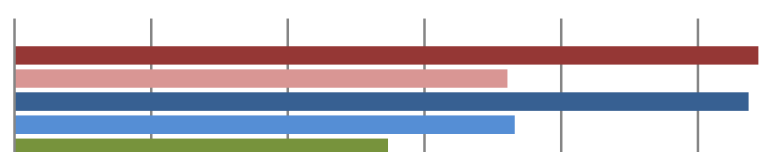

- Cellulosic ethanol

- Cellulosic ethanol (longterm)

- BTL

- BTL (longterm)

- Sugar cane ethanol

- Sugar cane ethanol (longterm)

- Corn ethanol

Corn ethanol (longterm)

- Rapeseed biodiesel

- Rapeseed biodiesel (longterm)

- Gasoline

$\begin{array}{lllllll}0.0 & 0.2 & 0.4 & 0.6 & 0.8 & 1.0 & 1.2\end{array}$

USD / lge

Source: IEA, 2009c

Currently the largest cost factor for BTL-diesel production is the capital costs. They account for $49 \%$ of total production costs with oil at USD $60 / \mathrm{bbl}$ and $51 \%$ of costs with oil at USD $120 / \mathrm{bbl}$. Feedstock costs account for $35 \%$ and $33 \%$ in the two scenarios, whereas all other cost factors like O\&M costs, energy demand and others have a share between 1-4\%. For lignocellulosic ethanol, feedstock costs are currently the largest cost factor, accounting for $42 \%$ of total production costs in both oil price scenarios. Capital costs are around $38 \%$ with oil at USD $60 / \mathrm{bbl}$ and around $42 \%$ with oil at USD $120 / \mathrm{bbl}$. The share of all other cost factors ranges between $2-6 \%$ of total production costs (Figure 17).

In the long term, feedstock costs are expected to account for the major share $(44 \%)$ of total BTL production costs at USD 60/bbl price levels, whereas capital costs are expected to be reduced by $49 \%$ of the present level, accounting for $37 \%$ of overall production costs for BTL-diesel. With oil price levels at USD $120 / \mathrm{bbl}$, feedstock costs are the main cost factor ( $44 \%$ of total), followed by capital costs (38\%) and others with shares between 2-8\%. For lignocellulosic ethanol, feedstock costs remain the largest cost factor in the long term, accounting for $55 \%$ of total production costs at an oil price of USD $60 / \mathrm{bbl}$ and $56 \%$ with oil at USD 120/bbl. Due to expected cost reductions by $44 \%$, capital costs account for roughly $31 \%$ of total production costs with the oil price at USD $60 / \mathrm{bbl}$ and for $37 \%$ in the long term with oil at USD $120 / \mathrm{bbl}$, making it significant to overall production costs. The cost reduction from by-products currently lies in the range of $9-14 \%$ and is estimated to reach between $15-25 \%$ of total production costs in the long term (Figure 17).

In many of the studied countries, residues from a cheap feedstock source would allow for reduced overall production costs of second-generation biofuels. Feedstock costs in the different countries vary from USD 8.6/ $\mathrm{t}_{\mathrm{FM}}$ to USD $70 / \mathrm{t}_{\mathrm{FM}}$ for primary agricultural residues, depending on abundance and opportunity costs. If the residues could be provided to a second-generation plant at the indicated costs, biofuel prices of USD 0.60-0.86/Ige for BTL-diesel and lignocellulosic ethanol could currently be achieved assuming an oil price of USD 60/bbl. In the long term, prices could drop to USD 0.34 $0.57 /$ Ige, if feedstock prices were to stay stable (Figure 18). 
Figure 17. Composition of second-generation biofuel fuel costs

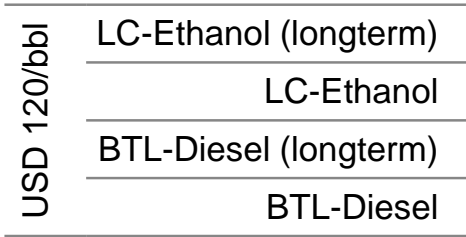

$$
\begin{aligned}
& \text { 응 } \frac{\text { LC-Ethanol (longterm) }}{\text { ¿ }}
\end{aligned}
$$

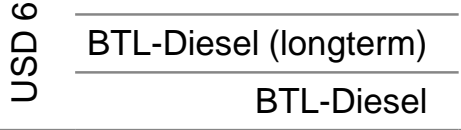$$
-0.5
$$

Capital costs

- Input streams (energy)

Co-product gain

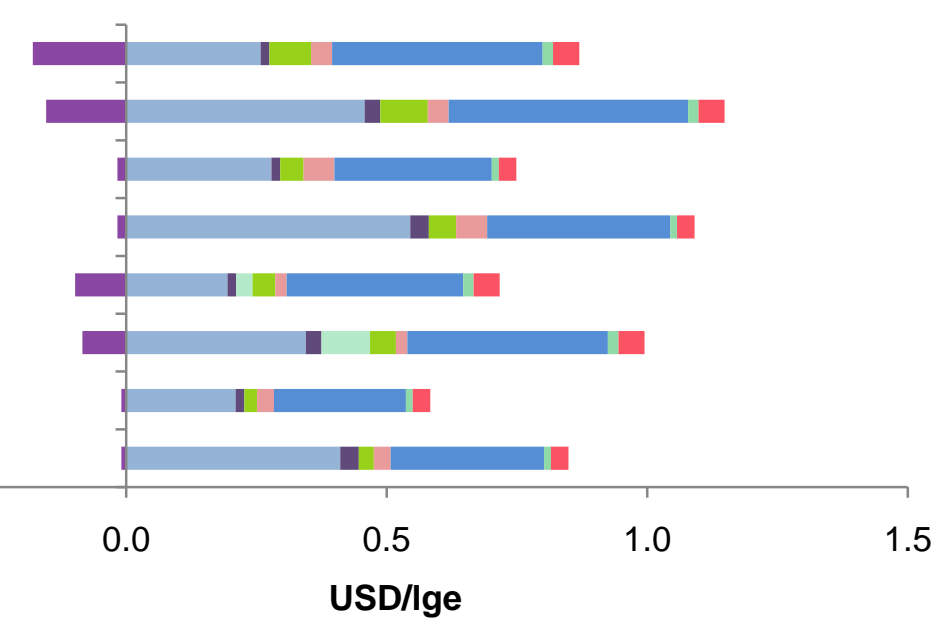

- O\&M costs

Electricty

Fuel transport

Source: IEA, 2009c

At the lower range of the estimates, these costs would be competitive with gasoline as well as ethanol from sugar cane and corn. However, the costs for feedstock supply are uncertain, in particular in regions with poor infrastructure. Thus production costs will vary between different countries and regions depending on feedstock availability and transport logistics.

For secondary residues, transport costs are expected to be less significant since the residues are already concentrated at the processing site. Bagasse, therefore, could be a highly cost-competitive feedstock for second-generation biofuels. The costs for this waste derived from sugar and ethanol production are currently lowest in Brazil and South Africa (USD 4-8.4/ $\mathrm{t}_{\mathrm{FM}}$ ). These prices could allow for BTL-diesel and lignocellulosic ethanol production costs to be around USD 0.57-0.60/Ige with oil at USD 60/bbl. In India and China, where the opportunity costs for bagasse are estimated to be at USD 20-30/t $\mathrm{t}_{\mathrm{FM}}$, BTL-diesel and lignocellulosic ethanol could be produced at costs of USD 0.68-0.79/Ige. In the long term, production costs could be decreased significantly to USD $0.30-0.51 /$ Ige if feedstock costs remain stable. More details on the estimated production costs for the studied countries can be found in the country profiles in Annex B.

The model results listed above underline the economic advantages of using residues for secondgeneration biofuel production. Based on the specific feedstock costs indicated for the selected countries, second-generation biofuels could be produced at lower costs than those of second-generation biofuels based on dedicated energy crops as feedstock. It has to be considered, though, that most of the indicated feedstock costs reflect assumptions on their current opportunity costs. With large-scale production of second-generation biofuels and an increase in feedstock demand, prices for agricultural and forestry residues could increase considerably. Koopmans and Koppejan (1997) reported significant price increases for rice husks in Nepal and rice straw in Vietnam caused by increased use as fuel. Given the fact that many residues in the studied countries are already in use, rising prices for the feedstock can be expected when second-generation biofuels will be produced. A further uncertainty are the different conditions for feedstock supply. Secondary residues do not require complex collection and transport logistics since they are concentrated at the crop-processing site. For primary residues, however, collection and transportation is more complex, and poor infrastructure in some countries could raise supply costs considerably, making the use of these residues economically unattractive. 
Figure 18. Second-generation biofuels cost estimates in selected countries

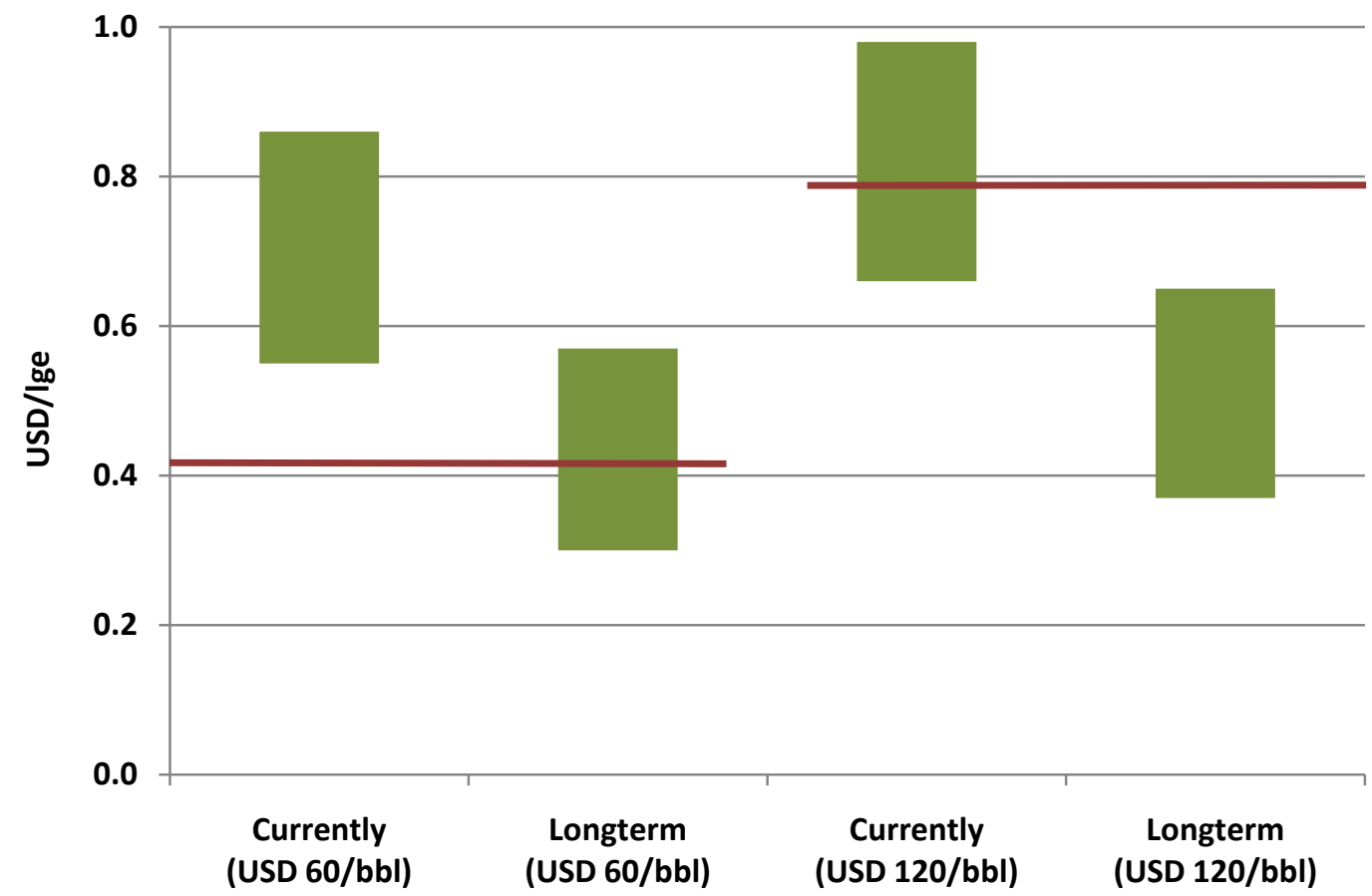

Gasoline reference

n BTL-diesel / Ic-Ethanol

*Note that feedstock prices reflect assumptions by local experts and might vary regionally.

Source: IEA analysis based on IEA 2009c and findings from country profiles.

\section{Welfare and effect to the national budget}

\section{Foreign currency savings}

Expenditures for importing petroleum products have fluctuated dramatically in most emerging and developing countries over the past several years. In 2006, Tanzania spent almost $24 \%$ of its national budget for oil and gas imports (International Trade Centre, 2009). Even oil producing and exporting countries like Cameroon or Mexico are affected by high derivate prices since limited or inadequate refinery capacities force these countries to import considerable amounts of refined oil products. Thus, if used in the domestic market, second-generation biofuels could contribute to reduced expenditures for oil imports. However, at current production costs, domestic consumption is not economically viable in many countries. Therefore, second-generation biofuels will rather be exported to regions with strong demand and effective support policies, like the United States and the European Union, which would help to increase foreign currency reserves.

\section{Necessity for subsidies}

In order to support the production and consumption of biofuels, countries usually adopt a mix of various policy regulations and measures. These measures affect various stages of the production 
and utilisation of bioenergy: for example, biomass production, biomass conversion, bioenergy distribution and final consumption. Typical support measures are direct subsidies per output of biomass, reduction of infrastructure costs (subsidised loans, capital grants), guaranteed prices for biofuels, mandatory quotas for biofuels, reduction of distribution costs and excise tax exemptions for biofuels (OECD, 2008a). Since estimates vary widely for production costs of second-generation biofuels in developing and emerging countries, the necessity for subsidies schemes is difficult to assess.

On the biomass production level, adding value to agricultural and forestry residues could help to reduce the necessity to support farmers and smallholders in these countries where the disparity between well-capitalised agribusiness and poor smallholders is growing. However, per-capita subsidies are very low in developing countries and, even though agricultural support is increasing in some emerging countries (e.g. USD 15 billion in China in 2008, USD 6 billion in Mexico in 2007), this support is considerably lower than in OECD countries (e.g. USD 24 billion in the US, USD 134 billion in the EU) (OECD, 2008b). On the other hand, it should be considered that adding value to agricultural residues could raise prices for competing uses (e.g. fodder, bedding) and thus could have a negative impact on farmers' income and create the necessity for new subsidies schemes.

Since production costs for second-generation biofuels are believed to be higher than for currentgeneration biofuels in the near future, subsidies would be needed for consumers who would otherwise have to pay higher fuel prices for blends derived from second-generation biofuels. As gasoline and diesel fuel are taxed in some of the selected countries, revenue from fossil fuel taxes could theoretically be used to cross-subsidise second-generation biofuels. However, compared to OECD countries, the overall potential for biofuel subsidies in emerging and particularly in developing countries is very limited. If mandatory blending quotas are set without applying any subsidies or tax exemptions for second-generation biofuels that are not competitive with fossil fuels, then higher general transport costs could occur, making important items in the consumer basket more expensive. In general, the necessity for subsidies will strongly depend upon the technology development, decreases in production prices, and the reference price for fossil fuels. However, since domestic fuel markets of some developing countries are relatively small, biofuels may be primarily destined for export to developed countries; direct fuel subsidy schemes would not be required in this case.

\section{Risks assessment}

\section{Legal-political framework for large investments}

As with any investment, the legal-political framework may promote or impede investments in second-generation biofuel technologies in specific countries. Since a typical BTL plant is projected to cost approximately 10 times more than a first-generation biodiesel plant with the same capacity, potential investors will naturally act with greater caution. This is particularly important if foreign investors are needed to set up a second-generation biofuel plant. Political crises, like those seen in Thailand, may temporarily reduce investment attractiveness, but, in general, the legal-political framework in the countries selected for this study was evaluated positive for large-scale investments. Significant administrative and governance problems may affect efficient large-scale investments in some countries in general, but not specifically investments in second-generation biofuels. 


\section{Financing and human resources}

Although second-generation biofuel plants require higher capital investment than current biofuels, lack of financing resources should not constrain implementation of biofuel industries in emerging countries. Most of the studied countries (e.g. Brazil, China, India, South Africa, Mexico and Thailand)

Page | 74 have stable investment grades and receive considerable foreign direct investments annually (Seeking Alpha, 2009; World Bank, 2008a). In developing countries like Tanzania, access to credit is limited to a small number of enterprises in urban areas, and the financial system is inefficient in supplying long-term funds to the local private sector. However, before the fall in energy prices and the on-set of the global economic crisis, bioethanol plants had been planned by international investors in Tanzania. Thus, international financing should enable projects to proceed even in countries with limited domestic financing resources.

With regard to human resources for second-generation biofuel production, differences between emerging and developing countries are more significant. While emerging countries (e.g. Brazil, China, India, South Africa, Mexico and partially Thailand) have highly skilled engineers due to those countries' long experience in energy industries, the shortage of skilled workers in Cameroon and Tanzania and other developing countries could complicate the establishment of a secondgeneration biofuel industry. Compared to current-generation biofuels, the new technologies ask for more-skilled workers, since the quality of feedstock and process technologies are more complex for thermo-chemical or bio-chemical conversion technologies compared to first-generation biofuels.

\section{Security of biomass supply}

To assess biomass supply security, it should be considered that annual biomass demand for secondgeneration biofuel plants (approximately 350 000-600 $000 \mathrm{t}$ of lignocellulosic biomass for a large commercial plant) is similar to current ethanol plants in Brazil (300 000-2 $000000 \mathrm{t}$ of fresh stalks/year) (IEA, 2008a). Due to lower yields per hectare and the lower density of the feedstock compared to sugar cane, larger areas would be required and would make supply logistics are more challenging. However, in the case of dedicated energy crops, regional differences can occur; for example, the $16 \mathrm{t}_{\mathrm{DM}} / \mathrm{ha} / \mathrm{yr}$ yields of woody short-rotation crops (SRC) on suitable lands in tropical countries are much higher than yields of SRC in temperate countries ( $\left.10 t_{D M} / h a / y r\right)$. This illustrates the competitive advantage of certain developing and emerging countries in terms of biomass production (OECD, 2008c).

Additionally, most agricultural products have residue-to-product ratios greater than one, and thus large amounts of primary residues would be available even under temporary unfavourable weather conditions. But biomass availability may not necessarily translate into secure biomass supply due to the lack of purchase contracts and lack of commitment to existing contracts in some developing and emerging countries. Risks for a second-generation biofuel plant based on biomass provided by third parties would be considerable in this case. Both primary agricultural residues (e.g. straw, stalks) and secondary residues (e.g. bagasse, rice husks, empty fruit bunches) are often already used as animal fodder or for bedding, or to provide process energy for the processing plant. Therefore, the economic potential for second-generation biofuels will certainly be much smaller than the technical potential.

The opportunity costs for these competing uses will be decisive for utilisation of the feedstocks and biomass supply security and may provoke major changes in material flows with impacts upon other agricultural markets. This can have both positive and negative impacts. In cases where residues are 
currently considered trash (e.g. bagasse in Brazil, peanut shells in South Africa), they are burned inefficiently, wasting a lot of the current energy potential. With increasing competition through second-generation biofuel production, more efficient use of the residues could occur and considerable amounts of biomass could be made available. On the other hand, interactions with other uses for residues (e.g. pulp and paper industry, animal fodder) can increase the biomass demand in certain sectors and cause supply interruptions. In general, agricultural markets in developing countries are considerably more complex than those of developed regions, so the impact of increased biomass demand is hard to project.

\subsection{Potential social impact}

\section{Jobs and income}

Job creation and regional growth are considered as two of the main social drivers for the implementation of biofuel projects (Domac et al., 2005). For both current- and second-generation biofuels, there are opportunities for new jobs along the entire pathway chain, from biomass production or collection, to biomass transport, biomass handling, conversion and finally product distribution. However, net job effects depend strongly on the agricultural structure (e.g. level of mechanisation) in the countries and not on the given biofuel option.

For dedicated energy crops (including first-generation feedstocks), feedstock production involves an agricultural workforce for soil preparation, cultivation, harvesting, on-field transport, etc. Collection of agricultural and forestry residues, however, could be done by the same workers involved in the main agricultural and forestry products; therefore, the number of new jobs in this part of the production chain would be limited. But the subsequent collection of residues after the harvest of the main product could extend seasonal occupation and improve job opportunities at least in manual harvesting systems. Downstream processes like biomass transport and biomass conversion may offer more jobs considering the increased biomass demand of scaled-up second-generation facilities, but would also require more qualified workers given the complexity of second-generation biofuel technologies. While unskilled and cheap labour force is abundant in developing countries, skilled engineers to manage plant operations and oversee complex production processes are relatively difficult to find. On the level of biomass conversion, contribution to rural development probably will be low or limited to selected regions, since second-generation biofuel plants will have to make use of economies of scale due to their technological complexity.

In terms of income creation, adding value to residues could increase and diversify rural incomes, while providing added value to the local agricultural sector. Use of these residues for secondgeneration biofuels could be one option to create additional market opportunities and to achieve this diversification. Depending on the type of residues there is an income increase in different parts of the chain and to the benefit of different actors; for example, farmers can profit from selling primary residues, while plant operators profit from increasing demand for processing residues. In the long term, additional income means that more money would flow into the region, therefore more indirect and induced jobs would be created, investment in other areas such as welfare and infrastructure would be reinforced and the region could witness economic growth (Domac et al., 2005). It should be considered, though, that increasing opportunity costs for agricultural and forestry residues could lead to relative income losses for traditional buyers of these residues. 


\section{Final use of product and access to energy services}

In many developing countries biomass is the primary source of energy, mainly in the form of firewood and charcoal for rural and urban use by residential, industrial or commercial sectors. Biomass is widely used because it is cheap, locally available, and its use does not require expensive

Page | 76 equipment. A transition to "modern fuels" may improve end-use efficiency and also reduce associated emissions, but will certainly raise new requirements in terms of appliances, distribution networks, and end-user's income. More competition for biomass sources induced by secondgeneration biofuel industries may also increase the price or reduce the availability of biomass fuels for the poorest people. In regions where the current use of biomass exceeds the sustainable potential, any increase in demand has to be met with better resource management practices in order to avoid further degradation of natural resources.

In many developing countries, communities in rural areas have no or limited access to energy (i.e. electricity and heat), a fact that complicates poverty alleviation; for example, social welfare is hindered if facilities have no electricity, access to pumped drinking water is limited, or energy demand of local industries cannot be covered. Therefore, rural electrification is often a greater priority than substituting fossil fuels with biofuels, even in countries with a high import dependency in the transport sector. Using the available lignocellulosic resources for transport biofuels instead of trying to improve efficiency and sustainability of stationary use may have negative impacts in the effort to increase overall domestic energy security. In some developing countries like Tanzania and Cameroon, for instance, the transport sector is not well developed and the vehicle fleet is relatively limited. Against this background, the technical and economic effort required for domestic secondgeneration biofuel development would be too high, considering the other energy priorities that could be satisfied with less effort.

From this viewpoint, first-generation biofuels (i.e. mainly vegetable oils) could be more adequate for stationary use than second-generation biofuels. Some trial efforts are already under way with the use of jatropha oil in Tanzania and palm oil in Cameroon (LARRRI, 2008; Libert, 2007; TATEDO, 2009). However, the sustainability of first-generation biofuel production is of primary concern, and major barriers have to be addressed to overcome challenges like limited land availability, land use changes and competition with food crop production.

On the other hand, second-generation biofuel development could also be export-driven and high capital expenditure could be covered by foreign investors. This would help to meet international demand and to develop inland infrastructure to benefit the producing country. The country could reconsider its export orientation in the future and dedicate a percentage of production for its own use. In this context, second-generation biofuels based on agricultural residues could be more advantageous than the export of current-generation of biofuels. The latter are often associated with issues such as forced eviction of local farmers in favour of large foreign privatised plantations, the depletion of domestic resources for the satisfaction of the international market, and the uncertainty of local benefits.

\section{Land issues}

One of the most controversial subjects in developing countries is the issue of land occupation. Especially in Africa, land ownership systems are surrounded with uncertainty, since land property is often not officially secured and cadastral registries are often non-existent. Land is often leased from the state or held communally and is not based on private property; therefore, land rights are often 
in dispute (ABN, 2007; Carrillo, 2009a). This uncertainty is crucial, since it does not allow for a calculation of how much land is actually available, how it is distributed across the country and how it is prevalently used.

Against this background, potential development of the biofuel sector could lead to increased demand for land and competition among actors, thus possibly exacerbating the aforementioned problems. This applies to both first- and second-generation biofuels that are based on crop feedstock that requires land for cultivation. If second-generation biofuels use agricultural residues as feedstock, land-competition is less of an issue. It is therefore important to investigate whether there is enough arable land available for food and feedstock production, and whether that land could be used sustainably in terms of soil conservation and efficient water use. Expansion of current biofuel production is criticised especially in countries where food security is precarious since it is believed that biofuel production aggravates competition about limited land resources. However, the reasons for insufficient food production and/or volatile food prices are complex and are caused by several factors like insufficient infrastructure or distribution logistics (OECD and FAO, 2009). Furthermore, large-scale production of current generation feedstock is often criticised for depriving small farmers of their properties. Unclear land rights and poorly regulated land acquisition conditions which often prevail in developing countries - lead to displacement of local farmers to non-arable regions or urban centres. These concerns are basically the same if dedicated energy crops are grown for second-generation biofuel production. The effect of large-scale feedstock plantations could be that workers have to work under worse conditions than on farms due to unsecured labour rights and the need to produce low-cost feedstock.

Second-generation biofuels produced from agricultural or forestry residues do not require cultivation of additional land. Thus, feedstock production for second generation biofuels may reduce competition on the level of land use at a first glance. However, the utilisation of residues may compete with traditional uses of the biomass (fodder, bedding, etc.). This should carefully be considered, since the exploitation of limited resources may imply changes in agricultural production, markets and uses, and even lead to additional land demand to produce fodder. A critical point is the level of intensification of agriculture and the quality of land required for secondgeneration biofuel feedstock. Theoretically, fertile land and water resources could be dedicated to food production (which will in turn yield more residues) while the remainder of the available land could be used for dedicated energy crop plantations. Due to the large amounts of lignocellulosic feedstock required for commercial production of second-generation biofuels, it seems currently not possible to integrate biomass production into existing food production via so-called "integrated food and energy systems" (e.g. hedges between fields that are harvested for biofuel production).

When discussing potential areas for the production of second-generation biofuels, "degraded" or "marginal" land is often mentioned as an option for sustainable feedstock production. However, while these areas might in fact be unsuitable to food production, they still provide other functions. Africa, for example, has been targeted as a region with abundant under-utilised land. Although not extensively utilised, this land has long been and continues to be the only source of income for some local farmers and pastoralists. Furthermore, much of this land is of low quality as a result of soil degradation and climatic conditions. Given the uncertainty concerning land ownership, the area of marginal or abandoned land in a country might be misleadingly large, implying that all such land waits to be exploited, while this may not be exactly the case (ABN, 2008; Bekunda et al., 2009).

On the recently held " 2 " Joint International Workshop on Bioenergy, Biodiversity Mapping and Degraded Lands", hosted by the UNEP in Paris, many of the participating experts agreed that current land use data are in many cases not accurate enough to classify land as "degraded" or "unused". During the discussions at the workshop, it was suggested that "social mapping" should 
become a pre-requisite for any feedstock production scheme on "degraded" or "unused" land in order to assess its current function and to avoid negative impact on local communities (OekoInstitut and UNEP, 2009). This clearly underlines the concerns, which are particularly present in many developing countries, regarding the identification of suitable land for sustainable feedstock production. Expectations to cultivate degraded land should, therefore, be considered carefully and conservative assumptions on its availability should be followed to avoid overestimation.

\section{Food security}

The issue of food security is another point of criticism related to the production of biofuels. Given the differences concerning economic growth, poverty and agricultural status, the issue of food security should be examined for each country individually. In some countries, food security is not related to the production of crops, but to distribution within the country. In Tanzania for instance, crop production in good years is sufficient to meet domestic demand, but the inefficient distribution network does not allow to transport food in undernourished regions.

In countries where food supply is not secured, cultivating crops for biofuel production on arable land can further weaken food security and thus have serious social impacts. Considering that cultivation of energy crops for second-generation biofuels could be more profitable, farmers may opt for growing a biofuel feedstock instead of growing food for the national market (ABF, 2009). However, these arguments are also true for opting to plant cash crops (e.g. coffee and cotton) instead of food crops. In general, profitability of the crops will be decisive for the decision of the farmers. If agricultural residues would be used as second-generation biofuel feedstock, this could increase the profitability of the crop cultivation and diversify the farmer's income. Moreover, residues from the agricultural and forestry sector do not compete with food crops and would help dedicate fertile lands to food production. However, it should be considered that the improvement of food security in developing countries is a very complex challenge that depends on several factors like market prices of agricultural products, food consumption patterns, climatic conditions, and income distribution (BEST, 2008). A stronger promotion of the agricultural sector is required with a priority to food production; simply not producing biofuels may not solve any problem or even exclude possible solutions since biofuel production may also imply some benefits (e.g. diversification of local markets, income creation, and rural development).

\section{Smallholder integration}

Given the social concerns about land use and local populations, it is widely accepted that integration of local farmers into the overall scheme would be beneficial for all parties involved. This integration should be sealed with contractual agreements, securing farmers from the potential failure of biofuel projects and allowing them to stop living under uncertain land-tenure condition (Milich, 2009). This integration could not only be limited to biomass production, but also allow farmers and their families to enjoy benefits from the entire value chain (e.g. jobs in the downstream industry, free use of the product, exploitation of by-products), which will increase the interest and willingness to engage in second-generation biofuel projects.

For second generation plants, economies of scale and economic viability of facilities require scaledup plant sizes and large annual biomass demands (up to $600000 \mathrm{t} / \mathrm{yr}$ ). This signifies a challenge in the integration of smallholders, since individual production outputs cannot cover the large feedstock demand. This issue can be resolved by forming larger cooperatives among smallholders 
and, from a logistic point of view, by establishing various collections points and gathering the feedstock in the plant area. However, prerequisite for that is a good and reliable transport and infrastructure network, which does not exist in many developing countries.

\section{Health and gender}

The potential effects of biofuel production on women will depend upon the social status and the rights of women in a specific country and in the agricultural context, and not upon a specific biofuel pathway. Therefore, it may be unnecessary to discuss health and gender issues within the specific biofuel context. However, since the situation of women and general health conditions in rural areas of developing and emerging countries are often very weak, these aspects should be at least considered within the greater agricultural and societal context.

Through traditional (and inefficient) use of biomass, like uncontrolled burning for cooking and heating, the indoor health situation is compromised and health problems occur more frequently in many developing countries. In Brazil, India and Thailand, the burning of sugar cane tops and leaves prior to manual harvesting is a further concern since it causes health problems and environmental pollution (e.g. the release of methane, a potent GHG). With the provision of the necessary technical know-how and continuous R\&D, biomass combustion and gasification could boost energy provision for local communities, leading to improvement of health and welfare services. Furthermore, the technical experience gained will be a valuable asset for the next step of fuel synthesis for the transport sector.

Traditional use of biomass and the absence of energy supply in developing countries have genderdifferentiating impacts, since women are primarily responsible for activities such as gathering firewood, fetching water, growing crops, etc. Since women are more vulnerable as a result of systematic discrimination, gender-specific impacts can also be observed in the biofuel industry but will not necessarily differ between first- and second-generation biofuel production (FAO, 2009a). Parameters that characterise the status of women in developing countries include limited access to land (only $5 \%$ of female farmers in developing countries own land), marginalisation in downstream socio-economic activities (e.g. trade), limited access to knowledge and discriminatory employment conditions. Therefore it is likely women would profit less from the potential benefits of the biofuel industry and suffer more from unsustainable development (FAO, 2008b; IUCN, 2007). The potential advantages of second-generation biofuels concerning land displacement and food competition may improve the situation for women, commensurate to the rest of the population, but the benefits will not be entirely grasped if their role is not upgraded and their needs are not separately defined.

\subsection{Potential environmental impacts}

\section{GHG balances}

Since second-generation biofuels can be produced from the whole plant or agricultural and forestry residues, they can help considerably reduce overall life cycle emissions and especially emissions related to feedstock production (per unit of produced fuel). Most of the published LCA studies for biofuels focus on the overall GHG mitigation potential compared to fossil fuels. Consolidated results of selected international studies for greenhouse gas emissions per energy content are shown in Figure 19 for conventional biofuel options as well as second-generation biofuel options. 
Figure 19. Comparison of well-to-wheel emission changes of different biofuels compared to fossil fuel

Page $\mid 80$

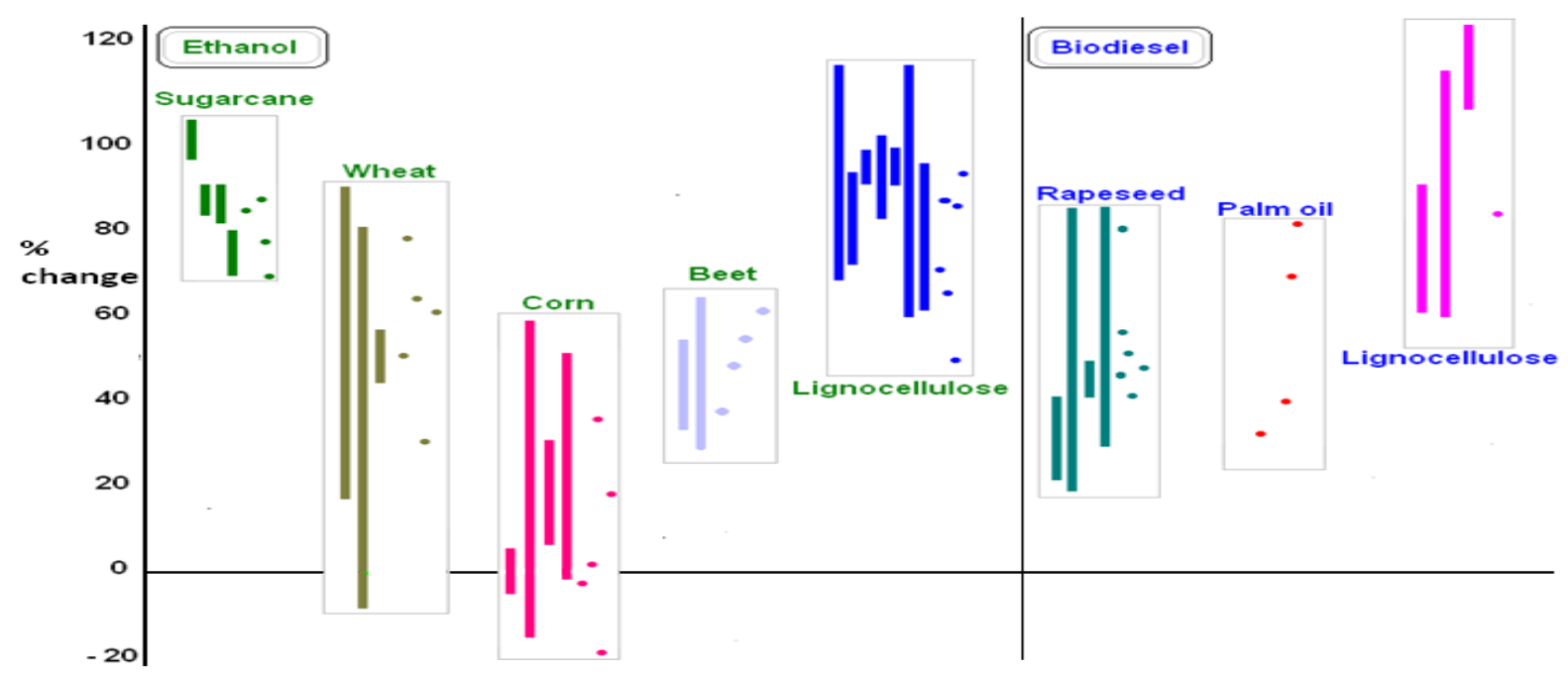

Source: IEA, 2008c based on IEA and UNEP analysis of 60 published life-cycle analysis studies giving either ranges (shown by the bars) or specific data (shown by the dots).

As the data show, there is a large range for each of the different biofuel options. Some available LCA case studies for first-generation biofuels (mainly bioethanol from sugar cane) in Brazil and Thailand show considerable GHG mitigation potentials compared to fossil fuels (see also country chapters). However, most current biofuel options do not promise high GHG mitigation, and in some cases they even have higher emissions than do reference fossil fuels. Second-generation biofuels have the potential to significantly mitigate GHG, but these results have been calculated for theoretical biofuel production concepts that are only just at the pilot/demonstration stage and not yet operating on a commercial scale (OECD, 2008d).

The use of agricultural and/or forestry residues as biofuel feedstock could significantly reduce emissions compared to the production and use of fossil fuels, as well as help to decrease local environmental impacts on biodiversity, acidification and eutrophication. However, there are important differences between primary and secondary residues. Secondary residues (e.g. rice husks, sugar cane bagasse, saw dust) are often considered trash (if they are not used to provide process energy) and are thus dumped at the plant site; on the other hand, primary residues (e.g. maize stalks, rice straw, sugar cane tops and leaves, tree tops) are either used as fodder or fuel or left on the field or in the forest. This means that the use of primary agriculture and forestry residues for second-generation biofuel production could require additional expenditure to achieve an equalised nutrient and humus balance in the soil. However, it is difficult to precisely assess carbon stock balances, since there is no consistent methodology to conduct such an assessment.

In general, the overall environmental performance of second-generation biofuels depends on the effectiveness and sustainability of the whole supply chain. Therefore, it is important to ensure a sustainable supply of energy for the conversion process through by-products or effective logistics handling for feedstock provision and biofuel distribution.

\section{Impact on soil}

The effects of removing agricultural residues on soil organic matter, soil erosion or crop yields may vary considerably due to site-specific conditions like climate, soil type and crop management 
(Cherubini et al., 2009). The removal of agricultural residues may reduce the input of organic matter to soil, which in turn would reduce soil fertility and plant productivity if nutrient loss is not replaced through fertilisers. However, since residues in conventional crop (and forest) management systems in developing countries are often burned after harvest, biomass removal may not change carbon inputs significantly in these systems. Even in systems in which the residues are not burned but rather are retained on the soil surface, impacts may be low since above-ground litter decays on the surface and often does not enter the soil carbon pool.

In general, it has to be considered that the amount of biomass removed at harvest represents only a fraction of total biomass produced; the major input to soil carbon are fine roots and leaf litter. Losses in soil carbon due to the removal of agricultural residues are thus considered to be low in crop systems (Cowie, 2006). Where forestry residues or whole tree cutting of short rotation coppices are used for second-generation biofuel production, the levels of soil organic matter and soil carbon may be reduced. Considering the high concentration of nutrients in leaves, branches and bark, as well as the high proportion of nutrient-rich biomass in young trees, short rotation whole tree-harvesting systems would remove greater amounts of nutrients than stem-only harvesting. This impact can be reduced if trees are harvested during winter, when leaves have already fallen (although this is not possible in evergreen tropical regions). In general, the effects of second-generation biofuel production from woody biomass on soil nutrient levels are strongly dependent on site-specific factors, such as the forest management system. As such, a general assessment on the chemical-biological impacts on soil is very difficult. The use of machinery in bioenergy production systems may increase soil bulk density (compaction) and create deep ruts, thereby decreasing the amount of aeration, water infiltration and root growth in the soil. But even though tree growth will decrease on most soils (e.g. clay), the water holding capacity of sandy soils may improve and help increase tree growth (Lattimore et al., 2009).

In the cases where dedicated energy plantations for second-generation biofuels replace other production systems, the impact on soil will depend on the features of the bioenergy system and the system being replaced. Substitution of cropland through short rotation bioenergy crops (i.e. perennial grasses, willow, eucalyptus) may increase soil carbon due to reduced frequencies of harvest and soil disturbance. If short-rotation bioenergy crops are substituting pastures, soil carbon balance will depend on the relative balance of organic inputs and the decomposition rate of the old and new land use; again, in such cases, a general assessment is difficult (Cowie, 2006). Regardless, in areas subject to strong erosion, like the loess plateau in China, perennial cultivation can significantly decrease the level of erosion and help to preserve fertile land from degradation.

\section{Impact on water}

Biofuel production can have significant impact on water quality and availability. These impacts may be caused by freshwater consumption for feedstock cultivation, the use of agro-chemicals in intensive production systems, the use of fertilisers (which pose a risk for eutrophication and acidification), and the consumption of water for processing and evaporative cooling in biofuel production.

Considering that the entire plant - including lignocellulosic fractions and not just the crop fraction - can be used in second-generation biofuel production, the water footprint (i.e. litre water/litre biofuel) for such production could be considerably lower than that of many current-generation biofuels. The water footprint, however, will depend upon the relationship between the lignocellulosic and the crop fraction, as well as the conversion efficiency of the second-generation technology.

With regard to the impact of biofuels from forestry residues and/or short rotation coppices, water yields and peak flow may change in and around sites of forestry systems dedicated to second- 
generation biofuel production. These impacts can vary in scale and intensity from site to site, depending on local climate, soils, and management practices. Short-rotation coppices requiring irrigation could contribute to groundwater depletion in areas with high water demand. The clearance of streamside vegetation in forest management systems may also change physical properties such as the turbidity, stream temperature and light infiltration of water bodies. If

Page | 82 nutrient inputs are required for wood plantations, infiltration and runoff of nitrogen may pose a risk to groundwater bodies (Lattimore et al., 2009).

Regarding the industrial conversion of biomass to second-generation biofuels, it is assumed that water requirements will be slightly above the current water requirement of first-generation biofuels due to additional conversion steps, in particular for lignocellulosic ethanol. For current corn ethanol production in the United States, for instance, processing water consumption can total up to $4 \mathrm{l} / \mathrm{l}$ ethanol, while for cellulosic ethanol processing it can reach $8 \mathrm{I} / \mathrm{I}$ (Institute for Agriculture and Trade Policy, 2006; Hargrove, 2007). Modern ethanol plants have sophisticated water treatment techniques to enable the recycling of water back to the boilers, so water consumption will decrease in the future. Since process-water consumption for biofuel production is only a fraction of water consumption in feedstock cultivation, these differences between first- and second-generation biofuels will not significantly affect the water footprint of the different biofuel options.

\section{Impact on biodiversity}

The impact of dedicated energy crops on biodiversity are manifold and can be both positive and negative. The replacement of native forests with mono-cropping plantations, for instance, significantly reduces plant biodiversity and may cause habitat loss for wildlife due to landscape and ecosystem changes, especially in tropical countries. Some typical species for wood energy production systems, like pinus and eucalyptus, are considered invasive species in many countries and their plantation may cause proliferation and threaten local ecosystems. But energy crop plantations also have the potential to increase biodiversity if former agricultural land is reforested and the replacement of degraded stands can improve forest structure (Lattimore et al., 2009).

Compared to the use of dedicated energy crops from plantations, the use of agricultural and/or forestry residues for second-generation biofuel production is expected to have a lower impact on biodiversity. Dedicated plantations for energy crops can lead to land use changes (see next section), which can increase pressure on areas with a high biodiversity value, like native forests.

Since the use of agricultural residues may have negative or positive impacts on biodiversity, depending on the cropping systems and the site-specific context, a general assessment is very difficult. Studies on the effects of the removal of sugar cane tops and leaves in Brazil showed that weed growth increased after the complete removal from the field (Hassuani et al., 2005). This may require increased use of herbicides and thus affect local biodiversity. Other impacts on biodiversity may arise as indirect impacts from the changes in the hydrologic balance and soil characteristics as described above. The use of forestry residues for second-generation biofuel production would reduce the amount of decaying wood and could thus reduce niche habitats and disturb wildlife due to increased forest access.

For secondary agricultural and forestry residues, the impacts on biodiversity are less severe in many cases. Often these residues are used for energy production or in other industries and are thus not returned to the field. The use of these residues for the production of second-generation biofuels would thus have no direct impact on biodiversity beyond the current situation; however, increased competition for secondary residues could lead to exploitation of other biomass resources and would thus have an indirect impact on biodiversity. 


\section{Box 2. Lignocellulosic energy crops in developing countries}

Poplar, willow and eucalyptus, as well as switchgrass and miscanthus, have been subject to intensive research mainly in the OECD region. Some of these crops are not suitable for cultivation in emerging and developing countries.

Major concerns for cultivation outside the natural habitats include: high water demand, sensitivity to drought and pests, and potential invasiveness. In South Africa, for instance, certain energy crops have been banned for these reasons.

To date, very little research has been undertaken to breed high-yielding lignocellulosic energy crops in most developing regions. Thus little is know about the suitability of indigenous second-generation feedstocks in these countries.

Intensive research on indigenous energy crops adapted to local conditions in developing countries is needed. However, the development of varieties suitable as second-generation biofuel feedstock could take decades and might seriously delay development of a second-generation biofuel industry in the respective regions.

\section{Direct and indirect land use changes}

The replacement of cropland with biofuel feedstock production and the subsequent destruction of rainforest and other valuable lands (so-called indirect land use change), have become an important topic in the sustainability discussion of biofuels. Some authors (Fargione et al., 2008; Searchinger et al., 2008) evaluated the impact of this indirect land use change. Fargione et al., for instance, estimated that if cerrado vegetation were cleared for a sugar cane plantation in Brazil, it would cause carbon emissions of about $165 \mathrm{t} \mathrm{CO}_{2} / \mathrm{ha} / \mathrm{yr}$. Thus, with an annual repayment of $9.8 \mathrm{t} \mathrm{CO}_{2} / \mathrm{ha} / \mathrm{yr}$ from the GHG mitigation potential of the produced biofuel, the carbon debt would be repaid after 17 years with ethanol fuel. If, however, peat forests or other ecosystems with high carbon stocks are replaced, the payback time would be much higher according to the calculations. However, the extent to which indirect land use change causes deforestation or the release of GHG is currently debated, and some authors argue that results in the aforementioned studies have been exaggerated or are based on biased methodology and argue that iLUC induced emissions are lower than suggested (e.g. Goldemberg \& Guardabassi, 2008; Mathews \& Tan, 2009). More research on this complex topic is, therefore, needed to evaluate iLUC effects in more detail.

For the production of second-generation biofuels, land use change can play a different role depending on the feedstock. If available residues are used, second-generation biofuels could help to decrease potential land use competition and reduce the effects of land use change. This applies for dedicated energy crops grown on abandoned land, as well. However, even in so-called "degraded" or "marginal" lands, cultivation of dedicated energy crops could have negative impacts upon biodiversity and ground water.

In the case of indirect land use change, it is difficult to assess the impact that the use of available residues for second-generation biofuel production would have. ILUC is difficult to analyse in general since proper definitions measurement methods are still under development. One approach from Fehrenbach et al. (2008) considers that using arable land for additional biomass feedstock production will induce indirect land use change risks due to displacement, but that the risk is small for feedstock produced from residues or on degraded land, as well as for biomass feedstock derived by increasing yields. However, if nutrient losses through the removal of biomass residues will not be balanced through increasing synthetic fertiliser application, decreasing crop yields may require the additional production of cereals somewhere else, thus resulting in indirect land use change (Cherubini et al., 2009). This example illustrates that the validity of LCA for biofuels should always 
be observed carefully, since complex indirect land use changes and related environmental impacts may not be fully reflected due to very limited system boundaries.

\section{Box 3. Indirect landuse change in current legislation}

\section{Page | 84 California Low Carbon Fuel Standard}

In an attempt to include iLUC in the LCA of biofuels, the state of California, through the California Air Resources Board of the California Environmental Protection Agency, recently proposed the Low Carbon Fuel Standard (LCFS), the first greenhouse gas standard of its kind for transport fuels. It defines the specific $\mathrm{CO}_{2}$-emissions per energy unit $\left(\mathrm{g} \mathrm{CO}_{2 \text {-eq }} / \mathrm{MJ}\right)$ of a variety of biofuels and considers $\mathrm{CO}_{2}$ emissions from indirect land use change as well. The defined carbon intensity of lignocellulosic ethanol based on forestry residues is $22 \mathrm{~g} \mathrm{CO}_{2 \text {-eq }} / \mathrm{MJ}$ (the use of residues causes no emissions from iLUC) compared to about 77-105 $\mathrm{g}$ $\mathrm{CO}_{2 \text {-eq }} / \mathrm{MJ}$ for corn ethanol (of which $30 \mathrm{~g} \mathrm{CO}_{2 \text {-eq }} / \mathrm{MJ}$ is from iLUC) and $95 \mathrm{~g} \mathrm{CO}_{2 \text {-eq }} / \mathrm{MJ}$ for gasoline (California Environmental Protection Agency, 2009).

\section{US Renewable Fuels Standard II}

A similar proposal has been announced by the U.S. Environmental Protection Agency, which proposed different default values to include iLUC in the lifecycle analysis of biofuels for the Renewable Fuels Standard. Due to the complexity of the topic and the absence of an accepted methodology, the proposed values will continue to be reviewed over the next few years before a new standard is fully adopted.

\subsection{Certification of second-generation biofuels}

Recent policy developments in the European Union (e.g. RED), the United States (e.g. RFS, LCFS) and other countries reflect policy makers' growing efforts to ensure sustainable biofuel production, as discussed in Chapter 4. Important focus points of these policy discussions are lifecycle GHG balances of biofuels, including the effects of direct and indirect land use change, as well as social and environmental standards along the biofuel production chain. In order to ensure compliance of biofuel production with the required sustainability standards, sound certification schemes will be needed. To work efficiently, these schemes need to be linked with other policy instruments that ensure sustainable land use patterns.

A number of initiatives are currently working on topics related to the sustainable production of biofuels. The Global Bioenergy Partnership (GBEP) is working on developing intergovernmental consensus on sustainability criteria and indicators for bioenergy production and use. Once second-generation biofuels are produced commercially, new definitions might be required to assess the sustainable production of these new fuels.

Since second-generation biofuels are not yet produced commercially, specific certification schemes do not yet exist, but many of the sustainability criteria for first-generation biofuels apply to secondgeneration production (e.g. minimum GHG emission savings, definition of suitable land for biofuel cultivation, social standards). Steps to develop certification schemes for biofuels are being undertaken by various public and private initiatives, including the Roundtable on Sustainable Biofuels (RSB) and the International Sustainability and Carbon Certification (ISCC).

For developing and emerging countries who want to export biofuels to certain OECD countries, certification will most likely be required in the near future, since producers will have to meet the sustainability standards of the importing countries. The additional costs that certification typically adds to biofuel production could have a considerable impact on the profitability of second-generation biofuels in developing and emerging countries, where certification is more costly than in industrialised countries (UNCTAD, 2008). Certification could, therefore, become an obstacle for the export of biofuels. 


\subsection{Alternative uses for residues}

\section{Bioenergy conversion}

The detailed discussion of different bioenergy conversion routes lies beyond the scope of this study. It is, however, important to consider that competing uses for biomass and lignocellulosic residues exist, which may impact the availability and opportunity costs for the material. Furthermore, other bioenergy options could be more beneficial to certain developing regions than the production of second-generation biofuels. This is mainly due to lower capital requirements, lower technology risks, and the possibility for small-scale installations in remote communities.

A brief overview of the alternative bioenergy uses of residues follows, based on IEA work (2008b). More details on successful bioenergy projects in developing countries can also be found in the work of Practical Action Consulting (2009).

Forestry and agricultural residues are traditionally used for energy production as fuel for residential cooking and heating. Residues are often burned in open fire places with efficiencies of 10-20\%, resulting in significant energy waste, not to mention increased health risks through smoke and CO-emissions.

\section{Box 4. Access to electricity in emerging and developing countries}

Energy alone is not sufficient for creating the conditions for economic growth, but it is certainly necessary. It is impossible to operate a factory, run a shop, grow crops or deliver goods to consumers without using some form of energy. Access to electricity is particularly crucial to human development as electricity is, in practice, indispensable for certain basic activities, such as lighting, refrigeration and the running of household appliances, and cannot easily be replaced by other forms of energy.

In particular in developing countries with low electrification rate (Table 11), it is therefore important to evaluate the possibilities for production of electricity from biomass. In the short-term this will be more beneficial and more feasible than production of second-generation biofuels, in most countries.

Table 11. Electricity access in different developing regions in 2008

\begin{tabular}{|l|ll|l|l|l|}
\hline \multirow{2}{*}{} & $\begin{array}{l}\text { Population } \\
\text { electricity }\end{array}$ & without & \multicolumn{2}{l|}{ Electrification rate } \\
\cline { 2 - 6 } & millions & $\begin{array}{l}\text { Total } \\
\%\end{array}$ & $\begin{array}{l}\text { Urban } \\
\%\end{array}$ & $\begin{array}{l}\text { Rural } \\
\%\end{array}$ \\
\hline North Africa & 2 & 98.9 & 99.6 & 98.2 \\
Sub-Saharan Africa & 587 & 28.5 & 57.5 & 11.9 \\
China \& East Asia & 195 & 90.2 & 96.2 & 85.5 \\
South Asia & 614 & 60.2 & 88.4 & 48.4 \\
Middle East & 21 & 89.1 & 98.5 & 70.6 \\
Developing countries & 1453 & 72 & 90 & 58.4 \\
Transition economies \& OECD & 3 & 99.8 & 100 & 99.5 \\
World & $\mathbf{1 4 5 6}$ & $\mathbf{7 8 . 2}$ & $\mathbf{9 3 . 4}$ & $\mathbf{6 3 . 2}$ \\
\hline
\end{tabular}

Source: WEO 2009 Electricity Database, http://www.worldenergyoutlook.org/electricity.asp 


\section{Efficient stoves for household cooking and heating}

- Typical capacity 5-50 kWth

- Efficiency $40-50 \%$

Page $\mid 86$

- Low capital investment; around USD 25-150/kWth for logwood stove

- Direct benefits like reduced biomass requirements, less health damage through smoke

\section{Industrial heat production}

- Typical capacity 1-5 MWth

- Efficiency between 70-90\% for modern furnaces

- Investment of USD 370-990/kW

In many developing countries, rural areas lack access to electricity, which is considered a key target for promoting rural development. Electricity generation from biomass would, therefore, be a valuable bioenergy option. It can be produced either through co-firing with fossil fuels or in a biomass-only power plant.

\section{Electricity generation}

- Typical capacity $5 \mathrm{MWe}$, up to more than $100 \mathrm{MWe}$

- Conversion efficiency $30-40 \%$

- Investment between USD 2 200-3 600/kW for biomass-only plants

\section{Combined heat and power generation}

- Typical capacity of 1-20 MWe; smaller plants $10 \mathrm{kWe}-1 \mathrm{MWe}$

- Conversion efficiency $80-100 \%$

- Investment costs between USD 3 300-4 300/kWe

- Smaller plants be suitable for rural energy supply in developing countries

The production of biogas via anaerobic digestion of biomass has been strongly promoted in some OECD countries (e.g. Germany), as well as in many developing regions including Asia, Latin America and some regions of West Africa (TAB, 2001).

\section{Biogas}

- Capacity varies from 3-8 $\mathrm{m}^{3}$ on household level up to $4000 \mathrm{~m}^{3}$

- Use as domestic fuel for cooking or in generator to produce electricity (10-15\% efficiency)

- Investment costs of USD 200-400 for household digester; up to USD 2.2 million (USD 3 000-4 000/kW) for commercial plant

- Use of wet feedstocks; digestate can be used as fertiliser 
Other uses for agricultural and forestry residues include the production of charcoal, which is a well known technology in developing regions and might also be a viable alternative for the use of residues as biofuel feedstock.

Comparing second-generation biofuel production with other bioenergy production routes reveals considerable differences in terms of capital investment, overall efficiency and capacity. That rural energy supply is still lacking in many developing and emerging countries suggests that power generation from biomass might be more beneficial to these countries than production of transport fuel. Lower investment needs translate into reduced financial risks if a project fails. Well-developed technology, which is in many cases less complex than production facilities for second-generation biofuels, is a further advantage for developing countries, since highly skilled technical labour is often scarce. In terms of efficiency, heat and power generation are producing more energy per unit biomass (efficiency $80-100 \%$ ) than do second-generation biofuels (efficiency $12-35 \%$ for BTL and ethanol, and up to $50 \%$ for bio-SNG) - a fact that should be considered especially in regions where biomass availability is limited.

\section{Non-energetic use of residues}

As mentioned earlier, a number of traditional uses for agricultural and forestry residues occurs in developing countries. Common uses in subsistence farming are for animal fodder and fertiliser.

A number of different industries are also using lignocellulosic residues, and the demand for biomass in the industry sector is expected to increase. Rice husks, for instance, are used in the carpet industry, whereas straw and stalks are used in China in different industry sectors. Forestry residues are often used in the fibreboard and paper industry (e.g. in Mexico, China, and Tanzania). Furthermore, biomass is gaining importance as a substitute for conventional raw materials in the automobile and chemical industries.

\subsection{Recommendations to ensure sustainability of second- generation biofuels}

Social sustainability of second-generation biofuels can only be achieved with the design of appropriate regulatory policies. Food production should always be the first priority, and adherence to land allocation procedures is a critical step to help integrate local communities. But social sustainability is unlikely to be ensured without economic sustainability; therefore, diverting financial resources to investment in technology and agricultural research is imperative. Furthermore, an equitable distribution of benefits among all stakeholders along the value chain should be achieved, with particular focus on the role of women and smallholders.

To ensure the environmental sustainability of second-generation biofuels, the potential for GHG emissions savings suggests the use of agricultural residues as feedstock. However, since there is little information about the importance of residues to nutrient cycles and soil conservation, the use of residues for second-generation biofuels should be assessed carefully. In general, in some emerging and developing countries, enforcement of environmental legislation for biomass cultivation and biofuel conversion is sometimes weak and has to be improved in order to guarantee environmental sustainability of biofuel production.

A question that should be carefully considered is whether first-generation biofuels are necessarily a prerequisite for the development of second-generation biofuels. In terms of infrastructure, they could provide the physical basis and the technical experience necessary for production and 
distribution. However, given the associated constraints discussed in the previous chapters, it is questionable how beneficial it is for developing countries to invest in large-scale first-generation biofuel production. Careful assessment of the potential negative social and environmental impacts is required. The Chilean government, for example, has announced a political commitment to develop second-generation biofuels without any commercial first-generation biofuel production yet

Page $\mid 88$ in place (Dufey, 2009).

On the other hand, first-generation biofuel projects, biogas production or heat and electricity generation might in some cases be beneficial options for emerging countries in order to promote rural development, especially when such bioenergy projects are integrated into food production systems.

In the end, without monitoring demonstration plants and the eventual implementation of commercial plants, no reliable data will be available to assess the economic, social and environmental impacts of second-generation biofuels in general, and in developing and emerging countries in particular. Thus, country-specific information on biomass supply and conversion costs, on local agricultural markets, and on nutrient cycles are required to draw specific conclusions and recommendations for each country. 


\section{Conclusions}

This study has attempted to answer whether or not major economies and developing countries can profit from the development of second-generation biofuel industries and under which conditions a sustainable implementation of this industry will be feasible in non-IEA countries. IEA scenarios project that demand for second-generation biofuels will increase considerably by 2030 and even more by 2050 in an energy sector that aims for significant reductions in global $\mathrm{CO}_{2}$ emissions. Although second-generation biofuel development is still in an early stage, and many developing countries have not yet looked into these new technologies, one important question to answer is whether sufficient feedstock quantities could be provided to meet future biofuel demand, thereby making the investment in the necessary R\&D and infrastructure worthwhile.

Recent studies have assessed the technical global biomass potential at ranges between $30 \mathrm{EJ}$ and $1500 \mathrm{EJ}$ in 2050 , which is between $10 \%$ and $300 \%$ of current global energy consumption. Particularly in developing regions, these global estimations indicate considerable potential for the cultivation of dedicated energy crops. Countries with good climatic conditions (such as wet tropical climates) or with the ability to intensify their agriculture to free large areas of land are generally assumed to have the highest potential. However, based on the findings from the eight countries analysed in this study, it appears that some of the assumptions made in previous studies are very ambitious - especially considering the high share of currently cultivated land and the steadily increasing population of some countries (e.g. India and Thailand). Therefore, the availability of land dedicated to energy crops for the production of second-generation biofuels may be limited and requires careful assessment; more research on available land resources is clearly needed in many countries.

Agricultural and forestry residues, on the other hand, are a readily available feedstock that can be purchased at its opportunity costs and would in many cases form a low-cost feedstock. In some cases, however, residues are already used (e.g. as fodder, organic fertiliser, domestic fuel) by rural populations as well as different industries. Furthermore, the possible environmental impact on soil nutrients, carbon and water resources, needs to be evaluated to ensure the sustainability of second-generation biofuels.

The assessment undertaken in this study shows that considerable amounts of second-generation biofuels could be produced from available agricultural and forestry residues. Assuming even a conservative value of $10 \%$ availability of global agricultural and forestry residues for secondgeneration biofuel production, there should be enough feedstock remaining for traditional uses. BTL-diesel, for instance, could cover around $45 \%$ of the projected biofuel demand, or $4 \%$ of the total transport fuel needs in 2030 in an energy scenario where considerable emission reductions are a priority (WEO 2009450 Scenario). This represents significant potential considering that no additional land would be required to produce these amounts.

The potential to use available residues from the agricultural and forestry sector to produce secondgeneration biofuels underscores the need for technology development. In the short term, this is likely to take place in developed countries and some large emerging economies like those of Brazil, China and India, where sufficient financing and R\&D capacities can be provided. For other developing countries like Cameroon and Tanzania, however, second-generation biofuels have only limited potential to promote sustainable development in the near future. Until the new technologies are commercially available, developing countries could revitalise rural economies by investing in rural infrastructure, agricultural production and improved energy supply (e.g. rural electrification). Different bioenergy systems could play an important role in this regard by providing 
access to cheap and clean domestic energy with significant potential to improve productivity and the overall standard of living in rural communities. This includes the use of biogas in China and India; several options at the village level in Thailand; a more efficient use of bagasse in Tanzania; and saw-mill residues in Cameroon for the generation of heat and power.

The assessment of sustainable biomass potential and the evaluation of benefits of different

Page | 90 bioenergy options, including first-generation biofuels, are important steps to increasing rural energy access. Investment to help build capacities in the field for feedstock supply and handling can create favourable conditions to establishing a second-generation biofuel industry. This way, countries that are currently not able to produce second-generation biofuels could profit from new technology and market opportunities once the technology is commercially available. Another key point is to enhance collaboration both with developed countries and among developing countries to build capacities in the field of second-generation biofuels and to ensure technology access, as is already the case, for example, in Brazil, China, India and Thailand.

\section{Key messages from this study}

- This study shows that there is a considerable potential for the production of secondgeneration biofuels. Even if only $10 \%$ of the global agricultural and forestry residues were available in 2030 , roughly $50 \%$ of the forecasted biofuel demand in the World Energy Outlook 2009450 Scenario could be covered - equal to around 5\% of the projected total transport fuel demand by that time.

- Demand for second-generation biofuels is growing, driven by ambitious biofuel mandates in particular in OECD countries, and a growing desire by scientists and policy makers to ensure the sustainability of biofuel production.

- To ensure a successful deployment of second-generation biofuels technologies requires intensive RD\&D efforts over the next 10-15 years.

- Technical development will mainly take place in OECD countries and emerging economies with sufficient RD\&D capacities like Brazil, China and India.

- In many developing countries, the framework conditions needed to set up a secondgeneration biofuel industry are not currently sufficient. The main obstacles that need to be overcome include poor infrastructure, lack of skilled labour and limited financing possibilities.

- Investments in agricultural production and infrastructure improvements would promote rural development and can significantly improve the framework for a second-generation biofuel industry. This will allow developing countries to enter second-generation biofuel production once technical and costs barriers have been reduced or eliminated.

- The suitability of second-generation biofuels for countries' respective needs has to be evaluated against other bioenergy options to achieve the best possible social and economic benefits. This should be part of an integrated land use and rural development strategy, to achieve the best possible social and economic benefits.

- Capacities should then be built slowly but continuously in order to avoid bottlenecks when the new technologies become technically available and economically feasible. To ensure technology access and transfer, co-operation on RD\&D between industrialised and developing countries as well as among developing countries should be enhanced.

- Agricultural and forestry residues should be the feedstock of choice in the initial stage of the production, since they are readily available and do not require additional land cultivation. 
- More detailed research is still needed to ensure that second-generation biofuels will provide economic benefits for developing countries. This research includes a global road map for technology development, an impact assessment of commercial second-generation biofuel production, and improved data on available land. Additionally, more case studies could enable further analyses of local agricultural markets, material flows, and specific social, economical and environmental benefits and risks in developing countries.

\section{Research gaps and next steps}

It is still too early to fully assess the potential social, economic, and environmental impacts of largescale second-generation biofuel production in practice. The following research steps are suggested to understand better the potential and impact of second-generation biofuels in developing countries and emerging economies:

- Creation of a global road map for second-generation biofuels, to enable governments and industry to identify steps needed and to implement measures to accelerate the required technology development and uptake.

- Pilot and demonstration plants outside the OECD in order to develop supply chain concepts, assess feedstock characteristics, and analyse production costs in different parts of the world.

- Collection of field data from commercial second-generation biofuel production from residues to better understand impacts on agricultural markets and the overall economic situation in developing countries.

- Improved data accuracy on sustainably available land in developing countries to determine the potential for dedicated energy crops. 



\section{Annex A - Country Profiles}

\section{A1 Introduction and Methodology}

Since RD\&D efforts on second-generation biofuels are mainly undertaken in developed countries, little is yet known about the opportunities and risks for developing and emerging countries, related to the production of lignocellulosic biofuels. The country profiles presented in this part of the study include Brazil, Cameroon, China, India, Mexico, South Africa, Tanzania and Thailand (Figure A1). These eight countries cover some of the major expanding biofuel markets, as well as different world regions with varying levels of development.

Figure A1. Overview of the eight countries selected for this study

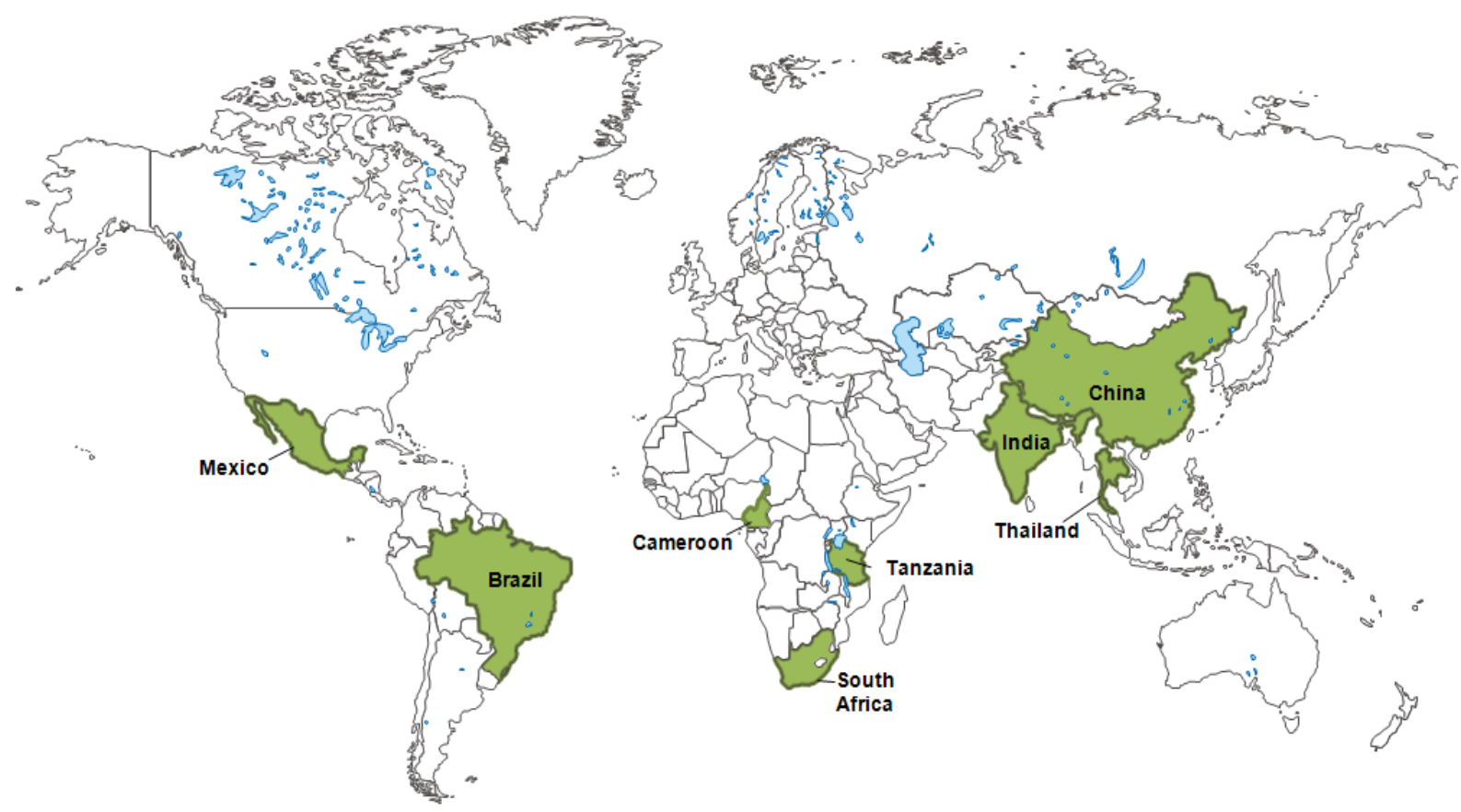

These country profiles cover the most important topics related to the sustainable production of second-generation biofuels. The first section includes a description of the current situation in the country in terms of economic situation, land availability, current biofuel production and infrastructure availability. Available sources of lignocellulosic feedstocks are identified in the next section, with particular focus on agricultural and forestry residues, since these most often constitute a readily available feedstock. The analysis also assesses the competing uses of agricultural residues and their availability for the production of second-generation biofuels. (Because of partial or poor data and significant differences between regions, the results partially reflect assumptions and therefore are only indicative values.) In the next section, the risks and opportunities of a second-generation biofuel industry for each country are evaluated in terms of 
possible economic, social and environmental impact. The final section reviews each country's feasibility to produce second-generation biofuels.

Four of the country profiles were conducted by local experts by order of the IEA Secretariat: Brazil (Biomass Users Network of Brazil), China (Institute of Energy and Environmental Protection), India (National Institute for Interdisciplinary Science and Technology), and South Africa (Council for

Page | 94 Scientific and Industrial Research). The other four country profiles were issued by order of the German Technical Collaboration (GTZ) and conducted by the German Biomass Research Centre (DBFZ) in collaboration with local consultants.

The authors and local experts involved in the writing of the different country profiles are:

Brazil

Suani T. Coelho, Patricia Guardabassi and Beatriz A. Lora (Biomass Users Network of Brazil, Brazil)

\section{Cameroon}

Franziska Müller-Langer, Jens Giersdorf, Anastasios Perimenis, Christian Pätz, Matthias Edel, Stefan Majer (German Biomass Research Centre [DBFZ]), Luis Antonio Carrillo (Delegation Provinciale MINFOF / MINEP, Cameroon)

\section{China}

Zhao Lixin, Yishui Tian and Meng Haibo (Institute of Energy and Environmental Protection, China)

India

Rajeev K. Sukumaran and Ashok Pandey (National Institute for Interdisciplinary Science and Technology, India)

\section{Mexico}

DBFZ authors (see above), Manuela Prehn and Enrique Riegelhaupt (Red Mexicana de Bioenergia [Rembio], Mexico)

\section{South Africa}

Graham P. von Maltitz and Martina R. van der Merwe (Council for Scientific and Industrial Research, South Africa)

\section{Tanzania}

DBFZ authors (see above), G.R. John and C.F. Mhilu (College of Engineering and Technology of the University of Dar-es-Salaam, Tanzania)

\section{Thailand}

DBFZ authors (see above), Werner Siemers (Joint Graduate School of Energy and Environment (JGSEE) at King Mongkut's University of Technology Thonburi [KMUTT], Thailand) 


\section{A2 Brazil}

\section{General country characteristics}

The territorial area of Brazil extends over 8.5 million $\mathrm{km}^{2}, 99 \%$ of which is land area, occupying just under half (47\%) of the area of Latin America. It has a coastline of $7491 \mathrm{~km}$ along the Atlantic Ocean which contains many of the country's major cities. From a geographic and politicaladministrative perspective, the country is divided into five regions based on climatic and physical characteristics (Brazilian Government, 2009). The country, which possesses 20\% of the entire world's biodiversity, has six main biomes, the largest of which is the Amazon biome, covering $49 \%$ of the land area, followed by the Cerrado biome (24\%), Atlantic Forest (13\%), Caatinga bioma (10\%), and the Pampa and Pantanal biomes.

The population of Brazil totalled 183 million inhabitants in 2007 and is the fifth-largest in the world. The majority of the population $(74 \%)$ is in the urban areas, and during recent years there has been significant migration from rural to urban areas (Brazilian Government, 2009). There are significant differences among Brazilian references in terms of the human development index (HDI), mainly related to energy access. HDI is highest in the south and south-east regions and is lowest in the north and north-east (GNESD, 2006). Brazil accounts for three-fifths of South America's industrial production and is part of various economic groups, such as Mercosur, G-22 and the Cairns Group. The Gross Domestic Product (GDP) was USD 1163 billion in 2007, with a growth rate of 5.4\% (BNDES, 2007) (Table A1).

Table A1. General population information and economy indices

\begin{tabular}{|l|l|r|r|}
\hline \multicolumn{1}{|c|}{ Parameter } & \multicolumn{1}{c|}{ Unit } & \multicolumn{1}{c|}{ Value } & \multicolumn{1}{c|}{ Year } \\
\hline Population & million & 183 & 2007 \\
\hline Population growth rate & \% & 1163 & 2007 \\
\hline GDP (PPP) & billion USD & 10200 & 2008 \\
\hline GDP per capita (PPP) & USD & 18.9 & 2005 \\
\hline Poverty rate & \% of total population & 0.8 & 2006 \\
\hline HDI & - & 7.5 & 2004 \\
\hline Undernourishment & \% of total population & 215.2 & 2007 \\
\hline Energy production & Mtoe & 231.8 & 2007 \\
\hline TPES & Mtoe & 24.8 & 2007 \\
\hline Net energy imports & Mtoe & 1.76 & 2006 \\
\hline CO ${ }_{2}$ emissions per capita & t CO capita $^{2}$ & & \\
\hline
\end{tabular}

Source: Brazilian Government, 2009; BNDES, 2007; UNDP, 2007; IEA Statistics, 2009 
About $45 \%$ of the total primary energy supply are derived from renewable sources, mainly biomass (31\%) and hydropower (13.8\%). The major share is, however, met by crude oil (40.3\%), natural gas (7.6\%) and coal (5.8\%) (Fig. A2). Nuclear power plays only a minor role, but the Brazilian government plans to build new nuclear power plants in the next decade in order to diversify its electricity supply (World Nuclear Association, 2009).

Page | 96 In general, problems of food security are less severe than poverty, as food growth has been significant during recent years, but there is still a lack of adequate food distribution in several parts of Brazil. In combination with poverty, this leads to approximately 13.8 million people (7.5\%) living under severe food insecurity (IBGE, 2008). In recent years, due to the social programmes of the government, the purchasing power of poor improved significantly. Concerns about the competition of food with biofuel are marginal since sugar cane crops occupy less than $1 \%$ of the land in Brazil (7.8 Mha). Even with the expected doubling of production through 2017 , no more than $1.7 \%$ of the total land will be used for sugar cane production, of which only $50 \%$ is used for ethanol production.

Figure A2. Total primary energy supply 2007

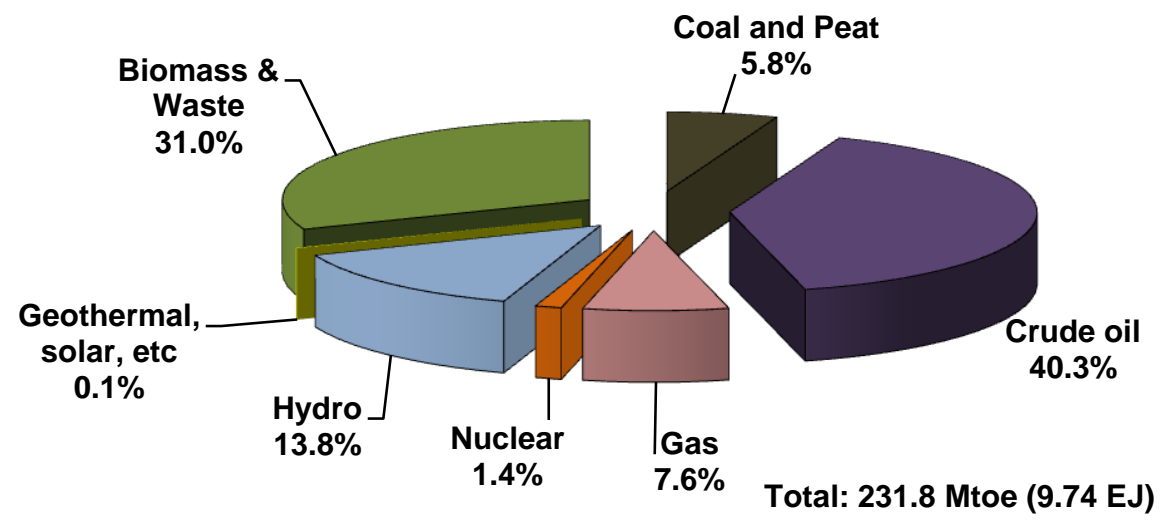

Source: IEA Statistics, 2009

\section{Natural conditions for biofuel feedstock production}

The climatic regions in Brazil are well defined and divided into the six previously mentioned major biomes. The duration of the rainy season varies according to the region and lasts from one to three months in the north-east and between six and twelve months in most other parts of the country. The mean annual precipitation varies between $300 \mathrm{~mm}$ and $3600 \mathrm{~mm}$ per year in different regions (Crepani et al., 2001).

In terms of potential biofuel production, the semi-arid region in the north-east provides suitable conditions to grow castor, jatropha and, to a lesser extent, sunflower and cotton crops as feedstock for biodiesel. In the south-east and central-western regions, the main energy crops are sugar cane and soy bean, which benefit from the climatic conditions in these regions. There is some sugar cane cultivation in the north-east, but with lower productivity, representing only $11.2 \%$ of national production. To expand sugar cane, the Brazilian government conducted a broad study of areas that are suited for sugar cane production and proposed new guidelines to include extension of credit lines to favour expansion into underused or degraded pasture land and to set restrictions on sugar cane production in areas that require irrigation (as nearly all cane is rain-fed today). Furthermore, 
there are measures being undertaken, as is the case in the state of Sao Paulo, to ensure the end of sugar cane burning by 2017 in all areas suitable for mechanised harvesting. These measures are expected to avoid negative impacts from indirect land-use change.

\section{Agriculture and forestry}

The agricultural area in Brazil totalled 263.5 Mha in 2007, about 62 Mha of which were cropland and around 197 Mha were occupied by pastures and permanent meadows (FAOStat, 2009) (Table A2). In 2007, agriculture accounted for $34 \%$ of Brazil's GDP and provided $37 \%$ of all jobs nation wide. It further accounted for $43 \%$ of all national exports, making it the only sector, among all the export sectors in the country, to produce a surplus (Brazilian Government, 2009). The sugar cane sector alone is responsible for 1 million jobs in the country.

Table A2. Agricultural and forestry production 2007

\begin{tabular}{|c|c|c|c|c|c|c|}
\hline \multicolumn{5}{|c|}{ Agricultural Production } & \multicolumn{2}{|c|}{ Forestry Production } \\
\hline Product & $\begin{array}{l}\text { Crop area } \\
(1000 \text { ha) }\end{array}$ & $\begin{array}{l}\text { Proportion of } \\
\text { Crop area (\%) }\end{array}$ & $\begin{array}{l}\text { Production } \\
(1000 \mathrm{t})\end{array}$ & Yield (t/ha) & Product & $\begin{array}{l}\text { Quantity } \\
\left(1000 \mathrm{~m}^{3}\right)\end{array}$ \\
\hline Soybeans & 22047 & 33.6 & 52465 & 2.4 & Roundwood & 239550 \\
\hline Maize & 12613 & 22.5 & 42662 & 3.4 & Wood fuel & 138783 \\
\hline Sugar cane & 6144 & 10.9 & 457246 & 74.4 & $\begin{array}{l}\text { Industrial } \\
\text { roundwood }\end{array}$ & 100767 \\
\hline Rice & 2971 & 4.7 & 11527 & 3.9 & Sawnwood & 23797 \\
\hline Coffee & 2312 & 3.7 & 2573 & 1.1 & Wood pulp & 11275 \\
\hline Cassava & 1897 & 3.2 & 26639 & 14.0 & $\begin{array}{l}\text { Wood-based } \\
\text { panels* }\end{array}$ & 8458 \\
\hline Wheat & 1560 & 3 & 2485 & 1.6 & $\begin{array}{l}\text { Paper and } \\
\text { paperboard* }\end{array}$ & 5834 \\
\hline Seed cotton & 899 & 1.8 & 2899 & 3.2 & \multirow{5}{*}{\multicolumn{2}{|c|}{$*[1000 \mathrm{t}]$}} \\
\hline Sorghum & 722 & 1.1 & 1605 & 2.2 & & \\
\hline Coconuts & 290 & 0.4 & 2978 & 10.3 & & \\
\hline Groundnuts & 111 & 0.2 & 250 & 2.3 & & \\
\hline Oil palm fruit & 57 & 0.1 & 590 & 10.4 & & \\
\hline Total & 62581 & & & 772877 & $\begin{array}{l}\text { Total forest } \\
\text { area } \\
\text { (1 000 ha) }\end{array}$ & 471492 \\
\hline
\end{tabular}

Source: FAOStat, 2009

The total forest area covers roughly $472 \mathrm{Mha}$, of which about 5.6 Mha was under management in 2007 (ABRAF, 2008). It permits the exploitation of 52.6 million tons of roundwood and includes only 
roundwood from planted forests. According to FAO (2009c), the gross value added (GVA) from roundwood production represents USD 18.2 billion, and the GVA of the total forestry sector accounts for USD 28.2 billion ( $2.8 \%$ of GDP). Roundwood from extractives represents $13 \%$ in Brazil, equal to 8.2 million tons in 2007 with a revenue of USD 819 million (IBGE, 2007). In Brazil, large scale agricultural crop production occurs mainly for soybeans (in the central-west)
and accounts for $45 \%$ of the total production (IBGE, 2007). Sugar cane is produced both at large and small scale (in the southeast and central-west), and in the state of Paraná sugar cane growers are organised in cooperatives.

Land prices vary in a wide range between and within the different regions. Prices are lower in the northeast (and semi-arid regions) and higher in the southeast. For example, the price of land varies from USD 24/ha in the Caatinga region in the state of Ceará to USD 9 350/ha in Ribeirão Preto city in the state of São Paulo (Agra Informa Ltd., 2008). Differences in land prices determine, for example, the sugar cane expansion in the state of São Paulo, which mainly occurred in the Pontal do Paranapanema region (in degraded areas with low land prices).

\section{Current situation of biofuel development}

\section{Production of first-generation biofuel}

For many years, Brazil used to be the world's largest biofuel producer. In 2004 the United States overtook it; nevertheless, Brazilian production accounted for 28 billion litres (or $34 \%$ of world biofuel production) in 2008 (IEA, 2009b). Most of this was ethanol derived by sugar cane, though about 1.1 billion litres of biodiesel have been produced as well. In 2005 it was mainly produced from soybean (122 kt), castor seed (11 kt), palm oil $(5 \mathrm{kt})$ and sunflower seed (1 kt). Biodiesel production in Brazil increased mainly due to the domestic B2 blending mandate.

Brazil is the world's largest exporter of fuel-grade bioethanol, totalling in 2008 approximately 5.1 billion litres of a total world-wide production of about 27 billion litres. Today, the primary destinations for ethanol exports are the US (including direct exports and under the Caribbean Basin Initiative and Central American Free Trade Agreement) and Europe, which together accounted for total exports of about 4.1 billion litres in 2008 (MME, 2009). Many countries that lack significant biomass resources, such as Japan, Chile and Sweden, have made Brazilian ethanol a part of their renewable fuel strategies.

Domestic use of bioethanol in Brazil remains strong. Rising demand for bioethanol - largely from the development of the flex-fuel vehicles market and somewhat from the policies in other countries - has created an impetus for new production capacity. Currently there are 423 plants, and it is estimated that annual production will reach around 43.4 billion litres in 2013 (IEA, 2009b).

By comparison, the biodiesel capacity across much of the country is idle. Currently, about $68 \%$ of the country's total authorised production capacity of 3.7 billion litres is idled. The increased biodiesel mandate (B5) will require about 2.3 billion litres over the next year. In 2008, biodiesel production was at record levels, reaching more than 1.1 billion litres. This industry uses soybean as a feedstock in $80 \%$ of its production (as of 2009), with other oilseeds, animal fats, and waste oils providing the remainder. This industry has largely been driven by a renewable fuel obligation.

Around $92 \%$ of the plants authorised for commercialisation have the "Social Fuel" seal, which is a certificate given to the companies that purchase a minimum amount of feedstock from family 
farmers and that have social and environmental concerns. There are reductions in excise duty along the biodiesel chain according to the type of feedstock used, according to the geographic region of production and according to the supplier (whether family farm or agribusiness).

The ethanol production foreseen in 2020 is expected to be 32.40 billion litres for the domestic Brazilian market and 18.6 billion litres for export. Though no commercial production of secondgeneration biofuels yet exists, projections suggest that about 4.5 million litres of cellulosic ethanol will be produced in 2020 (EPE, 2007).

\section{National policy target for biofuels}

The oldest example of widespread biofuel development is found in Brazil, which produces ethanol from sugar- or starch-based material in the form of sugar cane and sugar cane residues. In response to the first oil crisis of the 1970's, Brazil invested heavily in fuel alcohol primarily as a means of increasing fuel security and saving foreign currency on petroleum purchases. The National Ethanol Programme, Proálcool, was launched at this time. Several policies were introduced to promote biofuel consumption, including the development of vehicles capable of utilising hydrous (E100) fuel. In the late 1990s price regulation was removed, while Law 8.723/93 established that anhydrous ethanol blended in the gasoline would range between $20 \%$ and $25 \%$. After this law was enacted, all gasoline commercialised in Brazil must contain a percentage of ethanol that ranges from $20 \%$ to $25 \%$.

The original policy choice was to provide direct funding sources to create biofuel capacity. In 1975, Proálcool was created to be an alternative to the 1973 oil crisis. Proálcool was created with large public and private investments and was supported by a World Bank loan after 1981, allowing construction of alcohol distilleries, increased agricultural productivity, modernisation and enlargement of existing distilleries.

The second group of policies introduced in Brazil provided a subsidy for bioethanol use. During the Proálcool period, the oil industry was totally controlled by the state and some policies were created to stimulate the use of ethanol, including the setting of an ethanol (E100) price $25 \%$ less than the gasoline price; a $3 \%$ reduction in taxes for vehicles powered by ethanol; guaranteed remuneration for producers; public loans designated for production capacity increase; obligations for gas stations to sell ethanol; and maintenance of ethanol strategic stocks. From 1996 on, the Brazilian government initiated a programme to reduce subsidies and intervention. In 1999, the ethanol prices in the whole chain stopped being controlled by the government, and a complete elimination of industry subsidies took place.

The presence of a renewable fuel standard and of strong subsidies for E100 production, combined with the second oil shock of the early 1980's, resulted in the successful adaptation of vehicle engines to E100 fuel use. By 1984, E100 vehicles accounted for $94.4 \%$ of domestic automobile manufacturers' production, and in 1988 participation in the E100 programme reached $63 \%$ of total vehicle use in the country. The upward trend ended, however, when high global sugar prices led to a crash in availability of fuel alcohol, resulting in a consumer shift away from E100 vehicles. All vehicles today run on E20 to E25, but sales of flex-fuel vehicles (FFV) capable of operating E100 are strong, accounting for more than $90 \%$ of all vehicles sold. Brazil has developed a unique distribution infrastructure for this fuel, with a network of more than 37000 fuel stations with E25 pumps, of which 35000 list at least one E100 pump (MME, 2009).

In 2004, the National Programme of Biodiesel Production was launched by the federal government to allow the blending of $2 \%$ biodiesel (by volume) to diesel fuel on a voluntary basis; such targets 
became mandatory starting in 2008, and by 2013 a $5 \%$ blend will be mandatory. The biodiesel programme contains also a social element, which includes two mechanisms: a social fuel stamp and a tax-reduction system. The social fuel stamp (Selo Combustivel Social) programme reduces taxes for biodiesel producers who buy their feedstock from small-scale farms in poor regions. They can furthermore access financing from the Brazilian Development Bank (BNDES) (FAO, 2008a).

Page | 100 While biodiesel and ethanol no longer depend on government support policies, second-generation biofuels are currently not competitive with fossil fuels and state support might thus be required in the initial phase of the industry. However, no policies to promote second-generation biofuels in Brazil have yet been adopted.

\section{Financing and human resources}

Regarding foreign investments, the World Bank (2006) lists tax rates, macroeconomic instability, policy uncertainty and cost of financing as the most severe concerns of running a business in Brazil, ranking it 121 out of 175 countries surveyed. There is no particular investment policy either for firstor second-generation biofuels. In some states there are incentives on state taxes for firstgeneration sugar/alcohol mills, such as in the state of Goias. There are special loan conditions from BNDES to support more efficient technologies in the industrial sector, including more efficient boilers for bagasse cogeneration (BNDES, 2005). Recently there have been increasing foreign investments in the country, which include the biofuels sector.

There are qualified human resources for the production of first-generation biofuels, including the production and harvesting of sugar cane and other feedstocks, as well as the running of the refineries. Some workers receive special capacity building in different activities along the ethanol production chain, such as operating machines for mechanical sugar cane harvesting.

There is currently no commercial production of second-generation biofuels in Brazil. However, RD\&D efforts are under way by a number of companies and organisations, including Centro de Tecnologia Canavieira (CTC), PETROBRAS, IPT, UNICAMP, Dedini, Amyris and CTBE (www.bioetanol.org.br). While most efforts are taking place on a laboratory scale, some pilot-scale production should start by July 2010. In 2007, Danish enzyme producer Novozymes signed a cooperative agreement with CTC to develop a cost-competitive enzyme blend for the production of cellulosic-ethanol supported with roughly USD 2.4 million (EUR 1.5 million) from the European Union's Seventh Framework Programme. CTC for has furthermore set up a lignocellulosic-ethanol pilot plant in Piracicaba and is aiming to start a demonstration-scale plant in 2010/2011 (Jagger, 2009). While at the moment economical competitiveness is not given, existing ethanol-plants offer favourable conditions to help establish a second generation biofuel industry. The existing refinery infrastructure, in combination with vast amounts of bagasse, form a supportive environment for the development of second-generation biofuel production. Cenpes has planned a joint venture with Japan's Mitsui and Brazil's Itarumã Participacões to couple a demonstration-scale secondgeneration ethanol plant to an existing first-generation ethanol refinery in the state of Goiás (Jagger, 2009). Furthermore, Petrobras is currently developing a project for lignocellulosic ethanol which has already surpassed the phase of laboratory tests and is currently in pilot-scale tests through an experimental unit in the state of Rio de Janeiro (Petrobras, 2009).

Regarding the production of enzymes, Brazil currently has no domestic manufacturers, but companies like Danisco or Novozymes, worldwide manufacturers of enzymes, have plants in the country. Novozymes is currently undertaking research in cooperation with the Sugar cane 
Technology Centre CTC in order to produce a cost-competitive enzyme mix for the production of lignocellulosic-ethanol.

\section{Infrastructure}

Brazil's infrastructure for transportation is often in bad condition. Many roads are poorly maintained, ports are old and operate under bad conditions, and the rail-network is sparse and uncompetitive for transport issues (Virtual-Brazil.com, 2009).

Therefore, most of the country's grain production is currently transported by trucks. Efforts to modernise the Brazilian transport infrastructure have largely not successful, and it is considered uncompetitive compared to other countries. A case study for soybean suggested that significant disadvantages for soybean producers result from the deficiencies in transportation (VirtualBrazil.com, 2009). The transport costs vary significantly from region to region, depending on infrastructure availability. For the state of São Paulo, the average cost of sugar cane transport is USD 0.06/km/t in the base year 2003 (Chaves, 2004). International transportation costs for the route from the Port of Santos in Brazil to the Port of Rotterdam in the Netherlands total USD 102/1000I, including USD 16/1000 of storage and handling costs, USD 2/1000l for inspection, USD 30/1000l freight costs, USD 50/1000I transportation costs and USD 4/1000l for insurance and despatching (Cenbio, unpublished).

Brazil is in focus of any analysis on sugar and ethanol export infrastructure projects due to its dominance in world sugar and ethanol exports. Improvements in domestic sugar transport facilities are taking place through rail companies such as ALL (América Latina Logística), which are seeking to revamp the relatively small rail network in Brazil for the shipping of agricultural products. Rail networks as well as pipelines are being planned to transport ethanol to the ports. The main pipelines are being developed by Petrobras, and the project intends to install a $1150 \mathrm{~km}$ pipeline to link the expanding cane-growing region in Southern Goiás state to the Ribeirão Preto area (Brazil's main sugar cane producing region), then to the hub of Paulínia, and then either to the port terminal of São Sebastião in the state of São Paulo or to llha D'água in the state of Rio de Janeiro, two of the main ethanol export facilities in Brazil.

Several private companies, including Cargill and Noble group, have been investing in their own sugar and ethanol export terminals throughout Brazil's main ports. These, combined with the land transport infrastructure work, are significant investments that bode well for the long term. However, constraints remain for the short term since planning, financing and implementation of these projects longsome (ISO, 2009).

Table A3. Vehicle fleet in 2006

\begin{tabular}{|c|c|c|c|c|c|c|c|}
\hline Motorcycles & PC+SUV & LCV's & PLT's & MDT's & HDT's & Buses & Minibuses \\
\hline 5471000 & 18704513 & 3149366 & 4232304 & 877324 & 308586 & 271844 & 152271 \\
\hline
\end{tabular}

Source: IEA Mobility Model, 2009

The total vehicle fleet in Brazil in 2006 was about 33.2 million vehicles (Table A3). In the largest category, passenger cars, there is a high share of flex-fuel vehicles suited to drive on variable ethanol blends. The current (2009) fleet of flex-fuel vehicles is about 8.4 million, corresponding to 
nearly $90 \%$ of new vehicle sales (MME, 2009), although tax advantages are used to promote sales of these vehicles. Gasohol (gasoline with $20-25 \%$ anhydrous ethanol) is sold at every fuel station, whereas no pure fossil-petroleum fuel is sold. Most stations also sell diesel oil and biodiesel (currently B4), and 109 sell natural gas (ANP, 2009).

Table A4. Fuel consumption in 2007 and projection for 2030

\begin{tabular}{|l|l|l|l|l|}
\hline & \multicolumn{1}{|c|}{$\begin{array}{c}\text { Motor Gasoline } \\
1000 \mathrm{t}(\mathrm{PJ})\end{array}$} & $\begin{array}{c}\text { Diesel } \\
1000 \mathrm{t}(\mathrm{PJ})\end{array}$ & $\begin{array}{c}\text { Natural Gas } \\
1000 \mathrm{t}(\mathrm{PJ})\end{array}$ & $\begin{array}{c}\text { Biofuels } \\
1000 \mathrm{t}(\mathrm{PJ})\end{array}$ \\
\hline $\mathbf{2 0 0 7}$ & $13770(614)$ & $27141(1161)$ & $(99)$ & $13607(374)$ \\
\hline $\mathbf{2 0 3 0 *}$ & $20292(905)$ & $39995(1711)$ & $(183)$ & $42242(1210)$ \\
\hline
\end{tabular}

Source: IEA Statistics, 2009; *Assumption based on WEO 2008 data, assuming linear growth in each sector

The current total fuel consumption is about $2021 \mathrm{PJ}$, mainly diesel (1 $161 \mathrm{PJ})$, followed by gasoline (614 PJ) and biofuels (374 PJ) (Table A4). Diesel is used for trucks and buses but cannot be used in light vehicles, since it has a different tax regime. Gasoline is used for light vehicles and motorcycles. While the data refers to pure gasoline, the fuel sold at stations contains ethanol (20\%-25\%) but higher blends (E85/ E100) are available as well. In terms of volume, consumption of ethanol almost equals that of gasoline, mainly due to the large number of flex-fuel vehicles.

\section{Feedstock assessment and logistics}

\section{Feedstocks and cultivation area}

There are basically three types of lignocellulosic feedstock which can be exploited in Brazil: sugar cane (bagasse, tops and leaves), agricultural residues (from soya, corn, rice, peanut and coconut) and wood residues.

The assessed literature (Macedo \& Cortez, 2000) presents a theoretical value of $50 \%$ for the total amount of sugar cane tops and leaves that are left in the field, whilst the other $50 \%$ are utilised and transported to the sugar or ethanol plants. In order to estimate the potential energy generated from agricultural wastes, agricultural production values in each meso-region of the country were taken into account for the five geopolitics regions. The most abundant agricultural wastes used in Brazil are soya residues, corn stover, rice husks, coconut and peanut shells.

Today many of the agricultural residues mentioned in Table A5 are scarcely utilised. In a few situations they are utilised for burning in boilers for energy production, but in majority they are just considered as trash and left on the soil. For example, soya residues are completely left in the fields, whereas rice husks are burned in boilers for heat/electricity production for the industry, and coconut shells are burned in the field; in some rare cases coconut residues are burned in boilers, but there are no statistics about these amounts ${ }^{15}$. However, for soybean residues, Kline et al. (2007) indicated that no sustainable recovery of the residues is possible in Brazil, due to their scattered abundance and their function to prevent soil erosion.

15 CENBIO in 2008/2009 has prepared the "Brazilian Bioenergy Atlas" which shows the potential of bioenergy (electricity) in geo-referenced maps (http://cenbio.iee.usp.br/atlasbiomassa.html). 
Table A5. Assessment of residues from forestry and agriculture

\begin{tabular}{|c|c|c|c|c|c|}
\hline Type & $\begin{array}{c}\text { Actual } \\
\text { material } \\
\text { flow } \\
(1000 \\
\left.t_{D M} / y r\right)\end{array}$ & $\begin{array}{l}\text { Unused } \\
\text { residues } \\
(1000 \\
\left.t_{D M} / y r\right)\end{array}$ & $\begin{array}{l}\text { Feedstock } \\
\text { cost } \\
\text { (USD/t) }\end{array}$ & $\begin{array}{l}\text { Regional } \\
\text { availability }\end{array}$ & Main utilisation \\
\hline \multicolumn{6}{|l|}{ Primary Residues } \\
\hline Soybean (stalks, leaves)* & 118029 & n.a. & & $\begin{array}{l}\text { Middle West, } \\
\text { SE }\end{array}$ & $\begin{array}{l}\text { Currently the residues are left on } \\
\text { the ground }\end{array}$ \\
\hline Maize (stalks, stems) & 31007 & n.a. & & $\begin{array}{l}\text { S, SE, Middle } \\
\text { West }\end{array}$ & $\begin{array}{l}\text { Currently the residues are left on } \\
\text { the ground }\end{array}$ \\
\hline Rice (straw) & 14102 & n.a. & & S, Middle West & $\begin{array}{l}\text { Currently the residues are left on } \\
\text { the ground }\end{array}$ \\
\hline Cotton (stalk) & 8561 & n.a. & & Middle West & $\begin{array}{l}\text { Currently the residues are left on } \\
\text { the ground }\end{array}$ \\
\hline Sugar cane (tops) & 6400 & 3200 & $14-31$ & $\begin{array}{l}\text { SE, Middle } \\
\text { West, NE }\end{array}$ & $\begin{array}{l}\text { Only } 50 \% \text { of residues can be } \\
\text { used. The other part must remain } \\
\text { on the soil }\end{array}$ \\
\hline Wheat (straw) & 4966 & n.a. & & $\begin{array}{l}\text { S, SE, Middle } \\
\text { West }\end{array}$ & $\begin{array}{l}\text { Currently the residues are left on } \\
\text { the ground }\end{array}$ \\
\hline Sorghum (leaves, stems) & 1922 & n.a. & & $\begin{array}{l}\text { Middle West, } \\
\text { SE }\end{array}$ & $\begin{array}{l}\text { Currently the residues are left on } \\
\text { the ground }\end{array}$ \\
\hline Forestry logging residues & 14511 & 7256 & & $\mathrm{~N}, \mathrm{SE}, \mathrm{S}$ & $\begin{array}{l}\text { Only } 50 \% \text { of residues can be } \\
\text { used. The other part must remain } \\
\text { on the soil }\end{array}$ \\
\hline \multicolumn{6}{|l|}{ Secondary Residues } \\
\hline Maize (corn cob) & 10422 & n.a. & & $\begin{array}{l}\text { S, SE, Middle } \\
\text { West }\end{array}$ & $\begin{array}{l}100 \% \text { of these residues are used } \\
\text { for feed }\end{array}$ \\
\hline Sugar cane (bagasse) & 6400 & 704 & $3-8$ & $\begin{array}{l}\text { SE, Middle } \\
\text { West, NE }\end{array}$ & $\begin{array}{l}89 \% \text { of bagasse is used for } \\
\text { cogeneration }\end{array}$ \\
\hline Rice (husk) & 1772 & n.a. & & S, Middle West & $\begin{array}{l}100 \% \text { of residues are burned in } \\
\text { steam boilers }\end{array}$ \\
\hline Coconut husk & 452 & n.a. & & $\mathrm{NE}, \mathrm{N}, \mathrm{SE}$ & no use \\
\hline Coffee husk & 340 & 85 & & & \\
\hline $\begin{array}{l}\text { Oil palm empty fruit } \\
\text { bunches (EFB) }\end{array}$ & 123 & n.a. & & $\mathrm{N}, \mathrm{NE}$ & EFB back to the field \\
\hline Groundnut (shell) & 71 & n.a. & & $\begin{array}{l}\text { SE, Middle } \\
\text { West, NE }\end{array}$ & $\begin{array}{l}\text { Some are burned in steam } \\
\text { boilers, other left on the ground. }\end{array}$ \\
\hline Forestry processing residues & 14278 & 4284 & $16-23$ & $\mathrm{~N}, \mathrm{SE}, \mathrm{S}$ & \\
\hline Sawdust & 3950 & 1185 & $16-23$ & $\mathrm{SE}, \mathrm{S}$ & $\begin{array}{l}70 \% \text { currently used for energy } \\
\text { production }\end{array}$ \\
\hline
\end{tabular}

* Kline et al., 2007, indicated that no sustainable use of soybean residues is possible 
For the evaluation of the potential of second-generation biofuels in the forestry industry, residues were examined that come from forest logging operations as well as wood processing. In the early stages of this manufacture - for example, peeling and cutting - a great amount of bark and wood chips is produced; these residues can be used in the production of second-generation biofuel in nearby sites or easily transported since they are already concentrated and do not need to be Page | 104 collected.

In Brazil, roundwood production can generate 21.5 million tons of residue from logging and 7 million tons from processing (EPE, 2007). Currently in Brazil, around 1.5 million tons of round wood residues processed by industry are used for steam and electric energy for the furniture and paper industry. This total represents $20 \%$ of the estimated waste from wood production in Brazil (Uhlig, 2008). Another part is converted into charcoal used in metallurgy, but there is no reliable data about the use of forestry residues in the charcoal industry.

\section{Second generation biofuel options}

Table A6. Potential second-generation biofuel production and number of plants

\begin{tabular}{|c|c|c|c|c|c|c|c|c|}
\hline \multirow[b]{3}{*}{$\begin{array}{l}\text { Biofuel } \\
\text { option }\end{array}$} & \multicolumn{4}{|c|}{ Production } & \multicolumn{4}{|c|}{ Number of plants } \\
\hline & \multicolumn{2}{|c|}{ actual material flow } & \multicolumn{2}{|c|}{ unused residues } & \multicolumn{2}{|c|}{ actual material flow } & \multicolumn{2}{|c|}{ unused residues } \\
\hline & Mlge/yr* & $\mathrm{PJ} / \mathrm{yr}$ & Mlge/yr* & $\mathrm{PJ} / \mathrm{yr}$ & $\begin{array}{c}\text { small } \\
\text { scale** }\end{array}$ & $\begin{array}{c}\text { large } \\
\text { scale** }\end{array}$ & $\begin{array}{c}\text { small } \\
\text { scale** }\end{array}$ & $\begin{array}{c}\text { large } \\
\text { scale** }\end{array}$ \\
\hline \multicolumn{9}{|c|}{ Based on primary residues } \\
\hline Bio-SNG & 61230 & 2051.2 & 7776 & 260.5 & 3301 & 447 & 419 & 57 \\
\hline BTL & 43134 & 1445.0 & 5478 & 183.5 & 397 & 103 & 50 & 13 \\
\hline Bioethanol & 42528 & 1424.7 & 5401 & 180.9 & 3190 & 259 & 405 & 33 \\
\hline \multicolumn{9}{|c|}{ Based on secondary residues } \\
\hline Bio-SNG & 11429 & 382.9 & 1953 & 65.4 & 616 & 83 & 105 & 14 \\
\hline BTL & 8051 & 269.7 & 1376 & 46.1 & 74 & 19 & 13 & 3 \\
\hline Bioethanol & 7938 & 265.9 & 1357 & 45.5 & 595 & 48 & 102 & 8 \\
\hline \multicolumn{9}{|c|}{ 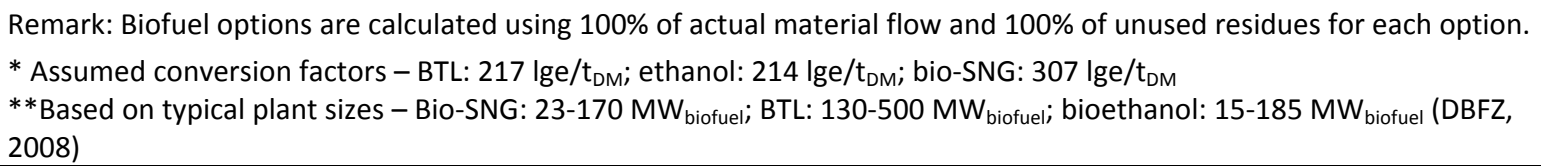 } \\
\hline
\end{tabular}

Based on biomass residues described above, the potential biofuel production and number of production plants can be defined. The calculations are based on actual material flows as well as unused residues and represent only a theoretical estimation. For every second-generation biofuel option, not all types of residues are considered suitable. However, since this is the aim of many further development efforts, all types of residues in the analysis were considered suitable for every pathway. Biofuel production as well as the potential number of conversion plants is higher based on primary residues than on secondary residues. Due to higher overall efficiency and lower technical 
complexity, the biomethane pathway has a higher fuel output, while BTL and bioethanol produce similar fuel outputs. The number of second-generation biofuel refineries that could theoretically be built based on available residues is in Table A6.

Though considerable amounts of second-generation biofuel could be produced from currently unused agricultural residues, the theoretical amounts would cover only a small portion of Brazil's current and future transport fuel demand.

\section{Estimated costs for feedstock / end-product}

Prices for sugar cane bagasse are relatively accurate since most of it is burned in boilers for cogeneration and only a small amount of surplus, approximately $10.8 \%$ on average, is available to be sold (Cenbio, 2009). Prices can vary between USD 3.0 and USD 8.0 per metric ton of bagasse (50\% wet). In the study developed by Hassuani et al. (2005) to evaluate final costs for sugar cane trash in the mills, the bagasse price was assumed to be USD 5.00/t of bagasse ( $50 \%$ wet). For tops and leaves, prices of USD 13.7-31.12/ $\mathrm{t}_{\mathrm{DM}}$ have been used. The average transport distance from harvesting to processing in the scenarios was $19 \mathrm{~km}$.

Table A7. Theoretical second-generation biofuel production costs in Brazil

\begin{tabular}{|c|c|c|c|c|c|}
\hline \multirow[t]{3}{*}{ Feedstock } & \multirow{3}{*}{$\begin{array}{c}\begin{array}{c}\text { Feedstock } \\
\text { price }\end{array} \\
\mathrm{USD} / \mathrm{t}_{\mathrm{FM}}\end{array}$} & \multicolumn{4}{|c|}{ oil USD $60 / \mathrm{bbl}$} \\
\hline & & \multicolumn{2}{|c|}{ today (USD/Ige) } & \multicolumn{2}{|c|}{ longterm (USD/Ige) } \\
\hline & & BTL-diesel & LC-ethanol & BTL-diesel & LC-ethanol \\
\hline $\begin{array}{l}\text { Sugar cane tops and } \\
\text { leaves }\end{array}$ & $14-31$ & $0.64-0.76$ & $0.65-0.80$ & $0.4-0.50$ & $0.39-0.52$ \\
\hline Bagasse & $4-8$ & $0.57-0.60$ & $0.55-0.60$ & $0.34-0.37$ & $0.3-0.34$ \\
\hline Saw mill residues & $16-23$ & $0.65-0.80$ & $0.67-0.86$ & $0.41-0.54$ & $0.4-0.57$ \\
\hline & & \multicolumn{4}{|c|}{ oil USD 120/bbl } \\
\hline $\begin{array}{l}\text { Sugar cane tops and } \\
\text { leaves }\end{array}$ & $14-31$ & $0.82-0.93$ & $0.75-0.9$ & $0.51-0.61$ & $0.42-0.56$ \\
\hline Bagasse & $4-8$ & $0.74-0.78$ & $0.66-0.70$ & $0.45-0.48$ & $0.34-0.38$ \\
\hline Saw mill residues & $16-23$ & $0.83-0.98$ & $0.77-0.96$ & $0.52-0.65$ & $0.44-0.61$ \\
\hline
\end{tabular}

Source: Based on IEA Mobility Model, 2009

Production costs for BTL diesel and lignocellulosic ethanol would currently range between USD 0.55-0.86/Ige (Table A7). Even if the cost of second-generation production will be significantly reduced, they will hardly be able to compete with first-generation ethanol prices of USD $0.40 /$ liter for some time to come (see discussion on production costs in chapter 8).

\section{Identification of "hot spots" for production plants}

According to a survey on regional availability of sugar cane, the central south-east of Brazil, especially the state of São Paulo, is identified as a "hot-spot" for second-generation biofuels. In this 
region, there are 44 of the country's 148 first-generation ethanol plants, milling around 100 million metric tons per year ${ }^{16}$. These 44 plants are systematically mapped by CTC (Centro de Tecnologia Canavieira, Piracicaba, SP, Brazil) and correspond to the database available in the country for prospective second-generation production of bioethanol in the country. A "standard plant" processes an average of 2 million metric tons of sugar cane per year (Macedo et al., 2008), and each one would cost approximately USD 150 million. The greatest potential for residue generation in wood processing lies in the south and southeast with $24.4 \%$ and $61.4 \%$, of all estimated residues respectively. In particular, the states of São Paulo and Minas Gerais are the ones that present the greatest potential with $29.6 \%$ and $22.2 \%$ of the assessed residues respectively. These regions with the greatest production potential are also the areas with better transportation infrastructure.

\section{Sustainability}

\section{Economic impact}

Seabra (2008) presented a technical-economic evaluation of options for the whole use of sugar cane biomass in Brazil and obtained prices for sugar cane, bagasse, tops and leaves. Since the mill owners also own about $80 \%$ of the sugar cane plantations, new venture opportunities must be analyzed carefully. These ventures could have a direct impact on the price of sugar cane bagasse, straw and trash; hence, the economic analysis is not a straightforward process (Bonomi, 2009). An opportunity could be the sale of extra sugar cane trash currently left on the fields to be either used for burning in boilers or hydrolysed and fermented to produce bioethanol.

In general, agricultural residues do not have commercial value and due to the high cost of collection and transportation, they are left in the fields. The only residues considered as possible candidates for biofuel production are sugar cane residues and wood residues. The selling of forestry residues could produce additional income for farmers, but there is not any specific study that quantifies or evaluates the potential of this income. Currently, the residues from deforestation are abandoned in the field, used as firewood in rural properties, or used in the production of charcoal, mainly in the northern and north-east regions of Brazil.

\section{Social impact}

The number of jobs in the sugar cane sector is expected to remain the same or even decrease somewhat, since the mechanical harvesting of green sugar cane will be increasingly adopted. As a consequence, the nature of future harvesting jobs will be different. For example, contract workers who used to cut cane manually in the fields have now received training and some of them are operating harvesting machines, which over the long term implies better working conditions and higher remuneration. With mechanical harvesting, the number of field jobs will decrease while the utilisation of residues for second-generation production increases, although these increases may not be enough to absorb all of previous workers. Social standards, such as labour rights and improved working conditions, are not currently implemented by sugar cane producers on a countrywide basis. To address this issue, a National Commitment to Labour Conditions in the Sugarcane Industry was installed through a dialogue table set up in July 2008. It seeks to implement new rights

\footnotetext{
${ }^{16}$ The season consists of 8 month between April and November.
} 
and guarantee a better quality of life for sugar cane workers while addressing questions that are also relevant for a second-generation biofuel industry.

The Commitment consists of government representatives, members of the private sector and representatives of sugar cane workers. It was based on the interest of social parties to improve labour conditions in the sugar cane and ethanol industry. Areas of focus include working contracts, labour and health security, education, child labour, unemployment protection and several others. The Commitment forms the bases for taking a set of public and private actions to improve viable working conditions and establish best practices. So far, adherence of the proposed standards is voluntary, but a system of recognition for companies who commit to the social standards will be created by the government. To evaluate the success of the National Commitment, a National Commission for Dialogue and Evaluation has been set up to propose and review the National Commitment to help assure dialogue and negotiation for continuous improvements in living and working conditions in the sugar and ethanol sector (MME, 2009).

It is also possible to consider the integration of small land holders into the second-generation biofuels production chain. Although this integration would occur mainly in the case of agricultural residues, logistics and commercial issues must be evaluated. In the case of forestry activities, the increase of forestry can generate new jobs in rural areas, and might thus compensate somewhat for the loss of jobs in the forestry sector that was caused by the mechanisation of forest harvesting in recent years. The number of jobs in this sector decreased from 544000 in 1996 to 239000 in 2007 (ABRAF, 2008).

Evaluating the social impacts of the integration of small producers in forestry production is complex. In general, the increasing mechanisation of both the forestry and agricultural sector makes smallholder participation more difficult and results in the loss of jobs for unskilled workers.

\section{Ecological impact}

The expansion of sugar cane in Brazil, mainly in southeast and central-west regions, has been cited as controversial. In general, it is believed that sugar cane expansion puts relatively low pressure on protected areas because it mainly takes place on former pasture land, but the impact on indirect land use change is not yet fully understood. Between 1996 and 2006, almost 90\% of the enlargement of sugar cane areas was concentrated in four states (São Paulo, Minas, Paraná and Goiás); in those states, there was significant phasing-out of pasturelands accompanied by the growth of forested areas. Except for São Paulo, the increase of forested areas was larger than the expansion of sugar cane areas, and expansion mainly occurred in pasture areas.

In Brazil, 172 Mha are used for cattle in a very extensive way (less than one head per hectare). If the same cattle density currently in place in Sao Paulo ( 1.56 heads/ha) were expanded for Brazil, an area of more than 60 Mha could be available, both for food and bioenergy crops. With the Agroecological Zoning of Sugar Cane (ZAE Cana) survey completed in 2009 and recommendations for protection sent by the president to the congress for approval, areas with prevalence of original native vegetation will be protected and cannot be used for sugar cane cultivation. Harvesting crops in protected biomes, such as the Amazon and the Pantanal, is prohibited. ZAE Cana orients the expansion of sugar cane in $7.5 \%$ of Brazilian lands (64.7 Mha) in a sustainable way, helping with the formulation of public policies by considering some restrictions, such as environmental, economic, social, climate risks and soil conditions (MME, 2009).

In addition to regulating future sugar cane expansion, the federal government is pursuing the banning of burnings in existing production areas. The eradication will be enforced according to a 
transition schedule that ends burning by 2017 in 100\% of areas suitable for mechanised harvesting. This measure will allow for the reduction of greenhouse gases by 6 million tons of $\mathrm{CO}_{2}$ equivalent per year (MME, 2009) and would theoretically allow for a larger quantity of sugar cane leaves and tops to be collected for second-generation biofuels.

For the use of woody energy crops, the ecological impact of that plantation forestry must be considered, including the loss of biodiversity and the contamination of soil, water and groundwater by agro-toxins. (These impacts are almost completely controlled in sugar cane crops.) Moreover, the use of residues from forestry can place additional pressures on forest lands and potentially increase deforestation. It is also important to consider the native forest participation in wood supply. Although participation has reduced in recent years, in 2007 35\% of wood used in Brazil was supplied from native forests, for which there is no information about the sustainability and legality of its use. The pulp and paper industry consumes about $40 \%$ of the total wood production and is the only sector that sources all of its wood from certified forestry.

\section{SWOT analysis}

Table A8. Summary of SWOT analysis

\begin{tabular}{|c|c|}
\hline STRENGTH & $\begin{array}{l}\text { - Favourable geographic location with access to the sea } \\
\text { - } \quad \text { Long experience with first-generation biofuel production } \\
\text { - Fast-growing economy with investment capacity for large scale projects } \\
\text { - Biofuel blending mandate and well-functioning distribution network }\end{array}$ \\
\hline WEAKNESS & $\begin{array}{l}\text { - Limited incentives to invest into second-generation biofuels due to high } \\
\text { profitability of current ethanol production } \\
\text { - Transportation costs are major concern for residue use in rural areas } \\
\text { - Bagasse, the most attractive feedstock, is already used mainly for heat and } \\
\text { power generation }\end{array}$ \\
\hline OPPORTUNITY & $\begin{array}{l}\text { - Potential to export second-generation biofuels to the US, which will need } \\
\text { - } \text { significant amounts of cellulosic biofuel } \\
\text { - } \text { production } \\
\text { - Existing research on laboratory-scale second-generation biofuel production } \\
\text { - Second-generation biofuel plants could be coupled to existing biofuel } \\
\text { refineries leading to reduced costs for infrastructure and logistics }\end{array}$ \\
\hline THREAT & $\begin{array}{l}\text { - Smallholder integration only to a limited extent } \\
\text { - High investment costs for second-generation plant imposes financial risks } \\
\text { - No specific funds for R\&D in second-generation biofuels in Brazil }\end{array}$ \\
\hline
\end{tabular}

\section{Conclusions}

In 2009 Brazil is expected to reach a 26 billion-litre ethanol production level using first-generation technology in a relatively sustainable way. Available technology and pilot experience in secondgeneration bioethanol from sugar cane residues does not seem to be economically competitive at 
the moment, despite the potential increase in biofuel production per hectare of sugar cane, as discussed in this study.

Last year's worldwide economic crisis has induced many companies (either national groups or multinationals) to postpone their plans on biofuel R\&D projects, including biorefineries and secondgeneration biofuels. Delays in the development of second-generation biofuel technology will likely continue for some time, although Brazil is expected to maintain its high level of research on biofuels.

The highest potential for ethanol from enzymatic hydrolysis is from sugar cane residues. However, sugar mill owners tend to be very conservative and do not consider this technology sufficiently compelling. It seems that the whole sector will not take financial risks under current economic conditions for second-generation biofuel production, which is one of the main barriers to broader development of this technology. However, once second-generation biofuels are competitive, the prospects for fast growth are good in Brazil.

Another major barrier is the investment needed in research, mainly in the implementation of pilot plants. Special funding for further research is urgently needed, but unlikely to happen soon. Prospects are higher in the state of Sao Paulo since it is the most industrialised state in the country; however, these efforts are still limited in number and might only become mature in the long term. Moreover, since first-generation ethanol production costs are extremely low, the economic competitiveness of second-generation in a short/medium term is a significant challenge.

Agricultural residues appear to be a good option for second-generation biofuels, but logistics and transportation issues continue to be a challenge. Since most residues are currently left in the field, it is difficult to transport them to a plant. Another option for second-generation biofuels is wood residues, especially in areas with large amounts of wood production and in regions where this material is processed. For the wood industry, the production and processing centres are located in the state of Pará, in Mato Grosso and in Rondônia (native forests), and in Santa Catarina, Paraná Rio Grande do Sul, São Paulo and Minas Gerais (planted forests). The main R\&D efforts on secondgeneration biofuels are currently focusing on the utilisation of bagasse. This resource is broadly used for heat and electricity generation, but boiler efficiency could be raised significantly. With second-generation biofuels in place and resulting competition for bagasse feedstock, boiler efficiencies could rise from current levels of $40 \%$ up to $60 \%$. In this way, the production of heat and electricity would require less bagasse, allowing for a greater share to be dedicated to biofuel production.

As it happens with all renewable sources of energy, the effective realisation of the potential of biofuel production from wood and agricultural residues requires the definition and implementation of supportive policies in medium and long terms, which define clear and effectively motivating conditions so that the full economic and strategic potential of these resources is fulfilled. 


\section{A3 Cameroon}

\section{General country characteristics}

Page | 110 Cameroon is located in central western Africa, bordering Nigeria to the northwest, Chad to the northeast, Central African Republic to the east, Equatorial Guinea, Gabon and Congo to the south, and the Atlantic Ocean to the west. It has a coast line of $402 \mathrm{~km}$, occupies a total area of $475440 \mathrm{~km}^{2}$ (CIA, 2008) and is divided into 10 provinces. Table A9 provides an overview of some basic economic indices and population information about Cameroon.

Table A9. General population information and economy indices

\begin{tabular}{|l|l|l|l|}
\hline Parameter & Unit & Value & Year \\
\hline Population & million & 18.47 & 2008 \\
\hline Population growth rate & $\%$ & 2.7 & \\
\hline GDP (PPP) & billion USD & 44 & $2001-2007$ \\
\hline & & & 2008 \\
\hline GDP per capita (PPP) & USD & 2382 & 2008 \\
\hline Poverty rate ${ }^{17}$ & $\%$ total population & 57.7 & 2006 \\
\hline HDI & - & 0.514 & 2006 \\
\hline Undernourishment & $\%$ of total population & 23 & $2003-2005$ \\
\hline TPES & Mtoe & 7.29 & 2007 \\
\hline Net Energy Imports & Mtoe & -1.79 & 2007 \\
\hline $\mathrm{CO}_{2}$ emissions & $\mathrm{t} \mathrm{CO}_{2} /$ capita & 0.17 & 2006 \\
\hline
\end{tabular}

Source: CIA, 2008; IEA Statistics, 2009; FAO Aquastat, 2009; NIS, 2006; UNDP, 2007; FAO, 2008c

Regarding industrial activity, Cameroon shows growth in the general production index, which includes sectors such as agro-alimentary, textile and plastics, wood and paper, chemical and petroleum, water and energy production and distribution, intermediate goods and construction (NIS, 2006). The country's primary energy supply is based on biomass (63.5\%), oil (27.9\%), hydropower (4.2\%) and gas (4.4\%) (Figure A3). Electricity generation reached $4000 \mathrm{GWh}$ in 2006, $94 \%$ of which originated from hydropower and the rest from oil. With $29 \mathrm{PJ} / \mathrm{yr}$, the transport sector consumes around $7 \%$ of petroleum products and approximately $12 \%$ of the total final energy consumption of the country (IEA Statistics, 2009). Despite being an oil producer, the country imports light petroleum products as a result of lack of refinery infrastructure.

The economic growth witnessed in the country during the late 1990s resulted in a decrease of the poverty rate by 13 percentage points between 1996 and 2001, reaching 40\%. However, this trend did not continue, resulting in poverty remaining flat over the period 2001-07. Poverty is concentrated in rural areas, where almost half of the population is living below the national poverty line due to isolation and also to the fact that earned income has not grown enough to enable farmers to maintain their standard of living (NIS, 2006).

\footnotetext{
${ }^{17}$ Poverty line: $<2$ USD/day.
} 
Figure A3. Total primary energy supply, 2007

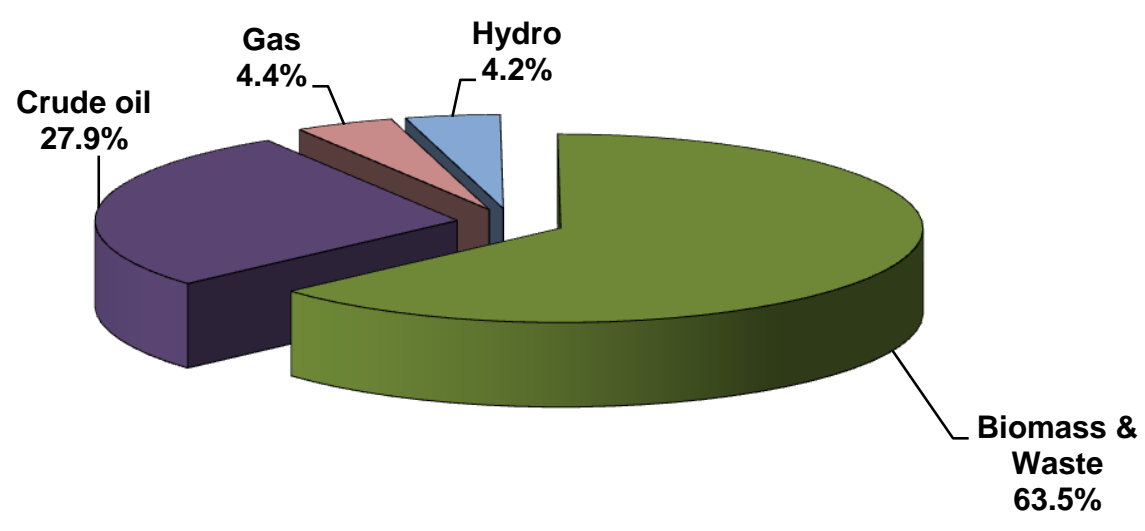

Total: 7.29 Mtoe (299 PJ)

Source: IEA Statistics, 2009

Although Cameroon is generally self-sufficient regarding its alimentary situation, this autarky is particularly fragile when bad harvests occur, and around $25 \%$ of the population lives under the status of food insecurity mainly in three provinces (Extreme North, North and Littoral). Food insecurity generally stems from poverty and the difficulty of transport between production zones and food shortage zones (NIS, 2006; SNI, 2008). The national food security programme is well planned but lacks funding (Carrillo, 2009b). Nonetheless, Cameroon remains the largest agriculture supplier in central Africa (FAO Aquastat, 2009).

\section{Natural conditions for biofuel feedstock production}

Based on topographic and climatic criteria, Cameroon can be divided into four regions. The plateau in the south is mainly influenced by equatorial climate. Average annual rainfall is over $1500 \mathrm{~mm}$ per year and there are only two dry months. With diminishing precipitation to the north of the country, the vegetation changes from dense rain forest to savannah. The lowlands of the coast belong to the equatorial domain and receive precipitation between 2000 and $4000 \mathrm{~mm}$ per year. Besides mangrove forests, oil palms, bananas and rubber grow in these areas.

Tropical climate characterises the north; arid periods can last up to nine months and average precipitation varies from 300 to $900 \mathrm{~mm}$ per year. It consists of two lowlands, the Benue depression and the plains along Lake Chad. The vegetation in the Extreme Northorth suffers from drought, and where more rain falls, cotton is cultivated. Since the mountains and highlands of western Cameroon are of volcanic origin, rich soils cover these mountains. Densely forested mountains in the south and savannah in the north are typical, and cocoa and coffee plantations could be found there. 


\section{Agriculture and forestry}

According to 2003 statistics, the agricultural sector contributed $30 \%$ of the country's GDP and occupies about 70\% of the labour force (Molua and Lambi, 2007). Of the total land area, 5.9 Mha are arable land and 1.2 Mha are designated for permanent crops.

Table A10. Agricultural and forestry production 2007

\begin{tabular}{|c|c|c|c|c|c|c|}
\hline \multicolumn{5}{|c|}{ Agricultural production } & \multicolumn{2}{|c|}{ Forestry production } \\
\hline Product & $\begin{array}{l}\text { Crop area } \\
\text { (1000 ha) }\end{array}$ & $\begin{array}{l}\text { Proportion of } \\
\text { crop area (\%) }\end{array}$ & $\begin{array}{c}\text { Production } \\
(1000 t)\end{array}$ & $\begin{array}{l}\text { Yield } \\
\text { (t/ha) }\end{array}$ & Product & $\begin{array}{c}\text { Production } \\
\left(1000 \mathrm{~m}^{3}\right)\end{array}$ \\
\hline Sorghum & 600 & 8.4 & 540 & 0.9 & Roundwood & 11448 \\
\hline Maize & 480 & 6.7 & 923 & 1.9 & \begin{tabular}{|l|} 
Industrial \\
roundwood
\end{tabular} & 1800 \\
\hline Cassava & 312 & 4.4 & 2076 & 6.7 & Wood fuel & 9648 \\
\hline Groundnuts & 300 & 4.2 & 160 & 0.5 & Sawnwood & 702 \\
\hline Beans, dry & 225 & 3.1 & 198 & 0.9 & $\begin{array}{l}\text { Wood based } \\
\text { panels }\end{array}$ & 87 \\
\hline Sugar cane & 143 & 2.0 & 1430 & 10.0 & & \\
\hline Bananas & 82 & 1.1 & 790 & 9.6 & & \\
\hline Oil palm fruit & 58 & 0.8 & 1300 & 22.4 & & \\
\hline Millet & 51 & 0.7 & 55 & 1.1 & & \\
\hline Natural rubber & 45 & 0.6 & 47 & 1.0 & & \\
\hline Total crop area & 7160 & & 13210 & & $\begin{array}{l}\text { Total forest } \\
\text { area } \\
\text { (1000 ha) }\end{array}$ & 21245 \\
\hline
\end{tabular}

Source: FAOStat, 2009

Its enormous rainforest endowment (about $45 \%$ of land area is under forest cover) makes Cameroon an important country for the production of roundwood and sawnwood. However, clearing for plantations and small-scale farmers, as well as the use of wood fuel, constitute the main threats to the rain forests (FAO, 2009b; MINEPN, 2008).

As Table A10 indicates, cassava, sorghum and maize are the main food crops. Sorghum is capable to withstand even extreme drought conditions, so it is also grown in the arid north of Cameroon. Most of the plantation crops, including palm oil, rubber and banana, are concentrated in areas with a tropical humid climate in the south-west of the country (Molua and Lambi, 2007). In 2002, the majority of these plantations were owned by industrial groups (Gerber, 2006). 


\section{Current situation of biofuel development}

\section{Current production of first-generation biofuels}

Currently no commercial production of biofuels is taking place in Cameroon. Only some isolated trials have been undertaken by companies like Cameroon Development Corporation, Sosucam, Ferme Suisse, Sodecoton, Maiscam and Socapalm. Governmental programmes and foreign capitals have supported the industrial production of palm oil with the aim to produce 250000 tons of oil by 2010 on 5000 ha/year (Soumonni \& Cozzens, 2008). Furthermore, a non-profit association called GREENERY is promoting the cultivation of jatropha plants across the Northwest province of Cameroon (Binyuy, 2007). It seems, however, that any biofuel development will be primarily oriented to stationary use and not to the transport sector (Libert, 2007). A classification of suitable regions and feedstock for potential biofuel production is shown in Table A11.

Table A11. Potential first-generation biofuel options

\begin{tabular}{|l|l|l|}
\hline Biofuel type & Location & Feedstock \\
\hline Vegetable oil & North, Southwest, Northwest & Cotton, oil palm, jatropha \\
\hline Bioethanol & Centre & Sugar \\
\hline Biodiesel & Southwest, Northwest & Oil palm, groundnut, jatropha \\
\hline Biogas & Centre, Littoral & Urban waste \\
\hline
\end{tabular}

Source: Carrillo, 2009b

\section{National policy target for biofuels}

Given that Cameroon is not currently involved in research programmes for the promotion of biofuels, there is no official biofuel policy. Overall, the country's energy policy does not take into consideration the use of biomass and other renewable energies. A lack of coordination among Cameroon's regulating bodies is the main obstacle concerning decisions and actions in this sector (Carrillo, 2009b).

\section{Financing and human resources}

Confronted with the difficult national and international economic situation, the government of Cameroon has prepared a number of strategies to boost some vital sectors of the economy. The overall portfolio comprises investment of around USD 590 million for the short, middle and long term in sectors such as electricity generation (including biomass), food and water security, and the reduction of poverty (SNI, 2008). However, corruption and poor governance encourage unproductive investments, leading to the deterioration of the quality of services (NIS, 2006).

There is a sufficient labour force in Cameroon in the agricultural sector. University graduates with technical training are well distributed across the country, but there is no specific specialisation relevant to biofuel production, since the experience of the country in the biofuel sector is so far non-existent (Carrillo, 2009b). 


\section{Infrastructure}

Cameroon has a reasonably diversified transport system but must also cope with an insufficient infrastructure that is often in poor condition due to the lack of management and investment. As a transit country for landlocked neighbouring countries (Central African Republic, Chad and Congo),

Page | 114 Cameroon has a transport system that is very important for regional integration. Cameroon has a road network of about $50000 \mathrm{~km}$, of which $28000 \mathrm{~km}$ are main roads under regular maintenance. Only $10 \%$ of total roads are paved, and the road system is characterised by many weaknesses, especially in the north and the east of the country. The rail network totals $1200 \mathrm{~km}$, stretching from Douala at the Atlantic Ocean to Yaoundé and then to Ngaoundéré. Railways are mainly used for freight transport, especially wood and container cargo. With regard to water transportation, on the Atlantic coast there are three sea ports (Limbe, Kribi and Douala), and in the north of Cameroon there is the river port of Garouna (OECD, 2008e; Carrillo, 2009b; World Bank, 2007).

Cameroon operates one oil refinery in Limbe on the Atlantic Ocean, which is suited to process imported light oil. There are plans for an upgrade to allow it to process domestically produced oil. The imports of light petroleum products are dedicated to the transport and residential sector of the country, while the domestic production (i.e. heavy oil) is designated to export (IEA Statistics, 2009; Carrillo, 2009b). Currently there are no facilities for the production of biofuels.

The transportation of feedstock like palm oil occurs by light and heavy trucks, normally over distances of less than $100 \mathrm{~km}$. Other feedstocks (e.g. rice and wood) are transported by train but only for distances above $100 \mathrm{~km}$ (Carrillo, 2009b).

Cameroon's automotive fleet totals 325121 vehicles, of which $18 \%$ are two wheelers, $62 \%$ are passenger cars and sports utility vehicles, $17 \%$ light and heavy trucks, and the remaining $4 \%$ are buses (Table A12). Many vehicles are scrap cars imported from abroad and are, consequently, in poor condition, since safety and pollution regulations are not very strict (Carrillo, 2009b).

Table A12. Vehicle fleet in 2006

\begin{tabular}{|c|c|c|c|c|}
\hline $\mathbf{2}$ wheelers & $\mathbf{3}$ wheelers & PC+SUV & LCV's, LT's, MDT's, HDT's & Buses, Minibuses \\
\hline 57000 & n.a. & 201000 & 54121 & 13000 \\
\hline
\end{tabular}

PC: passenger car; SUV: sport utility vehicle; LCV: light commercial vehicle ; LT: light truck; MDT: medium duty truck; HDT: heavy duty truck

Source: IEA Mobility Model, 2009

The domestic fuel consumption amounts to $29 \mathrm{PJ} /$ year, two-third of which is gasoline and remaining one-third is diesel (IEA Statistics, 2009). Consumption projections for the year 2030 with are shown in Table A13.

Table A13. Fuel consumption in 2007 and projection for 2030

\begin{tabular}{|r|r|r|r|r|}
\hline & \multicolumn{1}{|c|}{$\begin{array}{c}\text { Motor Gasoline } \\
1000 \mathrm{t}(\mathrm{PJ})\end{array}$} & $\begin{array}{c}\text { Gas/Diesel } \\
1000 \mathrm{t}(\mathrm{PJ})\end{array}$ & $\begin{array}{c}\text { Natural Gas } \\
1000 \mathrm{t}(\mathrm{PJ})\end{array}$ & $\begin{array}{c}\text { Biofuels } \\
1000 \mathrm{t}(\mathrm{PJ})\end{array}$ \\
\hline $\mathbf{2 0 0 7}$ & $377(17)$ & $266(12)$ & n.a. & n.a. \\
\hline $\mathbf{2 0 3 0 *}$ & $519(23)$ & $366(16)$ & n.a. & n.a. \\
\hline
\end{tabular}

Source: IEA Statistics, 2009; *Assumption based on WEO 2008 data, assuming linear growth in each sector 


\section{Feedstock assessment and logistics}

\section{Feedstock and cultivation areas}

Natural conditions constrain intensive agriculture to the littoral, west, centre and north of Cameroon and forestry to the southern and eastern parts of the country. Hence, residues suitable for the production of second-generation biofuels largely come from the cultivation of cassava in the littoral region and maize throughout most of the others. Straw, together with sorghum, is cultivated in the centre and north of Cameroon; the two crops constitute the primary agricultural residues used for heating and cooking applications. Other agricultural residues derive from peanut or rice cultivation, but they have limited technical-economic feasibility to be a potential biofuel because of their small quantities and fragmentation among several small farming systems. The by-products and residues of oil palm, sugar cane and peanut shell processing are large, but demand from cogeneration and other usages, mainly in the surrounding local populations, creates opportunity costs for their use as biofuel feedstock (Table A14).

In the dense forests of the south, east and the coastal area of the country, logging is a major economic activity and produces large amounts of wood residues. As with other biomass byproducts and residues, wood residues are an important source for heating and cooking. The quantity of saw dust emerging from wood processing is estimated to be almost 1.8 million $t_{D M}$ (Carrillo, 2009b).

Table A14. Assessment of residues from forestry and agriculture

\begin{tabular}{|c|c|c|c|c|}
\hline Type & $\begin{array}{c}\text { Actual material } \\
\text { flow } \\
\left(1000 t_{D M} / y r\right)\end{array}$ & $\begin{array}{l}\text { Unused residues } \\
\left(1000 t_{D M} / y r\right)\end{array}$ & $\begin{array}{l}\text { Regional } \\
\text { availability }\end{array}$ & Main utilisation \\
\hline \multicolumn{5}{|l|}{ Primary residues } \\
\hline $\begin{array}{l}\text { Maize (stem, } \\
\text { stalk) }\end{array}$ & 5734 & n.a. & $\begin{array}{l}\text { Adamawa, Centre, } \\
\text { E, N, Extreme } \\
\text { North, Littoral, } \\
\text { NW, SW, S, W }\end{array}$ & $\begin{array}{l}\text { Fertiliser, heating, } \\
\text { cooking }\end{array}$ \\
\hline Cassava stems & 834 & n.a. & $\begin{array}{l}\text { Adamawa, Centre, } \\
\text { E, N, Extreme } \\
\text { North, Littoral, } \\
\text { NW, SW, S, }\end{array}$ & $\begin{array}{l}\text { Fertiliser, heating, } \\
\text { cooking }\end{array}$ \\
\hline $\begin{array}{l}\text { Millet sorghum } \\
\text { straw }\end{array}$ & 389 & n.a. & $\begin{array}{l}\text { Adamawa, } \\
\text { Extreme North, N, } \\
\text { Littoral, NW, W }\end{array}$ & Heating cooking \\
\hline Peanut straw & 151 & n.a. & $\begin{array}{l}\text { Adamawa, Centre, } \\
\text { E, N, Extreme } \\
\text { North, Littoral, } \\
\text { NW, SW, S, W }\end{array}$ & Heating, cooking \\
\hline
\end{tabular}




\begin{tabular}{|c|c|c|c|c|}
\hline Type & $\begin{array}{c}\text { Actual material } \\
\text { flow } \\
\left(1000 \mathrm{t}_{\mathrm{DM}} / \mathrm{yr}\right)\end{array}$ & $\begin{array}{l}\text { Unused residues } \\
\qquad\left(1000 t_{D M} / y r\right)\end{array}$ & $\begin{array}{l}\text { Regional } \\
\text { availability }\end{array}$ & Main utilisation \\
\hline Rice straw & 32 & n.a. & $\begin{array}{l}\text { All but } E, S \text {, } \\
\text { Littoral }\end{array}$ & $\begin{array}{l}\text { Fertiliser, heating, } \\
\text { cooking }\end{array}$ \\
\hline Oil palm stalk & 13 & n.a. & $\begin{array}{l}\text { Centre, E, N, } \\
\text { Littoral, NW, SW, } \\
\text { S, }\end{array}$ & Fertiliser, forage \\
\hline Forest residues & 714 & n.a. & $\begin{array}{l}\text { Centre, E, Littoral, } \\
\text { NW, SW, S }\end{array}$ & Heating, cooking \\
\hline \multicolumn{5}{|c|}{ Secondary residues } \\
\hline Peanut shells & 828 & n.a. & & Heat, steam \\
\hline Oil palm shells & 362 & n.a. & $\begin{array}{l}\text { Centre, E, N, } \\
\text { Littoral, NW, SW, } \\
\text { S, }\end{array}$ & Heat, steam \\
\hline $\begin{array}{l}\text { Sugar cane } \\
\text { bagasse }\end{array}$ & 19.5 & n.a. & Centre & Heat, steam \\
\hline Oil palm fibres & 10.8 & n.a. & $\begin{array}{l}\text { Centre, E, N, } \\
\text { Littoral, NW, SW, } \\
S, W\end{array}$ & Forage \\
\hline Saw dust & 1790 & n.a. & $\begin{array}{l}\text { Centre, E, Littoral, } \\
\text { NW, SW, S }\end{array}$ & \\
\hline
\end{tabular}

Source: Carrillo, 2009a; Carrillo, 2009b

\section{Second-generation biofuel options}

Potential biofuel production and the number of potential production plants can be estimated based on biomass residues described above. The calculations are based on actual material flows and are, therefore, only a very general and theoretical estimation, since information about the unused shares of these products is not available. For every second-generation biofuel option, not all types of residues are considered suitable. However, since this is the aim of further research and development, all types of residues in this analysis were considered suitable for every pathway (Table A15). Biofuel production and the potential number of conversion plants are higher for primary residues than for secondary residues.

Thus, potential second-generation biofuel production would exceed the fuel demands of Cameroon (see also Table A13), but since calculations are based on the actual material flow and not on unused residues, this has to be considered the absolute maximum theoretical biofuel amount available. 
Table A15. Potential second-generation biofuel production and number of plants

\begin{tabular}{|c|c|c|c|c|}
\hline \multirow[b]{2}{*}{ Biofuel option } & \multicolumn{2}{|c|}{$\begin{array}{c}\text { Production } \\
\text { (based on actual material flow) }\end{array}$} & \multicolumn{2}{|c|}{ Number of plants } \\
\hline & Mlge*/yr & $\mathrm{PJ} / \mathrm{yr}$ & small scale** & large scale** \\
\hline \multicolumn{5}{|c|}{ Based on primary residues } \\
\hline Bio-SNG & 2423 & 81.2 & 131 & 18 \\
\hline BTL & 1707 & 57.2 & 16 & 4 \\
\hline Bioethanol & 1683 & 56.4 & 126 & 10 \\
\hline \multicolumn{5}{|c|}{ Based on secondary residues } \\
\hline Bio-SNG & 927 & 32.4 & 50 & 7 \\
\hline BTL & 653 & 22.9 & 6 & 2 \\
\hline Bioethanol & 644 & 22.5 & 48 & 4 \\
\hline \multicolumn{5}{|c|}{$\begin{array}{l}\text { Remark: Biofuel options are calculated using } 100 \% \text { of actual material flow and } 100 \% \text { of unused residues for each option. } \\
\text { * Assumed conversion factors - BTL: } 217 \text { Ige/ } \mathrm{t}_{\mathrm{DM}} \text {; ethanol: } 214 \text { Ige/ } \mathrm{t}_{\mathrm{DM}} \text {; bio-SNG: } 307 \text { Ige/ } \mathrm{t}_{\mathrm{DM}} \\
\text { **Based on typical plant sizes - Bio-SNG: } 23-170 \mathrm{MW}_{\text {biofuel; }} \text { BTL: } 130-500 \mathrm{MW}_{\text {biofuel }} \text { bioethanol: } 15-185 \mathrm{MW}_{\text {biofuel }} \text { (DBFZ, } \\
\text { 2008) }\end{array}$} \\
\hline
\end{tabular}

\section{Estimated costs for feedstock and end-product}

The estimation of feedstock costs is a difficult task due to lack of relevant information. It is expected that the transport network situation will contribute to the increase of feedstock provision costs, especially for second-generation technologies that require scaled-up facilities and large quantities of feedstock.

\section{Identification of hot spots for production-plants}

Cameroon has basic experience and infrastructure in producing fossil fuels but not in the field of biofuel production. Although only a theoretical estimation, a promising amount of potential biofuel production and number of plants have been calculated based on the actual material flow described above (Table A15). In the western part of the country, there are large quantities of agricultural residues, while in the south-eastern part forestry residues are quite abundant. Considering that the infrastructure network in the eastern part is in relatively worse condition, the western part seems to be more suitable for the establishment of second-generation biofuel facilities in terms of proximity, accessibility to potential markets, and efficient feedstock and product transport. However, it is difficult to identify specific "hot spots" since the appropriate location of plants is also determined by additional factors such as social infrastructure (like schools and medical facilities to help attract workers), efficient communication and banking networks, and commercial opportunities (Bekunda et al., 2009). 


\section{Sustainability}

\section{Economic impact}

Page | 118 Beside the overall high investment cost of second-generation biofuels, the cost of biomass provision is an important issue in Cameroon due to the inadequacies of the transport infrastructure. Feedstock costs have numerous uncertainties in terms of production, handling and provision. As a leading country in central Africa and enjoying the privilege of a favourable geographical location, Cameroon can play an important role with regard to trading activities. It is, however, not clear what would be the most suitable use of second-generation feedstock (i.e. energy production vs. transport sector) and whether export would be more financially beneficial than domestic use. It is suggested that the decentralised use of biofuel for energy purposes in rural areas would serve the country's interests more than its use in the transport sector or trade (Carrillo, 2009b). This is, however, difficult to determine since there is no biofuel production today and only assumptions can be made on the optimum balance between trade and domestic use.

In terms of the competitive position of the country, it is difficult to draw a conclusion. Domestic market demand is expected to remain low and no biofuel production is envisaged for the short and medium term. Therefore, Cameroon is not expected to hold a competitive position in terms of biofuel production. In terms of feedstock supply, however, the availability of residues in the agricultural and forestry sector could establish a positive position for the country over its neighbours. The favourable location of the country for trade could also reinforce this position. Feedstock availability, however, will be heavily dependent on the actual uses of residues and will greatly shape whether Cameroon's ability to actually supply feedstock is realistic.

\section{Social impact}

Considering that $23 \%$ of the population is undernourished, the competition for the use of feedstock as food or biofuel production will directly affect the basic needs of the population (Carrillo, 2009b).

The expected positive social impact of biomass exploitation in Cameroon is primarily linked to the stationary use of bioenergy instead of liquid biofuel use for the transport sector. Benefits include job creation along the entire pathway (i.e. collection, handling, transport, and production), improved access to pumping water, a larger percentage of electrified rural areas, and poverty reduction (e.g. reduced indoor pollution by firewood use, or reduced time for women and children gathering firewood and fetching water). Thus, the poverty gap between urban and rural areas could be narrowed. Commercial exploitation of residues would provide added value to agriculture and raise household income, limiting at the same time the issue of land use competition. Overall economic growth of the region could only be predicted if there is actual market demand for secondgeneration biofuels, which is currently not the case (Carrillo, 2009b).

Some land displacement issues are observed mainly in the Southwest region with agribusiness plantations or forest concessions. Peasants there have no sufficient land for their subsistence agriculture and have no other choice but to work for the enterprises (Carrillo, 2009b). The expansion of the palm oil industry is reported to take place at the cost of forests traditionally used by local populations, while land grabbing without compensation is also observed (Soumonni \& Cozzens, 2008). 


\section{Environmental impacts}

Since there is no commercial biofuel production in Cameroon yet, there is no data on the environmental impact of current or future biofuel production. Therefore, some general comparisons between different biofuel options are described in Chapter 8.3.

\section{SWOT analysis}

Table A16. Summary of SWOT Analysis

\begin{tabular}{|l|ll|}
\hline STRENGTH & $\begin{array}{l}\text { - } \\
\text { - }\end{array}$ & Favourable geographic location with access to the sea \\
- & Trading centre in the region
\end{tabular}

\section{Conclusions}

In terms of second-generation feedstock availability, there are sufficient amounts of forest residues in the eastern and south-eastern part of the country, as well as agricultural residues in the centralwestern part. Forestry residues could in some regions be exploited without substantial competition with other uses (Carrillo, 2009b). In the case of land availability, there is also land which is unsuitable for crop production but could be used for wood plantations. With an increasing interest 
in biofuels however, there are concerns that increased demand for such land would follow, possibly leading to competition for access among stakeholders. Moreover, tenure schemes in Cameroon are based on collective property and land rights remain an unclear issue.

Any initiative for an action plan concerning production and commercialisation of biofuels should focus on the establishment of policy and regulatory measures, the identification of suitable national

Page | 120 resources, their sustainable management and the search for partnerships. It is important to clearly define the market orientation of the country concerning the biofuel industry, since this will determine future action in terms of infrastructure development and policy reform.

In the case of second-generation biofuels, export seems to be more realistic in the short term, since demand for fuels is very low and could be covered by first-generation biofuels. In the long term, the development of an infrastructure network and the modernisation of the transport sector could enable a dedicated percentage of production to shift from export to domestic use.

In the short and medium term, Cameroon could allocate part of its domestic oil production to the transport sector, while investing in infrastructure for fuel processing activities to provide a foundation for future development. In the meantime, existing available biomass resources, such as forestry residues, could mainly be used to provide energy and to increase rural electrification. This is clearly a political priority today, rather than promoting alternative fuels for the transport sector, given that the transport market is not very extensive. Cameroon could wait and exploit the opportunity to obtain technical experience (for projects like biomass gasification) and further follow research trends for second-generation biofuels in order to be prepared when the technology is more mature and its costs are lower. 


\section{A4 China}

\section{General country characteristics}

\section{General description}

China is located in the eastern part of the Asian continent and is bounded by the Pacific Ocean in the east. With land area of about $9600000 \mathrm{~km}^{2}$ and a mainland coastline of $18000 \mathrm{~km}$, China is the third largest country in the world (Xinhua News Agency, 2008). China's urban population is 593.79 million, accounting for $44.9 \%$ of the country's total population; the rural population is 727.5 million, accounting for $55.1 \%$ (STATS, 2008a). However, the population distribution is quite unbalanced: the eastern coastal areas are densely populated, with over 400 people $/ \mathrm{km}^{2}$ while the western areas are sparsely populated, with less than 10 people $/ \mathrm{km}^{2}$ (Xinhuanet, 2009).

After undergoing reforms and becoming more open, China's economy has maintained steady and rapid growth for several years. Some key indicators can be found in Table A17 below.

Table A17. General population information and economy indices

\begin{tabular}{|l|l|r|r|}
\hline Parameter & Unit & Value & Year \\
\hline Population & million & 1321.3 & 2007 \\
\hline Population growth rate & \% & 0.508 & 2007 \\
\hline GDP (PPP) & billion USD & 2092 & 2006 \\
\hline GDP per capita (PPP) & USD & 826.5 & 2007 \\
\hline Poverty rate (urban) & \% of total population & 0.2 & 2007 \\
\hline Poverty rate (rural) & \% of total population & 1.1 & 2007 \\
\hline HDI & - & 0.77 & 2005 \\
\hline Undernourishment & \% of total population & 9.2 & $2003-2005$ \\
\hline Energy production & Mtoe & 1749 & 2006 \\
\hline TPES & Mtoe & 1956.7 & 2007 \\
\hline Net energy imports & Mtoe & 166.7 & 2007 \\
\hline $\mathrm{CO}_{2}$ emissions/capita & t CO $/$ capita & 4.27 & 2006 \\
\hline
\end{tabular}

Source: IEA Statistics, 2009; Stats, 2008a; Stats, 2008c; UNDP, 2007; FAO, 2008c

China's primary energy supply is mainly derived by fossil fuels. The main sources in the energy mix are coal and crude oil with $65.7 \%$ and $17.4 \%$ respectively. Biomass contributes only $9.9 \%$, while other renewables account for $2.4 \%$ (Figure A4). 
Figure A4. Total primary energy supply in 2007

Page | 122

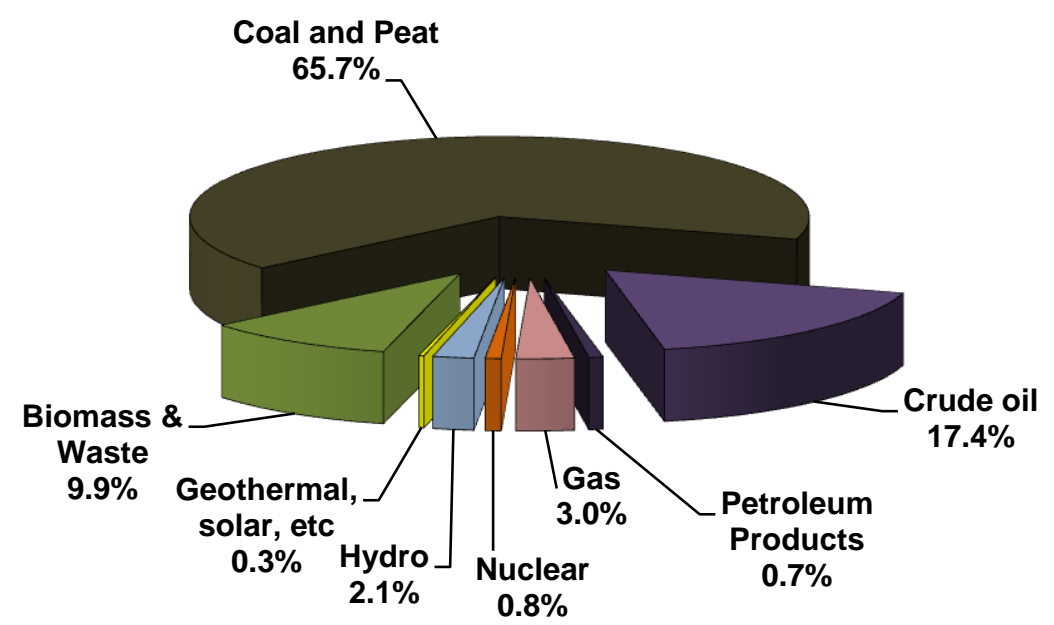

Total: 1956.7 Mtoe (82.18 EJ)

Source: IEA Statistics, 2009

The Chinese government has established the principle of self-sufficiency in food supply, with an expected grain self-sufficiency rate of $95 \%$ as early as 1996 . This means that only $5 \%$ of food supply depends on imports. The number of undernourished people is estimated to be around 122 million in 2003-05 (FAO, 2008c)

\section{Natural conditions (geographical and climatic) for bio-fuel feedstock production}

China is a country with a vast land mass covering a variety of climatic zones. The vegetation biomes include tropical rain forest, mangroves, desert and semi-desert, subtropical evergreen broadleaved, deciduous forest, and temperate grasslands.

The complexity of climate, topography, soil and crop varieties leads to intensive and complex farming systems. South of the Yangtze River, double cropping or three harvests a year of rice is prevailing, while north of the Yangtze river, south of Huaihe River and south-west of China, double cropping of wheat (rape) and rice is widespread. In the North China Plain, the wheat-corn and wheat-soybean double cropping system is prevailing; multiple cropping indexes are about $150 \%$. In the north-east and the north-west areas, one harvest a year of corn, spring wheat and millet is prevailing (Liu, 1993).

\section{Agriculture and forestry}

The total agricultural area in 2007 accounted for $552.8 \mathrm{Mha}$, with the major share occupied by permanent meadows and pastures (FAOStat, 2009). China's sown area of farm crops was 166 Mha. The sown area of grain was $105.6 \mathrm{Mha}$, accounting for $64 \%$ of the total sown area (STATS, 2008b).

China has a forest area of 205 Mha (Table A18); forest coverage is $18.2 \%$, ranking the fifth in the world in terms of forest area, and sixth in terms of forest reserves. The total volume of live stumpage is 13.6 billion $\mathrm{m}^{3}$, with 12.5 billion $\mathrm{m}^{3}$ of forest reserves (Xiao, 2005; SFA, 2005). 
The prevailing mode of farming in the vast majority of China's regions is a household small-scale operation. Agricultural production and management are characterised by a large rural population, small per-capita arable land, small-scale farm operations, and scattered household production that is independent and difficult to manage. In recent years, the country has been vigorously promoting the vertical industrialisation of agriculture, changing from the traditional farming mode based on individual household production to a modern mode of agricultural development.

Table A18. Agricultural and forestry production 2007

\begin{tabular}{|c|c|c|c|c|c|c|}
\hline \multicolumn{5}{|c|}{ Agricultural Production } & \multicolumn{2}{|c|}{ Forestry Production } \\
\hline & $\begin{array}{c}\text { Area } \\
(1000 \text { ha })\end{array}$ & $\begin{array}{l}\text { Proportion of } \\
\text { Crop area (\%) }\end{array}$ & $\begin{array}{c}\text { Production } \\
(1000 \mathrm{t})\end{array}$ & $\begin{array}{l}\text { Yield } \\
\text { (t/ha) }\end{array}$ & Product & $\begin{array}{l}\text { Quantity } \\
\left(1000 \mathrm{~m}^{3}\right)\end{array}$ \\
\hline Corn & 29497 & 17.8 & 151949 & 5.2 & $\begin{array}{l}\text { Industrial } \\
\text { Roundwood }\end{array}$ & 94665 \\
\hline Rice & 29179 & 17.6 & 187397 & 6.4 & Roundwood & 294402 \\
\hline Wheat & 23721 & 14.3 & 109298 & 4.6 & Wood Fuel & 29202 \\
\hline Soybeans & 8900 & 5.4 & 13800 & 1.6 & $\begin{array}{l}\text { Paper and } \\
\text { Paperboard* }\end{array}$ & 78026 \\
\hline Vegetables & 8573 & 5.2 & 147212 & 17.2 & $\begin{array}{l}\text { Wood-Based } \\
\text { Panels }\end{array}$ & 70955 \\
\hline Rapeseed & 7050 & 4.2 & 10375 & 1.5 & Sawnwood & 78026 \\
\hline Seed cotton & 5433 & 3.3 & 22872 & 4.2 & Wood Pulp* & 6435 \\
\hline Groundnuts & 4573 & 2.8 & 13068 & 2.9 & \multirow{4}{*}{\multicolumn{2}{|c|}{$* 1000 \mathrm{t}$}} \\
\hline Potatoes & 4437 & 2.7 & 56196 & 12.7 & & \\
\hline $\begin{array}{l}\text { Sweet } \\
\text { potatoes }\end{array}$ & 3657 & 2.2 & 84431 & 23.1 & & \\
\hline Watermelons & 2113 & 1.3 & 66455 & 31.4 & & \\
\hline Total & 165956 & - & 1349161 & - & $\begin{array}{l}\text { Total Area } \\
\text { (1 000 ha) }\end{array}$ & 205405 \\
\hline
\end{tabular}

Source: FAOStat, 2009

Currently, there are two forms of land ownership in China: state-owned and collectively owned. The Land Administration Law of the People's Republic of China stipulates that land in the rural areas and suburban areas, except otherwise provided for by the state, shall be collectively owned by peasants. China's agricultural added value in 2006 was USD 205.2 billion, and forest added value was USD 16.1 billion, with respective shares of GDP of $6.6 \%$ and $0.5 \%$ (MOA, 2008). 


\section{Current situation of biofuel development}

\section{Current production of first-generation biofuels}

Page | 124 China began bioethanol production in 2000 using surplus grain. In 2008, annual bioethanol output reached 1.51 billion litres (IEA, 2009b). In January 2008, Guangxi set up bioethanol projects with a capacity of 253 million litres ( 0.13 Mtoe) per year, taking cassava as the feedstock and establishing the use of ethanol gasoline throughout the whole region, consuming around 1.4 million tons of cassava annually (Qiu et al., 2009).

In recent years, private enterprises took the lead in biodiesel production in China and have built production plants with a capacity of 11.4-22.7 million litres/year. Biodiesel production reached approximately 362.8 million litres in 2008 , whereas ethanol production reached 1.5 billion litres in the same year (IEA, 2009b).

\section{National policy target for biofuels}

In order to support the production of fuel ethanol, the Chinese government introduced a number of preferential policies, including the investment of USD 70.6 million of treasury bond funds for the construction of bio-ethanol plants in Henan, Anhui and Jilin provinces; the implementation of preferential taxation policies for four state-approved pilot units to exempt them from a fuel ethanol consumption tax of 5\%; and the Central Financial Authority has allocated USD 294 million to subsidise loss-making, which effectively protects the normal production and operation of fuel ethanol pilot enterprises. According to the circular of the Ministry of Finance, the subsidy for the sale of fuel ethanol was USD 201.9 per ton in 2007 and 2008. (NDRC, 2007a)

According to the goals set in the "Mid-Long term Development Plan for Renewable Energy" by the National Development and Reform Commission, by 2020, the use of biofuel ethanol will reach 12.7 billion litres, automotive ethanol gasoline (E10) usage will be $100 \%$, and annual consumption of biodiesel will reach 2.3 billion litres (NDRC, 2007a). The plan further acknowledges that it is necessary to proactively develop biofuel technology taking cellulosic biomass as raw materials. The Ministry of Finance stated that "for the production of alcohol out of cellulose, the state encouraged the combination of production, study and research, and the expansion of the industrialisation pilots. The State financial and taxation support policy will integrate and use the existing funds channels, focusing on a number of key technology breakthroughs." However, clear support polices for second-generation biofuels have yet to be introduced (MOF, 2006).

The Chinese government is supporting research on second-generation biofuel. A project called the Use of Cellulosic Waste to Produce Ethanol, finished by East China University of Science and Technology, has achieved the process route of using cellulose material to produce ethanol through acid hydrolysis and has established a demonstration project which can produce roughly 700000 litres (600 t) of cellulosic-ethanol per year. Now, Tsinghua University, East China University of Science and Technology, Shandong University, Zhejiang University, Institute of Microbiology and Institute of Process Engineering of the Chinese Academy of Science, and Beijing University of Chemical Technology are also undertaking research work currently (MOST, 2009). Furthermore, Danish enzyme producer NOVOZYMES, in cooperation with the Chinese energy company SINOPEC and the China National Cereals, Oil and Foodstuff Corporation (COFCO), has set up a pilot plant with 
a capacity of $500 \mathrm{t} / \mathrm{yr}$. The project aims to develop commercially viable second-generation ethanol production by 2010 (NOVOZYMES, 2009).

\section{Financing and human resources}

At present, Chinese foreign investment projects have to be approved by the government authorities; according to the 2007 amendments to the Industrial Catalogue for Foreign Investment "bio-fuel [bioethanol, biodiesel] production" is subject to restrictions on foreign investment. Chinese investors must hold an investment ratio of $51 \%$ or more in foreign-invested projects (NDRC, 2007b).

China is rich in human resources. In 2007, of the total population of 1.3 billion people, the share of people 20-60 years old with work capability was 794.6 million, accounting for $60 \%$ of the total population. China has abundant labour for the development of biomass energy. Labour forces engaged in the collection of straw do not need highly developed skills. Labour forces planting energy crops and working at bio refineries would need some training to improve their skills, but since China has experience with first-generation biofuel production, skilled technicians for the operation of second-generation biofuel refineries could be provided.

\section{Infrastructure}

In 2006, China's vehicle fleet amounted to roughly 171 million vehicles (Table A19). China's gasoline consumption was $52.5 \mathrm{Mt}$, diesel consumption was $37.9 \mathrm{Mt}$, and LPG consumption was $0.5 \mathrm{Mt}$, equivalent to a total of 3.9 EJ (Table A20). Projections for 2030 show rapidly increasing fuel demand.

Table A19. Vehicle fleet in 2006

\begin{tabular}{|r|r|l|l|l|l|l|r|}
\hline Motorcycles & PC+SUV & LCV's & PLT's & \multicolumn{1}{|l|}{ MDT's } & \multicolumn{1}{l|}{ HDT's } & Buses & Minibuses \\
\hline 130295968 & 14986519 & 7864648 & 9377081 & 5065408 & 1283325 & 548729 & 1742972 \\
\hline
\end{tabular}

PC: passenger car; SUV: sport utility vehicle; LCV: light commercial vehicle ; LT: light truck; MDT: medium duty truck; HDT: heavy duty truck

Source: IEA Mobility Model, 2009

Over the last 20 years, China has invested intensively into public infrastructure resulting in improved market integration and lower production costs. Besides positive effects on economic growth, investment helped to mitigate poverty by increasing access to services and economic opportunities. As of the end of 2008, the total network of motorways reached $3730200 \mathrm{~km}$. National highway density is $38.86 \mathrm{~km} / 100 \mathrm{~km}^{2}$. At the end of 2007 , China's railway network totalled 77965.9 km, ranking first in Asia (Ministry of Railways, 2008).

Table A20. Fuel consumption in 2007 and projections for 2030

\begin{tabular}{|r|c|r|r|r|r|}
\hline & $\begin{array}{c}\text { Gasoline } \\
1000 \mathrm{t}(\mathrm{PJ})\end{array}$ & $\begin{array}{c}\text { Diesel } \\
1000 \mathrm{t}(\mathrm{PJ})\end{array}$ & $\begin{array}{c}\text { Natural Gas } \\
1000 \mathrm{t}(\mathrm{PJ})\end{array}$ & $\begin{array}{c}\text { LPG } \\
1000 \mathrm{t}(\mathrm{PJ})\end{array}$ & $\begin{array}{c}\text { Biofuels } \\
1000 \mathrm{t}(\mathrm{PJ})\end{array}$ \\
\hline $\mathbf{2 0 0 7}$ & $52537(2 \mathrm{266})$ & $37937(1620)$ & $(3)$ & $539(27)$ & $1620(46)$ \\
\hline $\mathbf{2 0 3 0 *}$ & $172313(7431)$ & $124427(5314)$ & $(6)$ & $1163(585)$ & $21120(605)$ \\
\hline
\end{tabular}

Source: IEA Statistics, 2009; *Assumption based on WEO 2008 data, assuming linear growth in each sector 
China currently has built five state-certified fuel ethanol production plants. Ethanol gasoline with a blending ratio of $10 \%$ in China is suitable for all kinds of vehicles equipped with Otto engines, without modification of vehicle. In the areas targeted for promotion, ethanol gasoline deployment centres have been built with a corresponding transformation of gas stations and an improvement of infrastructure (Qiu et al., 2009)

Page | 126

\section{Feedstock assessment and logistics}

\section{Feedstock and cultivation areas}

Available raw materials for second-generation biofuels in China include crop stalks, agro-processing residues, forestry residues, shrubs and energy crops cultivated on marginal land, among others.

According to a study by Tian in 2008 , the theoretical volume of crop straw and stalks (including rice, wheat, corn, soybean, oil-bearing crops, and cotton) in all of China was $543 \mathrm{Mt}$ (air-dry, moisture content 15\%) (Table A21). This volume is composed of $183 \mathrm{Mt}$ of rice straw, $109 \mathrm{Mt}$ of wheat straw, and $182 \mathrm{Mt}$ of corn stalks. As a by-product of crops, straw and stalks have a wide range of uses in both industry and agriculture. Among them, about $114 \mathrm{Mt}$ were used for energy, $194 \mathrm{Mt}$ for fertiliser, $108 \mathrm{Mt}$ for feed, $20 \mathrm{Mt}$ for paper pulp production, and about $108 \mathrm{Mt}$ were burned or discarded. Straw resources are relatively abundant in the provinces of Jilin, Liaoning, Shandong, Xinjiang, Jiangsu and Henan (Tian, 2008).

The total volume of processing for secondary residues exceeds $100 \mathrm{Mt}$. Corncobs are used for the preparation of chemical raw materials (e.g. furfural) and rural energy; rice husk for electricity generation; and bagasse is used for power generation and raw materials for paper production. According to expert estimates, $50 \mathrm{Mt}$ are available for the use of biomass energy (NDRC, 2007a).

Logging residues are distributed mainly in south, south-west, central and north-east areas, with a concentration in south China. Logging and timbering residues mainly lie in Yunnan, Fujian, Hunan, Jiangxi, Sichuan and Guangdong (SFA, 2007).

Based on a sample survey of wood processing plants, and taking into consideration the actual situation of different areas, it is estimated that wood processing residues account for about $34.4 \%$ of logs, equivalent to 320 million $\mathrm{m}^{3}$. At present, $30 \%$ of wood processing residues (equivalent to $5.2 \mathrm{Mt}$ dry weight) are used in the production of fibreboards and paper pulp, with a small amount used as fuel (Tian, 2008). The provinces with the highest production of wood processing residues in China are Shandong, Jiangsu, and Hebei, each with the production capacity of $4 \mathrm{Mt}$. The production capacity in each of the provinces of Zhejiang, Fujian, Guangdong, Jiangxi, Hunan, and Anhui is 1-4 Mt (SFA, 2007).

According to the Sixth Forest Resources Inventory data (Xiao, 2005), China has a shrubbery area of 45.3 Mha. Calculated from the area of main shrub species and productivity per acreage, the total national biomass of rejuvenation stubble shrubs is 300-400 Mt. However, most shrubs grow above the tree line, as well as in naturally adverse, ecologically fragile areas, and thus are difficult to be used. It is estimated that $60 \%$, or $25 \mathrm{Mt}$, of pruning residues can be used as energy biomass, except for some shrubs being used in the weaving and paper industries (Tian, 2008). Conditions for the growth of shrubs are complex, and there is no equipment suitable for bush logging in China. The local farmers still rely on manual and labour-intensive techniques to prune shrubs, which results in very low productivity. 
Table A21. Assessment of residues from forestry and agriculture

\begin{tabular}{|c|c|c|c|c|c|}
\hline Type & $\begin{array}{c}\text { Actual } \\
\text { material flow } \\
\left(1000 t_{D M} / y r\right)\end{array}$ & $\begin{array}{c}\begin{array}{c}\text { Unused } \\
\text { residues }\end{array} \\
\left(1000 \mathrm{t}_{\mathrm{DM}} / \mathrm{yr}\right)\end{array}$ & $\begin{array}{l}\text { Feedstock } \\
\text { cost (USD/t) }\end{array}$ & $\begin{array}{c}\text { Regional } \\
\text { availability }\end{array}$ & Main use \\
\hline \multicolumn{6}{|c|}{ Primary Residues } \\
\hline Rice straw & 158129 & 63252 & $30-60$ & $\begin{array}{l}\text { Northeast, North } \\
\text { China }\end{array}$ & $\begin{array}{l}\text { Feed, fertiliser, } \\
\text { fuel, industrial } \\
\text { raw materials } \\
\sim 40 \% \text { available }\end{array}$ \\
\hline $\begin{array}{l}\text { Corn (stalk, } \\
\text { stems) }\end{array}$ & 155346 & 62138 & $30-60$ & $\begin{array}{l}\text { North China, } \\
\text { Lower Yangtze } \\
\text { valley }\end{array}$ & $"$ \\
\hline Wheat straw & 92903 & 37161 & $30-60$ & $\begin{array}{l}\text { Lower Yangtze } \\
\text { valley, South } \\
\text { China, Southwest }\end{array}$ & $"$ \\
\hline Cotton stalk & 22681 & 9072 & $30-60$ & $\begin{array}{l}\text { North China, } \\
\text { Lower Yangtze } \\
\text { valley, Southwest }\end{array}$ & $"$ \\
\hline Oil crops & 21834 & 8734 & $30-60$ & $\begin{array}{l}\text { North China, } \\
\text { Inner Mongolia- } \\
\text { Xinjiang }\end{array}$ & $"$ \\
\hline $\begin{array}{l}\text { Logging } \\
\text { residues }\end{array}$ & 55000 & 11000 & $50-80$ & South China & $\begin{array}{l}\text { Fibreboard, pulp, } \\
\text { soil fertility }\end{array}$ \\
\hline \multicolumn{6}{|c|}{ Secondary Residues } \\
\hline Rice husk & 45206 & 22603 & Oct-40 & $\begin{array}{l}\text { North China, } \\
\text { Inner Mongolia- } \\
\text { Xinjiang }\end{array}$ & $\begin{array}{l}\text { fuel, industrial } \\
\text { raw materials } \\
\sim 50 \% \text { available }\end{array}$ \\
\hline Corncobs & 32364 & 16182 & $30-60$ & $\begin{array}{l}\text { North China, } \\
\text { Lower Yangtze } \\
\text { valley }\end{array}$ & $"$ \\
\hline Bagasse & 11295 & 5648 & 30 & $\begin{array}{l}\text { Lower Yangtze } \\
\text { valley, South } \\
\text { China, Southwest }\end{array}$ & $"$ \\
\hline $\begin{array}{l}\text { Saw mill } \\
\text { residues }\end{array}$ & 11520 & 3456 & $50-80$ & & $\begin{array}{l}\text { Fibreboard, pulp, } \\
\text { soil fertility }\end{array}$ \\
\hline
\end{tabular}

Source: Based on STATS, 2008; SFA, 2007

The Chinese government stipulates that the principle of developing energy crops is that they "do not struggle for grain with human[s], do not struggle for land with grain, and do not damage the environment"; therefore, the cultivated land ought not to be occupied. According to the survey on land use issued by the Ministry of Land and Resources, about 7.3 Mha of reserve arable land resources existed in 2003, mainly in western China (Chinability, 2009). Theoretically, this area could 
be made available for switchgrass and other energy crops, but increasing food demand and land use for construction might reduce this area in the near future.

\section{Second-generation biofuel options}

Page | 128 Based on the biomass residues described above, the potential biofuel production and number of production plants can be defined. The calculations are based on actual material flows, as well as on unused residues and represent only a theoretical estimation. For every second-generation biofuel option, not all types of residues are considered suitable. However, this is the aim of further development and, as a consequence, all types of residues were considered suitable for every pathway. In China, biofuel production as well as the potential number of conversion plants would be higher based on primary residues than on secondary residues. Due to higher overall efficiency and lower technical complexity, the biomethane pathway has a higher fuel output, while BTL and bioethanol produce similar fuel outputs.

Based on the indicated amount of currently unused agricultural and forestry residues, considerable quantities of second-generation biofuel could be produced. The theoretical maximum amount of bio-SNG could cover roughly $40 \%$ of current transport fuel demand in China if both primary and secondary residues were converted.

Table A22. Potential second-generation biofuel production and number of plants

\begin{tabular}{|c|c|c|c|c|c|c|c|c|}
\hline \multirow[b]{3}{*}{ Biofuel option } & \multicolumn{4}{|c|}{ Production } & \multicolumn{4}{|c|}{ Number of plants } \\
\hline & \multicolumn{2}{|c|}{$\begin{array}{l}\text { actual material } \\
\text { flow }\end{array}$} & \multicolumn{2}{|c|}{ unused residues } & \multicolumn{2}{|c|}{$\begin{array}{l}\text { actual material } \\
\text { flow }\end{array}$} & \multicolumn{2}{|c|}{ unused residues } \\
\hline & Mlge/yr* & $\mathrm{PJ} / \mathrm{yr}$ & Mlge/yr* & $\mathrm{PJ} / \mathrm{yr}$ & \begin{tabular}{|c|} 
small \\
scale**
\end{tabular} & $\begin{array}{c}\text { large } \\
\text { scale** }\end{array}$ & $\begin{array}{l}\text { small } \\
\text { scale** }\end{array}$ & $\begin{array}{l}\text { large } \\
\text { scale** }\end{array}$ \\
\hline \multicolumn{9}{|c|}{ Based on primary residues } \\
\hline Bio-SNG & 155815 & 5219.8 & 31163 & 1044.0 & 7880 & 1066 & 1576 & 213 \\
\hline BTL-diesel & 109765 & 3677.1 & 21953 & 735.4 & 982 & 255 & 196 & 51 \\
\hline Bioethanol & 108223 & 3625.5 & 21645 & 725.1 & 8392 & 680 & 1678 & 136 \\
\hline \multicolumn{9}{|c|}{ Based on secondary residues } \\
\hline Bio-SNG & 30919 & 1035.8 & 14750 & 494.1 & 1564 & 212 & 746 & 101 \\
\hline BTL-diesel & 21781 & 729.7 & 10391 & 348.1 & 195 & 51 & 93 & 24 \\
\hline Bioethanol & 21475 & 719.4 & 10245 & 343.2 & 1665 & 135 & 794 & 64 \\
\hline
\end{tabular}




\section{Estimated costs for feedstock and end-product}

As shown in Table A21, costs for agricultural residues vary between USD 30 and USD 60 per ton. Total straw collection costs consist of the cost of the straw and stalks themselves, as well as collection, washing, storage, pre-processing and transportation costs. Surveys on existing straw direct-combustion power plants show that collection cost is about USD 44.1 per ton, with an annual acquisition of 200000 tons of straw. The main raw material is corn, cotton and wheat straw, with a collection radius of $15 \mathrm{~km}$ (Tian, 2008).

Table A23 shows theoretical production costs for second-generation biofuels, based on the above feedstock costs and current IEA cost analysis (IEA Mobility Model, 2009). Currently, secondgeneration biofuels could be produced at costs of USD 0.66-0.79/Ige for straw, stalks or bagasse feedstock. In the case of forestry residues, production costs would be higher, at USD 0.88-1.07/Ige, but significant potential exists to decrease production prices in the long term. However, these prices are considerably higher than fossil fuel prices.

Table A23. Theoretical second-generation biofuel production costs in China

\begin{tabular}{|l|c|c|c|c|c|}
\hline Feedstock & \multirow{2}{*}{$\begin{array}{c}\text { Feedstock } \\
\text { price (USD/t }\end{array}$} & \multicolumn{4}{|c|}{ oil USD 60/bbl } \\
& \multicolumn{2}{|c|}{ today (USD/lge) } & \multicolumn{2}{c|}{ long term (USD/lge) } \\
\hline Straw/stalks & $30-60$ & $0.66-0.79$ & $0.68-0.85$ & $0.42-0.53$ & $0.42-0.56$ \\
\hline Forestry Residues & $50-80$ & $0.88-1.06$ & $0.97-1.07$ & $0.61-0.72$ & $0.67-0.70$ \\
\hline Bagasse & 30 & 0.75 & 0.79 & 0.5 & 0.51 \\
\hline & & \multicolumn{5}{|c|}{ oil USD 120/bbl } \\
\hline Straw/stalks & $30-60$ & $0.84-0.97$ & $0.78-0.95$ & $0.53-0.64$ & $0.45-0.60$ \\
\hline Forestry Residues & $50-80$ & $1.08-1.26$ & $1.23-1.33$ & $0.78-0.89$ & $0.9-0.94$ \\
\hline Bagasse & 30 & 0.92 & 0.89 & 0.6 & 0.55 \\
\hline
\end{tabular}

Source: Based on IEA Mobility Model, 2009

\section{Identification of hot spots for production plants}

After 30 years of rapid development, the eastern region of China has an efficient infrastructure, while that of the central region has improved more slowly and but is in the process of rapid improvement. The western region has lagged far behind with regard to infrastructure and a road network that has low density and low levels of access and poor quality.

In terms of feedstock availability, the north-east, northern and Yangtze River areas, could mainly provide straw, while in the south, south-west and north-east areas, the focus is on forestry residues. In the western region natural shrub vegetation could be utilised, while in the north-west dedicated energy crops could be the most promising option.

Therefore, second generation bio-fuels should first be developed in the eastern and central regions of China. For the establishment of a second-generation biofuel industry, the provinces of Jilin, Liaoning, Shandong, Jiangsu and Henan offer good conditions. They have rich feedstock resources and are relatively developed. In the future, the provinces of Xinjiang and Qinghai, which have large 
reserves of land that is considered unused, might be attractive for the establishment of a secondgeneration biofuel industry.

\section{Sustainability}

Page | 130

\section{Economic impact}

Currently, there is still a problem of high cost in the production of cellulosic ethanol in China. The enzyme cost for the production of 1 ton of fuel ethanol is between USD 40 and 90 on average, accounting for $50 \%$ of the total cost of production. That seriously restricts the development of the industry and means that in the short term production of cellulosic biofuels has to rely on state subsidies.

In 2008, China's net oil imports amounted to about 200 Mtoe and accounted for nearly $52 \%$ of the total domestic oil consumption, and future dependence on imported oil is expected to significantly increase (China Customs, 2009). The development of a domestic second-generation biofuel industry could reduce dependence on imported oil and foreign exchange payment. Thus, second-generation biofuels would generally be an attractive opportunity for China, but the economic benefits will be a decisive factor.

The widespread use of lignocellulosic feedstock, such as crop straw, for production of second generation biofuels, may cause increasing prices in other industries, such as paper, with market impacts that are difficult to assess.

\section{Social impact}

The need for intensive development of energy crops in the production of cellulosic ethanol will have an impact on the mode of production of farmers. Most of the potential energy crops are new varieties specially cultivated, and the demand for energy crops for second-generation biofuel plants must be planned carefully. With the industrial development of energy crops, the market awareness of farmers will be enhanced, which will facilitate a change to industrialisation.

The main raw materials for the second-generation biofuels are crop straw and herbaceous energy crops planted on virgin lands, which will increase employment opportunities for the rural labour force. Straw collection, storage and transport will offer additional jobs, as experience with straw power generation has proven. Energy crop cultivation and the downstream processing of cellulosic ethanol is a new industrial chain that will substantially increase employment opportunities, especially for farmers. For instance, an enterprise with an annual production capacity of 10000 tons of cellulosic ethanol will provide jobs for approximately 200 people. Farmers could benefit from the sale of agricultural residues, such as straw. New employment opportunities could also be created if marginal land were brought into cultivation and the labour inputs for farmers changed.

\section{Ecological impact}

The planting of energy crops like switchgrass could increase vegetation coverage and substantially improve the local environment. Planting switchgrass on the Loess Plateau in China could reduce the significant soil erosion seen in this area. 
In general, it should be noted that the ecological environment in China's western region is particularly fragile. The extensive use of tillage, fertilisation and irrigation could lead to the deterioration of the physical and chemical properties of soil, reduced fertility, the accumulation of toxic substances and reduced organic matter.

Residues left on the field improve the soil, return nutrients, improve land fertility, and inhibit weed growth to obtain a better yield. The purchase of straw and stalks for the development of cellulosic ethanol may cause farmers to sell a large amount of straw for the sake of increased income rather than return the straw to field, which will result in the lack of timely replenishment of soil nutrients, gradual decrease of organic matter, and poorer soils. In addition, farmers may apply large volumes of chemical fertilisers for the purpose of higher yields, which could result in hardened soil, declined fertility, malnutrition of crops and more pests and diseases.

Acid, alkalis and other substances are applied during the whole process of cellulosic ethanol production; moreover, the consumption of energy, reagents and enzyme is huge, which may cause secondary pollution to the environment.

\section{SWOT analysis}

Table A24. Summary of SWOT analysis

\begin{tabular}{|c|c|}
\hline STRENGTH & $\begin{array}{l}\text { - Existing first-generation biofuel production } \\
\text { - Good availability of skilled labour } \\
\text { - Biofuel blending mandate, including sustainability } \\
\text { criteria } \\
\text { - Fast-growing economy with investment capacity for } \\
\text { large scale projects }\end{array}$ \\
\hline WEAKNESS & $\begin{array}{l}\text { - Small-scale farming is dominating in many areas and is } \\
\text { difficult to organise } \\
\text { - Transportation costs are a major concern for residue } \\
\text { use in rural areas } \\
\text { - Only little experience with production of second- } \\
\text { generation biofuels }\end{array}$ \\
\hline OPPORTUNITY & $\begin{array}{l}\text { - Infrastructure has improved significantly over the last } \\
\text { decades } \\
\text { - Large unused land areas with potential for bioenergy } \\
\text { crops } \\
\text { - Fast growing demand for transport fuel }\end{array}$ \\
\hline THREAT & $\begin{array}{l}\text { - Limited smallholder integration } \\
\text { - Competitiveness of second-generation biofuel } \\
\text { compared to other bioenergy options (e.g. co-firing of } \\
\text { straw) } \\
\text { - Subsidies needed in the short term to promote second- } \\
\text { generation biofuels }\end{array}$ \\
\hline
\end{tabular}




\section{Conclusions}

China currently has over $200 \mathrm{Mt}$ of agricultural biomass and forestry biomass resources for the development of second-generation cellulosic ethanol; there are vast virgin lands for the cultivation of energy crops. But challenges regarding feedstock costs, transport logistics and production costs

Page | 132 are significant. If the bottleneck of development is eliminated in a short period of time, secondgeneration biofuels could be implemented rapidly.

Currently, the development of a cellulosic ethanol industry in China should give priority to the resource-rich and relatively well-developed regions, such as straw-rich regions like Jilin Province, Liaoning Province, Shandong Province, Xinjiang Autonomous Region, Jiangsu Province and Henan Province, and later to regions rich in virgin lands like Xinjiang Autonomous Region and Qinghai Province.

Power generation with biomass is occurring on a preliminary basis. Most of these power plants use bagasse as fuel and are part of sugar refineries located in the south. There are 300 power plants of this kind (with a total capacity of $800 \mathrm{MW}$ ) in Guangdong and Guangxi, and a number of these power plants use bagasse as fuel in Yunnan Province. Through the end of 2006, more than 50 biomass power plants have been approved by the National Development and Reform Commission (NDRC) and the Local Development and Reform Commissions (LDRC). The total installed capacity is $1500 \mathrm{MW}$, of which 38 power plants with installed capacity of $1284 \mathrm{MW}$ were approved in 2006. The total investment was about USD 1.5 billion (NDRC, 2007b). It is generally believed that the use of straw power generation is only temporary; if second-generation biofuel technology is mature, straw and other biomass will be required to produce bioethanol.

According to the statistics of the Chinese Ministry of Agriculture (MOA), the Chinese government has invested CNY 3.4 billion (Yuan renminbi) for rural households' biogas production, and a total of 3.74 million farmers from financing provided during the "15th Five-year Plan." By the end of 2005, rural biogas users had grown to 18.07 million nationwide, and annual biogas output amounted to about 70 billion $\mathrm{m}^{3}$ (equivalent to about $717.3 \mathrm{Mtoe}$ ), with 8.71 million users (48.2\%) in the western region, 7.9 million (37.1\%) in the middle region, and 1.59 million (8.8\%) in the eastern region.

Overall, in terms of resources, China is a vast country spanning a variety of climatic zones, which leads to a diversity of climate, topography, soil, and crop varieties. As a result, the description in this report is not fully applicable to every regions, and detailed region-by-region research and evaluation is needed. 


\section{A5 India}

\section{General country characteristics}

\section{General description}

India is the seventh largest nation in the world in terms of geographical area. Located in South Asia, the Indian Peninsula has the Bay of Bengal to the east and Arabian Sea to the west. The country is divided into 28 states and seven union territories for administration. The country has a land frontier of $15200 \mathrm{~km}$ and a coastline of $7516 \mathrm{~km}$, including those of the island territories. India has a total area of $3287590 \mathrm{~km}^{2}$ of which $2973190 \mathrm{~km}^{2}$ is land and $314400 \mathrm{~km}^{2}$ is water. Though the country constitutes only about $2.4 \%$ of the earth's surface, it supports $16 \%$ of the world's population. India has a reported forest cover of about $20 \%$ and more than half of the geographical area is under cultivation, versus a world average of $11 \%$. A significant share of the cultivated land is rain fed, and crop yields are often dependent on rains (MIB, 2009; Competition Review, 2009).

Some two-thirds of India's people depend on rural employment for a living. Agriculture, though contributing only $22 \%$ of GDP, is still the backbone of India's economy since it provides employment to about $58.4 \%$ of working population, with $65-70 \%$ of the total population dependent on it for their livelihood. The economy has been progressively globalising and trade has risen steadily as a proportion of GDP.

Table A25. General population information and economy indices

\begin{tabular}{|c|c|c|c|}
\hline Parameter & Unit & Value & Year \\
\hline Population & million & 1140 & 2009 \\
\hline Population growth rate & $\%$ & 1.40 & 2001-07 \\
\hline GDP (PPP) & bn USD & 1171 & 2007 \\
\hline GDP per capita (PPP) & USD & 103 & 2007 \\
\hline Poverty rate (urban) & $\%$ of total population & 26 & 2005 \\
\hline Poverty rate (rural) & $\%$ of total population & 28 & 2005 \\
\hline HDI & - & 0.629 & 2007 \\
\hline Undernourishment & $\%$ of total population & 20 & $2003-2005$ \\
\hline Energy Production & Mtoe & 435.64 & 2006 \\
\hline TPES & Mtoe & 565.82 & 2006 \\
\hline Net Energy Imports & Mtoe & 134.83 & 2006 \\
\hline $\mathrm{CO}_{2}$ Emissions/capita & $\mathrm{t} \mathrm{CO}_{2} /$ capita & 1.13 & 2006 \\
\hline
\end{tabular}

Sources: World Bank, 2009; MIB, 2009; UNDP, 2007; IEA Statistics, 2009 
According to the World Bank (2009), South Asia is home to half of the world's poor, and a significant number of them are Indian. Though the country's policies have helped to bring down the levels of poverty, it needs to be noted that the percentile reductions do not reflect the full situation. According to the National Sample Survey Report (MOSPI, 2007) by the government of India's planning commission in 2007, poverty in India declined by 4.3 percentage points from $26.1 \%$ in $1999-2000$ to $21.8 \%$ in $2004-05$. However, there are still 238.5 million Indian citizens living below the poverty line (Table A25).

Since the Green revolution in the late sixties and early seventies, India's food grain production has grown steadily, and throughout the years the country has been able to maintain foods stocks sufficiently higher than or close to domestic demand. There is an effective public distribution system which provides rations at heavily subsidised rates to those below the poverty line.

The total energy production in the country, according to the IEA statistics updated for 2007, was 594.5 Mtoe (25.0 EJ), mainly derived from coal (about 39\%), followed by crude oil and biomass waste (each about $26 \%$.) The total primary energy supply for India is given in Figure A5.

Figure A5. Total primary energy supply 2007

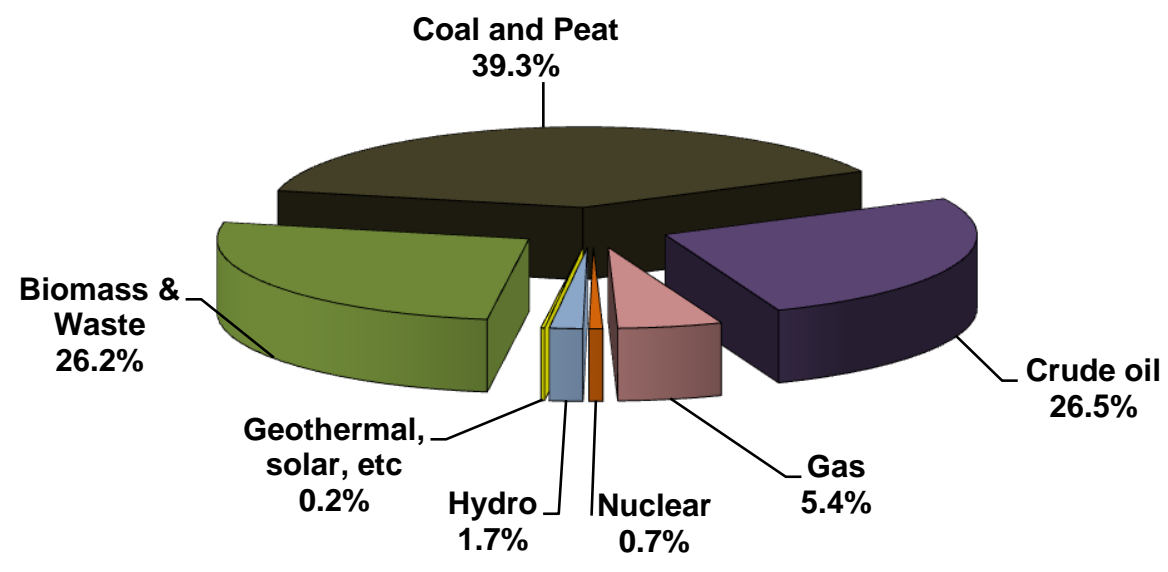

Total: 594.5 Mtoe (25.0 EJ)

Source: IEA Statistics, 2009

\section{Natural conditions for biofuel feedstock production}

The share of agricultural land in 2007 was significant, reaching roughly 53\% (158.8 Mha) of total land area. The main share of this land is under cultivation for food crops and only about $3.5 \%$ (10.4 Mha) of the total land area is dedicated to pasture (FAOStat, 2009). India has a wide and varied geography, ranging from high mountain ranges to wetlands, myriad river systems and plains, which means a significant portion of the land is fertile and suitable for agriculture food crops or feedstock.

India's climate is also very diverse. The temperature is high all over the country except in highaltitude regions. Monsoons are the most important factor shaping India's climate, since they affect almost all parts of the country and bring seasonal heavy rains. A significant share of India's 
agriculture - approximately $60 \%$ according to Ministry of Agriculture (DES, 2008) - is fed by rain, underlining the relevance of monsoons to India's agriculture. India's four seasons consist of winter (December-February), summer (March-May), the rainy season (June-September) and the season of the retreating south-west monsoon (October-November).

Alluvial soil covers almost a quarter of India's land surface and is the base for a major share of national agricultural production. This type of soil is found primarily in the Great Indian Plains of the north, defined by the river beds of Ganges Brahmaputa and Indus, which extends almost $2500 \mathrm{~km}$ from west to east. The Deccan plateau contains large regions of black soil suited especially to cotton cultivation. Red soils are another major soil type and occur mostly in the southern peninsula and are well-suited for the cultivation of rice.

There is only limited scope for increasing agricultural land area since India is already using $63 \%$ of its available land, with the remaining land in protected areas or unusable as non-arable or barren terrain (MIB, 2009). With the country struggling to meet food crop demand, allocating cropland for biofuel feedstock is impractical, which suggests the use of agricultural residues as feedstock for biofuels. A few years ago, the government of India put a biodiesel policy in place under which it promoted the cultivation of non-edible oilseeds, like jatropha, exclusively on marginal or waste lands, which cannot otherwise be used for the cultivation of food crops. The land suitable for this purpose has been estimated to be around $40 \mathrm{Mha}$, mainly concentrated in the states of Chattisgarh, Karnataka, Tamil Nadu, Rajasthan, Andrha Pradesh and Maharashtra. It is not advisable to apply manure or to irrigate these crops to avoid further pressure on water resources. Thus, using available agricultural land and the usual agricultural components of water and manure to cultivate dedicated energy crops for biofuel production in India is critical, since pressure on land is already extremely high for the cultivation of food crops.

\section{Agriculture and forestry}

Agriculture contributes about $22 \%$ of the nation's GDP, but the importance of this sector is much bigger in India's overall economy. The sector provides direct employment to nearly $60 \%$ of the working population, and nearly $65-70 \%$ of the population is dependent on agriculture for their livelihood. Out of 329 Mha of total geographical area, the net sown area is $158.7 \mathrm{Mha}$, of which only 60.2 Mha is irrigated. Food crops are grown on nearly $73 \%$ of the gross sown area. Forestry is another major sector which also contributes substantially to the nation's economic development. India has about $67.8 \mathrm{Mha}$ of forest land, which is $20.6 \%$ of the total geographical area. Additional information about the cultivated area and crop production is given in the Table A26.

India is a major exporter of agricultural products; average annual agricultural exports were valued at USD 10.3 billion during the period $2003-08$, representing $11.5 \%$ of all exports. India also imports agricultural products worth USD 1.55 billion annually, which represents $4 \%$ of national imports (DES, 2008). Sugar, rice, wheat, other cereals spices are the major agricultural exports, with rice enjoying a significant share in terms of both quantity and value (DGCIS, 2009).

India has a range of farming systems, moving from the historical subsistence farming to modern large-scale commercial farming. A total of 11 farming systems for South Asia have been identified (Dixon et al., 2001 and are also representative for India. Large-scale farms can be found in the plains where wheat, sugar cane and rice are cultivated, while cultivation in arid zones is scattered and limited to areas with irrigation. 
Table A26. Agricultural and forestry production 2007

\begin{tabular}{|c|c|c|c|c|c|c|}
\hline \multicolumn{5}{|c|}{ Agricultural Production } & \multicolumn{2}{|l|}{ Forestry Production } \\
\hline & $\begin{array}{c}\text { Area } \\
(1000 \mathrm{ha})\end{array}$ & $\begin{array}{l}\text { Proportion of } \\
\text { Crop area (\%) }\end{array}$ & $\begin{array}{l}\text { Production } \\
(1000 \mathrm{t})\end{array}$ & $\begin{array}{l}\text { Yield } \\
\text { (t/ha) }\end{array}$ & Product & $\begin{array}{l}\text { Quantity } \\
\left(1000 \mathrm{~m}^{3}\right)\end{array}$ \\
\hline Rice & 43770 & 23.5 & 144570 & 3.3 & Roundwood & 330210 \\
\hline Wheat & 28035 & 15.1 & 75800 & 2.7 & Wood fuel & 307018 \\
\hline Millet & 10800 & 5.8 & 12670 & 1.2 & $\begin{array}{l}\text { Industrial } \\
\text { roundwood }\end{array}$ & 23371 \\
\hline Seed cotton & 9430 & 5.1 & 13200 & 1.4 & Sawnwood & 14789 \\
\hline Beans & 9000 & 4.8 & 3000 & 0.3 & $\begin{array}{l}\text { Wood-Based } \\
\text { Panels }\end{array}$ & 2554 \\
\hline Soybeans & 8880 & 4.8 & 10968 & 1.2 & $\begin{array}{ll}\text { Paper } & \text { and } \\
\text { paperboard* }\end{array}$ & 1830 \\
\hline Sorghum & 8451 & 4.5 & 7150 & 0.8 & Wood pulp* & 1470 \\
\hline Maize & 7770 & 4.2 & 18960 & 2.4 & \multirow{5}{*}{\multicolumn{2}{|c|}{$* 1000 \mathrm{t}$}} \\
\hline Chick peas & 7490 & 4 & 6330 & 0.8 & & \\
\hline Rapeseed & 6790 & 3.6 & 7438 & 1.1 & & \\
\hline Groundnuts & 6410 & 3.4 & 9183 & 1.4 & & \\
\hline Sugar cane & 4900 & 2.6 & 355520 & 72.6 & & \\
\hline Total & 158800 & - & 860530 & - & $\begin{array}{l}\text { Total forest area } \\
\text { (1 000 ha) }\end{array}$ & 67759 \\
\hline
\end{tabular}

Source: FAOStat, 2009

India has a large share of arable land, but the small ratio of land per capita creates serious problems in land resource management and results in land degradation. With rapid urbanisation and industrialisation, there is increasing pressure on land, water and the environment, particularly in big metropolitan cities. Historically, India has had an agrarian system of land ownership introduced at the time of colonial rule; the system promoted non-cultivating intermediaries who held large tracts of land which were let to the farmers at exorbitantly high rents (Sethi, 2006). Years of land reforms have helped to abolish the intermediaries, but the actual farmers still hold very little land. India is dominated by small farms with peasants cultivating their ancestral lands mainly by means of family manual labour and cattle for draft power. The average farm size shrank from 2.7 hectares in 1960 to only about 1.6 ha in 1990 (Worldwatch Institute, 1999). Government policies, initiated to address this disparity by fixing a ceiling on the land holdings, have had only limited success so far.

Data for land prices in India are difficult to assess due to the high variability between and even within the states. It is hard to generalise about prices since they depend on numerous factors, including location, availability of water, proximity to transport, etc. There is no database on land prices, and government records are not considered accurate. 
Figure A6. Agricultural and forestry land use in India

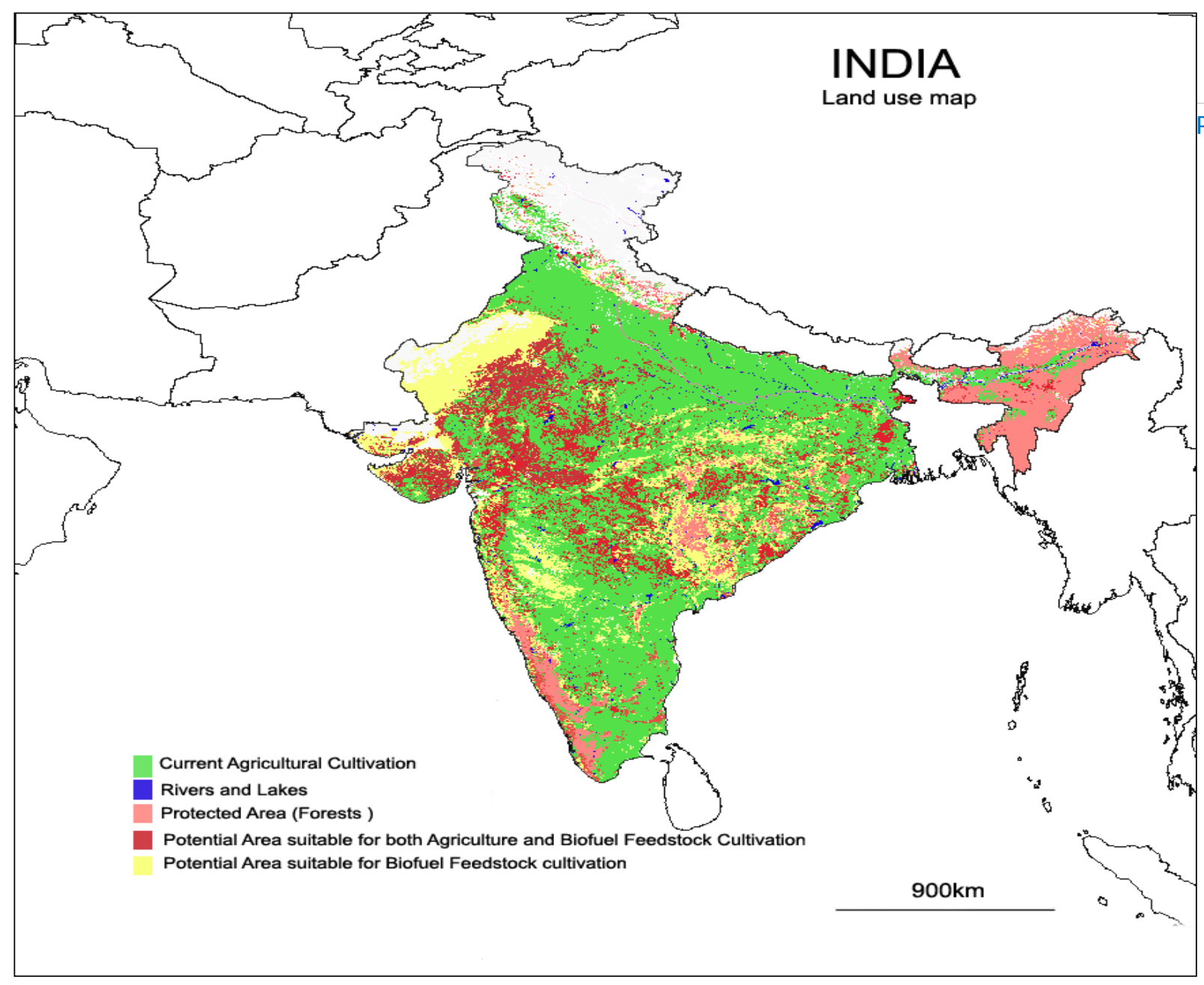

Source: Based on Indian Agriculture and land use database (Geoportal.org) and CGPL, 2009

\section{Current situation of biofuel development}

\section{Current production of first-generation biofuels}

According to the IEA's Medium Term Oil Market Report 2009, the production of biofuels in India reached 1.08 billion litres of ethanol and about 0.24 billion litres of biodiesel in 2008 (IEA, 2009b). The current share of biofuels in total fuel consumption is extremely low and is confined mainly to $5 \%$ blending of ethanol in gasoline, which the government has made mandatory in 10 states (MPNG, 2004). While this ethanol blending is mandatory, it is still subject to availability and market fluctuations, so exact figures of the amount of ethanol that goes into blending are not documented. The only available estimate is for the production surplus of molasses-based ethanol and for the demand of ethanol required for blending the total gasoline consumed in the country. Domestic ethanol production is currently sufficient to provide the ethanol required for $5 \%$ gasoline blending. However, even at $100 \%$ efficiency and with all available molasses being used for ethanol 
production, molasses cannot support the long-term demand of ethanol for gasoline blending if the blending levels are increased significantly (Sukumaran and Pandey, 2009).

Currently, biodiesel is not sold on the Indian fuel market, but the government plans to meet $20 \%$ of the country's diesel requirements by 2020 using biodiesel (Planning commission, 2003). Since the demand for edible oil seeds exceeds current production, the government promotes the use of nonedible oils from Jatropha curcas and Pongamia pinnata as feedstock for biodiesel production.

\section{National policy target for biofuels}

India is committed to the use of renewable sources to supplement its energy requirements. The country is among only a few countries that have a separate ministry for new and renewable energy to address the development of biofuels along with other renewable energy sources. In 2003, the Planning Commission of India brought out an extensive report on the development of biofuels (Planning Commission, 2003). The National Biodiesel Commission was set up to look exclusively into issues pertaining to biodiesel and the development of Jatropha curcas as the feedstock for biodiesel production (Planning commission, 2003). The blending targets for ethanol and biodiesel were proposed to be set at $10 \%$ and $20 \%$ respectively by $2011 / 12$.

\section{Financing and human resources}

India is a fast-developing economy with a wide range of industries and GDP exceeds USD 1 trillion. Cumulative FDI inflows to India since 2000 surpassed USD 100 billion in July 2009, with a decrease of 15\% between July 2008 and July 2009 that was far less than the 30\% decrease seen in industrialised countries (Financial Express, 2009; Ministry of Commerce and Industry, 2009). The government is enacting policies which will help biofuel production and there are incentives/subsidies for renewable energy and fuel production. Infrastructure for first-generation ethanol already exists, and there is both skilled and unskilled labour for an emerging biofuel industry. Therefore, India could be in a position to produce second-generation biofuels rather than only distribute feedstock for second-generation biofuels.

According to the World Bank (2006), India ranks 134 out of 175 countries, according to its investment climate. Corruption, tax rates and policy uncertainty were the most severe constraints.

However, the government offers several incentives and support measures for developing biofuels in the country. This includes capital subsidies, income tax holidays, sales tax concessions, electricity tax exemption, and other measures including financial support for R\&D, availability of cheap skilled labour and assistance in export promotion (USDC, 2009).

India's molasses based ethanol production and market is mature and there is an availability of human resources for tasks across the production chain. Skilled labour will be needed for running plants, though, and can be readily acquired due to the abundance of highly skilled engineers.

Currently no second-generation biofuel production exists, but research on production of cellulosic ethanol has been undertaken by Praj Indiustries in its new Praj Matrix Laboratory complex. In 2009, Praj Industries succeeded in producing ethanol from corncobs and sugar cane bagasse under varying conditions. Furthermore, the state-owned Indian Oil Company (IOC) just recently announced a partnership with the United States National Renewable Energy Laboratory (NREL) to set up a cellulosic ethanol production plant. The IOC is going to provide core funding of roughly USD 4 million while NREL assists with expertise on production, utilisation and marketing of biofuels (Business Standard, 2009). 


\section{Infrastructure}

The total vehicle fleet in India amounts to 63.5 million vehicles. By far the largest share are motorcycles (51.2 million) followed by passenger cars and SUV's (6.8 million), passenger light trucks (2.5 million) and medium duty trucks (1.4 million) (Table A27).

Table A27. Vehicle fleet in 2006

\begin{tabular}{|c|r|r|r|l|l|l|}
\hline Motorcycles & \multicolumn{1}{|l|}{ PC+SUV } & \multicolumn{1}{l|l}{ LCV's } & PLT's & \multicolumn{1}{l|}{ MDT's } & \multicolumn{1}{l|}{ HDT's } & \multicolumn{1}{l|}{ Buses } \\
\hline 51198616 & 6847202 & 884514 & 2501704 & 1425646 & 185107 & 449656 \\
\hline
\end{tabular}

PC: passenger car; SUV: sport utility vehicle; LCV: light commercial vehicle ; PLT: passenger light truck; MDT: medium duty truck; HDT: heavy duty truck

Source: IEA Mobility Model, 2009

Total fuel consumption in India was 1547 PJ in 2007, consisting mainly of diesel (1 020 PJ), followed by gasoline (463 PJ), natural gas (58 PJ) and a small share of biofuels (6 PJ) (Table A28). India imports $70 \%$ of its domestic requirement of crude oil, but petroleum prices are heavily subsidised. In 2008, fuel subsidies were an estimated USD 12.7 billion. While the subsidies in part were needed to meet domestic fuel needs and to provide cheap public transportation and transportation of food and goods (as an indirect way to keep commodity prices low), these subsidies have created a heavy burden on the government and state-owned petroleum companies, and are widely regarded as unsustainable in the long run. Meeting at least part of the demand through biofuels is one of the serious options for cutting down the fuel subsidies.

Table A28. Fuel consumption in 2007 and projection for 2030

\begin{tabular}{|r|r|r|r|r|}
\hline & $\begin{array}{c}\text { Motor Gasoline } \\
1000 \mathrm{t}(\mathrm{PJ})\end{array}$ & $\begin{array}{c}\text { Diesel } \\
1000 \mathrm{t}(\mathrm{PJ})\end{array}$ & $\begin{array}{c}\text { Natural Gas } \\
1000 \mathrm{t}(\mathrm{PJ})\end{array}$ & $\begin{array}{c}\text { Biofuels } \\
1000 \mathrm{t}(\mathrm{PJ})\end{array}$ \\
\hline $\mathbf{2 0 0 7}$ & $10327(463)$ & $23547(1020)$ & $(58)$ & $209(6)$ \\
\hline $\mathbf{2 0 3 0 *}$ & $41194(1845)$ & $93929(4067)$ & $(232)$ & $2982(85)$ \\
\hline
\end{tabular}

Source: IEA Statistics, 2009; *Assumption based on WEO 2008 data, assuming linear growth in each sector

The industrial and support infrastructures in India are very conducive for biofuel production. The country has the world's largest railways system under single management $(63327 \mathrm{~km})$ and the world's second largest road network, totalling 3.3 million km, of which 1.6 million km is paved. Shipping and inland water transport is also well developed; India has 12 major ports and 200 minor ports. With the necessary infrastructure in place to move feedstock and final biofuel products, the production and marketing of biofuels should not be a major concern (Competition Review, 2009).

Ethanol plants that use molasses as raw material already exist, and molasses ethanol is a mature technology in the country. The total annual demand of alcohol for purposes other than fuel was 1.3 billion litres in 2006 (AIDA, 2006). This accounts for only $40 \%$ of the installed capacity and at the current blending ratio of $5 \%$, the surplus is sufficient for gasoline blending. India's ethanol industry can meet even the projected demand of $10 \%$ blending in 2017, provided that the supply of molasses is stable and the installed distillery capacity is fully used. In several instances the 
distilleries are associated with sugar manufacture, which generates enormous quantities of bagasse on site that are either sometimes used for power generation or wasted.

Biodiesel industry in India is still in its infancy. There is only one operational biodiesel plant Naturol Bioenergy Ltd, a joint venture with Energea Gmbh (Austria) and Fe Clean Energy (United States) with an installed annual capacity of 90000 tons.

There is practically no biofuel-specific distribution infrastructure in the country. State funding is provided to government and autonomous R\&D institutes for the development and testing of Flex Fuel vehicles and for developing/converting engines and generators that can run on biofuels. Petroleum companies are already supplying 5\% ethanol blended gasoline and have in principle committed to supply ethanol blended biodiesel through their distribution network, which will take care of the problem of developing fuel station infrastructure.

\section{Feedstock assessment and logistics}

\section{Feedstock assessment}

Though no accurate data on biomass potentials exist, the country does have sufficient data on agricultural output and isolated studies on the amount of residues generated (Raveendranath et al., 2005). Another serious constraint when estimating the availability of biomass residues is the lack of data on the current usage for other competing applications of residues.

The statistics for agricultural crops in India (DEA-DAC, 2008) show that the major lignocellulosic residues with potential for exploitation as feedstock for ethanol production are rice straw, wheat straw and sugar cane bagasse (Table A29). Residues from corn and sorghum cultivation are also potential feedstocks. Regionally available material like bamboo biomass in the north-east or aquatic biomass, including water hyacinth in Kerala, may also serve as important feedstock material with the potential to be used in bioethanol production. An availability of $10 \%$ is assumed, based on various applications like burning for fuel, utilisation as cattle fodder and roof thatching. These estimates reflect a rather conservative value, but no reliable data on the percentage of utilised residues is available. For this reason, the National Institute of Interdisciplinary Science and Technology (NIIST) is currently undertaking more detailed research on this issue.

India does not have surplus agricultural land for the exclusive generation of bioethanol feedstock, and government policies rightly prevent the cultivation of energy crops on agricultural land that can be used for growing food. Forestry residues are consumed for fuel and firewood by forest-dwelling and border communities, with the excess often consumed by the pulp and paper industries. Plantation derived biomass in the country is almost exclusively used for timber and the paper and pulp industries, but the waste generated is not documented. The availability of forest and plantation residues is therefore not considered in this study. 
Table A29. Assessment of residues from forestry and agriculture

\begin{tabular}{|c|c|c|c|c|}
\hline Type & $\begin{array}{l}\text { Actual material flow } \\
\left(1000 t_{D M} / y r\right)\end{array}$ & $\begin{array}{l}\text { Unused residues } \\
\left(1000 t_{D M} / y r\right)\end{array}$ & $\begin{array}{c}\text { Feedstock cost } \\
\text { (USD/t) }\end{array}$ & $\begin{array}{c}\text { Regional } \\
\text { Availability }\end{array}$ \\
\hline \multicolumn{5}{|c|}{ Primary residues } \\
\hline Rice straw & 140924 & 14092 & $20-40$ & $\begin{array}{l}\mathrm{N} \text {, south-central, } \\
\text { SW, NE }\end{array}$ \\
\hline Wheat straw & 101880 & 10188 & $60-70$ & Central, N \\
\hline $\begin{array}{l}\text { Corn (stalk, } \\
\text { stems) }\end{array}$ & 31230 & 3123 & & Central, N \\
\hline $\begin{array}{l}\text { Sorghum } \\
\text { stalk }\end{array}$ & 12864 & 1286 & n.a. & $\begin{array}{l}\text { West-central, } \\
\text { central, N }\end{array}$ \\
\hline $\begin{array}{l}\text { Cotton Stalk } \\
+ \text { seed }\end{array}$ & 9061 & 906 & n.a. & $\begin{array}{l}\text { West-central, } \\
\text { central, S }\end{array}$ \\
\hline \multicolumn{5}{|c|}{ Secondary residues } \\
\hline Bagasse & 55802 & 5580 & $20-30$ & $\begin{array}{l}\mathrm{N}, \text { west-central, } \\
\text { east-central, S }\end{array}$ \\
\hline Rice husk & 15658 & 1565 & n.a. & $\begin{array}{l}\mathrm{N} \text {, south-central, } \\
\text { SW, NE }\end{array}$ \\
\hline Peanut shell & 13200 & 1320 & n.a. & $\mathrm{N}$, south-central, S \\
\hline
\end{tabular}

Source: DES, 2008

\section{Second-generation biofuel options}

Based on the biomass residues described above, the potential biofuel production and number of production plants can be defined. The calculations are based on actual material flows as well as unused residues and represent only a theoretical estimation. For every second-generation biofuel option, not all types of residues are considered suitable. However, because this is the aim of further $R \& D$, all types of residues were considered suitable for every pathway in this analysis. Biofuel production as well as the potential number of conversion plants is higher based on primary residues than on secondary residues in India. Due to higher overall efficiency and lower technical complexity, the bio-SNG pathway has a higher fuel output, while BTL and bioethanol produce similar fuel outputs.

The amount of second-generation biofuel indicated in Table A30 could theoretically cover $17 \%$ of total transport fuel demand to date if residues were converted into cellulosic-ethanol and could cover $27 \%$ if residues were converted into bio-SNG. 
Table A30. Potential second-generation biofuel production and number of plants

\begin{tabular}{|c|c|c|c|c|c|c|c|c|}
\hline \multirow[b]{3}{*}{$\begin{array}{l}\text { Biofuel } \\
\text { option }\end{array}$} & \multicolumn{4}{|c|}{ Production } & \multicolumn{4}{|c|}{ Number of plants } \\
\hline & \multicolumn{2}{|c|}{ actual material flow } & \multicolumn{2}{|c|}{ unused residues } & \multicolumn{2}{|c|}{ actual material flow } & \multicolumn{2}{|c|}{ unused residues } \\
\hline & $\mathrm{Ml}_{\mathrm{ge} / \mathrm{yr}}$ & $\mathrm{PJ} / \mathrm{yr}$ & $\mathrm{MI}_{\mathrm{ge}} / \mathrm{yr} *$ & $\mathrm{PJ} / \mathrm{yr}$ & $\begin{array}{c}\text { small } \\
\text { scale** }\end{array}$ & $\begin{array}{c}\text { large } \\
\text { scale** }\end{array}$ & $\begin{array}{c}\text { small } \\
\text { scale** }\end{array}$ & $\begin{array}{c}\text { large } \\
\text { scale** }\end{array}$ \\
\hline \multicolumn{9}{|c|}{ Based on primary residues } \\
\hline Bio-SNG & 91155 & 3053.7 & 9115.5 & 305.4 & 4915 & 665 & 491 & 66 \\
\hline BTL-diesel & 64215 & 2151.2 & 6421.5 & 215.1 & 591 & 154 & 59 & 15 \\
\hline Bioethanol & 63313 & 2121.0 & 6331.3 & 212.1 & 4748 & 385 & 475 & 39 \\
\hline \multicolumn{9}{|c|}{ Based on secondary residues } \\
\hline Bio-SNG & 26075 & 873.5 & 2607.5 & 87.4 & 1406 & 190 & 141 & 19 \\
\hline BTL-diesel & 18369 & 615.4 & 1836.9 & 61.5 & 169 & 44 & 17 & 4 \\
\hline Bioethanol & 18111 & 606.7 & 1811.1 & 60.7 & 1358 & 110 & 136 & 11 \\
\hline $\begin{array}{l}\text { Remark: Biofue } \\
\text { * Assumed con }^{*} \\
\text { **Based on typ }^{*}\end{array}$ & ptions are calc & ted using 10 & of actual ma & al flow an & $\begin{array}{l}100 \% \text { of unus } \\
: 307 \mathrm{lge} / \mathrm{t}_{\mathrm{DM}}\end{array}$ & esidues for ec & option. & \\
\hline
\end{tabular}

\section{Estimated costs for feedstock / end-product}

India is a large country with several regions and subregions which differ significantly from each other. Therefore, it is beyond the scope of this study to indicate highly accurate prices for most of the feedstocks mentioned in Table A29. However, the indicated opportunity costs can be used to get theoretical production costs for second-generation biofuels in India. According to current IEA cost estimates in combination with the indicated feedstock prices, second-generation biofuels could be produced at costs of USD 0.62-0.86/Ige (Table A31), which is still considerably higher than India's subsidised gasoline prices.

Table A31. Theoretical second-generation biofuel production costs in India

\begin{tabular}{|l|c|c|c|c|c|}
\hline Feedstock & \multirow{2}{*}{$\begin{array}{c}\text { Feedstock price } \\
\text { (USD/t) }\end{array}$} & \multicolumn{4}{|c|}{ oil USD 60/bbl } \\
& $20-70$ & $0.62-0.80$ & $0.63-0.86$ & $0.39-0.54$ & $0.37-0.57$ \\
\hline Straw/stalks & $20-30$ & $0.68-0.75$ & $0.70-0.79$ & $0.44-0.5$ & $0.44-0.51$ \\
\hline Bagasse & & \multicolumn{5}{|c|}{ oil USD 120/bbl } \\
\hline \multicolumn{2}{|c|}{} & $0.80-0.98$ & $0.73-0.96$ & $0.50-0.65$ & $0.41-0.61$ \\
\hline Straw/stalks & $20-70$ & $0.86-0.92$ & $0.81-0.89$ & $0.55-0.6$ & $0.47-0.55$ \\
\hline Bagasse & $20-30$ & &
\end{tabular}

Source: Based on IEA Mobility Model, 2009 


\section{Identification of hot spots for production plants}

The states and the districts with the highest production levels of rice, wheat and sugar cane can be potential hot spots for setting up second-generation biofuel plants. Residues of the main crops - rice, wheat and sugar cane - are mainly found in West Bengal, Andhra Pradesch, Uttar Pradesh, Punjab, Orissa, Tamil Nadu, Madhya Pradesh, Rajastan, Maharashtra and Karnataka (DES, 2008). There are also other potential feedstock sources like corn stover and sorghum stover, which could add other states as hot spots for production. The states with greatest production of corn stover are Andhra Pradesh, Karnataka, Bihar, Rajasthan, Maharastra and Madhya Pradesh, while those states with high yields of sorghum are Maharashtra, Karnataka, Madhya Pradesh and Andhra Pradesh. Due to geographical peculiarities, soil types and irrigation, many regions can provide more than one type of feedstock; in such cases, plants that run on mixed feedstock may be envisaged.

\section{Sustainability}

\section{Economic impact}

All of the fuel ethanol currently used in India for gasoline blending comes from molasses, which is a byproduct of the sugar industry. Though the availability of subsidised molasses can help to keep the prices of molasses ethanol lower, such a system is not sustainable in the long run. The projected increasing demand for bioethanol cannot be met solely by molasses and alternative feedstocks will need to be used. A competitive second-generation bioethanol production scheme using lignocellulosic biomass could be relatively more stable against market fluctuations and could become self-sustaining in the long run, even though government subsidies will be necessary in its early stages. With petroleum prices expected to increase, the second-generation ethanol will become more competitive in price, and advances in technology for lignocellulosic ethanol generation will reduce prices further. Prices are expected to be highly competitive against molasses ethanol in the medium to long term.

Selling unutilised agro-residues for bioethanol can create additional income for farmers, although exclusive cultivation of fuel stock on agricultural land is not a feasible option in the Indian context. Farmers cultivating marginal areas for biodiesel feedstock (e.g. jatropha), however, do stand to benefit from the additional income they can obtain through selling oil seeds and oil cake.

The major competition for lignocellulosic agro-residues, especially those discussed under earlier sections of this document, comes from its use in pulp and paper manufacturing. There is further competition for these resources for farmers' own applications at the source, like roof thatching, fodder for cattle, household fuel and heating. There are also other minor applications where the residues are used in areas like packaging and handicrafts.

\section{Social impact}

The biofuels sector has the potential to become a source of substantial employment. The sugar industry is the source of livelihood of 45 million farmers and their dependants, comprising $7.5 \%$ of the rural population. Another 500000 people are employed as skilled or semi-skilled labourers in sugar cane cultivation (Gonsalves, 2006). With second-generation biofuel industries becoming more established, there is greater potential to generate both direct and indirect jobs. These jobs may not be in the agricultural plantation sector since the proposed feedstocks are by-products of 
agriculture. Nevertheless, jobs will be generated in the collection and transport of residues, preprocessing, and the generation of bioethanol and by-products.

A large part of India's population, mostly in rural areas, does not have access to energy services. The enhanced use of renewables (mainly biofuels) in rural areas is closely linked to poverty reductions because greater access to energy services can 1 ) improve access to pumped drinking water; 2 ) reduce the time spent by women and children on basic survival activities, such gathering firewood, fetching water and cooking; 3) allow the lighting of rural households; and 4) reduce deforestation and indoor pollution caused by firewood use. Providing electricity through transmission lines to many rural areas is unlikely to happen in the near future, so access to modern decentralised energy technologies, particularly renewables (including biofuels), is an important element for effective poverty alleviation policies. A programme that develops energy from raw material grown in rural areas will go a long way in providing energy security to rural people (Gonsalves, 2006).

Smallholders stand to benefit directly from the additional income generated by selling residues and from cropping marginal lands/waste lands for second-generation biofuel feed stock cultivation. Farmers' cooperatives, self-support groups and NGOs can assemble smallholders, impart training when needed and organise support activities in order to ensure a competitive market position for these groups.

\section{Ecological impacts}

Environmental impact assessment studies have not been done for biofuels in India and information on the exact dimensions of impact on the environment is not available.

\section{SWOT analysis}

Table A32. Summary of SWOT analysis

\begin{tabular}{|c|c|}
\hline STRENGTH & $\begin{array}{l}\text { - } \quad \text { Fast growing economy with investment capacity for large-scale projects } \\
\text { - } \quad \text { Large agricultural sector that produces significant amounts of residues } \\
\text { - Good infrastructure in regions with high residue potential } \\
\text { - State initiatives for first-generation and second-generation biofuel promotion, plus } \\
\text { public and private funding for second-generation biofuel RD\&D }\end{array}$ \\
\hline WEAKNESS & $\begin{array}{l}\text { - Biofuel-specific infrastructure (fuel stations, flex fuel vehicles, etc.) is } \\
\text { currently non-existent } \\
\text { - No experience with second-generation biofuels } \\
\text { - No additional cropland available for bioenergy crops }\end{array}$ \\
\hline OPPORTUNITY & $\begin{array}{l}\text { - Smallholders could benefit through co-operatives that organise provision of } \\
\text { residues } \\
\text { - Laws to encourage direct foreign investment that could be favourable for the } \\
\text { development of second-generation production } \\
\text { - Improvement in rural income and employment generation } \\
\text { - Private investment in biofuel sector }\end{array}$ \\
\hline THREAT & $\begin{array}{l}\text { - Subsidies needed in the short term to promote second-generation biofuels } \\
\text { - } \quad \text { Fossil fuel is subsidised by the state and is thus more competitive than biofuel } \\
\text { - Bureaucratic hurdles still exist for new projects despite government support } \\
\text { initiatives }\end{array}$ \\
\hline
\end{tabular}




\section{Conclusions}

With the ever increasing demand for transportation fuels and rapidly depleting petroleum resources, India has to develop alternative fuels, especially for the transportation sector. Currently, biomass seems to be the only feasible resource for renewable fuel, but the lack of cost-effective technologies for biomass conversion to fuel hinders progress in this direction. The government's decision for mandatory blending of ethanol at a 5\% level in gasoline in 11 states and three union territories has created an increased demand for fuel-grade ethanol, which at present can be met by the current production capacity; however, demand will exceed current production capacity once the blending has been implemented nation wide or if the blending ratio is increased.

The availability, variability and sustainability of feedstock for second-generation biofuel production are important issues to be addressed by R\&D personnel as well as policy makers. Statistics indicate that India has ample biomass resources in the form of agro-residues to support production of lignocellulosic biofuels, though this potential is restricted by current uses of the residues as cattle fodder, fertiliser and products. It also points to rice and wheat straw and sugar cane bagasse as the possible feed stocks for ethanol production in India. The most likely hot spots for second generation biofuel production based on rice straw will be the states of West Bengal, Andhra Pradesh, Uttar Pradesh and Punjab, while wheat straw-based second-generation biofuel production is most likely to be located in the states of Uttar Pradesh, Punjab, Haryana, Madhya Pradesh and Rajasthan. All these states have the required infrastructure, and production plants can be located near the areas of raw material availability. Sugar cane bagasse enjoys a rather centralised availability near major sugar factories and distilleries, and the most likely producers for biofuel from this raw material are the existing distilleries themselves, since the incorporation of lignocellulosic biofuel production into their existing infrastructure would be easier than starting new. However, there could be entirely new plants based on biomass likely to be concentrated in the sugar-producing areas of the states of Uttar Pradesh, Maharastra, Tamil Nadu and Karnataka.

India lacks mature technologies for second-generation biofuel production from lignocellulosic biomass, which is an abundant source of renewable energy that may be exploited in most parts of the country. Though biomass itself is cheap, the costs of its processing are relatively high. Technologies for biomass-to-biofuel conversion are also under various stages of development.

The government should take positive steps towards promoting the use of ethanol and biodiesel as a fuel by providing tax exemptions at least in initial stages. Establishing markets for biofuels and increasing subsidies can stimulate R\&D activities in this field and help spur growth of investment in technology development and deployment. It is important to bring fuel-ethanol programmes to the attention of big investors, especially the petroleum companies, since this can hasten the commercialisation of second-generation biofuel technology. Private investors should be encouraged to invest in biofuel programmes and government policies should be conducive to their participation. 


\section{A6 Mexico}

\section{General country characteristics}

\section{General description}

Mexico is located in North America and has a total coast line of $9330 \mathrm{~km}$, with the Pacific Ocean to the west and south and the Gulf of Mexico and the Caribbean Sea to the east. Mexico occupies a total area of $1972550 \mathrm{~km}^{2}$, almost $98 \%$ of which is land, including islands. The 31 Mexican provinces can be aggregated to seven regions: north-west (Baja California, Baja California Sur, Sonora, Chihuahua, Durango, Sinaloa); north-east (Coahuila, Nuevo Leon, Tamaulipas); centre-north (Zacatecas, San Luis Potosí, Aguas Calientes, Querétaro, Guanajato); centre-south (Morelos, Mexico State, Hidalgo); west (Nayarit, Jalisco, Colima, Michoacan); east (Veracruz, Puebla, Tlaxcala); southwest (Guerrero, Oaxaca, Chiapas); and south-east (Yucatan, Quintana, Campeche, Tabasco). Table A33 provides an overview of some basic economic indices and population information about Mexico.

Table A33. General population information and economy indices

\begin{tabular}{|l|l|r|r|}
\hline Parameter & Unit & Value & Year \\
\hline Population & Million & 109.96 & 2008 \\
\hline Population growth rate & \% & 1.14 & 2008 \\
\hline GDP (PPP) & bn USD & 1578 & 2008 \\
\hline GDP per capita (PPP) & & 1435 & 2006 \\
\hline Poverty rate & \% of total pop. & 4.8 & 2006 \\
\hline HDI & - & 0.842 & $2003-2005$ \\
\hline Undernourishment & \% of total pop. & $<5 \%$ & 2006 \\
\hline Energy production & Mtoe & 255.97 & 2006 \\
\hline TPES & Mtoe & 177.43 & 2006 \\
\hline Net energy imports & Mtoe & -76.75 & 2006 \\
\hline CO ${ }_{2}$-emissions/capita & t CO $/$ capita & 3.97 & \\
\hline
\end{tabular}

Source: CIA, 2008; IEA Statistics, 2009; FAO Aquastat, 2009; UNDP, 2007

Mexico is the sixth-largest oil producer world wide, but production has been steeply declining since 2004. Approximately $25 \%$ of the natural gas and almost $75 \%$ of the coal used in Mexico have to be imported. The country's primary energy supply is met primarily by oil, with a share of $49 \%$, followed by natural gas ( $27 \%$ share) and petroleum products ( $8 \%$ share) (Figure A7). Electricity generation reached $249700 \mathrm{GWh}$ in 2006, supplied mainly by natural gas, with a share of $46 \%$, oil (22\% share) and coal (13\% share) (IEA Statistics, 2009). 
Figure A7. Total primary energy supply

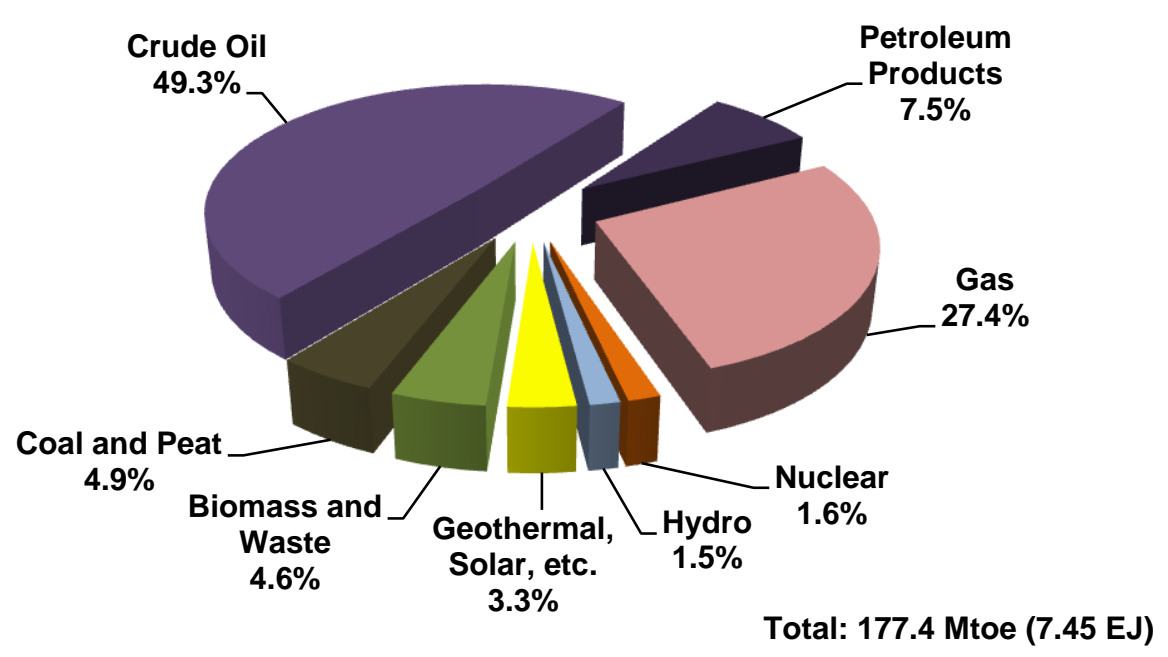

Source: IEA Statistics, 2009

Roughly 5.3 million people, or $5 \%$ of Mexico's population, live in absolute poverty ( $<2$ USD/day) (UNDP, 2007). Income distribution in Mexico is quite unequal (the Gini Index was 44.8 in 2006), with slight improvements seen in recent years (Cámara de Diputados, 2008a). Poverty is concentrated in rural regions in the mountainous Sierra Madre Occidental area and in indigenous areas found mainly in central and southern Mexico, in addition to the mountainous regions of north-west Mexico (Bellon, 2005). Mexico's percentage of undernourished people is less than 5\% (2003-05) and is below the Latin American average of $8 \%$ (FAO, 2008c). Access to food may have deteriorated due to price increases of $25 \%$ from December 2005 to December 2008 that were disproportionately higher than the general accumulated inflation rate of 15\% (Cámara de Diputados, 2008c).

\section{Natural conditions for biofuel feedstock production}

Owing to its mountain ranges and great expanse from north to south, Mexico has a wide array of climatic conditions. About $61 \%$ of Mexico are under arid to semi-arid climate, with most of these dry areas located in the north and centre of the country. In the central plateau, precipitation increases toward the south and ranges from $300 \mathrm{~mm}$ per year to about $600 \mathrm{~mm}$ per year in the southern part of the plateau. Coastal areas in the north are very arid and on average receive less than $130 \mathrm{~mm}$ per year along the Pacific coast and 250 to $600 \mathrm{~mm}$ per year along the Gulf coast. The southern region of Mexico is characterised by a tropical climate with seasonal rainfalls ranging from 1500 to $2000 \mathrm{~mm}$ per year and temperatures of $21-27^{\circ} \mathrm{C}$ throughout the year. Temperatures are moderate in the highlands but also create a natural barrier to the cultivation of crops. Erosion is a problem in the mountainous central and the south-west regions. The most fertile soils are of volcanic origin and are located in the central plateau. Irrigation in the arid and semi-arid north can also lead to very productive land (FAO, 2009b; Martinez, 2006).

Mexico's vegetation is characterised by scrubland in the arid and semi-arid regions and changes to grassland in areas with increasing annual precipitation and to pine-oak forests in the highlands. In the south, the natural vegetation consists of tropical semi-deciduous and deciduous forests and, where forests have been cleared, pastures predominate. 


\section{Agriculture and forestry}

Mexico's agricultural sector contributes about $4 \%$ to GDP, which is a relatively small amount compared to an agricultural workforce that accounts for about 6.37 million workers or $16 \%$ of the active population. The lack of precipitation makes Mexico's agriculture very dependent on water

Page | 148 availability and irrigation. As a result, only $16 \%$ of total land area is arable, of which almost $20 \%$ is irrigated. Forest area - which includes various types of scrubland, oaks, pines, and broadleaved tropical forests - accounts for $65 \%$ of total land. In the past, forest area has diminished at the expense of agricultural area, and the current deforestation rate is around 350000 ha per year. The forest industry is of minor importance, but in rural areas, wood is used as fuel for heating and cooking applications or as construction material (Rembio, 2009).

In recent years Mexican agriculture has undergone some strong changes due to the transformation of property rights for land and free trade treaties. Maize is still the main ingredient in Mexican cuisine and covers larges areas in the central valley. Another important cereal in Mexico is sorghum, generally cultivated in the regions of Tamaulipas and Michoacàn for grain or fodder. The cultivation and processing of sugar cane form Mexico's largest agricultural industry, but the smallholding structure makes production expensive and limits competitiveness (Rembio, 2009; Martinez, 2006; FAO, 2009b) (see Table A34).

Table A34. Agricultural and forestry production 2007

\begin{tabular}{|c|c|c|c|c|c|c|}
\hline \multicolumn{5}{|c|}{ Agricultural Production } & \multicolumn{2}{|c|}{ Forestry Production } \\
\hline & $\begin{array}{l}\text { Crop area } \\
\text { (1000 ha) }\end{array}$ & $\begin{array}{l}\text { Proportion of } \\
\text { crop area (\%) }\end{array}$ & $\begin{array}{l}\text { Production } \\
(1000 \mathrm{t})\end{array}$ & $\begin{array}{l}\text { Yield } \\
\text { (t/ha) }\end{array}$ & Product & $\begin{array}{l}\text { Production } \\
\left(1000 \mathrm{~m}^{3}\right)\end{array}$ \\
\hline Maize & 7800 & 28.3 & 22500 & 2.9 & Roundwood & 24841 \\
\hline Beans & 1730 & 6.3 & 1390 & 0.8 & Wood fuel & 22209 \\
\hline Sorghum & 1600 & 5.8 & 5500 & 3.4 & $\begin{array}{l}\text { Industrial } \\
\text { roundwood }\end{array}$ & 6382 \\
\hline Sugar cane & 680 & 2.5 & 50680 & 74.5 & $\begin{array}{l}\text { Paper and } \\
\text { paperboard* }\end{array}$ & 5172 \\
\hline Wheat & 602 & 2.2 & 3000 & 5 & Sawn-wood & 2743 \\
\hline Barley & 329 & 1.2 & 895 & 2.7 & $\begin{array}{l}\text { Wood based } \\
\text { panels }\end{array}$ & 431 \\
\hline Bananas & 75 & 0.3 & 2200 & 29.3 & Wood pulp* & 340 \\
\hline Rice & 71 & 0.3 & 350 & 4.9 & \multirow{3}{*}{\multicolumn{2}{|c|}{$* 1000$}} \\
\hline Soybeans & 55 & 0.2 & 82 & 1.5 & & \\
\hline Groundnuts & 45 & 0.2 & 69 & 1.5 & & \\
\hline Total area & 16153 & & 121007 & & $\begin{array}{l}\text { Total forest } \\
\text { area } \\
(1000 \text { ha) }\end{array}$ & 64238 \\
\hline
\end{tabular}

Source: FAO Stat, 2009 
Since 1992, a new law has been in force giving the community, or ejidos, the right either to use arable and pastoral lands commonly, to parcel them into smallholdings, or to sell them for private use. However, forest lands cannot be sold or parcelled and must be kept as commons. About $56 \%$ and $70 \%$ of all forest land is under this social ownership. Although a programme started in 1993 to certify land ownership, there is still high uncertainty of land rights.

\section{Current situation of biofuel development}

\section{Current production of first generation biofuels}

Currently, there is no large-scale ethanol or biodiesel production in Mexico. Sugar cane, maize, yucca, sorghum and sugar beet could be potential feedstocks for first-generation ethanol production, but only the sugar cane sector produces surplus while the other sectors cannot satisfy domestic demand (Martinez, 2006). Despite not being globally competitive, sugar cane growers and refiners have the strongest technological capacity to produce ethanol fuel (Rothkopf, 2007). Sugar cane is cultivated on 680000 ha ( $2 \%$ of arable land) with a production of $51 \mathrm{Mt}$ of raw sugar cane (approximately $76 \mathrm{t} / \mathrm{ha} / \mathrm{yr}$ ) and $5.5 \mathrm{Mt}$ of sugar in 2008/09 harvest (SAGARPA, 2009). Ethanol production is limited to 80 million I of ethanol for use in the beverage and pharmaceutical industries; production capacity of the 13 sugar cane mills with distilling facilities is only 170 million I/yr (USDA-FAS, 2007).

The production of biodiesel is limited to small-scale plants with a few thousand tonnes per year (USDA-FAS, 2007). Feedstock availability is a major restriction for the development of a biodiesel industry since $90 \%$ of oilseed demand and $35 \%$ of fodder demand are imported (ISTA Mielke GmbH, 2008). The current cultivated area of 63000 ha for soybean would have to increase by 50 times in order to supply vegetable oil demand for a $5 \%$ biodiesel blending mandate in Mexico, while the current safflower area of 113000 ha would have to increase by 22 times (Comite Nacional SistemaProductos Oleaginosas, 2008; Martinez, 2006).

\section{National policy target for biofuels}

Since February 2008, Mexico has had the national Promotion and Development Law for Bioenergetics (Cámara de Diputados, 2008b). But this framework has not been further developed with elements such as blending targets and financial support for biofuels production and consumption, thereby limiting full implementation of the law. The Federal Ministry of Agriculture has announced a blending of $7 \%$ ethanol in gasoline only for the metropolitan zone of Guadalajara in the state of Jalisco, starting in 2010 (Presidencia, 2008). There are not any specific promotion policies for second-generation biofuels, but they may be included in a new national research program on biofuels, which is being designed currently by the National Council for Science and Technology (CONACYT) (Rembio, 2009).

\section{Financing and human resources}

Mexico has a medium-risk but stable investment grade of BBB ${ }^{18}$ (Seeking Alpha, 2009). Business regulations are evaluated as mediocre by World Bank experts, with the main barriers consisting of

\footnotetext{
${ }^{18}$ According to the credit rating system of Standard \& Poor's or Fitch, BBB+ expresses a medium-safe long-
} term investment grade. It occurs often when an economy has deteriorated. 
authorisations when starting a business, a high tax burden and regulations for employing workers (World Bank, 2008b). The strength of the country's agricultural unions may be interpreted as a factor contributing to the diminished competitiveness of future biomass and biofuel production (Rothkopf, 2007). Due to the highly developed oil, gas and petrochemical industries, Mexico possesses highly skilled engineers with top-level universities and agricultural and technological institutions (Rembio, 2009). For large investments in second-generation biofuel plants and/or blending facilities, the state oil company PEMEX probably would be one key actor, although PEMEX's commitment to biofuels has been limited in the past. However, especially because of Mexico's integration into NAFTA, international investors could fill this gap were second-generation biofuel production to be evaluated as promising. Corruption is perceived as a problem in Mexico, and in 2007 the Mexican spent an average 8\% of his income to pay bribes (Transparencia Mexicana, 2008). However this is not considered a key barrier to second-generation biofuel development.

\section{Infrastructure}

Mexico's road network is faced with growing traffic volumes, but as a result of low expenditures for maintenance in some regions, it is in poor condition, especially in rural areas. Due to structural reforms, the quality and efficiency of railroads and ports have improved in recent years (World Bank, 2005). Mexico has a road network of about $360000 \mathrm{~km}$, of which one-third is paved. Nearly $67000 \mathrm{~km}$ are dirt roads in poor condition. The rail network measures a total of $27000 \mathrm{~km}$, mostly running in a south-north direction with some connections to gulf and pacific ports. There are no commercially navigable inland water ways in Mexico, but, due to its favourable location between the Pacific Ocean and the Gulf of Mexico, the country has 21 ports, eight on the Gulf coast and 13 on the Pacific coast (NATS, 2009). The major ports are Manzanillo and Lazaro Cárdenas on the Pacific Ocean, and Veracruz, Progreso, Coatzacoalcos and Tuxpan on the Gulf of Mexico. Delays in moving cargo from terminal to rail or truck transportation are still a problem and are caused by a shortage of terminal infrastructure as well as the poor management of logistics chains (World Bank, 2005). Roads are the most important mode of transport and are responsible for $86 \%$ of the domestic freight activity. Rail and coastal shipping account for about $7 \%$ each of overall freight transport volume (NATS, 2009).

Since there is only limited biofuel production in Mexico, there is no biofuel production infrastructure. Only one corn-ethanol plant has been built for biofuel purposes, but it is not operating. Furthermore, three biodiesel pilot plants are in place but with a negligible amount of production. The bioethanol fuel plant and two of the biodiesel plants are located around Mexico's centre in Sinaloa, Michoacán and Nuevo León. The third biodiesel plant is located in Chiapas, in the south (USDA-FAS, 2007; Rembio, 2009). As a crude oil-producing country, Mexico runs six oil refineries, with three located on the Gulf coast (Reynosa, Madero and Minatitlan), one on the Pacific coast (Salina Cruz), and two in the central valley (Salamanca and Tula). Because of delayed investment, there is a lack of refinery capacity and, as a consequence, Mexico imports up to $40 \%$ of its domestically consumed gasoline and up to $15 \%$ of its diesel (PEMEX, 2008).

The transportation of feedstock is performed mainly by light and heavy trucks. While light trucks are used for shorter distances, heavy trucks are used for short as well as long distance transportation. Except for maize and sorghum, which are transported up to $3000 \mathrm{~km}$ if they are imported from the US, other feedstock is transported regionally at much shorter distances; distances of less than $70 \mathrm{~km}$ are typical for sugar cane, and less than $30 \mathrm{~km}$ is typical for oil palm. Depending on the type of transport vehicle used, the estimated transportation cost amounts to $0.03-0.75 \mathrm{USD} /(\mathrm{t} \mathrm{km})$ (Rembio, 2009). 
Since no considerable amounts of biofuel are produced or imported, there is no commercial biofuel consumption and no refuelling stations for biofuels (USDA-FAS, 2007). Mexico's total automotive fleet amounts to 25.7 million vehicles, of which passenger cars and sport utility vehicles account for nearly $60 \%$ (Table A35).

Table A35. Vehicle fleet in 2006

\begin{tabular}{|c|c|c|c|c|c|c|c|}
\hline 2 wheelers & PC+SUV & LCV's & LT's & MDT's & HDT's & Buses & Minibuses \\
\hline 605954 & 15354378 & 2663217 & 4938477 & 1587064 & 299252 & 32158 & 205719 \\
\hline
\end{tabular}

Legend: PC: Passenger car; SUV: Sport utility vehicle; LCV: Light commercial vehicle; LT: Light truck; MDT: Medium duty truck; HDT: Heavy duty truck

Source: IEA Mobility Model, 2009

Mexico's domestic fuel consumption amounted to nearly $2010 \mathrm{PJ}$ in the year 2007, with the share of consumption is as follows: $70 \%$ gasoline, $27 \%$ diesel and less than $3 \%$ liquefied petroleum gas (LPG) (IEA Statistics, 2009). A projection for the year 2030 is shown in Table A36.

Table A36. Fuel consumption in 2006 and projection for 2030

\begin{tabular}{|r|c|c|r|r|r|}
\hline & $\begin{array}{c}\text { Gasoline } \\
1000 \mathrm{t}(\mathrm{PJ})\end{array}$ & $\begin{array}{c}\text { Diesel } \\
1000 \mathrm{t}(\mathrm{PJ})\end{array}$ & $\begin{array}{r}\text { Natural Gas } \\
1000 \mathrm{t}(\mathrm{PJ})\end{array}$ & $\begin{array}{c}\text { LPG } \\
1000 \mathrm{t}(\mathrm{PJ})\end{array}$ & $\begin{array}{c}\text { Biofuels } \\
1000 \mathrm{t}(\mathrm{PJ})\end{array}$ \\
\hline $\mathbf{2 0 0 7}$ & $31427(1401)$ & $12515(537)$ & $(1)$ & $1391(70)$ & 0 \\
\hline $\mathbf{2 0 3 0 *}$ & $46311(2056)$ & $18442(791)$ & $(2)$ & $2567(129)$ & n.a. \\
\hline
\end{tabular}

Source: IEA Statistics, 2009; *Assumption based on WEO 2008 data, assuming linear growth in each sector

\section{Feedstock assessment and logistics}

\section{Assessment on agricultural and forestry residues}

The main sources of feedstocks for second-generation biofuel production in Mexico derive from harvesting and processing agricultural crops. Since corn is the most important agricultural crop, large amounts of residues are concentrated in the central valley, the main growing area for maize. Huge quantities of residues also remain after the harvest of sorghum in the more arid regions of Tamaulipas, Guanajuato, and Michoacàn, and sugar cane in the tropical sub-humid and humid regions. However, considering the competing uses of the residues as fodder for livestock or as fertiliser, the amount of unused residues is significantly smaller. Residues from processing sugar cane (bagasse) or maize (corncobs) form another potential major source of biomass residues, but these have other uses, as well; for example, bagasse is often used for power and heat production. The fact that the wood processing industry is a small sector in Mexico explains the limited quantity of logging and wood residues. Some $20-40 \%$ of the $2 \mathrm{Mt}_{\mathrm{DM}}$ of wood residues are used in the pulp and cellulose industry (SIAP, 2009; Arias Chalico et al., 2009).

Besides these agricultural and forest residues, Mexico is endowed with numerous areas suitable for the cultivation of additional crops and the production of wood using sustainable forest management. This potential is estimated to be several million $t_{D M} / y r$ and is mainly situated on the temperate to humid areas located along the Gulf of Mexico and the south of the country (Arias Chalico et al., 2009). 
Table A37. Assessment of residues from forestry and agriculture

\begin{tabular}{|c|c|c|c|c|}
\hline Type & $\begin{array}{c}\text { Actual } \\
\text { material flow } \\
\left(1000 t_{D M} / y r\right)\end{array}$ & $\begin{array}{c}\text { Unused } \\
\text { residues } \\
\left(1000 t_{D M} / y r\right)\end{array}$ & Regional availability & $\begin{array}{l}\text { Main } \\
\text { utilisation }\end{array}$ \\
\hline \multicolumn{5}{|l|}{ Primary residues } \\
\hline Corn (stalk, stems) & 18424 & 5521 & Mostly Central Valley and NW & Used as fodder \\
\hline $\begin{array}{l}\text { Sorghum (stalk, } \\
\text { stems) }\end{array}$ & 4400 & 1540 & $\begin{array}{l}\text { Tamaulipas, Guanajuato, } \\
\text { Michoacán }\end{array}$ & Used as fodder \\
\hline Sugar cane (tops) & 1786 & 1250 & $\begin{array}{l}\text { Tropical sub-humid and humid } \\
\text { areas: Veracruz, Michoacán, } \\
\text { Jalisco }\end{array}$ & Used as fertiliser \\
\hline Cotton (stalk) & 449 & 314 & NW Mexico & Used as fodder \\
\hline Oil palm (frond) & 246 & - & SE: Chiapas, Veracruz, Tabasco & Used as fertiliser \\
\hline Rice (straw) & 145 & 87 & Tabasco, Veracruz & Used as fodder \\
\hline Soybean (stalks) & 43 & 31 & Dispersed & Used as fodder \\
\hline Logging residues & 380 & 228 & $\begin{array}{l}\text { Temperate areas: Durango, } \\
\text { Chihuahua, Michoacán }\end{array}$ & $\begin{array}{l}\text { Used for } \\
\text { cellulose } \\
\text { production }\end{array}$ \\
\hline \multicolumn{5}{|c|}{ Secondary residues } \\
\hline $\begin{array}{l}\text { Sugar cane } \\
\text { (bagasse) }\end{array}$ & 6757 & - & $\begin{array}{l}\text { Tropical sub-humid and humid } \\
\text { areas: Veracruz, Michoacan, } \\
\text { Jalisco }\end{array}$ & $\begin{array}{l}\text { Used for energy } \\
\text { and heat }\end{array}$ \\
\hline Corn (cobs) & 1842 & 552 & SE, SW & $\begin{array}{l}\text { Used for energy } \\
\text { and heat }\end{array}$ \\
\hline Oil palm (EFB) & 32 & 32 & SE: Chiapas, Veracruz, Tabasco & \\
\hline Oil palm (fibres) & 12 & 2 & SE: Chiapas, Veracruz, Tabasco & \\
\hline $\begin{array}{l}\text { Peanut (shell)Oil } \\
\text { palm (shells) }\end{array}$ & 7 & 7 & n.a. & \\
\hline Oil palm (shells) & 4 & 4 & SE: Chiapas, Veracruz, Tabasco & \\
\hline Slabs and edgings & 1344 & 538 & $\begin{array}{l}\text { Temperate areas: Durango, } \\
\text { Chihuahua, Michoacán }\end{array}$ & \\
\hline Saw dust & 400 & 320 & $\begin{array}{l}\text { Temperate areas: Durango, } \\
\text { Chihuahua, Michoacán }\end{array}$ & \\
\hline
\end{tabular}




\section{Second-generation biofuel options}

Based on the biomass residues described above, the potential biofuel production and number of production plants can be defined. The calculations are based on actual material flows as well as unused residues and are, therefore, only a very gross and theoretical estimation. For every secondgeneration biofuel option, not all types of residues are considered suitable. However, since this is the aim of further development, all types of residues were considered suitable for every pathway in this analysis.

For Mexico, potential second-generation biofuel production as well as the potential number of conversion plants is higher based on primary residues than on secondary residues. The assessed amounts of residues could theoretically provide 16 small-scale BTL plants and 133 bio-SNG plants for primary residues, and 3 BTL and 24 bio-SNG plants for secondary residues (Table A38). Thus, considering second-generation biofuels production based exclusively on unused residues, Mexico could meet $2-4 \%$ of the projected transport fuel demand in 2030 by using BTL-diesel or bio-SNG.

Table A38. Potential second-generation biofuel production and number of plants

\begin{tabular}{|c|c|c|c|c|c|c|}
\hline & \multicolumn{4}{|c|}{ Production } & \multicolumn{2}{|c|}{$\begin{array}{c}\text { Number of plants (based } \\
\text { on unused residues) }\end{array}$} \\
\hline & \multicolumn{2}{|c|}{ Actual flow } & \multicolumn{2}{|c|}{ Unused residues } & \multirow[b]{2}{*}{ small scale** } & \multirow[b]{2}{*}{$\begin{array}{c}\text { large } \\
\text { scale** }\end{array}$} \\
\hline & million lge/yr* & $\mathrm{PJ} / \mathrm{yr}$ & $\begin{array}{l}\text { million } \\
\text { lge/yr* }\end{array}$ & $\mathrm{PJ} / \mathrm{yr}$ & & \\
\hline \multicolumn{7}{|c|}{ Based on primary residues } \\
\hline Bio-SNG & 7969 & 267.0 & 2464 & 82.5 & 133 & 18 \\
\hline BTL & 5614 & 188.1 & 1736 & 58.2 & 16 & 4 \\
\hline Bioethanol & 5535 & 185.4 & 1711 & 57.3 & 128 & 10 \\
\hline \multicolumn{7}{|c|}{ Based on secondary residues } \\
\hline Bio-SNG & 3203 & 107.3 & 448 & 15.0 & 24 & 3 \\
\hline BTL & 2256 & 75.6 & 316 & 10.6 & 3 & 1 \\
\hline Bioethanol & 2224 & 74.5 & 311 & 10.4 & 23 & 2 \\
\hline \multicolumn{7}{|c|}{ 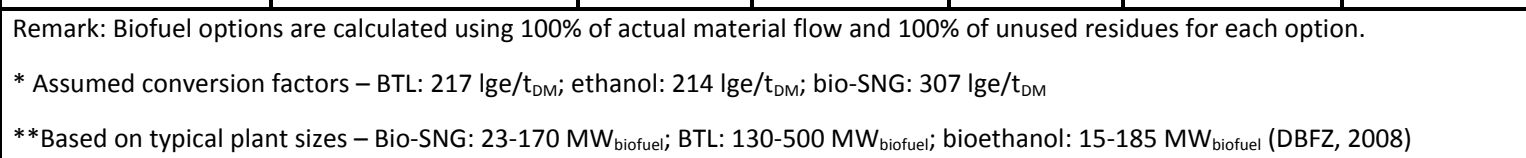 } \\
\hline
\end{tabular}

\section{Estimated costs for feedstock and end-product}

Feedstock costs of agricultural products are quite high in Mexico due to the low efficiency and comparatively high wages for agricultural workers. Sugar cane production costs and pro-rated costs for sugar tops and leaves as a feedstock for second-generation biofuels are higher than in the US. Maize production costs in peasant systems are also quite high (Ibarra, 2007). First-generation ethanol production costs are estimated to be USD $0.40-0.80 /$, depending on the feedstock 
(Martinez, 2006). For second-generation biofuels, prices for feedstocks range from USD $20 / \mathrm{t}_{\mathrm{FM}}$ (for logging chips) to USD 50/t $\mathrm{t}_{\mathrm{FM}}$ (for wheat straw).

Table A39. Theoretical second-generation production costs in Mexico

\begin{tabular}{|l|c|c|c|c|c|}
\hline Feedstock & \multirow{2}{*}{$\begin{array}{c}\text { Feedstock } \\
\text { price }\end{array}$} & \multicolumn{5}{|c|}{ oil USD 60/bbl } \\
& USD/t $\mathrm{t}_{\mathrm{FM}}$ & BTL-diesel & LC-ethanol & BTL-diesel & LC-ethanol \\
\hline & 50 & 0.74 & 0.79 & 0.52 & 0.51 \\
\hline Straw/stalks & 20 & 0.68 & 0.7 & 0.44 & 0.44 \\
\hline Forestry residues & & \multicolumn{5}{|c|}{ oil USD 120/bbl } \\
\hline \multicolumn{2}{|c|}{} & 0.92 & 0.89 & 0.6 & 0.55 \\
\hline Straw/stalks & 50 & 0.86 & 0.81 & 0.55 & 0.47 \\
\hline Forestry residues & 20 & &
\end{tabular}

Source: Based on IEA Mobility Model, 2009

As opposed to first-generation biofuel production, for which Mexico has limited competitiveness due to high feedstock costs, second-generation production could be more feasible. Due to the highly developed oil and gas industry, the country has deep experience in engineering technologies; moreover, transport prices are comparatively low due to the extensive road network and good infrastructure. Given that the biomass could be provided at low costs and in quite large amounts, conditions along the processing and distribution value chain are quite good in Mexico. The country is also well connected to export markets within NAFTA, which provides options to export biomass for second-generation biofuels.

Based on current IEA cost projections for second-generation biofuel production, theoretical values can be calculated for Mexico. According to the analysis, BTL-diesel could currently be produced for USD 0.68-USD 0.74/lge, whereas the costs for lignocellulosic ethanol are slightly higher at USD 0.700.79/lge (Table A39).

\section{Identification of "hot spots" for production plants}

Mexico is a crude oil-producing country without oil refining capacity, as a result of delayed investments; hence, it is a net importer of diesel and gasoline. Furthermore, its production of biofuels is negligible. On the biomass supply side, it has large amounts of agricultural residues, like straw from various crops, and bagasse from sugar cane in areas in the east near the Gulf of Mexico . Also short rotation coppices from eucalyptus in the south-east have high potential as a feedstock for second generation biofuels. On the demand side, there is the need to increase fuel production. But because Mexico has much experience in fuel production and good infrastructure in the production regions that includes ports close to important biofuel markets (i.e. the US), Mexico meets some important preconditions for second-generation biofuel production. The coastal region in the east by the Gulf of Mexico would appear to be a feasible hot spot for the production of second-generation biofuels. 


\section{Sustainability}

\section{Potential economic impact}

Even though Mexico is a net crude oil-exporting country ${ }^{19}$, second-generation biofuels production could help reduce expenditure for derivates imports. Mexico needs to import roughly $40 \%$ of its gasoline because of the lack of refinery capacity and thus spent some USD 22 billion for importing oil derivates and natural gas in 2008 (PEMEX, 2009). With roughly USD 6 billion in 2007, Mexico spent a considerable amount on supporting agricultural activities compared with other developing and emerging countries, such as USD 24 billion in the US and USD 134 billion in the EU (OECD, 2008f). Thus, adding value to agricultural by-products and residues through second-generation biofuels production could help reduce the necessity to support sugar cane growers and forestry communities in general. Currently there are special payments for jatropha plantations (USD 500/ha/yr) but the overall impact of specific biofuel-related subsidies on the national budget is quite limited (Rembio, 2009).

\section{Potential social impacts}

The potential for additional job creation through second-generation biofuels production in Mexico is high, at least at the agricultural or forestry level; for example, 0.005-0.3 person days/t could be realised in forestry for logging, crosscutting and piling (Rembio, 2009). The diversification of income through selling forestry by-products or residues would be especially beneficial for the 12 million people that live in or adjacent to forests in Mexico, since they are generally considered the poorest segment of the rural population (ITTO, 2005). The added value to forestry products could also reduce the high deforestation rate in Mexico, since deforestation often results from the absence of economic alternatives (Ibarra, 2007). Since sugar cane and maize are also cultivated in smallholder systems with low remuneration (158000 cane growers with an average of 4 ha), income diversification could help to reduce rural poverty in general and thus migration to cities from these less developed rural areas (Rembio, 2009; PNUD, 2007).

Eighty percent of Mexico's forests are part of the 8500 ejidos (communal lands), and thus the contractual and organisational challenges for the integration of these groups into woody feedstock production would be significant. Land ownership rights are not always clear, but impact on land issues is expected to be low since the share of private property has not increased in the past and forest lands in units above 1000 ha cannot be sold because they are considered communal property (El Mañana, 2009; Rembio, 2009).

As one safeguard to prevent competition between food and biofuel production, Mexico's Federal Ministry for Agriculture (Sagarpa) must authorise the use of corn for bioethanol production. The authorisation will be only given if national corn production results in a surplus, which is currently not the case (Cámara de Diputados, 2008c). This position is due to the increasing tortilla prices seen in 2008, which were partly attributed to increasing corn demand in the US for ethanol fuel and the reduction in US corn flour exports to Mexico. Mexico's government has since maintained a very cautious policy with regard to the use of food crops for bioenergy production.

\footnotetext{
${ }^{19}$ In 2008, Mexico exported 512 mn barrels of crude oil with a value of 43.3 bn USD (PEMEX, 2009).
} 


\section{Potential environmental impact}

There are no specific Ica-studies for second-generation biofuels in Mexico. In general, it must be considered that the use of sugar cane and maize straw in Mexico could lead to higher expenditures to achieve an equalised nutrient and humus balance, resulting in an increase in the environmental impact

Page | 156 of the feedstock production for second-generation biofuels. However, since $97 \%$ of dry straw is burnt before harvest and $50 \%$ of sugar cane tops and leaves are burnt after harvest, current contribution of cane residues to nutrient cycles is limited at present. Therefore, the removal of this biomass for secondgeneration biofuels would not significantly reduce nutrient contribution, which is currently limited to nutrients in the ash. The environmental impact of removing maize stalks would be low as well, since most of them are grazed or harvested to be used as fodder (Rembio, 2009).

\section{SWOT analysis}

Table A40. Summary of SWOT analysis

\begin{tabular}{|c|c|}
\hline STRENGTHS & $\begin{array}{l}\text { - High level of biodiversity; various plants, seeds, fruits, etc., or their by- } \\
\text { products/residues, could be used for second generation biofuels production } \\
\text { - Skilled engineers from gas and oil industries and top-level universities that could be } \\
\text { trained for second-generation conversion technologies } \\
\text { - Strong engineering industry with experience in energy technologies } \\
\text { - Good infrastructure (e.g. roads, electricity grid, and ports) for biomass and biofuel } \\
\text { transport } \\
\text { - Good financing conditions for investment in second-generation biofuel production } \\
\text { - General support from population for environmental policies and biofuel promotion }\end{array}$ \\
\hline WEAKNESSES & $\begin{array}{l}\text { - High import dependency on most agricultural products } \\
\text { - High biomass production costs; low global competitiveness in the agricultural sector } \\
\text { - Climate conditions unfavourable for energy crops in many regions } \\
\text { - No experience with first-generation biofuels production and distribution } \\
\text { - Low interest of state oil company PEMEX in biofuels production and distribution }\end{array}$ \\
\hline OPPORTUNITIES & $\begin{array}{l}\text { - Second-generation biofuels could reduce dependency on oil and gas production, the } \\
\text { levels of which are currently decreasing } \\
\text { - Alternative opportunities for engineering industries } \\
\text { - Income diversification in rural areas and for forestry communities; reduction of } \\
\text { migration flows } \\
\text { - Large export opportunities, since Mexico is well connected to and commercially } \\
\text { integrated into dynamic export markets (NAFTA) }\end{array}$ \\
\hline THREATS & $\begin{array}{l}\text { - Shift from food production to production of biofuel feedstocks } \\
\text { - Unequal distribution of benefits from second-generation biofuels production if } \\
\text { smallholders are not integrated into the entire value chain } \\
\text { - Pressure on native forest and communal lands (ejidos); increase of already high } \\
\text { deforestation rate }\end{array}$ \\
\hline
\end{tabular}




\section{Conclusions and recommendations}

Biomass availability for first-generation biofuels in Mexico is limited, since the country has to import large amounts of food and feed, and since the agricultural and forestry sectors are not very competitive. Residues such as sugar cane straw, maize straw and logging chips could be potential feedstocks for second-generation biofuels production, but regional distribution is not very concentrated. Due to recent developments on international food markets, the Mexican government is very cautious with the promotion of first-generation and even second-generation biofuels, so competing uses for residues (e.g. maize stalks) as fodder would have to be considered. Thus, the structural problems of Mexican agriculture (smallholding systems with low productivity) limit the potential for the provision of low-cost biomass.

On the other hand, Mexico has large financing and highly skilled human resources with deep experience in engineering technologies; these are important factors that could contribute to successful investment in second-generation biofuel technologies. Additionally, good infrastructure (e.g. road networks, the electricity grid, and ports) and proximity to interesting export markets through NAFTA could favour this development in Mexico. The Gulf of Mexico and to a minor extent the Pacific coast could be worthwhile locations for second-generation biofuel plants, since the refinery locations match areas where agricultural residues are available and favourable conditions exist for the cultivation of short rotation coppices.

Currently, promotion policies for biofuels are not yet well defined; moreover, the support of the state oil company, PEMEX, the most important actor in the fuel sector, for biofuel production is low. However, decreasing oil reserves and increasing needs to import petroleum derivates may change this position in the middle term. Thus, public policies will need to address these issues and focus on second-generation biofuels research, development, production and distribution. The policies would also have to balance the interests of the biomass providers (e.g. smallholders) with the biofuel producers and distributors, or at least try to integrate the biomass providers into the whole value chain to enhance social benefits for the poorest segments of the Mexican population. Thus, when formulating and implementing the biofuel policies, a stakeholder process assembling the actors to be involved would be particularly necessary for development of second generation biofuels since they imply major important contractual and logistical challenges. 


\section{A7 South Africa}

\section{General country characteristics}

\section{General description}

South Africa is regarded as the most developed country in sub-Sahara Africa. Its total area is about $1221040 \mathrm{~km}^{2}$. Despite being largely arid, it has large and successful commercial forestry and agriculture sectors. Ecologically, the country is classified into nine vegetation biomes, the most dominant of which are the Grassland biome, the Nama-Karoo biome, Savannah, Succulent Karoo and the Fynbos biome. South Africa has exceptionally high levels of biodiversity, much of it endemic, an important consideration when considering land conversion (Mucina and Rutherford, 2006; Cowling et al., 1997).

Table A41. General population information and economy indices

\begin{tabular}{|l|l|c|r|}
\hline Parameter & Unit & \multicolumn{1}{|l|}{ Value } & \multicolumn{1}{l|}{ Year } \\
\hline Population & million & 47.8 & 1.7 \\
\hline Population growth rate & $\%$ & 489.7 & 2009 \\
\hline GDP (PPP) & billion USD & 10007 \\
\hline GDP per capita (PPP) & USD/capita & 48 & 2008 \\
\hline Poverty rate & \% of total population & 0.67 & 2005 \\
\hline HDI & - & $<5$ & 2006 \\
\hline Undernourishment & \% of total population & 159.59 & 2005 \\
\hline Energy production & Mtoe & 134.59 & 2007 \\
\hline TPES & Mtoe & -21.86 & 2007 \\
\hline Net energy imports & Mtoe & 7.22 & 2006 \\
\hline $\mathrm{CO}_{2}$ emissions/capita & t CO $/$ capita & & \\
\hline
\end{tabular}

Sources: Stats SA, 2008; UNICEF, 2009; CIA, 2008; UNDP, 2007; IEA Statistics, 2009

South Africa's population is estimated to be about 47.8 million (Stats SA, 2008), which is distributed unevenly across the country in response to climatic conditions and the location of mineral resources, and as a relict of apartheid policies which designated $13 \%$ of land for black settlement (the so-called "homelands"). These rural areas, with customary tenure, have a disproportionally high population density compared to adjacent commercial farms.

GDP is approximately USD 489.7 billion (purchase price parity) (CIA, 2008). Of this, agriculture contributes only $2 \%$ and forestry contributes approximately $1 \%$, though backwards and forwards linkages to the agricultural sector bring its influence on GDP up to an estimated $15 \%$ (GCIS, 2009). 
By African standards, South Africa is a relatively prosperous country, with a GDP per capita of USD 10000 per year (CIA, 2008). Wealth is highly inequitably distributed. Rural and urban poverty is widespread, and areas of the ex-homelands ${ }^{20}$ in particular have high poverty and unemployment levels. Food security follows similar patterns to those of poverty. A large proportion of the poor are considered to have low food security, despite many of these people living in areas with untapped agricultural potential. A social security system which includes old-age pensions and child support grants plays a key role as a food security safety net.

South Africa's main energy source is coal, with a share of $71.2 \%$, followed by crude oil and biomass with $13.8 \%$ and $10 \%$ respectively (Figure $\mathrm{A} 8$ ) and smaller shares from nuclear, hydro and solar.

South Africa uses its extensive coal reserves to produce $91 \%$ of its electricity. In addition, to overcome a total reliance on imported oil, South Africa has developed synthetic fuel using coal-toliquid fuel and natural gas-to-liquid refineries using the Fischer-Tropsch (FT) process. Currently about $23 \%$ of liquid fuel is derived from coal, $5 \%$ from natural gas and $72 \%$ from imported crude oil (Winkler, 2006). Biomass, in the form of fuelwood, remains a key energy for rural communities. It is estimated that about $7 \mathrm{Mt}$ of wood is burned annually. A further $7 \mathrm{Mt}$ of bagasse (in the sugar industry) and wood waste (in the timber industry) is combusted for steam and in some instances electricity generation (Muller et al., 1999).

Figure A8. Total primary energy supply 2007.

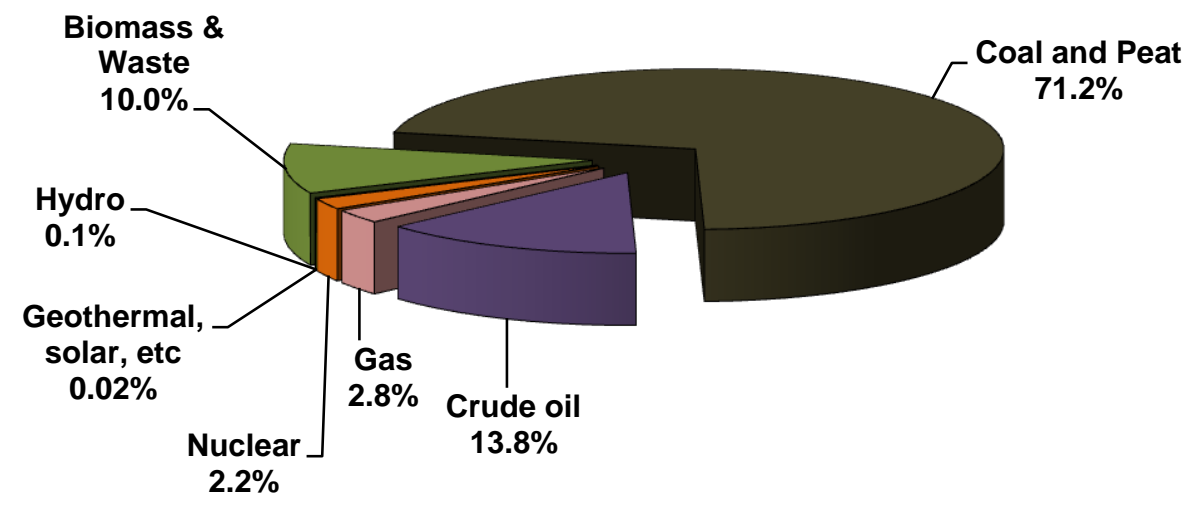

Total: 134.59 Mtoe (5.65 EJ)

IEA Statistics, 2009

\section{Natural conditions for biofuel feedstock production}

The western half of South Africa is too dry for rain-fed crop agriculture. As Figure A9 shows, most cropping occurs on the high-lying eastern part of the inland plateau or along the southern and eastern coastal belt. Forestry is largely on the eastern escarpment. Summer rainfall is affected by El Niño Southern Ocean events, resulting in multi-year periods of below- and above-average precipitation, so marginal areas for have the largest relative climatic extremes (Tyson, 1986). Timing of the onset of the rainy season varies greatly between seasons, and mid-season drought is common. The Western Cape is

\footnotetext{
${ }^{20}$ Homeland or Bantustan was the land dedicated to the black inhabitants during apartheid.
} 
a predominantly winter rainfall region with more predictable frontal rainfall. Climate change is anticipated to reduce rainfall in the west and increase rainfall in the east; thus, already-arid areas are likely to become more arid and variable in the future (Biggs et. al., 2004).

\section{Agriculture and forestry}

Between $12 \%$ and $14 \%$ of South Africa's $1221040 \mathrm{~km}^{2}$ land area is considered suitable for crops, but only $22 \%$ of this arable land is considered to have high potential. Just $1.5 \%$ (1.3 Mha) of arable land has irrigation potential (GCIS, 2009). The total agricultural land in 2007 covered 99.4 Mha (81\% of total land), mainly occupied by permanent meadows and pastures. Only $14.5 \%$ of the agricultural area is arable land, with roughly 5 Mha under crops (FAOStat, 2009).

Total forest area is 9.2 Mha, of which 1.3 Mha are used for plantation forestry in 2007 (Forestry South Africa, 2008). Water and biodiversity conservation constraints dictate that very little additional land can be made available for forestry. Permits for forestry expansion are currently only available for parts of the Eastern Cape and KwaZulu Natal (DWAF, 2006).

Figure A9. Agricultural and forestry production areas

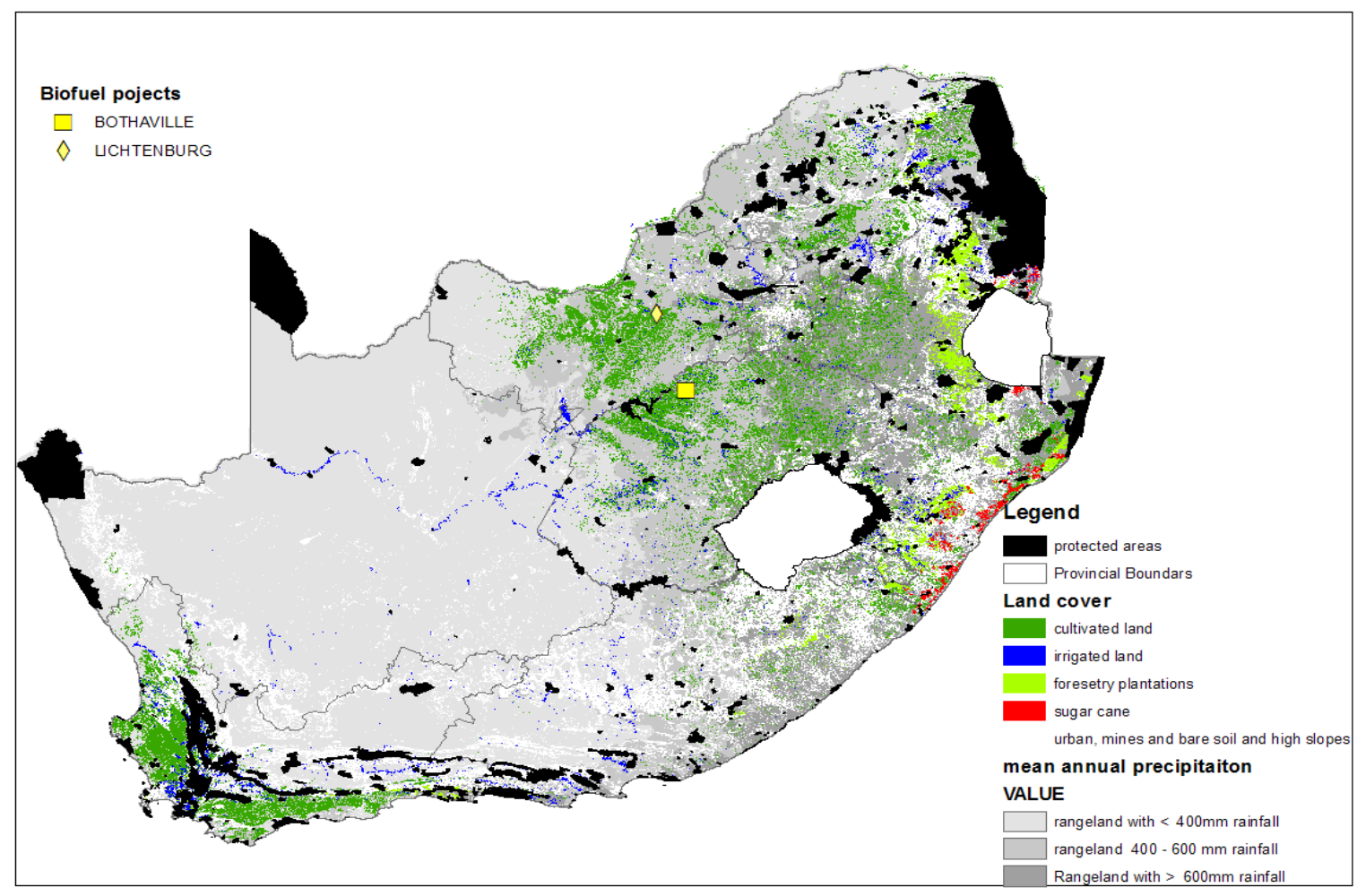

Source: Based on land cover (NLC 2000) with precipitation overlay. Areas of steep slopes, urban settlement and water bodies have been excluded. Areas that are not under conservation or crop are used for livestock or wildlife production.

The total area planted per crop has decreased for all grain crops over the past 30 years, largely due to improved yields (DoA, 2009); in addition, farmers have learned that a national surplus has devastating impacts on the profitability of farming. Aggregate long-term maize yield has fluctuated around the national demand level of $9 \mathrm{Mt}$, despite there being an agronomic potential for $12 \mathrm{Mt}$ (Makenete et al., 2007). It is therefore possible that 3 Mha or more could be brought back into 
production, but much of this is likely to be more-marginal lands and 2 Mha are located in the former homelands (DME, 2007; DoA, 2009). Bringing the land from the ex-homelands into commercial production will be difficult due to complex tenure issues, small land holdings and a history of failed agricultural development.

Most of the rural land that is not under either crop or forestry production, and is not in state conservation areas or subject to other proscribed uses, is used for livestock or wildlife ranching (71.99 Mha) (DoA, 2009). Many farmers have a joint crop and animal husbandry farming system in which waste from the crop farming is used as a feed supplement for the livestock.

Gross farm income for 2006/7 was ZAR 90965 million (USD 10829 million) with a net income of ZAR 28150 million (USD 3351 million). Field crops contributed ZAR 24308 million (USD 2894 million) and horticulture ZAR 22736 million (USD 2700 million) to the total, while livestock contributed the rest with ZAR 44749 million (USD 5330 million) (GCIS, 2009). The breakdown of field crops and forestry products is given in Table A42.

Table A42. Agricultural and forestry production 2007

\begin{tabular}{|c|c|c|c|c|c|c|}
\hline \multicolumn{5}{|c|}{$\begin{array}{c}\text { Agricultural Production } \\
\text { (n.b.: this was a drought year so maize yields were low) }\end{array}$} & \multicolumn{2}{|c|}{ Forestry Production } \\
\hline & $\begin{array}{c}\text { Area } \\
(1000 \text { ha })\end{array}$ & $\begin{array}{l}\text { Proportion of } \\
\text { crop area (\%) }\end{array}$ & $\begin{array}{l}\text { Production } \\
\text { (1000t) }\end{array}$ & $\begin{array}{l}\text { Yield } \\
\text { (t/ha) }\end{array}$ & Product & $\begin{array}{l}\text { Quantity } \\
\left(1000 \mathrm{~m}^{3}\right)\end{array}$ \\
\hline Maize & 2897 & 54.1 & 7339 & 2.5 & Roundwood & 30063 \\
\hline Wheat & 632 & 11.8 & 1820 & 2.9 & $\begin{array}{l}\text { Industrial } \\
\text { roundwood }\end{array}$ & 18063 \\
\hline Sugar Cane & 423 & 7.9 & 20693 & 48.9 & Wood Fuel & 12000 \\
\hline $\begin{array}{l}\text { Sunflower } \\
\text { seeds }\end{array}$ & 316 & 5.9 & 312 & 1 & $\begin{array}{l}\text { Paper and } \\
\text { paperboard* }\end{array}$ & 3033 \\
\hline Soyabeans & 183 & 3.4 & 205 & 1.1 & Sawnwood & 2091 \\
\hline Barley & 73 & 1.4 & 213 & 2.9 & Wood pulp* & 1862 \\
\hline Grain sorghum & 69 & 1.3 & 202 & 2.9 & $\begin{array}{l}\text { Wood-based } \\
\text { panels }\end{array}$ & 786 \\
\hline Dry bean & 51 & 1 & 44 & 0.86 & \multirow{2}{*}{\multicolumn{2}{|c|}{$* 1000 \mathrm{t}$}} \\
\hline Groundnuts & 41 & 0.8 & 66 & 1.6 & & \\
\hline Cotton & 11 & 0.2 & & & \multirow{2}{*}{$\begin{array}{l}\text { Total forest area } \\
(1000 \mathrm{ha})\end{array}$} & \multirow[b]{2}{*}{9203} \\
\hline Total & 5352 & & 40543 & . & & \\
\hline
\end{tabular}

Sources: FAOStat, 2009

The South African farming sector can be divided into a large, well-managed commercial farming sector on private (freehold) land, and a much smaller "subsistence farmer" sector in the exhomelands on land that is held under customary tenure. The commercial farming sector occupies about $80 \%$ of the agricultural land, the subsistence farming sector $13 \%$, with most of the balance in 
conservation. Most subsidies and protection for the commercial sector were dropped after 1994. There are political ambitions to improve the small-scale "subsistence" sector, but to date little real progress has been made. Biofuels have been promoted as one strategy to bring about this change. Two industrial crops - sugar cane and timber - are also grown in the ex-homelands using an outgrower model where the industry assists small growers in their agricultural or forestry initiatives.

Page | 162 A land reform process is under way in South Africa. It has three components: a restitution process that restores land alienated from black communities during the apartheid period; a redistribution process based on a willing-buyer-willing-seller model; and in addition, tenure in the ex-homelands is being reformed. The intent is to transfer $30 \%$ of freehold land to emerging black farmers by 2015 , but to date progress has been slow (Hall, 2004). Furthermore, ongoing land reform has placed great uncertainty on current farmers who are reluctant to invest in capital expenditure when there is uncertainty over their long-term tenure security.

\section{Current situation of biofuel development}

\section{Current production of biofuels}

South Africa has a long history of bioethanol production. Sugar cane-derived ethanol was blended with petrol from the 1920s until the early 1960s. This practice stopped for economic reasons - it was cheaper to import fossil fuel. Interest in biofuels has been rekindled in the past few years as a consequence of rising oil prices. The maize sector in particular was very keen on biofuel as a mechanism for stabilising prices and expanding the maize market.

Currently, biofuel effectively provides no contribution to the liquid fuel consumed overall. The only biofuel currently consumed comes from small refineries and is mostly used on-farm by the producers. A small quantity of biodiesel is produced from recycled cooking oil. The few small projects where farmers produce biofuels for their own use are mainly focussing on biodiesel from oil seed crops, but one farmer is also producing small quantities of first-generation ethanol from Johnson grass (Sorghum halepense). In addition, a small-scale bioethanol project (1 $000000 \mathrm{l} / \mathrm{year}$ ) currently produces bioethanol from maize for the production of ethanol gel used in low-cost cooking stoves. It is possible they may change to sorghum in the future as a consequence of the National Biofuel Strategy not supporting maize as a feedstock. A project has been initiated in Limpopo province which assists emerging farmers with producing oil seeds for biodiesel off 10 ha plots (Adams et al., 2009), but they do not yet have a processing facility; the seed produced is sold into the food market. Six large-scale ethanol plants were proposed to be established in Bothaville in the Free State, using maize as a feedstock. These projects have been put on hold due to the national biofuel strategy not supporting biofuels from maize. Jatropha is also excluded from the strategy due to concerns over its potential invasiveness. Large-scale canola projects are proposed for 500000 ha in the Eastern Cape, but this project is still in the planning phase (Makenete et al., 2007).

\section{National policy target for biofuels}

The South African Biofuel Strategy was launched in December 2007, after lengthy consultation and deliberation (DME, 2007). The South African government reduced its targets for biofuel from $4.5 \%$ of liquid fuel consumption, suggested in the draft strategy, to a five-year target of $2 \%$. The South African biofuels strategy is very specific that biofuel production is primarily about rural development, and in particular is to be used to bring emerging black farmers into the commercial 
farming fold. The strategy recognises that second-generation biofuels might be very important, but due to current uncertainties simply recommends that ongoing research should be continued in this direction. Targets are not mandatory, and there is concern that the petroleum industry may be reluctant to undertake the blending. The feedstocks proposed in the biofuel strategy include sugar cane, soya, peanuts and sunflower (DME, 2007).

Currently South Africa exports $50 \%$ of the sugar it produces (GCIS, 2009). It is therefore feasible to divert sugar to biofuel without a negative consequence on local food security. The biofuel strategy, however, requires feedstock to come from new land and through black economic empowerment (DME, 2007). It is therefore most likely that sugar-based biofuel will be sourced from new rather than existing sugar cane plantations; three such projects are currently under consideration. Existing sugar milling infrastructure is well established. Most of the bagasse is burned as a fuel, with a small amount used as livestock fodder.

\section{Financing and human resources}

As an emerging market, South Africa is particularly exposed to international trends relating to investment and perceived risk. It has, however, proved itself to be a relatively stable investment environment for foreign investors and currently has an A2/Baa1 investment rating from Moody's and a BBB+ investment rating from Fitch. South Africa has fared better than most countries during the current global recession, thanks to a well-managed and well-regulated banking sector and sound economic fundamentals. The inflation targeting policy of the reserve bank has kept the currency strong.

South Africa has substantial qualified human resources, particularly in the private sector. This includes extensive forestry, agricultural and engineering expertise. The country has a high level of unemployment, and unskilled labour is plentiful but relatively expensive by developing world standards. Stringent labour regulations prevent bad labour practices, but are sometimes considered restrictive by industry.

\section{Infrastructure}

IEA fuel consumption figures for South Africa are given in Table A44. Diesel consumption is marginally higher than gasoline use, and this ratio may well remain in the future as diesel cars become more common and as the mini-bus taxi industry (which uses $15 \%$ of liquid fuel) replaces current gasoline-powered vehicles with slightly larger diesel powered buses. It is estimated that there were about 14.1 million registered motor vehicles in 2006. Table A43 shows the share of different vehicle types.

Table A43. Vehicle fleet in 2006

\begin{tabular}{|r|l|l|l|l|l|l|r|}
\hline Motorcycles & LDV & PC+SUV & LCV's & MDT's & HDT's & Buses & Minibuses \\
\hline 376702 & 6578624 & 4890206 & 1688418 & 110000 & 260000 & 40000 & 270000 \\
\hline
\end{tabular}

PC: Passenger car; SUV: Sport utility vehicle; LCV: Light commercial vehicle; LDV: Light duty vehicle; LT: Light truck; MDT: Medium duty truck; HDT: Heavy duty truck

Source: IEA Mobility Model, 2009 
The main fuel consumed in South Africa is diesel (487 PJ), derived from coal-to-liquid synthesis, followed by gasoline (362 PJ), and a small share of Natural Gas (9 PJ) (Table A44).

Table A44. Fuel consumption in 2007 and projection for 2030

\begin{tabular}{|c|c|c|c|c|}
\hline & $\begin{array}{c}\text { Gasoline } \\
1000 \mathrm{t}(\mathrm{PJ})\end{array}$ & $\begin{array}{c}\text { Diesel } \\
1000 \mathrm{t}(\mathrm{PJ})\end{array}$ & $\begin{array}{c}\text { Natural Gas } \\
1000 \mathrm{t}(\mathrm{PJ})\end{array}$ & $\begin{array}{c}\text { Biofuels } \\
1000 \mathrm{t}(\mathrm{PJ})\end{array}$ \\
\hline $\mathbf{2 0 0 7}$ & $8214(362)$ & $11501(487)$ & $(9)$ & 0 \\
\hline $\mathbf{2 0 3 0 *}$ & $11309(498)$ & $7856(337)$ & n.a. & n.a. \\
\hline
\end{tabular}

Source: IEA Statistics, 2009; *Assumption based on WEO 2008 data, assuming linear growth in each sector

Based on developing world and Africa standards, South Africa has superb transport infrastructure, including seven harbours with a total of 16 terminals and 65 berths (Ndlovu, 2007). The rail system has deteriorated somewhat, but still connects major centres relatively efficiently. South Africa has an extensive road infrastructure, though the road infrastructure in the ex-homelands - the area suggested for first-generation biofuel expansion - is underdeveloped in some places (NDT, 2001). The country is also serviced by modern telecommunication and banking sectors.

\section{Feedstock assessment and logistics}

\section{Feedstock and cultivation area}

South Africa's agricultural and forestry sector are both constrained due to the country's arid climate and variable rainfall. Therefore, the expansion potential of both sectors, while existent, is fairly limited. However, potential exists for the utilisation of agricultural residues for biofuel production, as well as the cultivation of lignocellulosic feedstocks on surplus land. Nevertheless, virtually all crops and their residues are currently used in some way, as indicated in Table A45. Their use for biofuels will therefore compete with alternative uses, and the economics of alternatives must to be considered.

The main food crop cultivated in South Africa is maize, covering more than $60 \%$ ( $3.7 \mathrm{Mha}$ ) of the total area under grain crop cultivation. In addition, a further potential 3 Mha of maize could be grown, provided this additional land was not utilised for an alternative crop such as a dedicated biofuel crop (see above). Given current market and economic limitations to maize expansion, it is possible that dedicated energy crops may give better returns.

Maize stover and wheat straw are currently used as fodder for domestic livestock or left on the field as a soil-enhancing mulch. Wheat straw is also used to a lesser extent for pulping and heat generation purposes. About $90 \%$ of the sugar cane tops and leaves are currently burnt when harvested (Hurly et al., 2003) which could potentially contribute to biofuel production. Agricultural residues have some potential, but the large spatial extent of the production area, coupled with the relatively low yield per hectare, make transportation a major cost consideration.

South Africa produces about $112 \mathrm{kt}$ of peanuts per year that are mainly shelled at the processing plants, a distinct advantage when considering the shells as a potential feedstock. Currently the shells are mainly composted. 
As a further processing residue, sugar cane bagasse is considered suitable for second-generation biofuel production. Currently the bagasse is mainly used for steam generation and to a lesser extent as fodder and as feedstock for pulping. Though the sugar cane area is expected to grow in the future, additional residues are most likely burned for heat and electricity production. The cost of the feedstock was assumed the same as the price currently paid for Johnson grass, i.e. USD 13/t.

Forest residues left after logging are potentially available for biodiesel production. The total plantation area is 1.3 Mha. An additional area of 120000 ha (about 9\% increase in current plantation area) was considered (EDCD, n.d.). A yield of forest residue of 2-2.3 t/ha was assumed based on the total amount of forest residue calculated to be produced after logging (Muller et al., 1999). The residues are currently mainly left in the field for nutrient cycling or are used as fuel wood; a total cost of USD 9.45/dt was assumed and includes harvesting and recovery costs.

The amount of residue from saw and pulp mills equates to about $4.4 \mathrm{t} / \mathrm{ha}$ for sawmills and $7.9 \mathrm{t} / \mathrm{ha}$ for the pulp industry. This translates to a maximum of about 1.5 t/ha when using 671292 ha planted to pulpwood. Currently, most of the waste is used for steam generation and therefore only $10 \%$ of the residues could be used for biofuel production.

The garden waste proportion of the total amount of municipal waste put into landfills includes leafs, bark, twigs, small branches, grass clippings, prunings, flowers, and weeds. Currently only one site (Panorama) in the Johannesburg area is dedicated to the dumping and composting of garden waste. Timber from trees logged and disposed of in landfills is mainly recovered by the informal sector and used as firewood.

Table A45. Assessment of residues from forestry and agriculture

\begin{tabular}{|c|c|c|c|c|c|}
\hline Type & $\begin{array}{c}\text { Actual } \\
\text { material flow } \\
\left(1000 t_{\mathrm{DM}} / \mathrm{yr}\right)\end{array}$ & $\begin{array}{c}\text { Unused } \\
\text { residues } \\
\left(1000 \mathrm{t}_{\mathrm{DM}} / \mathrm{yr}\right)\end{array}$ & $\begin{array}{l}\text { Feedstock } \\
\text { cost } \\
(\mathrm{USD} / \mathrm{t})\end{array}$ & $\begin{array}{l}\text { Regional } \\
\text { Availability }\end{array}$ & $\begin{array}{c}\text { Main } \\
\text { utilisation }\end{array}$ \\
\hline \multicolumn{6}{|c|}{ Primary Residues } \\
\hline Wheat straw & 3027 & n.a. & $13-50$ & $\begin{array}{l}\text { Western Cape } \\
(43 \%) ; \text { Free State } \\
(27 \%)\end{array}$ & $\begin{array}{l}\text { Nutrient } \\
\text { cycling, } \\
\text { fodder, fuel }\end{array}$ \\
\hline Maize stover & 8100 & n.a. & $13-50$ & $\begin{array}{l}\text { Free State (33\%), } \\
\text { North West } \\
(30 \%), \\
\text { Mpumalanga } \\
(21 \%)\end{array}$ & $\begin{array}{l}\text { Fodder, } \\
\text { nutrient } \\
\text { cycling }\end{array}$ \\
\hline $\begin{array}{l}\text { Sugar cane } \\
\text { tops and } \\
\text { leaves }\end{array}$ & 3836 & 384 & $8-10$ & KwaZulu (83\%) & $\begin{array}{l}90 \% \text { are } \\
\text { currently } \\
\text { burned in the } \\
\text { field }\end{array}$ \\
\hline $\begin{array}{l}\text { Forestry } \\
\text { logging } \\
\text { residues }\end{array}$ & 6700 & n.a. & $9-10$ & $\begin{array}{l}\text { Mpumalanga } \\
(49 \%), \text { KZN (29\%), } \\
\text { Eastern Cape } \\
(12 \%)\end{array}$ & $\begin{array}{l}\text { fuelwood, } \\
\text { nutrient } \\
\text { cycling }\end{array}$ \\
\hline
\end{tabular}




\begin{tabular}{|c|c|c|c|c|c|c|}
\hline & Type & $\begin{array}{c}\text { Actual } \\
\text { material flow } \\
\left(1000 t_{D M} / y r\right)\end{array}$ & $\begin{array}{c}\text { Unused } \\
\text { residues } \\
\left(1000 t_{D M} / y r\right)\end{array}$ & $\begin{array}{l}\text { Feedstock } \\
\text { cost } \\
(U S D / t)\end{array}$ & $\begin{array}{l}\text { Regional } \\
\text { Availability }\end{array}$ & $\begin{array}{c}\text { Main } \\
\text { utilisation }\end{array}$ \\
\hline & \multicolumn{6}{|c|}{ Secondary Residues } \\
\hline \multirow[t]{6}{*}{ Page | 166} & $\begin{array}{l}\text { Sugar cane } \\
\text { bagasse }\end{array}$ & 5985 & 598 & $7.3-8.4$ & $\begin{array}{l}\text { KwaZulu (83\%), } \\
\text { Mpumalanga } \\
(17 \%)\end{array}$ & $\begin{array}{l}90 \% \text { are } \\
\text { currently } \\
\text { burned to } \\
\text { produce Heat } \\
\text { and electricity }\end{array}$ \\
\hline & Peanut shells & 37 & 18 & n.a. & $\begin{array}{l}\text { North West } \\
(46 \%), \text { Free State } \\
(32 \%), \text { Northern } \\
\text { Cape }(16 \%)\end{array}$ & $\begin{array}{l}\text { Assumed } \\
\text { about } 50 \% \text { is } \\
\text { used for } \\
\text { composting }\end{array}$ \\
\hline & $\begin{array}{l}\text { Forestry } \\
\text { processing } \\
\text { residues }\end{array}$ & 2289 & 229 & $0.7-1$ & $\begin{array}{l}\text { Mpumalanga } \\
(49 \%), \text { KZN (29\%), } \\
\text { Eastern Cape } \\
(12 \%)\end{array}$ & $\begin{array}{l}90 \% \text { are } \\
\text { assumed to be } \\
\text { used for } \\
\text { electricity } \\
\text { generation }\end{array}$ \\
\hline & $\begin{array}{l}\text { Pulp \& paper } \\
\text { industry, } \\
\text { mainly black } \\
\text { liquor }\end{array}$ & 5310 & 531 & $0.7-1$ & $\begin{array}{l}\text { KZN }(72 \%), \\
\text { Mpumalanga } \\
(25 \%)\end{array}$ & $\begin{array}{l}90 \% \text { are } \\
\text { assumed to be } \\
\text { used for } \\
\text { electricity } \\
\text { generation }\end{array}$ \\
\hline & Garden waste & 41 & 41 & $20-26$ & $\begin{array}{l}\text { mainly } \\
\text { Johannesburg, } \\
\text { Cape Town, } \\
\text { Pretoria, } \\
\text { Bloemfontein, } \\
\text { and Durban }\end{array}$ & $\begin{array}{l}\text { Disposed with } \\
\text { other solid } \\
\text { waste, partly } \\
\text { composted }\end{array}$ \\
\hline & MSW timber & 324 & n.a. & $20-26$ & same as above & $\begin{array}{l}\text { collected by } \\
\text { informal } \\
\text { sector as fuel } \\
\text { wood }\end{array}$ \\
\hline
\end{tabular}

Sources: DoA, 2009; Demirbas, 2004; Muller et al., 1999; Grasoline South Africa, 2009; Kluyts et al., 2007; Pordesimo et al., 2004; DME, 2005; Sezela Cane Growers' Association, n.d.; DME, 2004; Meyer and Rusk, 2003; Forestry South Africa, 2008; DWAF, 2008

If additional land was made available for forestry, then short rotation coppice of Eucalyptus, Wattle or other tree species could theoretically be grown for dedicated second-generation biofuel production. But even though about 120000 ha in the Eastern Cape are potentially available for additional plantations (ECDC, n.d.), it is unlikely that they would be dedicated to energy production under current economic conditions. The forest industry currently has a shortage in hardwood supply, amounting to nearly 2 Mt of pulpwood in 2004/2005 (Forestry South Africa, 2007); therefore, additional forest plantations would more likely be dedicated to meet the existing shortage in pulpwood supply than to produce biofuels. 
Another potential source for lignocellulosic feedstock is the perennial cultivation of Johnson grass (Sorghum halepense) and indigenous grasses on grasslands and savannahs that are currently accounting for about 5.2 Mha, with biomass yields ranging from 0.3-6.0 t/ha (average 1.25 t/ha) (Muller et al., 1999). A conservative $12.5 \%$ in the higher yielding areas has been deemed suitable for harvest, but this is not based on rigorous empirical data. Preliminary research showed Johnson grass to be a potential feedstock for biofuel production in South Africa due to its relatively high annual yields (18-24 t/ha) (Grasoline South Africa, 2009). However, the potential for fast-growing grasses is considered as relatively limited due to two factors: the first is the lack of available areas with relatively good soils and rainfall, which would result in direct competition with agricultural crops; the second is strong environmental resistance to this type of expansion due to concerns over invasiveness.

Besides the possible cultivation of natural grasslands, the possibility exists to grow dedicated biofuel crops on the 3 Mha of currently unused agricultural land. This area could potentially be used for different food or bioenergy crops. Though poorly researched for South African conditions, sweet sorghum (Sorghum bicolor) is currently the most likely contender and could produce feedstock for both, first and second generation biofuels. It could additionally also provide grain and fodder and thus increase food security.

A further potential source for lignocellulosic feedstock under the South African conditions, are invasive woody plants. Approximately 18 Mha of South Africa's total surface area is infested by alien vegetation (mainly woody biomass) amounting to a total of 120 million tons available for harvesting over a 20 year period (Muller et. al. 1999). The costs of harvesting this material would be subsidised through public works programs engaged in clearing the alien vegetation. In addition farmers are keen to clear areas where indigenous woody biomass (biushes) is growing on pastures with negative effects on the grazing potential and costs for grass.

\section{Second-generation biofuel options}

Based on the biomass residues described above, the potential biofuel production and number of production plants can be defined.

The calculations are based on actual material flows as well as unused residues and represent only a theoretical estimation. Based on the amount of unused residues, even if all unused residues were converted into second-generation biofuel, only a minor share of South Africa's current fuel demand could be covered. Considering that fuel demand is expected to grow, significant new feedstock sources would be needed if second-generation biofuels were to play a considerable role in the domestic transport sector. 
Table A46. Potential second-generation biofuel production and number of plants

\begin{tabular}{|c|c|c|c|c|c|c|c|c|}
\hline \multirow[b]{3}{*}{$\begin{array}{l}\text { Biofuel } \\
\text { option }\end{array}$} & \multicolumn{4}{|c|}{ Production } & \multicolumn{4}{|c|}{ Number of plants } \\
\hline & \multicolumn{2}{|c|}{ Actual material flow } & \multicolumn{2}{|c|}{ Unused residues } & \multicolumn{2}{|c|}{$\begin{array}{c}\text { Actual material } \\
\text { flow }\end{array}$} & \multicolumn{2}{|c|}{ Unused residues } \\
\hline & million $\mathrm{I}_{\mathrm{ge}} / \mathrm{yr} *$ & $\mathrm{PJ} / \mathrm{yr}$ & million $\mathrm{I}_{\mathrm{ge}} / \mathrm{yr} *$ & $\mathrm{PJ} / \mathrm{yr}$ & $\begin{array}{c}\text { Small } \\
\text { scale** }\end{array}$ & $\begin{array}{l}\text { Large } \\
\text { scale** }\end{array}$ & $\begin{array}{c}\text { small } \\
\text { scale** }\end{array}$ & $\begin{array}{l}\text { Large } \\
\text { scale** }\end{array}$ \\
\hline \multicolumn{9}{|c|}{ Based on primary residues } \\
\hline Bio-SNG & 4680 & 156.8 & 375 & 12.6 & 252 & 34 & 20 & 3 \\
\hline BTL & 3297 & 110.4 & 264 & 8.9 & 30 & 8 & 2 & 1 \\
\hline Bioethanol & 3251 & 108.9 & 261 & 8.7 & 244 & 20 & 20 & 2 \\
\hline \multicolumn{9}{|c|}{ Based on secondary residues } \\
\hline Bio-SNG & 2209 & 74.0 & 225 & 7.5 & 119 & 16 & 12 & 2 \\
\hline BTL & 1556 & 52.1 & 158 & 5.3 & 14 & 4 & 1 & 0 \\
\hline Bioethanol & 1534 & 51.4 & 156 & 5.2 & 115 & 9 & 12 & 1 \\
\hline \multicolumn{9}{|c|}{ 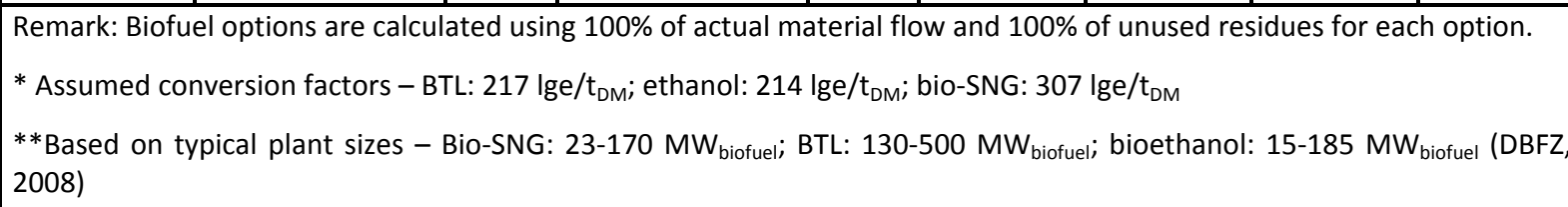 } \\
\hline
\end{tabular}

\section{Estimated costs for feedstock and end product}

Processing residues are the most favourable feedstock source since they are concentrated at the processing site and available for relatively low costs. However, these residues are often already in use and the value of current utilisation defines the feedstock costs; therefore, only indicative values can be given. The price of sawmill residues was assumed to be around USD $0.7 / t$, while a recovery cost (i.e. not market price) of USD 26/t was estimated for garden waste (Wit, 2009). Primary agricultural residues are estimated to be USD 9/t for sugar cane residues and USD 13.4-50.0/t for straw or stover. The feedstock costs depend on their current value as fodder, pulping material or fuel.

Harvesting of indigenous grass from select high rainfall areas has potential, but is subject to the same low yield per hectare transport-related constraints as agricultural residue. The relative aridity of South Africa means that biomass resources, whether agricultural residues, natural grass or savannah trees, though large in total amount, are distributed over large areas with a low production level per hectare, which will make large transportation distances inevitable.

Based on the indicated feedstock costs and current IEA analysis of second-generation biofuel production costs, South Africa has potential for low-cost biofuel production. However, some of the feedstock costs are assumptions due to a lack of market data. Therefore, prices might in fact be higher than currently assumed. According to the analysis, second-generation biofuels could currently be produced at costs ranging from USD 0.55 to USD 0.79/Ige (Table A47). 
Table A47. Theoretical second-generation biofuel production costs in South Africa

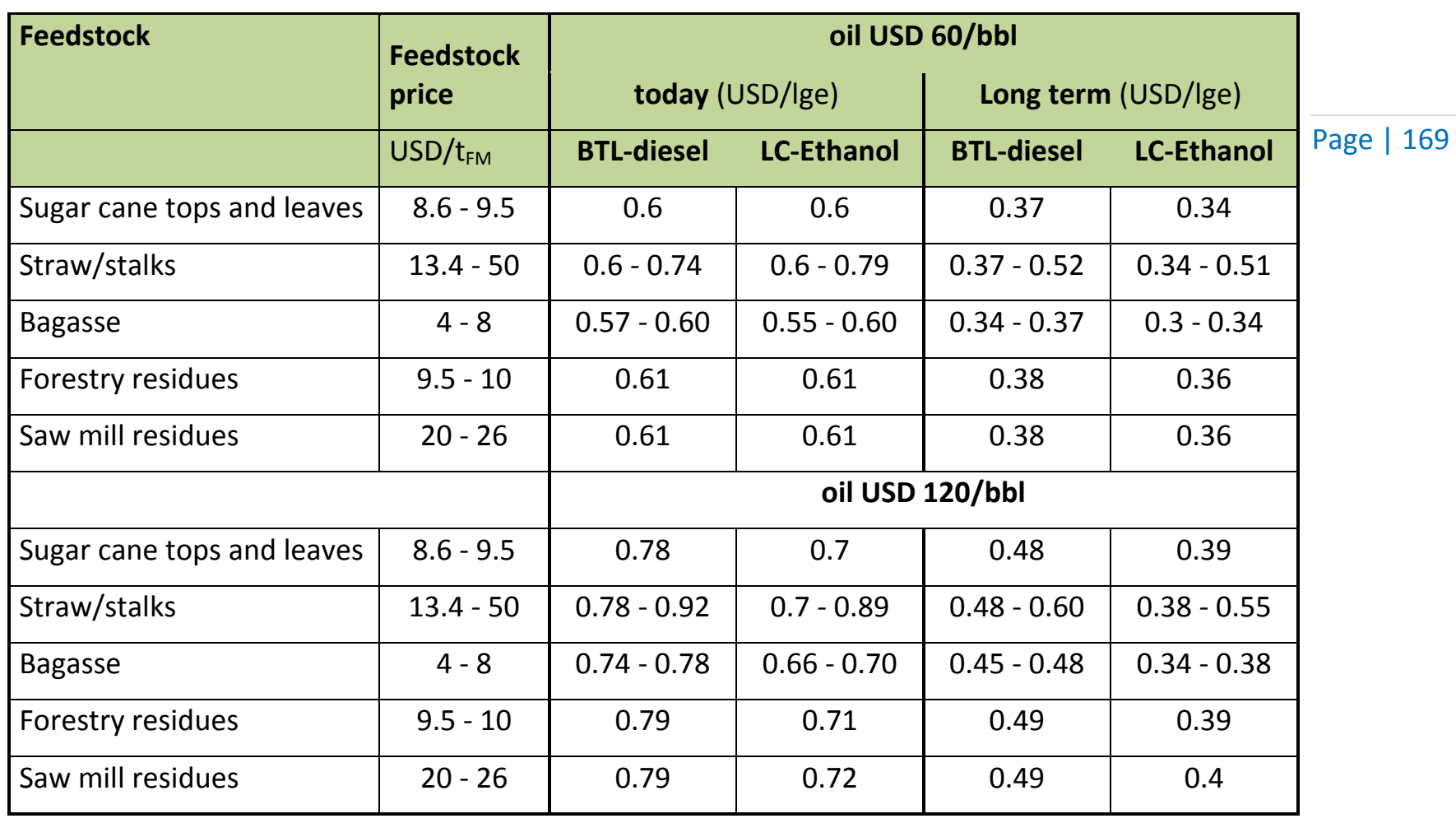

Source: based on IEA Mobility Model, 2009

\section{Sustainability}

\section{Economic impact}

At this stage there are no data on the financial requirements for a competitive second-generation biofuels industry. Key uncertainties include the future cost of crude oil and the cost of production of second-generation biofuels based on the locally available feedstocks. It was suggested that a firstgeneration bioethanol production would be financially viable at crude oil prices of more than USD 65 per barrel (NBTT, 2006), and second-generation biofuels would require even higher oil prices to be competitive. The biofuel strategy recommends a $100 \%$ rebate on the current fuel tax of petroleum for bioethanol, and a 50\% rebate for biodiesel (DME, 2007).

Job opportunities from first-generation biofuels have been computed for South Africa. An E8/B2 blend was anticipated to create 55000 job opportunities (NBTT, 2006). No such study has been undertaken for second-generation biofuels. If biofuels use crop residues from existing agriculture, the job creation benefits will be modest compared to those envisaged from first-generation biofuels, and would largely be limited to jobs in new refineries. However, if additional agricultural land is brought into production to meet biofuel needs, then the job creation potential is large. Agriculture accounts for $8 \%$ of formal jobs, despite contributing less than $3 \%$ of GDP (GCIS, 2009).

Additional income to farmers from second-generation biofuel production will be dependent on the market price for feedstock. The opportunity costs will be the difference between the selling price of biofuel feedstock and the alternative value derived from the feedstock. Transportation costs could 
greatly reduce this value. The most favourable feedstocks are sawdust, surplus bagasse and municipal waste that are already accumulated at the processing side. However all of those are in part already used.

Seven million metric tons of bagasse are currently burnt to fuel the energy needs of sugar mills, though this is done in an inefficient manner. With changing legislation (e.g. the renewable energy

Page | 170 feed-in tariffs), mills will have the option to sell surplus electricity to the national grid and may choose to increase the amount of bagasse burnt. The economics of electricity sales versus biofuel production will determine which use will be more profitable in the future.

\section{Social impact}

Increasing rural job opportunities is a key national priority. The South African biofuel strategy is clear that this is the main driver for biofuel expansion in South Africa. Stabilising and expanding existing commercial farming activities is a key concern to the commercial agricultural sector, but from the government's perspective, it is the development of a black farming sector that is the primary concern. Biofuels are therefore seen as being potentially beneficial in meeting both these development objectives. The success of the small-grower forestry and sugar projects would seem to indicate that where an industrial sector is prepared to invest heavily in promoting and supporting smallholder rural development, positive benefits can be achieved. However in both these sectors it is the large-scale producers that remain the core of the production model, with the small-scale producers only providing $10-20 \%$ of the feedstock.

There are potential concerns that if large-scale feedstock production is undertaken in the exhomelands, negative social consequences could result due to the current insecurity of tenure. Though some individuals may clearly benefit from such initiatives, it is also likely that many of those currently receiving benefits from the land could lose these benefits.

\section{Environmental impact}

South Africa's impressive biodiversity has high economic value through tourism, the production of exotic niche crops and traditional medicines. In addition, less easily monetised ecosystem services such as catchment hydrology are based on biodiversity. Two impacts are of special concern regarding second-generation biofuels. The first is biodiversity impacts resulting from the conversion of natural land to cropland. The second is the potential invasiveness of new crops. The very characteristics that are considered favourable for second-generation biofuels (such as rapid growth rates and the ability to establish easily) are also the characteristics of invasive species. As a waterlimited country, South Africa is exceptionally concerned about water availability. Deep-rooted, perennial, fast-growing tree species in particular have been shown to have a highly negative impact on the water yield from catchments.

The grasslands of South Africa are already extensively transformed for forestry and agriculture. Climate change is predicted to shrink the current area of grasslands. Conservation of the remaining grasslands is therefore a high priority. One consequence is that even in catchments where there is the potential to expand forestry due to the availability of water permits, or increase the area of crop agriculture due to the presence of suitable climate and soils, there is likely to be strong opposition based on biodiversity concerns (Rutherford et al., 1999). 
There is a strong civil society environmental lobby in South Africa. One of its concerns relates to the unsustainability of high-input agriculture in general, and mono-cropped biofuels in particular. Part of this concern is the anticipated high use of fertiliser and pesticide, which have a large environment footprint.

\section{SWOT analysis}

Table A48. Summary of SWOT analysis

\begin{tabular}{|c|c|}
\hline STRENGHTS & 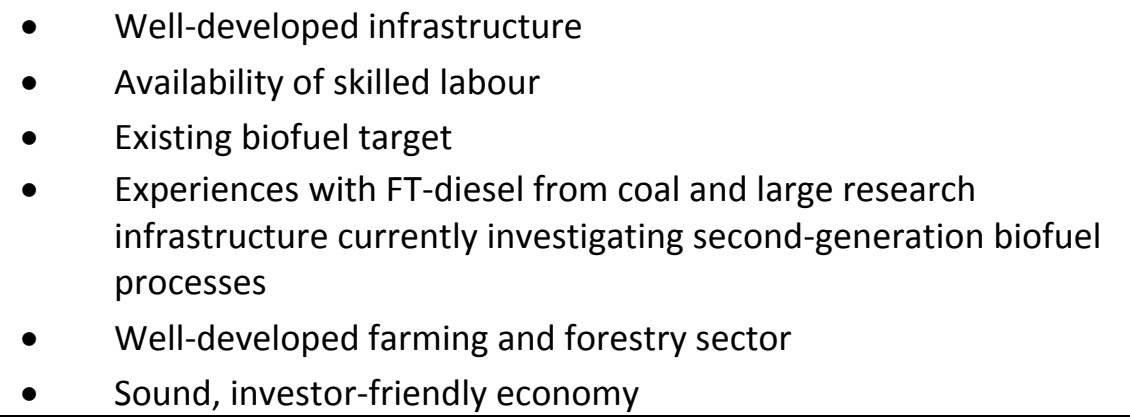 \\
\hline WEAKNESSES & $\begin{array}{l}\text { - } \quad \text { Large areas face water constraints } \\
\text { - } \quad \text { Competition between biofuel production and current use of } \\
\text { - } \quad \text { Insecuridues } \\
\text { - } \quad \text { Residues are often already used } \\
\text { - } \quad \text { Relatively low levels of primary production and low biomass } \\
\text { production per hectare }\end{array}$ \\
\hline OPPORTUNITIES & $\begin{array}{l}\text { - } \quad \text { Cultivation of currently fallow cropland } \\
\text { - Utilisation of alien vegetation and woody biomass from "bush- } \\
\text { encroached" rangeland with low cost } \\
\text { - } \quad \text { Export of skills to surrounding countries } \\
\text { - } \quad \text { High demand for liquid fuel in the domestic market }\end{array}$ \\
\hline THREATS & $\begin{array}{l}\text { - Impacts on costs of cattle feed and thus the farming system } \\
\text { - } \\
\text { - } \\
\text { - } \quad \text { Concerns of impact on biodiversity } \\
\text { Increasing aridity, in particular in the west, due to climate change }\end{array}$ \\
\hline
\end{tabular}

\section{Conclusions}

South Africa has limited land with good agricultural production potential. Currently, not all crop land is fully utilised, allowing some opportunity for expansion of new fuel crops or existing crops into new areas. There is almost no opportunity for dedicated forestry expansion for biofuels, but extensive opportunity to use forestry waste. 
Second generation biofuels could only make a partial (but nevertheless significant) contribution to national fuel security. The largest contributors to this potential fuel supply are maize stover and sustainable production from indigenous woodlands. Both these energy sources are spatially distributed, imposing high transportation costs and reducing both the climate benefits and profitability. Additionally, current utilisation of the considered feedstocks reduces this amount Page | 172 significantly. To get true benefit from second-generation biofuels would require planting of dedicated fast-growing biofuel crops. Although this could potentially be achieved through short rotation forestry, this option is not likely due to water use concerns and the current shortage of pulpwood in the country, as well as potentially adverse ecological impacts.

As a country with extensive coal reserves, but almost no oil reserves, liquid transportation fuels are the key limiting fuel. Being a relatively warm country, most households do not have central heating, and currently the more affluent areas use electricity for heating whilst poorer areas are often dependent on collected fuelwood. A move to reduce GHG emissions is forcing the country to look at alternatives to coal for electricity generation, but at this stage biomass is not a key contender. Nevertheless, sugar mills and sawmills where waste biomass is already being accumulated are looking at options of electricity generation, which is suddenly becoming more favourable due to predicted major electricity tariff hikes and a change in policy that will for the first time allow them to sell back into the national grid. This niche burning of biomass for electricity generation is likely to be driven more by economic opportunity rather than national strategy, and if second generation biofuels are more lucrative there is no reason why the industries would not support biofuel production. A South African company is planning to launch a locally produced electric car within the next two years, but reliance on liquid fuels as the main fuel for road transportation is not likely to diminish in the foreseeable future.

Many uncertainties including environmental impacts and economic viability remain before a second-generation biofuel industry can be contemplated for South Africa. If biofuels are produced in South Africa, it is most probable that they would be used predominantly for local markets rather than export, as the estimated production potential is less than national liquid fuel demand. Any move to extensive biofuel production will be driven primarily from a job creation perspective, with GHG reduction and fuel security being important, but secondary, considerations.

South Africa is distinctly different from surrounding southern African states, particularly in terms of infrastructure and human capital. South Africa also has a far better-developed commercial agricultural and forestry sectors than are found surrounding countries. As such, the technical ability to implement biofuel projects is very different between South Africa and its neighbouring countries. From an agricultural production potential perspective, many other southern African countries have greater potential than South Africa; as such, the potential exists to use South African infrastructure and know-how to assist biofuel production in neighbouring countries. 


\section{A8 Tanzania}

\section{General country characteristics}

\section{General description}

The United Republic of Tanzania is located in central eastern Africa, bordering Kenya and Uganda to the north, Ruanda and Burundi to the north-west, the Democratic Republic of Congo to the west, Zambia, Malawi and Mozambique to the south and the Indian Ocean to the east. It has a coastline of around $1400 \mathrm{~km}$ and shorelines of $1420 \mathrm{~km}$ with Lake Victoria in the north, $650 \mathrm{~km}$ with Lake Tanganyika in the west and $305 \mathrm{~km}$ with Lake Malawi in the south. It occupies a total area of $945090 \mathrm{~km}^{2}$ (CIA, 2008; FAO Aquastat, 2009). Table A49 provides an overview of some basic population information and economic indices of the country.

Tanzania has experienced important economic growth of $6.5 \%$ of GDP during the period 2000-06, affecting many sectors, including industry, services and agriculture (OECD, 2008e). However, poverty remains one of the main issues, and the government has set specific goals to reduce poverty by half. The overall vision is total poverty eradication by the year 2025 . Inequalities are observed whereby urban areas show faster poverty reduction than do rural areas (Utz, 2008; MEM, 2007).

Table A49. General population information and economy indices

\begin{tabular}{|l|l|l|r|}
\hline Parameter & Unit & Value & Year \\
\hline Population & million & 40.2 & 2008 \\
\hline Population growth rate & $\%$ & 2.07 & 2008 \\
\hline GDP (PPP) & billion USD & 56.22 & 2008 \\
\hline GDP per capita (PPP) & USD & 1398 & 2008 \\
\hline Poverty rate & $\%$ of total pop. & 96.6 & 2006 \\
\hline HDI & - & 0.503 & $2000-2006$ \\
\hline Undernourishment & $\%$ of total pop. & 35 & $2003-2005$ \\
\hline Energy production & Mtoe & 16.9 & 2007 \\
\hline TPES & Mtoe & 18.28 & 2007 \\
\hline Net energy imports & Mtoe & 1.5 & 2006 \\
\hline $\mathrm{CO}_{2}$ emissions & t CO 2 /capita & 0.12 & \\
\hline
\end{tabular}

Sources: CIA, 2008; UNDP, 2007; FAO Aquastat, 2009; NBST, 2004; IEA Statistics, 2009

Tanzania's primary energy supply is largely based on biomass with $88.6 \%$, followed by petroleum products with $7.5 \%$ and natural gas with $2.4 \%$ (Fig. A10). Electricity generation reached $2776 \mathrm{GWh}$ in $2006,96 \%$ of which originated in roughly equal amounts from hydropower and natural gas. The 
transport sector is entirely import-dependent, with $42 \mathrm{PJ} / \mathrm{yr}$ consuming $75 \%$ of petroleum products and approximately $6 \%$ of the total final energy consumption of the country (IEA Statistics, 2009).

Figure A10. Total primary energy supply

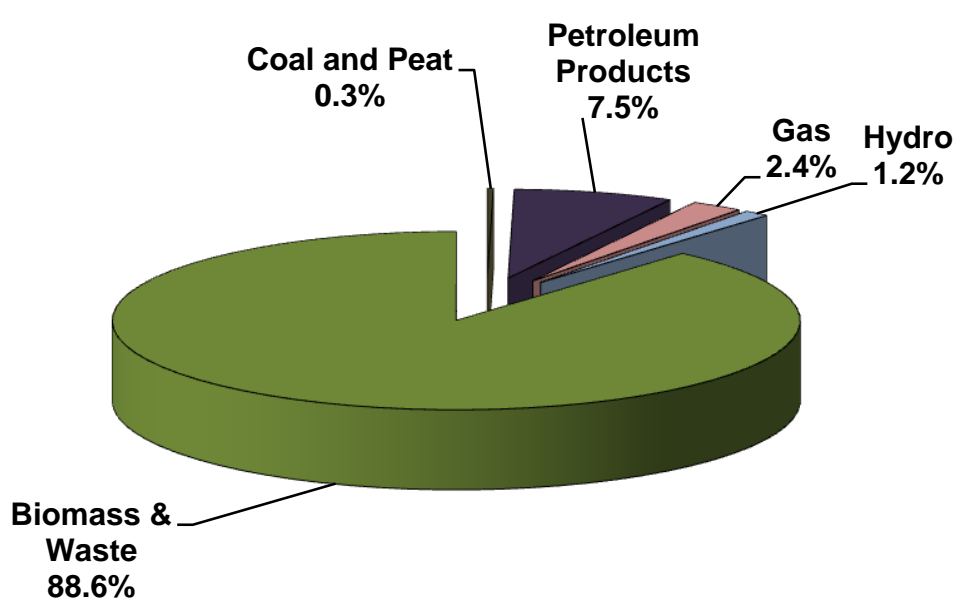

Total: 18.28 Mtoe (767.66 PJ)

Source: IEA Statistics, 2009

Regarding food security, in seasons with adequate rainfall, Tanzania can produce enough food to cover its domestic demand, and hence any food insecurity is a result of inefficient distribution network from surplus regions to deficit regions. However, the rainfall situation has worsened in recent years due to often recurring periods of drought, forcing the government to import increasing amounts of food aid directed mainly to the north-eastern part of the country (RAWG, 2007; ABN, 2007).

\section{Natural conditions for biofuel feedstock production}

The climatic zones of Tanzania can be divided into the coastal plains (with a hot and humid climate), a plateau zone (mostly dry with moderate temperatures), and highlands in the north, south and east of the country. Rainfall distribution is bimodal and allows for two growing seasons in the northeast highlands, the Lake Victoria basin and the coastal area. Most of the plateau area in the central and the west of Tanzania is very dry with precipitation between 625 and $1000 \mathrm{~mm}$ per year. Volcanic ashes and sediments form fertile soils on the food of Mount Kilimanjaro and the Serengeti National Park. Except in river basin areas, intense rainfalls and sands have created infertile soils along the coastal area. On the plateau, soils of low to high fertility can be found.

Due to the lack of precipitation in many parts of the country, forests only grow in highland areas with high amounts of rainfall. In drier regions, bush lands and grassland dominate, while shifting cultivation practices in the plains of the coastal area is creating not only agricultural land for cassava but grasslands as well.

\section{Agriculture and forestry}

Tanzania's agricultural sector contributes about $40-50 \%$ to GDP and $75 \%$ to foreign exchange earnings, deriving from exports of products like cashew nuts, cotton and coffee. In comparison, 
forestry is relatively small and officially accounts for around 3\% of the GDP and 10-15\% of export earnings. Nevertheless, $75 \%$ of building materials and $95 \%$ of energy consumption is provided by the forests or wooded lands (GTZ, 2005; Gordon, 2009).

Although agriculture is the most important economic sector, only a modest proportion of land is actually cultivated (Table A50). Deforestation and degradation has caused a decrease in forest area, but forests still cover one-third of Tanzania's total area.

Table A50. Agricultural and forestry production 2007

\begin{tabular}{|c|c|c|c|c|c|c|}
\hline \multicolumn{5}{|c|}{ Agricultural Production } & \multicolumn{2}{|c|}{ Forestry Production } \\
\hline Product & $\begin{array}{l}\text { Crop area } \\
(1000 \text { ha })\end{array}$ & $\begin{array}{l}\text { Proportion of } \\
\text { crop area (\%) }\end{array}$ & $\begin{array}{l}\text { Production } \\
(1000 \mathrm{t})\end{array}$ & $\begin{array}{l}\text { Yield } \\
\text { (t/ha) }\end{array}$ & Product & $\begin{array}{l}\text { Quantity } \\
\left(1000 \mathrm{~m}^{3} / \mathrm{yr}\right)\end{array}$ \\
\hline Maize & 3000 & 29 & 3400 & 1.13 & Roundwood & 24128 \\
\hline Sorghum & 900 & 9 & 900 & 10.00 & Wood fuel & 21814 \\
\hline Cassava & 675 & 7 & 6600 & 9.78 & $\begin{array}{l}\text { Industrial } \\
\text { roundwood }\end{array}$ & 2314 \\
\hline Rice & 665 & 6 & 1240 & 18.65 & Sawnwood & 24 \\
\hline Beans & 375 & 4 & 290 & 0.77 & $\begin{array}{l}\text { Wood based } \\
\text { panels }\end{array}$ & 4.5 \\
\hline Coconuts & 310 & 3 & 370 & 1.19 & Wood pulp* & 56 \\
\hline Millet & 265 & 3 & 219 & 0.83 & $\begin{array}{l}\text { Paper/ } \\
\text { Paperboard* }\end{array}$ & 25 \\
\hline Groundnuts & 122 & 1 & 55 & 0.45 & & $* 1000 \mathrm{t}$ \\
\hline Wheat & 92 & 1 & 115 & 1.25 & & \\
\hline Cashew nuts & 90 & 1 & 92 & 1.02 & & \\
\hline Total & 10350 & & 25227 & & $\begin{array}{l}\text { Total forest } \\
\text { area } \\
(1000 \mathrm{ha})\end{array}$ & 35257 \\
\hline
\end{tabular}

Source: FAOStat, 2009

Maize and sorghum are grown as important cash crops as well as for subsistence consumption. Where agricultural conditions are worse, cassava and cashew nuts are also cultivated. Sugar cane production has increased significantly in recent years and now is one of the most important crops. The majority of harvested wood is used as wood fuel, while industrial usage of wood includes production of sawnwood and paper and paperboard (Table A50).

Agriculture is dominated by badly equipped smallholders with average farm sizes of 1-3 ha, but a shift from subsistence to market oriented production can be observed (GTZ, 2005). The number of large-scale farms is increasing and the area under management for 2002/03 accounted for 1.1 Mha (NBST, 2004). Although land seems to be abundant, agriculture suffers from disputes over land ownership and insecurity of tenure (Gordon, 2009). 


\section{Current situation of biofuel development}

\section{Current production of first generation biofuels}

Page | 176 Currently, there is no commercial biofuel production in Tanzania - rather, there are only discussions and plans about the potential of biofuel market development. Several foreign-owned companies are investing in land acquisition with an eye to large-scale biofuel production that will be directed to supply the international market. Apart from foreign investors, domestic enterprises and organisations (ABF Ltd, FELISA, and TATEDO) $)^{21}$ are also involved in the promotion of the biofuel sector, with initiatives on a regional scale. An example of foreign and non-foreign investors is shown in Table A51. Sugar cane for ethanol, as well as jatropha, oil palm and croton tree ${ }^{22}$ for biodiesel, are the feedstock options under consideration. Special attention has been given to the cultivation and exploitation of jatropha for recovery of vegetable oil, but not yet for biodiesel production. In small scale efforts across the country, jatropha oil is used for rural electrification (TATEDO, 2009), but it has been reported that some of the mentioned projects have recently been stopped due to the economic situation of the companies. However, data on the current status of the projects is difficult to obtain.

Table A51. Investments in agrofuel production in Tanzania

\begin{tabular}{|l|l|l|l|}
\hline Investor & Area (ha) & Feedstock & Region \\
\hline SEKAB, Sweden & 400000 & Sugar cane & $\begin{array}{l}\text { Wami Basin, delta of Wami river in } \\
\text { the Indian Ocean }\end{array}$ \\
\hline D1 Oils, UK & n.a. & $\begin{array}{l}\text { Jatropha, } \\
\text { sunflower }\end{array}$ & \\
\hline PROKON, Germany & 10000 & Jatropha & $\begin{array}{l}\text { Mpanda district, west, close to lake } \\
\text { Tanganyika }\end{array}$ \\
\hline $\begin{array}{l}\text { Diligent Energy } \\
\text { Nystems, the }\end{array}$ & n.a. & Jatropha & $\begin{array}{l}\text { Several production and collection } \\
\text { points in central/north-east region } \\
\text { Handeni, Singida, Pangani) }\end{array}$ \\
\hline Sun Biofuels, UK & 18000 & Jatropha & $\begin{array}{l}\text { Lindi district, south-east, close to the } \\
\text { Indian Ocean }\end{array}$ \\
\hline ABF Tanzania Ltd & 6000 & Jatropha & $\begin{array}{l}\text { Kisarawe district, east, close to Dar El } \\
\text { Salaam }\end{array}$ \\
\hline TATEDO & 6000 & Croton tree & $\begin{array}{l}\text { Kagera region, north, close to Lake } \\
\text { Victoria }\end{array}$ \\
\hline
\end{tabular}

Sources: ABN, 2007; ABF, 2009; TATEDO, 2009; Hönicke \& Meischner, 2009

\footnotetext{
${ }^{21}$ ABF: Africa Biofuel and Emission Reduction (Tanzania) Ltd; FELISA: Farming for Energy for Better Livelihoods in Southern Africa; TATEDO: Tanzania Traditional Energy Development and Environment Organisation.

${ }^{22}$ Croton megalocarpus tree is a species indigenous in East Africa with nuts containing 32\% oil by weight (ABF, 2009).
} 


\section{National policy target for biofuels}

Given that biofuels are now starting to gain attention, only first-generation biofuels are being investigated while second-generation biofuels remain unexplored in Tanzania. Under the guidance of the Ministry of Energy and Minerals, the National Biofuel Task Force was established in March 2006, consisting of a number of actors and NGOs aiming to promote the development of the biofuel sector. Some goals of the task force, among others, are to design biofuel policies and regulations, to introduce fiscal incentives for potential investors, to identify suitable areas of production and to contribute to the research and development of the sector (MAFD, 2009; ABN, 2007).

So far, no official policy or legislation has been introduced or set into motion. Possible targets for biofuel introduction into transport fuels suggest blends of $10 \%$ for ethanol and $20 \%$ for biodiesel. These targets would require 26.7 million I of ethanol and 138 million I of biodiesel in 2010 (ABN, 2007; Janssen, 2006).

There are currently discussions regarding whether biofuels should be used domestically or exported, but there are no mechanisms that could ensure one or the other. The government is welcoming foreign investors but there are fears that every development will be foreign driven and the local communities will benefit the least (LARRRI, 2008).

\section{Financing and human resources}

Credit to the private sector has maintained an upward trend since 2000; however access to credit is limited to a small number of enterprises in urban areas and virtually non-existent in rural areas. In addition, the financial system is inefficient in supplying long-term funds to the local private sector, since banks are showing increasing risk aversion in lending. Foreign direct investment (FDI) is concentrated in the natural resource sector (e.g. mining and tourism) and there are efforts, thereby, to complement domestic investment as well as spread to other sectors. Conditions for international investments are rated below average, with a slight deterioration in the past year due to time-consuming processes for opening a new business and a complicated tax system (Tanzania Invest, 2008).

Labour force in Tanzania is cheap and abundant, but often unskilled. The lack of a skilled workforce must be considered a comparative disadvantage for the country when it comes to advanced biofuel technologies, since in industrial production processes (such as the operation of biorefineries), the real labour cost is dependent on actual productivity, which is determined, among other factors, by the quality of labour (i.e. level of education, skills, experience and discipline) (RAWG, 2007).

\section{Infrastructure}

Tanzania has an underdeveloped transport network, which is a key structural weakness. The transport system is, however, very important for integrating domestic markets, and furthermore, it plays an important role for landlocked neighbouring countries (Burundi, Malawi, Rwanda, Uganda and Zambia) to handle its transit traffic. The road network amounts to $85000 \mathrm{~km}$ and consists of $56000 \mathrm{~km}$ of urban, district and feeder roads and $29000 \mathrm{~km}$ of regional and national roads. Less than $10 \%$ of all roads are paved. Tanzania's total rail network amounts to about $3700 \mathrm{~km}$ and is divided into two networks of different grid width. The first rail network connects the western, northern and north-eastern parts of Tanzania (as well as related neighbouring countries) with Dar- 
es-Salaam on Tanzania's coast; it is approximately $2700 \mathrm{~km}$ long. The second rail network is less than $1000 \mathrm{~km}$ and links Zambia and the south-western part of Tanzania with Dar-es-Salaam. Along the Indian Ocean, Tanzania has eight ports, including the major ports of Dar-es-Salaam, Tanga and Mtwara. There are no navigable rivers, but several major lakes: Lake Victoria, Lake Tanganyika and Lake Nyasa. The rehabilitation and construction of roads has led to an increased competition between road and rail transport, with an advantage for road transport. Furthermore, privatisation in the transport sector is occurring, as is growth in the number of road carriers. At the moment, $70 \%$ of freight transport is done by road in Tanzania (OECD, 2008e; World Bank, 2007).

Tanzania produces neither biofuels nor fossil fuels like gasoline or diesel. It depends completely on imports of refined products since it has neither refineries nor crude production. Imported gasoline and diesel are distributed via road and rail from the port of Dar-es-Salaam to storage throughout the country and to about 250 refuelling stations (GTZ, 2005).

Table A52. Vehicle fleet in 2006

\begin{tabular}{|c|c|c|c|c|}
\hline 2-wheelers & 3-wheelers & PC+SUV & LCV's, LT's, MDT's, HDT's & Buses, Minibuses \\
\hline 103000 & n.a. & 45000 & 59223 & 166000 \\
\hline
\end{tabular}

PC: Passenger car; SUV: Sport utility vehicle; LCV: Light commercial vehicle; LT: Light truck; MDT: Medium duty truck; HDT: Heavy duty truck

Source: IEA Mobility Model, 2009

Tanzania's automotive fleet amounts to 373223 vehicles, of which $28 \%$ are two-wheelers, $12 \%$ are passenger cars and sports utility vehicles, $16 \%$ light and heavy trucks, and the remaining $44 \%$ are buses (Table A52).

The share of gasoline vehicles amounts to $45 \%$, while diesel is used by $55 \%$ of the vehicle fleet. Fuel consumption amounted to $42 \mathrm{PJ}$ in 2006 , of which $75 \%$ was diesel and $25 \%$ was gasoline (Wilson, 1997; IEA Statistics, 2009); projections for the year 2030 are also shown in Table A53.

Table A53. Fuel consumption in 2007 and projection for 2030

\begin{tabular}{|r|c|c|c|}
\hline & $\begin{array}{c}\text { Gasoline } \\
1000 \mathrm{t}(\mathrm{PJ})\end{array}$ & $\begin{array}{c}\text { Diesel } \\
1000 \mathrm{t}(\mathrm{PJ})\end{array}$ & $\begin{array}{c}\text { Biofuels } \\
1000 \mathrm{t}(\mathrm{PJ})\end{array}$ \\
\hline $\mathbf{2 0 0 7}$ & $229(10)$ & $735(32)$ & 0 \\
\hline $\mathbf{2 0 3 0 *}$ & $315(14)$ & $1012(44)$ & n.a. \\
\hline
\end{tabular}

Source: IEA Statistics, 2009; *Assumption based on WEO 2008 data, assuming linear growth in each sector

\section{Feedstock assessment and logistics}

\section{Feedstock and cultivation areas}

A large amount of agricultural residues and by-products suitable for second-generation biofuel production are actually dumped, burnt or inefficiently used and thus provide a wide variety of feedstock. Residues are only partly used, so competition with other uses is not considered as an 
issue. Bagasse and molasses from sugar cane processing are only partly used and form a concentrated biomass potential in the region of Morogoro, Kilimanjaro and Lake Victoria. Residues of the main cash and food crops (maize and rice) also contribute to the Tanzanian biomass potential, but only where they could be made available in large volumesthey form a considerable potential for biofuel production. Such regions are characterised by large private estates or intensive smallholder farming (e.g. Arusha, Kilimanjaro, Tanga, Morogoro and the lake regions). The feedstock usage for second-generation biofuel could be further constrained by the low level of employment of machines and the use of residues for fodder and cooking activities. Table A54 provides an overview of agricultural and forestry residues in Tanzania.

Wood residues are derived from the logging of roundwood or the cultivation of plantations. Still, wood is the most important energy source in Tanzania used for cooking and heating; therefore, the amount of unused residues is marginal (MAFD, 2009). Unused by-products from the processing of wood are also limited, since they are feedstock for the pulp and paper industry (GTZ, 2005).

Furthermore, large additional agricultural area is forecast to be available for cultivation in Tanzania, but the lack of water availability in many regions of the country and undetermined land tenure build large barriers to the utilisation of this land. As a result, a precise statement regarding the additional area for the crop cultivation is difficult, but the intensification and expansion of agricultural activities should be possible (GTZ, 2005).

Table A54. Assessment of residues from forestry and agriculture

\begin{tabular}{|c|c|c|c|c|}
\hline Type & $\begin{array}{c}\text { Actual material } \\
\text { flow } \\
\left(1000 t_{D M} / y r\right)\end{array}$ & $\begin{array}{c}\text { Unused } \\
\text { residues } \\
\left(1000 t_{D M} / y r\right)\end{array}$ & Regional availability & Main utilisation \\
\hline \multicolumn{5}{|l|}{ Primary residues } \\
\hline Maize (stalk) & 4484 & n.a. & $\begin{array}{l}\text { Mbeya, Rukwa, Iringa, } \\
\text { Shinyanga, Ruvuma }\end{array}$ & $\begin{array}{l}\text { Fertiliser, forage, } \\
\text { heating, cooking }\end{array}$ \\
\hline Rice (straw) & 3310 & n.a. & n.a. & " \\
\hline Sorghum (straw) & 735 & n.a. & \begin{tabular}{|lr} 
Iringa, & Ruvuma, \\
Rukwa, & Singida, \\
Shinyanga, coast
\end{tabular} & " \\
\hline Cotton (stalk) & 587 & n.a. & $\begin{array}{l}\text { Mwanza, shinyanga, } \\
\text { Mtwara, cost area }\end{array}$ & " \\
\hline Millet (straw) & 307 & n.a. & $\begin{array}{l}\text { Mbeya, Rukwa, Iringa, } \\
\text { Shinyanga, Ruvuma }\end{array}$ & " \\
\hline Oil palm (stalk) & 288 & n.a. & Kigoma & " \\
\hline Wheat (straw) & 181 & n.a. & \begin{tabular}{|lr} 
Arusha, & Manyara, \\
Iringa, & Rukwa \\
Kilimanjaro, & Mbeya, \\
Tanga &
\end{tabular} & " \\
\hline Sisal (waste) & 39 & n.a. & $\begin{array}{l}\text { Tanga, Morongoro, } \\
\text { Kilimanjaro }\end{array}$ & " \\
\hline
\end{tabular}




\begin{tabular}{|c|c|c|c|c|}
\hline Type & $\begin{array}{c}\text { Actual material } \\
\text { flow } \\
\left(1000 t_{D M} / y r\right)\end{array}$ & $\begin{array}{c}\begin{array}{c}\text { Unused } \\
\text { residues }\end{array} \\
\left(1000 \mathrm{t}_{\mathrm{DM}} / \mathrm{yr}\right)\end{array}$ & Regional availability & Main utilisation \\
\hline $\begin{array}{l}\text { Groundnut } \\
\text { (straw) }\end{array}$ & 11 & n.a. & Tabora & " \\
\hline Logging residues & 175 & n.a. & Iringa, Mbeya, Songea & Heating, cooking \\
\hline \multicolumn{5}{|c|}{ Secondary residues } \\
\hline Maize (cob) & 613 & n.a. & $\begin{array}{l}\text { Mbeya, Rukwa, Iringa, } \\
\text { Shinyanga, Ruvuma }\end{array}$ & Heat, steam \\
\hline Rice (husk) & 290 & n.a & $\begin{array}{l}\text { Morogoro, Tabora, } \\
\text { Shinyanga, coast area }\end{array}$ & “ \\
\hline $\begin{array}{ll}\text { Sugar } & \text { cane } \\
\text { (bagasse) } & \end{array}$ & 222 & n.a. & $\begin{array}{l}\text { Masaki, Ruipa, Ikongo, } \\
\text { Wami Mahurunga, } \\
\text { Usangu, Malagarasi }\end{array}$ & " \\
\hline Oil palm (fibres) & 72 & n.a. & Kigoma & Fertiliser, forage \\
\hline Oil palm (EFB) & 48 & n.a. & Kigoma & Heat, steam \\
\hline Oil seed (shells) & 26 & n.a. & Kigoma & “ \\
\hline Coffee (husk) & 9 & n.a. & & “ \\
\hline Coconut (shell) & 6 & n.a. & $\begin{array}{ll}\text { Zanzibar, } & \text { Tanga, } \\
\text { Coast, Mafia } & \end{array}$ & “ \\
\hline $\begin{array}{l}\text { Groundnut } \\
\text { (shell) }\end{array}$ & 5 & n.a. & Tabora & “ \\
\hline Coconut (husk) & 2 & n.a. & $\begin{array}{ll}\text { Zanzibar, } & \text { Tanga, } \\
\text { Coast, Mafia } & \end{array}$ & “ \\
\hline Saw dust & 41 & n.a & Iringa, Mbeya, Songea & $\begin{array}{l}\text { Pulp and paper } \\
\text { industry }\end{array}$ \\
\hline
\end{tabular}

Source: John and Mhilu, 2009; GTZ, 2005.

\section{Second-generation biofuel options}

Based on biomass residues described above, the potential biofuel production and number of production plants can be defined. The calculations are based on actual material flows and is, therefore, only a theoretical estimation since information regarding the unused percentage is not available. For every second-generation biofuel option, not all types of residues are considered suitable. However, this is the aim of further development and, as a consequence, all types of residues were considered suitable for every pathway in the analysis (Table A55). Biofuel production as well as the potential number of conversion plants is higher for primary residues than for secondary residues. 
The potential second-generation biofuel production would exceed the current transport fuel demand of Tanzania, but since calculations are based on the actual material flow and not on unused residues, this has to be considered the maximum theoretical biofuel amount.

Table A55. Potential second-generation biofuel production and number of plants

\begin{tabular}{|c|c|c|c|c|}
\hline \multirow[b]{2}{*}{ Biofuel option } & \multicolumn{2}{|c|}{$\begin{array}{l}\text { Production } \\
\text { (based on actual material flow) }\end{array}$} & \multicolumn{2}{|c|}{ Number of plants } \\
\hline & Mlge/yr* & $\mathrm{PJ} / \mathrm{yr}$ & small scale** & large scale** \\
\hline \multicolumn{5}{|c|}{ Based on primary residues } \\
\hline Bio-SNG & 3116 & 104.4 & 168 & 23 \\
\hline BTL & 2195 & 73.5 & 20 & 5 \\
\hline Bioethanol & 2164 & 72.5 & 162 & 13 \\
\hline \multicolumn{5}{|c|}{ Based on secondary residues } \\
\hline Bio-SNG & 411 & 13.8 & 22 & 3 \\
\hline BTL & 289 & 9.7 & 3 & 1 \\
\hline Bioethanol & 285 & 9.5 & 21 & 2 \\
\hline \multicolumn{5}{|c|}{ 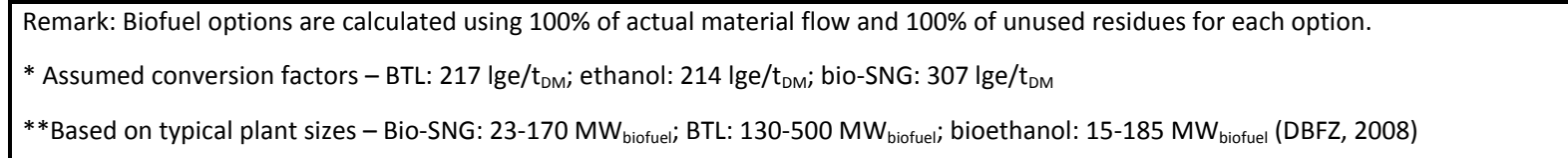 } \\
\hline
\end{tabular}

\section{Estimated costs for feedstock and end product}

The estimation of feedstock costs is a difficult task due to lack of relevant information. It is expected that the transport network situation will contribute to the increase of feedstock provision costs, especially for second-generation technologies that require scaled-up facilities and large amounts of feedstock.

\section{Identification of hot spots for production plants}

Tanzania has a relatively poor transport infrastructure and no fuel production industries. There is neither a refinery for fossil fuels nor a production plant for biofuels in place. This results in the lack of experience in this particular field of technical knowledge. And while it is only a theoretical estimate, there is a promising amount of potential biofuel production, based on calculations using actual material flow. Coastal areas are the ones considered more suitable in terms of proximity and accessibility to energy supply and potential markets, and could provide a more efficient transport of feedstock and products. However, given the insufficient infrastructure situation of the country, it is hard to determine specific hot spots for second-generation biofuel production plants. Furthermore, it is difficult to estimate factors that are attractive to workers, like communication, banking or social infrastructure, which are important for the determination of an appropriate plant location (Bekunda et al., 2009). 


\section{Sustainability}

\section{Economic impact}

Page | 182 The increased capital investments associated with second-generation technologies require a reliable credit source and a thorough financial plan with a long-term perspective in order to prove that the investor is committed to the project. On a political level, the government is willing to participate in projects concerning biofuel development, thus spreading the risk of potential investments ( $A B F, 2009)$. Such an investment could also release Tanzania of the economic burden of petroleum imports, which constitute around $24 \%$ of its total import expenditures (ITC, 2009).

Capital costs, as well as biomass provision and biofuel distribution costs, are of vital importance for the determination of the economic impact. Residues and agricultural by-products reduce feedstock costs far more than do crop feedstocks, on account of lower labour costs; however, the infrastructure situation of Tanzania is a limiting factor for low-cost biomass and biofuel provision. Moreover, Tanzania is covering almost $90 \%$ of its energy supply with biomass. This biomass is used in traditional and rather unsustainable ways (e.g. traditional stoves), and it is unclear what the economic impact will be if part of this biomass is shifted to second-generation biofuel production.

Due to its favourable location, Tanzania could develop into a biofuel trade centre in the region, and it seems that the government is opting to reinforce this role rather than promote biofuel development for local use, although one of the goals of biofuel development is access to energy for rural areas.

There is a fear in Tanzania, and in developing countries in general, that farmers may opt for growing crops that can be used for biofuel production (e.g. sugar cane) instead of basic food crops (e.g. beans, rice and potatoes), especially when production is subsidised by the government. Subsidies for biofuel feedstock are measures that can be beneficial in the short term, but the long-term viability of a biofuel project should not rely on these subsidies. Adding value to agricultural residues and by-products through their use as second-generation feedstock may increase the gross margin of certain crops and decrease the necessity for subsidies in crop production and forestry in general. In this case, subsidies could be either avoided or shifted to the biofuel production sector and thus help promote the development of second-generation biofuel technologies (ABF, 2009).

\section{Social impact}

The actual and proper integration of local communities along the entire biofuel chain will offer new jobs, while adding value to forestry and agricultural residues will increase household income and help lead to regional growth and poverty reduction. The quality and extent of job creation depends on the level of involvement within the entire chain. This has been globally one of the main reasons for the promotion of biofuel projects in a regional scale.

In export-oriented large-scale production, as in the case of Tanzania, there are requirements for increased efficiency, economies of scale and profit maximisation, possibly leading to displacement of small-scale farmers in favour of large mechanised and privatised plantations (ABN, 2007). This risk also exists with second-generation feedstock, such as short rotation forestry, if land use management is not undertaken with the required care.

Suitable areas for first-generation biofuel production in Tanzania include fertile areas with good rainfall and access to water resources, which therefore would not be considered "marginal" land 
and would displace food production (ABN, 2007). Applying this land for food production and using residues as feedstock for second-generation biofuel production would limit this problem. Another controversial issue is the definition of "unused"; what is considered as unused or degraded or marginal still remains a source of income for local farmers and pastoralists (ABN, 2008).

Integration of smallholder producers should be secured with contractual agreements and ideally oriented along the entire biofuel chain, in order to increase the interest of the farmer for the final product. However, reality shows that no job is assured and local farmers remain in a status of uncertainty because they have nothing in writing. Apart from that, inconsistencies and vagueness concerning land occupation and land ownership in Tanzania render the distribution of land a difficult task. As result, "land grabbing" occurs, which excludes local farmers and favours large privatised plantations. Compensation in such cases is either lower than supposed or even missed due to insufficient information. Moreover, rural population claims that they are in the middle of decisions taken beforehand, without consideration of alternatives and without their participation (LARRRI, 2008).

Recently, droughts have occurred more frequently in Tanzania, leading to bad harvests and forcing the government to import increasing amounts of food aid. Therefore, there is a concern that subsidised biofuel feedstock could divert farmers from food production, thus creating imbalances in national food reserves and contributing to food insecurity (ABF, 2009). These issues are expected to dominate the biofuel discussion in the coming years, especially since current efforts do not include plans for second-generation biofuels, which could limit the problems of land use, land occupation and food competition.

\section{Environmental impact}

Since there is no commercial biofuel production in Tanzania yet, there is no data on environmental impacts of current biofuel production. With regard to planned investments in first-generation biofuel production, there is a fear that feedstock like sugar cane and oil palms will be cultivated in areas with high water availability and thus displace rice plantations (The East African, 2009). The same could apply to dedicated energy crops for second-generation biofuels. Eucalyptus, for instance, is known to require large amounts of water, and thus plantations for second-generation biofuel feedstock should be well evaluated. If residues such as rice husks are used, this would not require additional cultivation areas. However, since neither first- nor second-generation biofuels are currently being produced in Tanzania, general comparisons between different biofuel options are described in Chapter 8.3.

\section{SWOT analysis}

The following table presents an overview of strengths, weaknesses, opportunities and threats concerning the development of the biofuel industry with special regard to second generation biofuels. 
Table A56. Summary of SWOT Analysis

\begin{tabular}{|c|c|}
\hline STRENGTH & $\begin{array}{l}\text { - Favourable geographic location with access to the sea } \\
\text { - } \quad \text { Political will for the development of the biofuel sector } \\
\text { - } \quad \text { Stable political situation and a solid economic status with projected on-going } \\
\text { growth in comparison to neighbouring countries } \\
\text { - } \quad \text { Attractive for actors willing to invest in Africa } \\
\text { - } \quad \text { Abundance of agricultural residues; no strong competition with other uses } \\
\text { - } \quad \text { Sufficient land }\end{array}$ \\
\hline WEAKNESS & $\begin{array}{l}\text { - } \\
\text { - } \quad \text { Limited skilled labour force related to the industry } \\
\text { - } \quad \text { Undeveloped inland infrastructure situation } \\
\text { - } \quad \text { Limited vehicle fleet } \\
\text { - } \quad \text { Power supply for large scale facilities is not secured. Development of the power } \\
\text { distribution network is essential }\end{array}$ \\
\hline OPPORTUNITY & 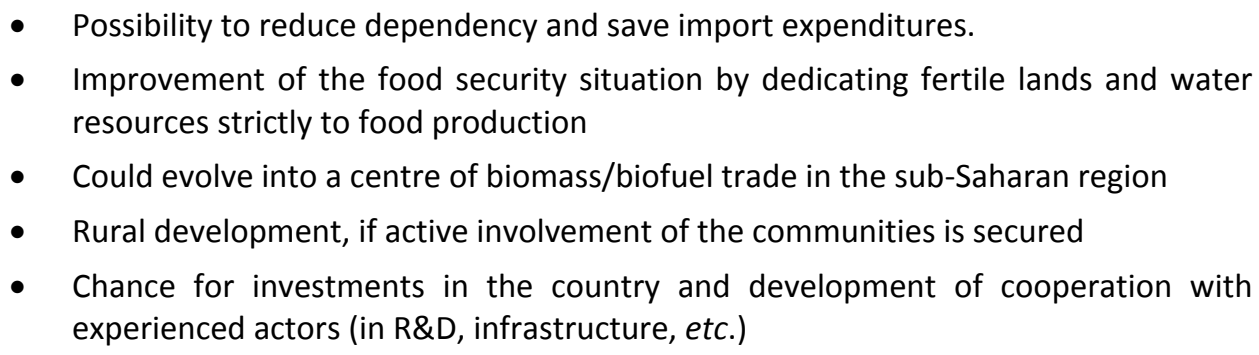 \\
\hline THREAT & $\begin{array}{l}\text { - Large-scale export-oriented biofuel production may neglect local benefits in favour } \\
\text { of attracting foreign investors } \\
\text { - } \quad \text { Diversion of interest from rural energy provision } \\
\text { - Uncontrolled land acquisition/land grabbing (either for energy wood plantations or } \\
\text { for expansion of agricultural crops for their residues) } \\
\text { - Lack of monitoring and regulations may lead to adverse social and environmental } \\
\text { impacts (e.g. deforestation, competition for land) }\end{array}$ \\
\hline
\end{tabular}

\section{Conclusions}

In terms of feedstock availability, the amount of agricultural residues produced could potentially justify efforts for second generation biofuels. Considering that the market for these residues is not well documented, it is difficult to determine any kind of competition with other uses. Furthermore, Tanzania is considered to have plenty of unused land that could be used for woody feedstock if certain safeguards (like not cultivating on fertile lands or not shifting water resources) would be incorporated.

However, Tanzania has no experience whatsoever in the biofuel sector. The high capital investment and associated financial risks of large second-generation facilities is a prohibiting factor for implementation in Tanzania, especially where financing is a bottleneck. Such plant size results in increased logistic complexity in feedstock provision (i.e. larger distances, higher handling and storage demand), which is reflected in the provision costs. For Tanzania, where the transport and 
infrastructure network is not well developed and distributed, and where experience in the fuel sector is lacking, biomass provision is an important issue.

Given that only $14 \%$ of Tanzania is electrified, one discussion point is the stationary use of lignocellulosic residues for heat and electricity, instead of using liquid biofuel for the transport sector. Research on biomass gasification technology is ongoing in the University of Dar-es-Salaam that will provide experience for the long term (John and Mhilu, 2009).

Whether using first- or second-generation, it is important to determine whether biofuels will be used to cover the country's internal fuel demand or will be exported in order to satisfy the international market. Given the absence of a tangible regulatory policy and the lack of infrastructure (e.g. distribution network and vehicle fleet), the export option seems to be the one followed by the government, in the case of first generation biofuels. However, issues such as food competition and land displacement, as analysed in previous chapters, raise doubts over the benefits of this strategy. In the case of second-generation biofuels, however the export strategy could be beneficial for both parties: the high costs associated with second-generation technologies could be covered by foreign investors who would also invest in inland infrastructure activities for biofuel production, as well as for export that would satisfy the international market. In the long term, the export orientation could be reconsidered and the country could dedicate part of the production also for domestic use.

Due to the uncertainties associated and the lack of experience, production of second-generation biofuels seems unrealistic in the near future in Tanzania. However, the potential does exist, especially in terms of biomass and land availability. Effort is needed to mobilise this potential and invest on research and infrastructure in order to set the ground for the country to become more involved when the time comes. 


\section{A9 Thailand}

\section{General country characteristics}

\section{General description}

Thailand is located in south-eastern Asia, occupies a total area of $514000 \mathrm{~km}^{2}$ and has a total coast line of $3219 \mathrm{~km}$, with the Thailand Gulf to south-east and the Malacca Strait to the south-west. Table A57 provides an overview of some basic economic indices and population information about Thailand.

Despite Thailand's economic recovery, 7 million people (11.5\% of total population) still live in absolute poverty. Poverty levels are lowest in Bangkok $(<2 \%)$ and central Thailand $(5 \%)$, and highest in the north $(16 \%)$, the northeast (17\%), and some Muslim provinces in the far south (18-23\%). Income inequality is high; the richest quintile holds $55 \%$ of the income while the poorest quintile holds only $4 \%$ (UNDP, 2007). This explains the slightly higher percentage of undernourished people (17\% during 2003-05) compared to the south-east Asian average (16\%), despite Thailand's food surplus. Especially in the rural communities in the north and north-east, food insecurity is an issue (FIVIMS, 2005). Thailand witnessed the strongest price transmission effect (130\%) of increasing international rice prices between May 2007 and May 2008 due to the devaluation of the US-Dollar and Thailand's importance as a rice exporter, thus showing the vulnerability of Thai rice consumers (FAO, 2008c).

Table A57. General population information and economy indices

\begin{tabular}{|l|l|r|r|}
\hline Parameter & Unit & \multicolumn{1}{|l|}{ Value } & Year \\
\hline Population & million & 66.8 & 2008 \\
\hline Population growth rate & \% & 0.64 & 2008 \\
\hline GDP (PPP) & billion USD & 570 & 2008 \\
\hline GDP per capita (PPP) & USD & 8700 & 2008 \\
\hline Poverty rate & \% of total population & 11.5 & $2000-2006$ \\
\hline HDI & - & 0.786 & 2006 \\
\hline Undernourishment & \% of total population & 17 & $2003-2005$ \\
\hline Energy production & Mtoe & 59.37 & 2007 \\
\hline TPES & Mtoe & 103.7 & 2007 \\
\hline Net energy imports & Mtoe & 47.95 & 2006 \\
\hline CO ${ }_{2}$ emissions/capita & t CO ${ }_{2} /$ capita & 3.42 & \\
\hline
\end{tabular}

Source: CIA, 2008; IEA Statistics 2009, JGSEE, 2009; NSO, 2008; UNDP, 2007

Thailand is strongly dependent on oil imports. The country's primary energy supply is covered mainly by oil with $47 \%$, followed by gas with $25 \%$, biomass with $16 \%$, coal with $12 \%$ and finally 
hydropower with $1 \%$ (see Figure A11). Electricity generation reached $139000 \mathrm{GWh}$ in 2006, originating mainly from natural gas and coal $(86 \%)$, but also from oil, biomass and hydropower. At $895 \mathrm{PJ} / \mathrm{yr}$, the transport sector consumes approximately $60 \%$ of the petroleum products and approximately $30 \%$ of the total final energy consumption of $2953 \mathrm{PJ} / \mathrm{yr}$.

Figure A11. Total primary energy supply

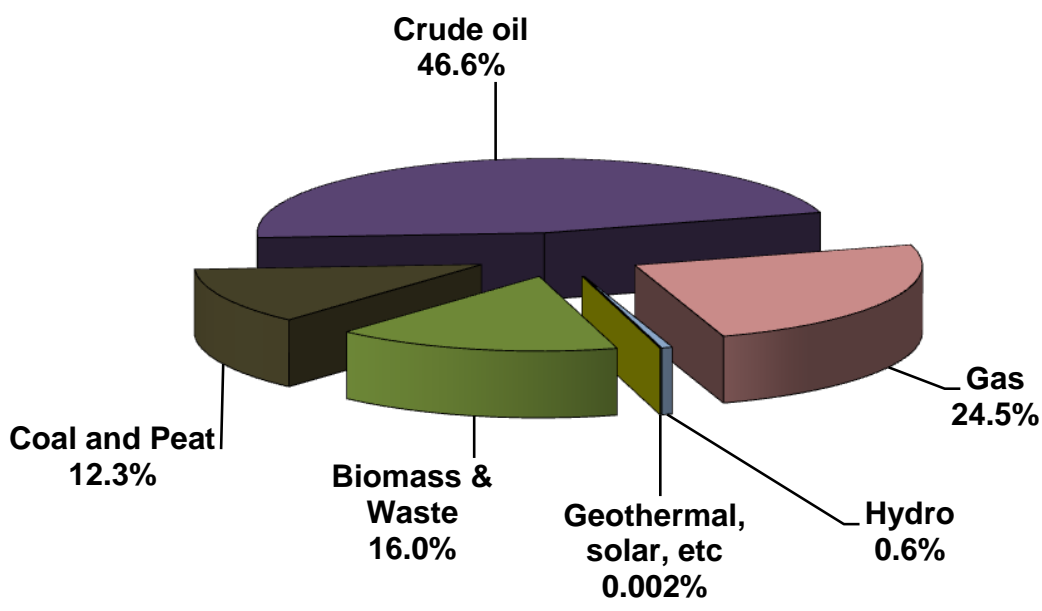

Total: 103.7 Mtoe (4.35 EJ)

Source: IEA Statistics, 2009

\section{Natural conditions for biofuel feedstock production}

Apart from the topographic features, climate and therefore natural conditions for agricultural production are mainly influenced by the annual monsoon. In the wet season from April to September, rainfalls are highest and cause a maximum of precipitation in the southern and western regions (up to $3000 \mathrm{~mm}$ per year). In the uplands ( $1300 \mathrm{~mm}$ per year) and in the rain shadow of the mountains in the central and north-east regions, precipitation is lowest (1 100 to $1600 \mathrm{~mm}$ per year). Nevertheless, these regions receive 80 to $90 \%$ of annual rainfalls during the monsoon time, creating fertile alluvial soils in the river basins which are seasonally flooded. Due to the tropical climate, the temperatures are very stable in the southern and south-eastern regions, while winter temperature in the uplands of the north can fall to approximately $10^{\circ} \mathrm{C}$ or lower (FAO, 2009b; Shelton \& Phaikaew, 2006).

Since the 1950s, excessive logging and clearing for agriculture have been the main causes for a sharp decline in the total forest area that now mainly consists of hardwood, bamboo and palm. The uplands and plains are mainly cultivated with rice; in the north-east, cassava and sugar cane are also grown. The southern regions are dominated by plantations of rubber, oil palms and coconut (Thaienvimonitor, 2009; FAO Aquastat, 2009; Shelton \& Phaikaew, 2006).

\section{Agriculture and forestry}

Being a major exporter of rice and vegetable oils to the world, the agricultural sector ${ }^{23}$ contributes approximately $11 \%$ to Thailand's GDP. The agricultural area accounts for about $36 \%$ of total land

\footnotetext{
${ }^{23}$ Besides agriculture, the agricultural sector encompasses fishery and forestry.
} 
area and is mainly cultivated with rice. Besides rice, the farmers in the central, northern and northeastern regions mainly earn their money from selling sugar cane and cassava. In recent years there has been a shift from maize and fruit plantations to oil palm and cassava cultivation - in part due to increased biofuel production as well as to the cultivation of unused land. Large plantations of oil palm and rubber can be found in the southern part of Thailand (FAO, 2009b).

Page | 188 Almost 30\% of Thailand is covered with forests, which are dominated by tropical evergreen and deciduous forests. The harvested wood is mainly used for roundwood production and as wood fuel in rural households. To meet total wood demand, imports are necessary (see Table A58).

Table A58. Agricultural and forestry production 2007

\begin{tabular}{|c|c|c|c|c|c|c|}
\hline \multicolumn{5}{|c|}{ Agricultural production } & \multicolumn{2}{|c|}{ Forestry production } \\
\hline & $\begin{array}{l}\text { Crop area } \\
\text { (1 } 000 \text { ha) }\end{array}$ & $\begin{array}{c}\text { Proportion } \\
\text { of crop area } \\
\text { (\%) }\end{array}$ & $\begin{array}{l}\text { Production } \\
(1000 \mathrm{t} / \mathrm{yr})\end{array}$ & $\begin{array}{l}\text { Yield } \\
\text { (t/ha) }\end{array}$ & Product & $\begin{array}{l}\text { Production } \\
\left(1000 \mathrm{~m}^{3} / \mathrm{yr}\right)\end{array}$ \\
\hline Rice & 10360 & 58 & 27879 & 2.7 & Roundwood & 28315 \\
\hline $\begin{array}{l}\text { Natural } \\
\text { rubber }\end{array}$ & 1762 & 10 & 3121 & 1.8 & Wood fuel & 19615 \\
\hline Cassava & 1152 & 6 & 26411 & 22.9 & $\begin{array}{l}\text { Industrial } \\
\text { roundwood }\end{array}$ & 8700 \\
\hline $\begin{array}{l}\text { Sugar } \\
\text { cane }\end{array}$ & 1010 & 6 & 64365 & 63.7 & $\begin{array}{l}\text { Paper and } \\
\text { paperboard* }\end{array}$ & 4484 \\
\hline Maize & 942 & 5 & 3619 & 3.8 & $\begin{array}{l}\text { Wood-based } \\
\text { panels }\end{array}$ & 1365 \\
\hline $\begin{array}{l}\text { Oil palm } \\
\text { fruit }\end{array}$ & 435 & 2 & 7642 & 17.6 & Wood pulp* & 1025 \\
\hline Coconuts & 255 & 1 & 1705 & 6.7 & \multirow{4}{*}{\multicolumn{2}{|c|}{$* 1000 t$}} \\
\hline Bananas & 153 & 1 & 2000 & 13.1 & & \\
\hline $\begin{array}{l}\text { Beans, } \\
\text { dry }\end{array}$ & 144 & 1 & 113 & 0.78 & & \\
\hline Soybeans & 139 & 1 & 217 & 1.56 & & \\
\hline Total & 17800 & & 152085 & & 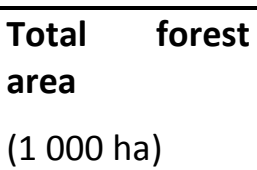 & 14520 \\
\hline
\end{tabular}

Source: FAOStat, 2009

Large-scale farming dominates export industries, but more than $80 \%$ of the farmers cultivate less than 6 ha of farmland. The majority of agricultural land is owned; only about $10 \%$ of total agricultural area is leased (TNSO, 2008). 


\section{Current situation of biofuel development}

\section{Current production of first-generation biofuels}

The main feedstock for bioethanol production in Thailand is sugar cane-based molasses. Sugar cane is cultivated on $1 \mathrm{Mha}$ ( $7 \%$ of arable land), with an annual production in 2008 totalling around $76 \mathrm{Mt}$ of sugar cane, 7.9 Mt of sugar and $3.8 \mathrm{Mt}$ of molasses, of which roughly $50 \%$ is used for bioethanol production (Bank of Thailand, 2009a). Most of the bioethanol plants use molasses, but the government promotes direct utilisation of sugar cane to increase bioethanol production (USDA-FAS, 2009). However, due to cost sharing agreements between farmers and sugar plants, utilisation of sugar cane juice is limited to single contaminated (e.g. through heavy metals) sugar cane areas. Cassava is another feedstock for bioethanol production with a cultivated area of 1 Mha and an annual production of $25 \mathrm{Mt}$. The single bioethanol plant based exclusively on cassava was running at full capacity in January 2009 producing 4.5 million I per month and utilising $25000 \mathrm{t}$ per month of cassava $^{24}$. Fuel ethanol production of the 11 operational bioethanol plants amounted to 309 million I in 2008 (IEA, 2009b). Capacity utilisation accounted for 77\% in January 2009 (1.3 million I per day), but actually Thailand holds a bioethanol surplus with twelve bioethanol plants under construction, since the government was expected to promote fuel ethanol more aggressively (F.O. Licht's, 2009; USDA-FAS, 2009).

The main feedstocks for biodiesel production are crude palm oil (CPO) (72\%), animal fat (24\%) and to a minor extent waste cooking oil (4\%) (JGSEE, 2009). The area for oil palm plantations increased to 450000 ha by replacing old orchards; fresh fruit bunch production is 6-7 Mt/yr (USDA-FAS, 2009) and CPO production amounted to $1.2 \mathrm{Mt}$ in 2008 (ISTA Mielke $\mathrm{GmbH}, 2009$ ). Nine B100 biodiesel plants operated at half their production capacity in 2008, with an annual production of 453 million I in 2008 (Thai Ministry of Energy, 2009; IEA, 2009b). Commercial biodiesel production only started in 2005 and has increased rapidly in recent years. Demand for raw material (CPO and stearin) is expected to increase to more than 1 million t per year until 2011, with almost 50\% of total palm oil production directed towards biodiesel production. The joint Committee on Biofuel Development and Promotion (CBDP) of the Ministry of Agriculture and Cooperatives and the Ministry of Energy plans to expand palm acreage by $0.4 \mathrm{Mha}$ and to increase fresh fruit bunch productivity from 18 to $22 \mathrm{t} / \mathrm{ha} / \mathrm{yr}$ (USDA-FAS, 2009).

\section{National policy target for biofuels}

There are various support measures promoting first-generation biofuel production and consumption in Thailand, such as price stabilisation programmes with guaranteed prices for sugar cane, cassava and fresh fruit bunches; import tax exemptions; investment subsidies for biofuel plants; guaranteed prices for biofuels ex-refinery; and reductions on excise taxes on E20 gasoholfuelled cars (JGSEE, 2009). There is no compulsory blending target for bioethanol, but consumption of different bioethanol-gasoline blends (E10, E20 and E85) is promoted by direct subsidies from the Energy Conservation Promotion Fund (ENCON) fund. Prices for bioethanol-gasoline blends are usually 0.25-0.35 USD/I below prices for pure gasoline (F.O. Licht's, 2009). In February 2008, compulsory production of $\mathrm{B} 2$ biodiesel and voluntary production of $\mathrm{B} 5$ biodiesel began. A subsidy of USD $0.01 /{ }^{25}$ is granted to B2 manufacturers (USDA-FAS, 2008).

\footnotetext{
${ }^{24}$ With an extraction rate of $5.6 \mathrm{~kg}$ cassava per litre bioethanol.

${ }^{25}$ Exchange rate 2008: 33.31Thai Baht/USD (Bank of Thailand, 2009b).
} 
The Thai government plans to support research on second-generation technology within a first phase through 2011 and to promote explicitly biodiesel and bioethanol produced from seaweed, jatropha, cellulose as well as BTL and hydrogenated biofuels (Thai Ministry of Energy, 2008).

\section{Financing and human resources}

Investment for energy projects are being promoted strongly by the Thai government, and business regulations were regarded very highly by World Bank experts in 2008 (World Bank, 2008a). Shortage of skilled production workers with English-language skills and IT knowledge is seen as a major constraint for the development of the economy, and it takes more time in Thailand to fill a vacancy for skilled personnel than in other Asian countries (World Bank, 2008c). Thailand ranks rather low in the Corruption Perceptions Index (Transparency International, 2008), and ongoing political instability threatens Thailand's BBB $+{ }^{26}$ credit rating, which could worsen access to external financing in the future (Top News, 2009).

\section{Infrastructure}

Thailand has a road network of about $57000 \mathrm{~km}$, of which approximately $99 \%$ is paved. Road conditions are good in central Thailand but are weak in the northern and hilly areas. The rail network totals about $4100 \mathrm{~km}$, for which development is focused on the improvement of facilities for freight/container transport, as opposed to network expansion. In terms of water transport, there are $1750 \mathrm{~km}$ of navigable inland waterways, and Thailand has eight deep-sea ports, with Bangkok Port and Laem Chabang Port as the largest. Water transport is mainly used for freight and has a strong potential to become an important part of Thailand's transport system, especially for container transport (World Bank, 2007; World Bank, 2008c; International Road Federation, 2006). The most important mode of transport today is road transport, with an $86 \%$ share of overall domestic freight transport. Rail transport accounts for only $2 \%$, while inland waterways along the two coasts account for $6 \%$ each (World Bank, 2008c).

The production of bioethanol is situated in the sugar cane regions in the northern, north-eastern and central parts of Thailand. At the moment, 11 plants, mainly based on sugar cane molasses or cassava, are producing bioethanol, but others have been licensed and are already under construction. Biodiesel production is situated in the southern and central parts of Thailand, where nine biodiesel plants are in operation (F.O. Licht's, 2009; USDA-FAS, 2009). In Thailand's industrial zones in the central region, about seven oil refineries of different sizes are situated and are used for blending diesel and petrol with biofuels.

Since biofuel production plants are mainly in the same regions as the processed feedstock, the typical transport distances between biomass source and plant are less than $100 \mathrm{~km}$ (e.g. less than $25 \mathrm{~km}$ for cassava and less than $50 \mathrm{~km}$ for sugar cane). The entire feedstock transport is done by road transport with light motor vehicles (e.g. pickup trucks) for short distances and heavy trucks for short and long distances. Depending on the transport vehicle used, the estimated transportation costs are between USD $0.03 / \mathrm{t} / \mathrm{km}$ for pickup trucks and USD $0.08 / \mathrm{t} / \mathrm{km}$ for commercial transportation trucks (Fiscal Policy Office Thailand, 2009).

\footnotetext{
${ }^{26}$ By credit rating of Standard \& Poor's or Fitch, BBB+ expresses a medium-safe long-term investment grade. It occurs often when an economy has deteriorated.
} 
The main share of biofuel produced in Thailand is used domestically in about $75 \%$ of the refuelling stations all over the country. Biodiesel is available at an estimated 3000 stations; bioethanol is available at more than 4000 stations, with 4000 E10, 290 E20, and three E85 stations (JGSEE, 2009). Thailand's total automotive fleet totals 20.7 million vehicles, $61 \%$ of which are motorcycles or three-wheelers (Table A59).

Table A59. Vehicle fleet in 2006

\begin{tabular}{|c|c|c|c|c|}
\hline 2 wheelers & $\mathbf{3}$ wheelers & PC+SUV & LCV's, LT's, MDT's, HDT's & Buses, Minibuses \\
\hline 11366000 & 1263000 & 3770000 & 4340000 & 49000 \\
\hline
\end{tabular}

PC: Passenger car; SUV: Sport utility vehicle; LCV: Light commercial vehicle; LT: Light truck; MDT: Medium duty truck; HDT: Heavy duty truck

Source: IEA Mobility Model, 2009

Domestic fuel consumption in the transport sector was $756 \mathrm{PJ}$ in 2007; diesel accounted for 65\%, gasoline for $30 \%$, LPG for $3 \%$ and biofuels for $2 \%$ (IEA Statistics, 2009). A projection for consumption in 2030 is also shown in Table A60.

Table A60. Fuel consumption in 2007 and projection for 2030

\begin{tabular}{|r|r|r|r|r|r|}
\hline & $\begin{array}{c}\text { Gasoline } \\
1000 \mathrm{t}(\mathrm{PJ})\end{array}$ & $\begin{array}{c}\text { Diesel } \\
1000 \mathrm{t}(\mathrm{PJ})\end{array}$ & $\begin{array}{c}\text { Natural Gas } \\
1000 \mathrm{t}(\mathrm{PJ})\end{array}$ & $\begin{array}{c}\text { LPG } \\
1000 \mathrm{t}(\mathrm{PJ})\end{array}$ & $\begin{array}{c}\text { Biofuels } \\
1000 \mathrm{t}(\mathrm{PJ})\end{array}$ \\
\hline $\mathbf{2 0 0 7}$ & $5229(226)$ & $11501(487)$ & $(9)$ & $561(28)$ & $200(6)$ \\
\hline $\mathbf{2 0 3 0 *}$ & $14078(607)$ & $30963(1312)$ & $(23)$ & $1477(74)$ & $900(27)$ \\
\hline
\end{tabular}

Source: IEA Statistics, 2009; *Assumption based on WEO 2008 data, assuming linear growth in each sector

\section{Feedstock assessment and logistics}

\section{Feedstock and cultivation areas}

As Thailand is one of the world leaders in agricultural production, residues from harvesting and processing of agricultural biomass are abundant. Since these residues contain lignocellulose, they are an adequate feedstock for the production of second-generation biofuels. As shown in Table A50, high energy potentials exist from processing rice (husks); sugar cane (bagasse) in the central, northern and north-eastern regions; and oil palm (EFB) and rubberwood in the southern regions. A considerable amount of this biomass potential is used for energy production and other purposes; other possible resources are residues from harvesting, which include rice straw, sugar cane leaves and tops or oil palm fronds. Other non-plantation biomass resources like stalks and leaves of sorghum or soybean are small and very scattered compared to rice and sugar cane residues, but also could be made available as a feedstock for second-generation biofuels (Sajjakulnukit et al., 2005; Prasertsan \& Sajjakulnukit, 2006; JGSEE, 2009; Laohalidanond et al., 2006).

Apart from annual crops, in the south of Thailand, large areas are cultivated with rubber and palm oil plantations. As the economic life of the trees is 25 to 30 years, $3-4 \%$ of the plantations are annually felled for reforestation and, together with the empty fruit bunches of oil palms, form a high biomass potential that is hardly used (Krukanont et al., 2005; Prasertsan \& Sajjakulnukit, 2006). 
There is currently no cultivation of dedicated energy crops for second-generation biofuel production in Thailand. As population density and agricultural activity are high, the amount of fallow or degraded land is small. Official statistics report 352000 ha of degraded land throughout Thailand, which could be activated as an additional source of biomass feedstock (TNSO, 2008).

Table A61. Assessment of residues from agriculture

\begin{tabular}{|c|c|c|c|c|}
\hline Type & $\begin{array}{c}\text { Actual material } \\
\text { flow } \\
\left(1000 t_{D M} / y r\right)\end{array}$ & $\begin{array}{l}\text { Unused residues } \\
\left.\text { (1000 } t_{D M} / \mathrm{yr}\right)\end{array}$ & $\begin{array}{c}\text { Regional } \\
\text { availability }\end{array}$ & Main utilisation \\
\hline \multicolumn{5}{|l|}{ Primary residues } \\
\hline Rice straw & 20250 & 9900 & $\mathrm{~N}, \mathrm{NE}$, Central & Used as fodder \\
\hline Oil palm frond & 8065 & n.a. & $S$ & Used as fertiliser \\
\hline $\begin{array}{ll}\text { Sugar } & \text { cane } \\
\text { residues }^{\mathrm{a}} & \end{array}$ & 7525 & 3500 & $\mathrm{~N}, \mathrm{NE}$, Central & $\begin{array}{l}50 \% \text { is burnt, rest left } \\
\text { on the fields }\end{array}$ \\
\hline $\begin{array}{l}\text { Maize } \\
\text { stems) }\end{array}$ & 3112 & n.a. & $\mathrm{N}, \mathrm{NE}$, Central & Used as fodder \\
\hline Cassava rhizome & 2446 & n.a. & $\mathrm{N}, \mathrm{NE}$, Central & $\begin{array}{l}\text { Given back to the } \\
\text { farmers }\end{array}$ \\
\hline Eucalyptus & 2324 & n.a. & NE & \\
\hline Rubber wood & 1510 & n.a. & $S$ & \\
\hline Cassava stalk & 854 & n.a. & $\mathrm{N}, \mathrm{NE}$, Central & \\
\hline $\begin{array}{l}\text { Soybean stalks, } \\
\text { leaves }\end{array}$ & 238 & n.a. & $N, N E$ & \\
\hline Coconut frond & 165 & 165 & $S$ & \\
\hline $\begin{array}{l}\text { Sorghum (leaves, } \\
\text { stems) }\end{array}$ & 35 & 0 & $\mathrm{~N}$, Central & \\
\hline Cotton stalk & 4 & 0 & $\mathrm{~N}$, Central & Used as fodder \\
\hline \multicolumn{5}{|l|}{ Secondary residues } \\
\hline Bagasse & 9835 & 0 & $\mathrm{~N}, \mathrm{NE}$, Central & $\begin{array}{l}\text { Used for energy and } \\
\text { heat production at } \\
\text { sugar mills, surplus } \\
\text { electricity fed into } \\
\text { the grid }\end{array}$ \\
\hline Rice husk & 5783 & 1446 & $\mathrm{~N}, \mathrm{NE}$, Central & $\begin{array}{l}\text { Used for heat and } \\
\text { energy production }\end{array}$ \\
\hline Oil palm EFB & 1142 & n.a. & $S$ & $\begin{array}{l}\text { Used for heat and } \\
\text { energy production }\end{array}$ \\
\hline
\end{tabular}




\begin{tabular}{|l|r|r|l|l|}
\hline \multicolumn{1}{|c|}{ Type } & $\begin{array}{c}\text { Actual material } \\
\text { flow } \\
\left(1000 \mathrm{t}_{\mathrm{DM}} / \mathrm{yr}\right)\end{array}$ & $\begin{array}{c}\text { Unused residues } \\
\left(1000 \mathrm{t}_{\mathrm{DM}} / \mathrm{yr}\right)\end{array}$ & $\begin{array}{c}\text { Regional } \\
\text { availability }\end{array}$ & \multicolumn{1}{|c|}{ Main utilisation } \\
\hline Oil palm fibres & 924 & 0 & $\mathrm{~S}$ & $\begin{array}{l}\text { Used for heat and } \\
\text { energy production }\end{array}$ \\
\hline $\begin{array}{l}\text { Rubberwood (saw } \\
\text { dust) }\end{array}$ & 755 & n.a. & S & Used for heat and \\
\hline energy production
\end{tabular}

Sources: Sajjakulnukit et al., 2005; Prasertsan \& Sajjakulnukit, 2006; Krukanont et al., 2005; JGSEE, 2009; Laohalidanond et al., 2006; TNSO, 2008

\section{Second generation biofuel options}

The calculations presented below, are based on actual material flows as well as unused residues (Table A62) and are, only a theoretical estimation. For every second-generation biofuel option, not all types of residues are considered suitable. However, this is the aim of further development and as a consequence all types of residues were considered suitable for every pathway. Biofuel production as well as the potential number of conversion plants is higher based on primary residues than on secondary residues.

Potential second-generation biofuel production based on the unused residues could provide $6-8 \%$ of the projected fuel demand for 2030. As there are high opportunity costs and high costs associated with biomass provision, only a small percentage of the residues could be used; nevertheless, the potential for second-generation biofuel production in Thailand is considerable. 
Table A62. Potential second-generation biofuel production and number of plants

\begin{tabular}{|c|c|c|c|c|c|c|}
\hline \multirow{3}{*}{$\begin{array}{l}\text { Biofuel } \\
\text { option }\end{array}$} & \multicolumn{4}{|c|}{ Production } & \multicolumn{2}{|c|}{$\begin{array}{l}\text { Number of plants } \\
\text { (based on unused residues) }\end{array}$} \\
\hline & \multicolumn{2}{|c|}{ Actual flow } & \multicolumn{2}{|c|}{ Unused residues } & \multirow[b]{2}{*}{ small scale* } & \multirow[b]{2}{*}{ large scale* } \\
\hline & Mlge/yr* & $\mathrm{PJ} / \mathrm{yr}$ & Mlge/yr* & $\mathrm{PJ} / \mathrm{yr}$ & & \\
\hline \multicolumn{7}{|c|}{ Based on primary residues } \\
\hline Bio-SNG & 14564 & 487.9 & 4178 & 140.0 & 225 & 30 \\
\hline BTL & 10259 & 343.7 & 2943 & 98.6 & 27 & 7 \\
\hline Bioethanol & 10115 & 338.9 & 2902 & 97.2 & 218 & 18 \\
\hline \multicolumn{7}{|c|}{ Based on secondary residues } \\
\hline Bio-SNG & 5942 & 199.1 & 657 & 22.0 & 35 & 5 \\
\hline BTL & 4186 & 140.2 & 463 & 15.5 & 4 & 1 \\
\hline Bioethanol & 4127 & 138.3 & 456 & 15.3 & 34 & 3 \\
\hline \multicolumn{7}{|c|}{$\begin{array}{l}\text { Remark: Biofuel options are calculated using 100\% of actual material flow and 100\% of unused residues for each option. } \\
\text { * Assumed conversion factors - BTL: } 217 \text { Ige/ } \mathrm{t}_{\mathrm{DM}} \text {; ethanol: } 214 \text { Ige/ } \mathrm{t}_{\mathrm{DM}} \text {; bio-SNG: } 307 \text { Ige/ } \mathrm{t}_{\mathrm{DM}} \\
\text { **Based on typical plant sizes - Bio-SNG: } 23-170 \mathrm{MW}_{\text {biofuel }} \text { BTL: } 130-500 \mathrm{MW}_{\text {biofuel }} \text { bioethanol: } 15-185 \mathrm{MW}_{\text {biofuel }}(\mathrm{DBFZ}, 2008)\end{array}$} \\
\hline
\end{tabular}

\section{Estimated costs for feedstock and end product}

Thailand offers various feedstocks that could be used for second-generation biofuels production. The general infrastructure provides favourable conditions for large biofuel plants with high biomass demand and transport over various kilometres. Abundant agricultural residues, such as rice straw (USD 33-45/ $\mathrm{t}_{\mathrm{FM}}$ for baled straw) and tops and leaves of sugar cane (no price yet), have rather low prices; thus, total feedstock costs could be low. However, rice straw availability is dispersed among millions of smallholder producers and poses a logistical challenge which would increase provision costs considerably. By-products of sugar cane and rice processing such as bagasse (USD 8-15/ $\mathrm{t}_{\mathrm{FM}}$ ) and rice husks (USD 8-35/ $\mathrm{t}_{\mathrm{FM}}$ ) present a broad range of prices, but since they are already used for power generation and electricity surplus exports at production plants, prices would probably increase through competing demand for second-generation biofuels production (JGSEE, 2009).

Theoretical production costs for BTL-diesel and lignocellulosic ethanol are given in Table A63. The costs are base on current IEA analysis and the feedstock costs mentioned above. Currently, secondgeneration biofuels could be produced at costs of USD $0.58-0.68 /$ Ige if rice husks or bagasse are used, and USD 0.67-0.77/Ige if straw is used (Table A63).

Despite being a major rice and sugar producer and exporter, production costs in Thailand are higher than in neighbouring south-east Asian countries. Therefore, Thai agricultural companies are already investing in these countries because of their larger land resources and cheaper labour forces. Thus, rather than a feedstock distributor within the region, Thailand could be a promising location for biofuel conversion technologies, since Thailand has had experience with first-generation biofuels 
and possesses good infrastructure. Currently there is an oversupply of molasses-based bioethanol in the domestic market; therefore, Thailand could expand its bioethanol production with cellulosic ethanol if it could be produced economically for export.

Table A63. Theoretical second-generation biofuel production costs in Thailand

\begin{tabular}{|c|c|c|c|c|c|}
\hline \multirow[t]{3}{*}{ Feedstock } & \multirow{3}{*}{$\begin{array}{l}\text { Feedstock } \\
\text { price }\end{array}$} & \multicolumn{4}{|c|}{ oil USD $60 / \mathrm{bbl}$} \\
\hline & & \multicolumn{2}{|c|}{ Today (USD/Ige) } & \multicolumn{2}{|c|}{ Long term (USD/Ige) } \\
\hline & & BTL-diesel & LC-ethanol & BTL-diesel & LC-ethanol \\
\hline Straw/stalks & $33-45$ & $0.67-0.72$ & $0.67-0.77$ & $0.41-0.50$ & $0.41-0.50$ \\
\hline Rice husks & $8-15$ & $0.58-0.61$ & $0.58-0.61$ & $0.35-0.39$ & $0.39-0.43$ \\
\hline \multirow[t]{2}{*}{ Bagasse } & $8-15$ & $0.60-0.66$ & $0.60-0.68$ & $0.37-0.42$ & $0.34-0.42$ \\
\hline & & \multicolumn{4}{|c|}{ oil USD 120/bbl } \\
\hline Straw/stalks & $33-45$ & $0.84-0.91$ & $0.78-0.88$ & $0.53-0.58$ & $0.45-0.54$ \\
\hline Rice husks & $8-15$ & $0.75-0.79$ & $0.67-0.72$ & $0.46-0.62$ & $0.36-0.57$ \\
\hline Bagasse & $8-15$ & $0.77-0.85$ & $0.69-0.80$ & $0.47-0.54$ & $0.37-0.46$ \\
\hline
\end{tabular}

Source: Based on IEA Mobility Model, 2009

\section{Identification of hot spots for production plants}

As already mentioned above, Thailand promotes both bioethanol and biodiesel production, but there is a large bioethanol surplus already. Today, biodiesel is produced solely from oil palm, and there are only limited possibilities to increase plantations. Thus, additional biomass sources would have to be exploited in order to satisfy increasing diesel demand. Large amounts of unused lignocellulosic primary residues like rice straw and sugar cane trash would be suitable for secondgeneration biofuels and are available in the central and north-eastern parts of the country. Low yields and the large size of potential production plants make biomass supply a challenging issue. Due to its good transportation and infrastructure, and its proximity to raw materials, Thailand's central area seems to be a feasible hot spot for the production of second-generation biofuels. Large amounts of crude palm oil are already transported from the south to the biodiesel plants located close to Bangkok and to the refineries for blending with diesel. Central Thailand is also the country's industrial zone, which makes it easier to sell by-products like process-heat and help increase overall efficiencies.

In the south of Thailand, large amounts of palm oil residues (e.g. empty fruit bunches) and residues of rubberwood (e.g. bark) are available. Since $50 \%$ of existing biodiesel production is already established in this region because of feedstock availability, this part of Thailand seems to be a second hot spot for the production of second-generation biofuels.

Another option is to produce bio-SNG (gaseous biomethane) in a bio-SNG plant, which is also possible on a small scale as with bioethanol. The gas could be fed into a gas pipeline and distributed to different applications. However, the utilisation of gaseous biofuels does not seem realistic in the mid term since there are only a few gas pipelines and an infrastructure (e.g. refuelling stations and vehicle fleets) would have to be established. 


\section{Sustainability}

\section{Potential economic impact}

Page | 196 Thailand is highly dependent on imports of crude oil and fossil oil products (and to a lesser extent on gas and coal imports) and spends roughly $10 \%$ of GDP on these imports. Thus, the production of second-generation biofuels could increase energy security and contribute to foreign currency savings.

Production costs for some agricultural products, such as sugar, rice and palm oil, are comparatively high; since their by-products and/or residues would be potential feedstocks for second-generation technologies, a first step could be to reduce feedstock production costs in general through agricultural R\&D (Fresh Plaza, 2008). However, since the government frequently intervenes in agricultural markets in order to combat rural poverty, the incentives to increase cost-efficiency are low (Reuters, 2009). The necessity for agricultural subsidies could be reduced if agricultural residues like rice straw could be used for second-generation biofuels production.

At the end of the supply chain, first-generation biofuels are currently subsidised through the ENCON fund. This fund is financed in part by taxes on gasoline, which means that extra costs are passed along to consumers. Hence, if this approach were adopted for second-generation biofuels, the impact on the national budget would be limited. However, if first-generation biofuel consumption increases, as planned by the government, there would be few resources to promote secondgeneration biofuels. In the case of lignocellulosic residues and by-products, opportunity costs could be high, since import dependency for electricity generation in Thailand is high, and bagasse and rice husks for second-generation biofuels already compete with their use at sugar/rice plants and biomass power plants (JGSEE, 2009).

\section{Potential social impact}

Since the most promising feedstock in Thailand for second-generation biofuels production would be agricultural by-products and residues, material effects on the size of the agricultural sector workforce would be limited. However, the utilisation of by-products like rice straw could help secure farmers' income by adding value to these materials (JGSEE, 2009). The use of these residues also offers opportunities for the integration of smallholders into feedstock provision for secondgeneration biofuels. However, the question remains how the contractual and logistical problems could be solved.

Net effects on the labour force would likely be limited to the biomass conversion process, but since only few large plants would be feasible for Thailand, the actual number of jobs created would not be very high. Because of the specialised labour and skill sets required in production plants, the current shortage of skilled engineers could be a bottleneck to the establishment of a secondgeneration biofuel industry.

Since Thailand is a food-exporting country, competition between land for food or feed is not yet an issue (FAOStat, 2009). Despite the food surplus, the percentage of undernourished people is slightly worse (17\% in 2003-05) than the south-east Asian average (16\%), which indicates that the access to food is distributed unequally (FAO, 2008c). Rural communities in the northern and north-eastern regions are particularly vulnerable to food price increases (FIVIMS, 2005). Thus, food prices rather than food availability are decisive for food security in Thailand. Using agricultural or forestry 
residues for second-generation biofuels could contribute to an increase of farmers' income and thus enhance purchasing power of these vulnerable groups. However, since hot-spot locations for second-generation plants are in the more developed regions in central Thailand, such development seems rather unlikely.

\section{Potential environmental impact}

Since there is no commercial biofuel production in Thailand yet, there is no data on the environmental impact of current biofuel production. Therefore, some general comparisons between different biofuel options are described in Chapter 8.3.

The use of the potential available residues and wastes (e.g. rice husks, bagasse, sugar cane tops, oil palm residues, fibres, shells) as feedstock for second-generation biofuels in Thailand could help to reduce the possible environmental impact from feedstock production and help to take pressure off areas that are not used for agricultural purposes. Therefore, using these residues could significantly increase the mitigation of GHG emissions compared to the production and use of fossil fuels and could help to decrease local negative environmental impacts on biodiversity, acidification and eutrophication.

\section{SWOT analysis}

Table A64. Summary of SWOT analysis

\begin{tabular}{|c|c|}
\hline STRENGTHS & $\begin{array}{l}\text { - Huge availability of by-products and residues } \\
\text { - Experience in large-scale biofuel production } \\
\text { - Established biofuel support policies } \\
\text { - Public promotion of investment in energy projects }\end{array}$ \\
\hline WEAKNESSES & $\begin{array}{l}\text { - } \quad \text { Logistics for feedstocks on a large scale (e.g. straw, tops/leaves) } \\
\text { - } \quad \text { Competition for use of by-products (e.g. bagasse, rice husks, wood residues) } \\
\text { - } \quad \text { Shortage of skilled engineers } \\
\text { - } \quad \text { Contracts and logistics related to the integration of smallholders } \\
\text { - Unstable policy environment }\end{array}$ \\
\hline OPPORTUNITIES & $\begin{array}{l}\text { - Integration of smallholders (income diversification) } \\
\text { - Reduction of dependency on fossil fuels } \\
\text { - Regional centre for technology dissemination } \\
\text { - Regional hub for biofuel exports }\end{array}$ \\
\hline THREATS & $\begin{array}{l}\text { - Credibility risk for un-established technologies } \\
\text { - Competition for agricultural land }\end{array}$ \\
\hline
\end{tabular}

\section{Conclusions}

As a major agricultural producing and exporting country, Thailand has considerable amounts of agricultural residues and by-products suitable for second-generation biofuels production. But the 
competing uses for agricultural by-products (e.g. rice husks and bagasse) for heat and power generation, plus the logistical challenges related to provisioning agricultural residues (as with straw), reduce the technical biomass potential and increase costs significantly. However, the availability of biomass feedstock is considerable, and since land availability for dedicated energy crops or short rotation coppice is limited, second-generation biofuels based on residues and by-

Page | 198 products would be an option for Thailand to explore. Sugar cane residues in central Thailand, woody biomass and residues from oil palm production in the south, and sugar cane, rice and cassava residues in the north-east could all be interesting feedstock options and overlap well with the main fuel consumption centres of the country.

The general infrastructure in Thailand, as well as the infrastructure related to biomass provision and biofuel production and distribution, favour the development of second-generation biofuels. The country has an extensive road network and already has a well-developed infrastructure for distribution of first-generation biofuels, such as bioethanol-gasoline blends (E10, E20, E85) and biodiesel-diesel blends (B2, B5). Thailand has already implemented specific promotion policies for first-generation biofuels and plans to promote research and development on second-generation policies. Second-generation biofuel production could help to meet biofuel targets in the diesel segment particularly, since the production potential of biodiesel from crude palm oil is limited due to restrictions on palm oil expansion.

Thus, despite current political instability, the biofuel-specific policy framework is quite favourable and stable in Thailand. Specific policies for second-generation biofuels should focus on regional cooperation and dissemination of R\&D in order to integrate Thailand's capacity as a biofuel producer with the capacity of neighbouring countries, like Vietnam, to be feedstock providers. 


\section{Annex B}

Table A57. Overview of applied residue-to-product (RPR) ratios

\begin{tabular}{|c|c|c|c|c|c|}
\hline Product & $\begin{array}{l}\text { Moisture } \\
\text { content } \\
(\%)\end{array}$ & $\begin{array}{l}\text { Residue- } \\
\text { to-product } \\
\text { ratio }\end{array}$ & Product & $\begin{array}{l}\text { Moisture } \\
\text { content } \\
(\%)\end{array}$ & $\begin{array}{l}\text { Residue-to- } \\
\text { product } \\
\text { ratio }\end{array}$ \\
\hline Agave Fibres & 15 & 2.00 & Mangoes, guavas & 40 & 1.00 \\
\hline $\begin{array}{l}\text { Almonds, with } \\
\text { shell }\end{array}$ & 15 & 2.00 & Melonseed & 40 & 1.50 \\
\hline Apples & 40 & 1.00 & Millet & 15 & 3.00 \\
\hline Apricots & 40 & 1.00 & Mixed grain & 15 & 1.50 \\
\hline Arecanuts & 15 & 2.00 & Mustard seed & 40 & 2.00 \\
\hline Artichokes & 85 & 1.25 & Nuts & 15 & 2.00 \\
\hline Asparagus & 85 & 1.25 & Oats & 15 & 2.00 \\
\hline Avocados & 40 & 1.00 & Oil palm fruit & 60 & 0.25 \\
\hline Bambara beans & 10 & 2.50 & Oilseeds & 40 & 1.50 \\
\hline Bananas & 40 & 1.00 & Okra & 85 & 1.25 \\
\hline Barley & 15 & 1.70 & Olives & 35 & 1.50 \\
\hline Beans, dry & 10 & 2.50 & Onions, green & 85 & 1.25 \\
\hline Beans, green & 85 & 1.25 & Onions, dry & 85 & 1.25 \\
\hline $\begin{array}{l}\text { Brazil nuts, with } \\
\text { shell }\end{array}$ & 15 & 2.00 & Oranges & 40 & 1.00 \\
\hline $\begin{array}{l}\text { Broad beans, horse } \\
\text { beans, dry }\end{array}$ & 10 & 2.50 & Papayas & 40 & 1.00 \\
\hline Buckwheat & 15 & 1.50 & $\begin{array}{l}\text { Peaches and } \\
\text { nectarines }\end{array}$ & 40 & 1.00 \\
\hline $\begin{array}{l}\text { Cabbages and } \\
\text { other brassicas }\end{array}$ & 85 & 1.25 & Pears & 40 & 1.00 \\
\hline Canary seed & 15 & 1.50 & Peas, dry & 10 & 2.50 \\
\hline Carobs & 85 & 1.25 & Peas, green & 85 & 1.25 \\
\hline Carrots and turnips & 85 & 1.25 & Persimmons & 40 & 1.00 \\
\hline $\begin{array}{l}\text { Cashew nuts, with } \\
\text { shell }\end{array}$ & 15 & 2.00 & Pigeon peas & 10 & 2.50 \\
\hline Cashewapple & 40 & 1.00 & Pineapples & 40 & 1.00 \\
\hline
\end{tabular}




\begin{tabular}{|c|c|c|c|c|c|}
\hline Product & $\begin{array}{l}\text { Moisture } \\
\text { content } \\
(\%)\end{array}$ & $\begin{array}{l}\text { Residue- } \\
\text { to-product } \\
\text { ratio }\end{array}$ & Product & $\begin{array}{l}\text { Moisture } \\
\text { content } \\
(\%)\end{array}$ & $\begin{array}{l}\text { Residue-to- } \\
\text { product } \\
\text { ratio }\end{array}$ \\
\hline Cassava & 65 & 0.20 & Pistachios & 15 & 2.00 \\
\hline $\begin{array}{l}\text { Cauliflowers and } \\
\text { broccoli }\end{array}$ & 85 & 1.25 & Plantains & 40 & 1.00 \\
\hline Cereals & 15 & 1.50 & Plums and sloes & 40 & 1.00 \\
\hline Cherries & 40 & 1.00 & Popcorn & 15 & 1.50 \\
\hline Chestnuts & 15 & 2.00 & Poppy seed & 40 & 1.50 \\
\hline Chick peas & 10 & 2.50 & Potatoes & 65 & 0.75 \\
\hline Chicory roots & 85 & 1.25 & Pulses & 10 & 2.50 \\
\hline $\begin{array}{l}\text { Chillies and } \\
\text { peppers, green }\end{array}$ & 85 & 1.25 & $\begin{array}{l}\text { Pumpkins, squash } \\
\text { and gourds }\end{array}$ & 85 & 1.25 \\
\hline Citrus fruit & 40 & 1.00 & Quinces & 40 & 1.00 \\
\hline Cocoa beans & 15 & 1.00 & Quinoa & 15 & 1.50 \\
\hline Coconuts & 10 & 0.60 & Ramie & 15 & 2.00 \\
\hline Coffee, green & 15 & 2.10 & Rapeseed & 40 & 2.75 \\
\hline Cow peas, dry & 10 & 2.50 & Rice, paddy & 15 & 1.50 \\
\hline $\begin{array}{l}\text { Cucumbers and } \\
\text { gherkins }\end{array}$ & 85 & 1.25 & Roots and Tubers & 65 & 0.50 \\
\hline Dates & 40 & 1.00 & Rye & 15 & 2.00 \\
\hline $\begin{array}{l}\text { Eggplants } \\
\text { (aubergines) }\end{array}$ & 85 & 1.25 & Safflower seed & 40 & 1.50 \\
\hline Fibre Crops & 15 & 2.00 & Seed cotton & 15 & 3.50 \\
\hline Figs & 40 & 1.00 & Sesame seed & 40 & 2.00 \\
\hline Fonio & 15 & 1.50 & Sisal & 15 & 2.00 \\
\hline Fruit, fresh & 40 & 1.00 & Sorghum & 15 & 2.62 \\
\hline $\begin{array}{l}\text { Fruit, tropical, } \\
\text { fresh }\end{array}$ & 40 & 1.00 & Sour cherries & 40 & 1.00 \\
\hline Garlic & 85 & 1.25 & Soybeans & 15 & 2.50 \\
\hline $\begin{array}{l}\text { Grapefruit } \quad \text { (inc. } \\
\text { pomelos) }\end{array}$ & 40 & 1.00 & Spinach & 85 & 1.25 \\
\hline Grapes & 40 & 1.20 & Stone fruit & 40 & 1.00 \\
\hline $\begin{array}{l}\text { Groundnuts, with } \\
\text { shell }\end{array}$ & 15 & 2.50 & String beans & 85 & 1.25 \\
\hline
\end{tabular}




\begin{tabular}{|l|r|r|l|r|r|}
\hline Product & $\begin{array}{l}\text { Moisture } \\
\text { content } \\
\text { (\%) }\end{array}$ & \multicolumn{1}{|l|}{$\begin{array}{l}\text { Residue- } \\
\text { to-product } \\
\text { ratio }\end{array}$} & Product & $\begin{array}{l}\text { Moisture } \\
\text { content } \\
\text { (\%) }\end{array}$ & $\begin{array}{l}\text { Residue-to- } \\
\text { product } \\
\text { ratio }\end{array}$ \\
\hline Gums Natural & 15 & 2.00 & Sugar beet & 75 & 0.65 \\
\hline $\begin{array}{l}\text { Hazelnuts, with } \\
\text { shell }\end{array}$ & 15 & 2.00 & Sugar cane & 75 & 0.30 \\
\hline Hempseed & 40 & 1.50 & Sunflower seed & 40 & 2.62 \\
\hline Jute & 15 & 2.00 & Sweet potatoes & 65 & 0.60 \\
\hline Kapokseed in shell & 40 & 2.00 & Taro & 65 & 0.20 \\
\hline Karite nuts & 40 & 1.50 & Tobacco & 75 & 1.00 \\
\hline Kiwi fruit & 40 & 1.00 & Tomatoes & 15 & 1.25 \\
\hline Kolanuts & 15 & 2.00 & Triticale & 40 & 1.50 \\
\hline Lemons and limes & 40 & 1.00 & Tung nuts & 15 & 1.25 \\
\hline Lentils & 10 & 2.50 & Vegetables, fresh & 15 & 2.00 \\
\hline Lettuce and chicory & 85 & 1.25 & Walnuts, with shell & 65 & 0.20 \\
\hline Linseed & 40 & 1.50 & Wheat & 65 & 0.20 \\
\hline Maize & 15 & 1.50 & Yams & & \\
\hline Maize, green & 85 & 1.25 & Yautia & & \\
\hline
\end{tabular}

Source: Koopmans \& Koppejahn, 1997; OECD, 2004; Fischer et al., 2007

Table A58. Theoretical second-generation biofuel production costs in studied countries

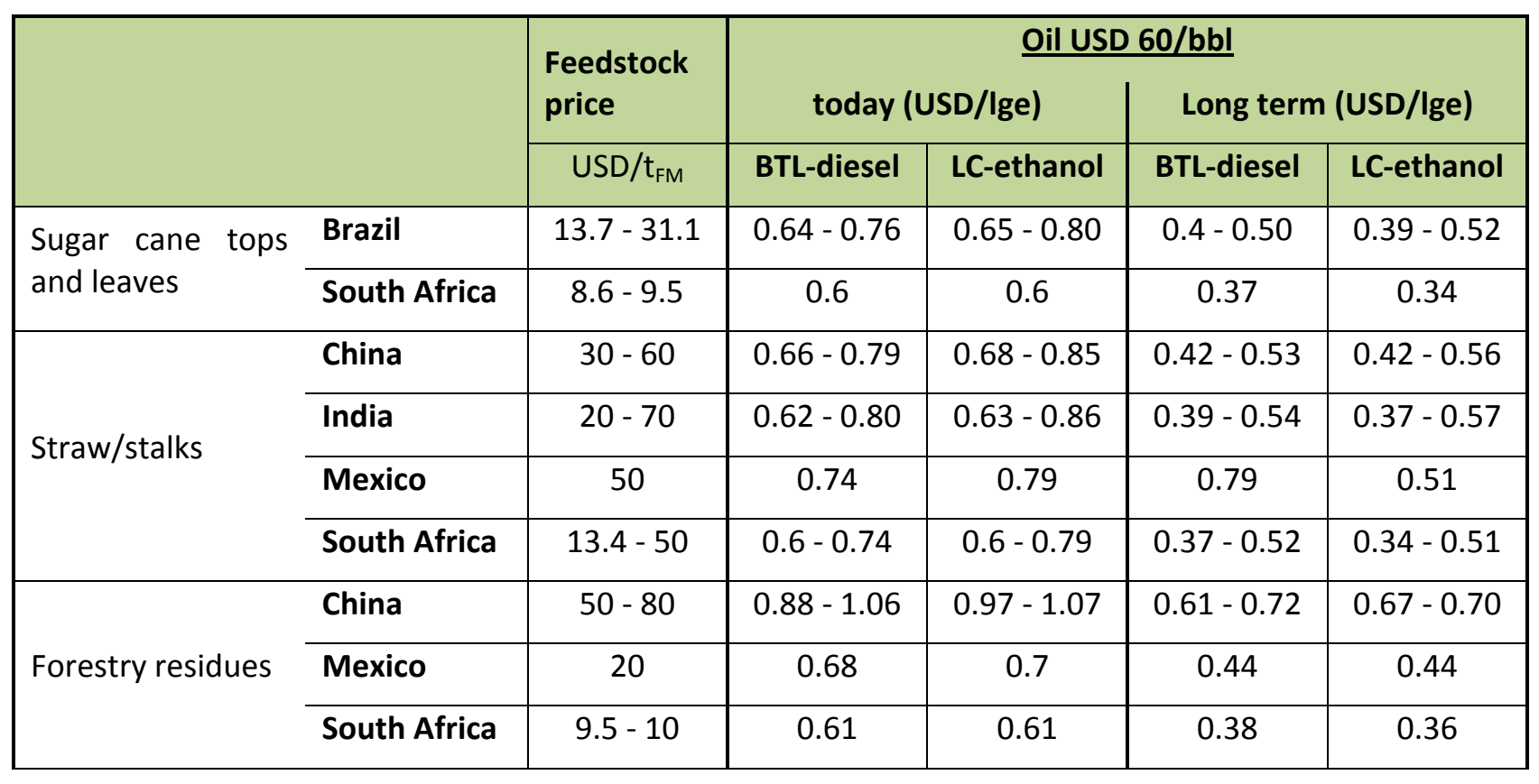




\begin{tabular}{|c|c|c|c|c|c|c|}
\hline & \multirow{3}{*}{$\begin{array}{l}\begin{array}{l}\text { Feedstock } \\
\text { price }\end{array} \\
\text { USD/t } t_{\mathrm{FM}}\end{array}$} & \multicolumn{4}{|c|}{ Oil USD $60 / \mathrm{bbl}$} \\
\hline & & & \multicolumn{2}{|c|}{ today (USD/Ige) } & \multicolumn{2}{|c|}{ Long term (USD/Ige) } \\
\hline & & & BTL-diesel & LC-ethanol & BTL-diesel & LC-ethanol \\
\hline \multirow{4}{*}{ Bagasse } & Brazil & $4-8$ & $0.57-0.60$ & $0.55-0.60$ & $0.34-0.37$ & $0.3-0.34$ \\
\hline & China & 30 & 0.75 & 0.79 & 0.5 & 0.51 \\
\hline & India & $20-30$ & $0.68-0.75$ & $0.70-0.79$ & $0.44-0.5$ & $0.44-0.51$ \\
\hline & South Africa & $7.3-8.4$ & $0.59-0.6$ & $0.59-0.6$ & $0.36-0.37$ & 0.34 \\
\hline \multirow{2}{*}{ Saw mill residues } & Brazil & $16-23$ & $0.65-0.80$ & $0.67-0.86$ & $0.41-0.54$ & $0.4-0.57$ \\
\hline & South Africa & $20-26$ & 0.61 & 0.61 & 0.38 & 0.36 \\
\hline & & \multirow{2}{*}{$\begin{array}{l}\text { Feedstock } \\
\text { price }\end{array}$} & \multicolumn{4}{|c|}{ Oil USD $120 / \mathrm{bbl}$} \\
\hline & & & \multicolumn{2}{|c|}{ today (USD/Ige) } & \multicolumn{2}{|c|}{ long term (USD/Ige) } \\
\hline & & $\mathrm{USD} / \mathrm{t}_{\mathrm{FM}}$ & BTL-diesel & LC-ethanol & BTL-diesel & LC-ethanol \\
\hline \multirow{2}{*}{$\begin{array}{l}\text { Sugar cane tops } \\
\text { and leaves }\end{array}$} & Brazil & $13.7-31.1$ & $0.82-0.93$ & $0.75-0.9$ & $0.51-0.61$ & $0.42-0.56$ \\
\hline & South Africa & $8.6-9.5$ & 0.78 & 0.7 & 0.48 & 0.39 \\
\hline \multirow{4}{*}{ Straw/stalks } & China & $30-60$ & $0.84-0.97$ & $0.78-0.95$ & $0.53-0.64$ & $0.45-0.60$ \\
\hline & India & $20-70$ & $0.80-0.98$ & $0.73-0.96$ & $0.50-0.65$ & $0.41-0.61$ \\
\hline & Mexico & 50 & 0.92 & 0.89 & 0.6 & 0.55 \\
\hline & South Africa & $13.4-50$ & $0.78-0.92$ & $0.7-0.89$ & $0.48-0.60$ & $0.38-0.55$ \\
\hline \multirow{3}{*}{ Forestry residues } & China & $50-80$ & $1.08-1.26$ & $1.23-1.33$ & $0.78-0.89$ & $0.9-0.94$ \\
\hline & Mexico & 20 & 0.86 & 0.81 & 0.55 & 0.47 \\
\hline & South Africa & $9.5-10$ & 0.79 & 0.71 & 0.49 & 0.39 \\
\hline \multirow{4}{*}{ Bagasse } & Brazil & $4-8$ & $0.74-0.78$ & $0.66-0.70$ & $0.45-0.48$ & $0.34-0.38$ \\
\hline & China & 30 & 0.92 & 0.89 & 0.6 & 0.55 \\
\hline & India & $20-30$ & $0.86-0.92$ & $0.81-0.89$ & $0.55-0.6$ & $0.47-0.55$ \\
\hline & South Africa & $7.3-8.4$ & $0.77-0.78$ & $0.69-0.7$ & $0.47-0.48$ & $0.37-0.38$ \\
\hline \multirow{2}{*}{ Saw mill residues } & Brazil & $16-23$ & $0.83-0.98$ & $0.77-0.96$ & $0.52-0.65$ & $0.44-0.61$ \\
\hline & South Africa & $20-26$ & 0.79 & 0.72 & 0.49 & 0.4 \\
\hline
\end{tabular}




\section{Abbreviations}

\begin{tabular}{|c|c|}
\hline$A R$ & as received \\
\hline B2 & biodiesel-diesel blend with $2 \%$ biodiesel (B5 = 5\% biodiesel; B100 = pure biodiesel) \\
\hline BNDES & Banco Nacional de Desenvolvimento Econômico e Social (Brazilian Development Bank) \\
\hline BTL & biomass-to-liquid \\
\hline CBI & Caribbean Basin Initiative \\
\hline CBPD & Committee on Biofuel Development and Promotion \\
\hline CDM & clean development mechanism \\
\hline CONACYT & Consejo Nacional de Ciencia y Tecnología \\
\hline CPO & crude palm oil \\
\hline CTL & coal-to-liquid \\
\hline DM & dry matter \\
\hline E85 & ethanol-gasoline blend with $85 \%$ ethanol (E10 $=10 \%$ ethanol; $E 100=$ pure ethanol) \\
\hline EC & European Commission \\
\hline EFB & empty fruit bunch \\
\hline EISA & Energy Independence and Security Act \\
\hline ENCON & Energy Conservation Promotion Fund \\
\hline $\mathrm{EtOH}$ & ethanol \\
\hline ETP & Energy Technology Perspectives \\
\hline EU & European Union \\
\hline EUR & Euro \\
\hline FAO & Food and Agriculture Organization of the United Nations \\
\hline FCFA & Franc Communauté Financière Africaine (Franc of the African Financial Community) \\
\hline FDI & foreign direct investment \\
\hline FM & fresh matter \\
\hline FT & Fischer-Tropsch \\
\hline GDP & gross domestic product \\
\hline GE & gasoline equivalent \\
\hline GHG & greenhouse gas \\
\hline GSP & Generalised System of Preferences \\
\hline GVA & gross value added \\
\hline HDI & human development index \\
\hline IDB & Inter-American Development Bank \\
\hline IEA & International Energy Agency \\
\hline IIASA & International Institute for Applied Systems Analysis \\
\hline IOC & Indian Oil Company \\
\hline IPCC & Intergovernmental Panel on Climate Change \\
\hline ITTO & International Tropical Timber Organisation \\
\hline JGSEE & The Joint Graduate School of Energy and Environment \\
\hline kW & kilowatt (1000 W) \\
\hline LC & lignocellulosic \\
\hline LCA & life cycle assessment \\
\hline LPG & liquefied petroleum gas \\
\hline MTBE & methyl tertiary butyl ether \\
\hline MWe & megawatt electric \\
\hline
\end{tabular}


MWth megawatt thermal

NAFTA North American Free Trade Agreement

NES not elsewhere specified

NGO Non-governmental organisation

NREL US National Renewable Energy Laboratory not available

OECD Organisation for Economic Co-operation and Development

PEMEX Petróleos Mexicanos

PESA Programa Especial para la Seguridad Alimentaria (Special Programme for Food Security) PPP purchasing power parity

RED European Union Renewable Energy Directive (Directive 2009/28/EC)

RD\&D Research development and demonstration

RPR Residue-to-Product ratio

SAGARPA Secretaría de Agricultura, Ganadería, Desarrollo Rural, Pesca y Alimentación (Ministry of Agriculture, Livestock, Rural Development, Fisheries and Food)

SNG Synthetic natural gas

SRF short-rotation forestry

$\mathrm{TCl} \quad$ total capital investment

TOE ton of oil equivalent

TPES total primary energy supply

UN United Nations

UNCTAD United Nations Conference on Trade and Development

UNEP United Nations Environment Programme

USD United States dollar

USDA United States Department of Agriculture

USDOE United States Department of Energy

US RFS United States Renewable Fuels Standard

WEO World Energy Outlook 


\section{References}

ABF (Africa Biofuel and Emission Reduction Tanzania Ltd) (2009), "Environmental Comparisons of Croton megalocarpus vs. Other Tropical Feedstocks" in ABF company documents, www.africabiofuel.com/Company Documents.aspx

ABN (African Biodiversity Network) (2007), Agrofuels in Africa: The impacts on Land, Food and Forests - Case studies from Benin, Tanzania, Uganda and Zambia, www.africanbiodiversity.org/media/1210585739.pdf

ABN (2008), "Agrofuels and the Myth of Marginal Lands", Briefing by the GAIA Foundation, Biofuelwatch, ABN, Salva la Selva, Watch Indonesia and EcoNexus, September 2008, www.africanbiodiversity.org/media/1221812708.pdf

ABRAF (Brazilian Association of Forest Plantation Producers) (2008), Statistical Yearbook 2008: Base Year 2007. ABRAF, Brasília, 2008.

ACE (American Coalition for Ethanol) (2009), Ethanol Trade Policy, http://www.ethanol.org/index.php?id=78\&parentid=26

Adams, N., P. Hubbard, N. Marquez, and F. Weiler (2009), "Biofuels and Rural Poor in South Africa: An Examination of the Industrial Biofuel Strategy as a Mechanism for Poverty Reduction and Rural Development", report prepared for the CSIR. School of Advanced International Studies, Johns Hopkins University, Washington DC.

Agra Informa Ltd. (2008), Brazil Agrianual 2008, http://www.agrianual.com.br/prodserv/anuarios/brazil agria.php.

ANP (Agencia Nacional do Petroleo, Gas Natural e Biocombustiveis) (2009), www.anp.gov.br

Antilla, P., T. Karjalainen and A. Asikainen (2009), Global Potential of Modern Fuelwood. Working Paper of the Finish Forest Research Institute, Metla, Finland. http://www.metla.fi/julkaisut/workingpapers/2009/mwp118.pdf

Arias Chalico, T., M. G. García Burgos and G. Guerrero Pacheco (2009), Mexico, Task 2.1: Feedstock production in Latin America, Biofuels Assessment on Technical Opportunities and Research Needs for Latin America, BioTop Project No: FP7-213320 (unpublished).

Bank of Thailand (2009a), Output of Major Agricultural Production, http://www2.bot.or.th/statistics/BOTWEBSTAT.aspx?reportID=83\&language=ENG

Bank of Thailand (2009b), Exchange Rates of Commercial Banks in Bangkok Metropolis (2002-present), http://www2.bot.or.th/statistics/ReportPage.aspx?reportID=123\&language=eng

Bassam, N. El (1998), Energy Plant Species - Their Use and Impact on Environment, James and James (science publishers) Ltd., London.

Bekunda, M., R.L. Victoria, H. Watson, J. Woods, C.A. Palm, C. de Fraiture, P. Leadley, L. Maene, L.A. Martinelli, J. McNeely, M. Otto, and N.H. Ravindranath (2009), "Biofuels in Developing Countries", in R.W. Howarth and S. Bringezu (eds.), Biofuels: Environmental Consequences and Interactions with Changing Land Use, Proceedings of the Scientific Committee on Problems of the Environment (SCOPE), Gummersbach Germany, Cornell University, Ithaca NY, USA, pp. 249-269.

Bellon, M. R., D. Hodson, D. Bergvinson, D. Beck, E. Martinez-Romero and Y. Montoya (2005), "Targeting Agricultural Research to Benefit Poor Farmers: Relating Poverty Mapping to Maize Environments in Mexico", Food Policy 30 (2005), pp. 476-492.

Berndes, G., M. Hoogwijk and R. van den Broek (2003), "The Contribution of Biomass in the Future Global Energy Supply: A Review of 17 Studies." Biomass and Bioenergy, Vol. 25, pp. 1-28. 
BEST (Bioethanol for Sustainable Transport) (2008), Biofuels Impact on Food Prices - A Myth?, http://www.best-europe.org/Pages/NewsLetterPage.aspx?id=501

Biggs, R., E. Bohensky, C. Fabricius, T. Lynam, A. Misselhorn, C. Musvoto, M. Mutale, B. Reyers, R. J. Scholes, S. Shikongo, and A.S. van Jaarsveld (2004), Nature Supporting People: The Southern African Millennium Ecosystem Assessment. CSIR, Pretoria.

Page | 206 Binyuy, W. E. (2007) "Cameroonians Get Involved in Biofuel Cultivation", in BEAHRS - Environmental Leadership Program, Alumni Newsletter, College of Natural Resources, University of Berkley, California.

BNDES (Banco Nacional de Desenvolvimento Econômico e Social) (2005), BNDES destines $R \$ 100$ million to an alternative energy project in Paraná, http://inter.bndes.gov.br/english/news/not038 05.asp

BNDES (2007). Annual report 2007. http://inter.bndes.gov.br

Bradley, D., F. Diesenreiter and E. Tromborg (2009), World Biofuel Maritime Shipping Study, Report prepared for IEA Bioenergy Task 40, http://www.bioenergytrade.org/downloads/worldbiofuelmaritimeshippingstudyapril152009.pdf

Business Standard (2009), IOC May Tie up with US Lab to Produce Biofuel, http://www.businessstandard.com/india/news/ioc-may-tie-upus-lab-to-produce-biofuel/357829/

California Environmental Protection Agency (2009), The California Low Carbon Fuel Standard Regulation, California Air Resource Board, California Environmental Protection Agency, Sacramento.

Cámara de Diputados (2008a), "Distribución del Ingreso y desigualdad en México: un análisis sobre la ENIGH 2000 - 2006" (Income Distribution and Inequality in Mexico: an analysis of ENIGH 2000-2006) www.cefp.gob.mx/intr/edocumentos/pdf/cefp/2008/cefp0092008.pdf

Cámara de Diputados (2008b), "Ley de Promoción y Desarrollo de los Bioenergéticos, Nueva Ley DOF 01-022008" (Law on the Promotion and Development of Bioenergy, New Law DOF 01/02/2008), www.cddhcu.gob.mx/LeyesBiblio/pdf/LPDB.pdf

Cámara de Diputados (2008c), "Impacto del incremento de precios en los alimentos en la pobreza en México" (Impact of rising food prices on poverty in Mexico), www.cefp.gob.mx/intr/edocumentos/pdf/cefp/2008/cefp0452008.pdf

Carrillo (2009a), "Second Generation Biofuels: Challenges and Perspectives in Cameroon", presentation held at the workshop "Potential for Sustainable Production of Second Generation Biofuels", IEA Headquarters, Paris, 9-10 February 2009.

Carrillo (2009b), Expert opinion based on delivered questionnaire, April 2009.

CENBIO (Centro Nacional de Referência em Biomassa) (2009), "Atlas de Bioenergia do Brasil” (Bioenergy Atlas of Brazil), http://cenbio.iee.usp.br/download/atlas cenbio.pdf

Chaves, I.C. (2004), "De Custos de produção de cana" (Sugar cane production costs), Cana Crua: Experiência acumulada. Jaboticaba. UNESP/STAB, Piracicaba.

Cherubini, F., N.D. Bird, A. Cowie, G. Jungmeier, B. Schlamadinger, S. Woess-Gallasch (2009), "Energy- and greenhouse gas-based LCA of biofuel and bioenergy systems: Key issues, ranges and recommendations", Resources, Conservation and Recycling, Vol. 53, pp. 434-447.

Chinability (2009), China's land and resources. http://www.chinability.com/chinas land and resources.htm

CGPL (Combustion Gasification \& Propulsion Laboratory) (2009), Biomass Resource Atlas of India, http://lab.cgpl.iisc.ernet.in/Atlas/

CHOREN Industries GmbH (2008), German Federal Chancellor and Prime Minister of Saxony visit CHOREN, http://www.choren.com/en/choren industries/information press/press releases/?nid=185

CIA (Central Intelligence Agency) (2008), The 2008 World Factbook, https://www.cia.gov/library/publications/the-world-factbook/index.html 
Comite Nacional Sistema-Productos Oleaginosas (2008), "Parámetros productivos nacionales de las principales oleaginosas" (National productivity parameters of major oilcrops), www.oleaginosas.org/archivos/basesdedatos/Parametros\%20productivos\%20nacionales.pdf

Competition Review (2009), Competition Success Yearbook 2009, Competition Review Pvt Ltd, New Delhi.

Cowie, A. (2006), The Role of Soil Carbon in the GHG Balance of Bioenergy Systems, IEA Bioenergy Task 38.

Cowling, R. M., D.M. Richardson and S. M. Pierce (eds.) (1997), Vegetation of Southern Africa, Cambridge Univ. Press, UK.

DBFZ (Deutsches Biomasse Forschungszentrum) (2008), Second Generation Biofuels: Risks and Opportunities for Developing Countries, Background paper prepared by order of the German Technical Cooperation (GTZ), Leipzig.

Demirbas, A. (2004), "Effect of Initial Moisture Content on the Yields of Oily Products from Pyrolysis of Biomass", Journal of Analytical and Applied Pyrolysis, Vol. 71, Iss. 2, pp 803-815.

Department of Resources, Energy and Tourism (2009), Second Generation Biofuels Research and Development Program (Gen2), http://www.ret.gov.au/resources/resources programs/

DGCIS (Directorate General of Commercial Intelligence and Statistics) (2009), Foreign Trade Statistics, Ministry of Commerce and Industry, Government of India. www.dgciskol.nic.in/

Dixon, J., A. Gulliver, and D. Gibbon (2001), "Farming Systems and Poverty", in Hall, M. (ed.) Improving Farmers' Livelihoods in a Changing World, FAO and World Bank, Rome and Washington D.C. 2001, pp 169-214.

DME (Department of Minerals and Energy) (2004), "Assessment of Commercially Exploitable Biomass Resources: Bagasse, Wood \& Sawmill Waste and Pulp, in South Africa", Capacity Building in Energy Efficiency and Renewable Energy, Report No. 2.3.4-29.

DME (2005), Energy Price Report: 2005, www.dme.gov.za/energy/statistics.stm

DME (2007), Biofuel Industrial Strategy of the Republic of South Africa, www.dme.gov.za

DOA (South African Department of Agriculture) (2009), Abstract of Agricultural Statistics 2008, DoA, Pretoria.

Domac, J., K. Richards and S. Risovic (2005), "Socio-economic drivers in implementing bioenergy projects", Biomass \& Bioenergy, Vol. 28, No. 11, pp. 97-106

Dufey, A. (2009), "Towards a Sustainable $2^{\text {nd }}$ Biofuels Generation in Chile", presentation held at the workshop "Potential for Sustainable Production of Second Generation Biofuels", IEA Headquarters, Paris, 9-10 February 2009.

DWAF (2006), Strategic Plan: 2007/08-2009/10, www.dwaf.gov.za/strategicPlan2007.asp

DWAF (2008), Report on Commercial Timber Resources and Primary Roundwood Processing in South Africa 2006/2007, Directorate: Forestry Technical and Information Services, Pretoria, South Africa, www.forestry.co.za/

EC (European Comission) (2008), Directive on the Promotion of Energy from Renewable Sources - Citizens Summary. http://ec.europa.eu/energy/climate actions/doc/2008 res citizens summary en.pdf

ECDC (Eastern Cape Development Corporation) (n.d.), Forestry and Wood Products, www.ecdc.co.za/Forestry

El Mañana (2009), "Aumenta el espacio de ejidos" (Ejidos space increases), www.elmanana.com. $\mathrm{mx} /$ notas.asp?id=112735

EPE (Empresa de Pesiqua Energetica) (2007), National Energy Plan 2030: Biomass (Plano Nacional de Energia 2030: Biomassa). EPE, Brasília.

Essent (2008), Great Potential for Green Energy from Agricultural Residues, www.essent.eu/content/about essent/news/archive/great potential for green energy from agricultur al_residues.jsp 
EUCAR (European Council for Automotive R\&D), CONCAWE (Conservation of Clean Air and Water in Europe) and EC JRC/IES (European Commission Joint Research Centre - Institute for Environment and Sustainability) (2007), Well to Wheels Analysis of Future Automotive Fuels and Powertrains in the European Context, Well-to-Tank Report, Brussels. http://ies.jrc.ec.europa.eu/WTW

Faaij, A., J. van Doorn, T. Curvers, L. Waldheim, E. Olsson, A. van Wijk and C. Daey-Ouwens (1997), "Characteristics and Availability of Biomass Waste and Residues in the Netherlands for Gasification", Biomass and Bioenergy, Vol. 12, No. 4, Elsevier Science Ltd, Great Britain, pp. 225-240.

Faaij, A. (Lead Author) (2007), Potential Contribution of Bioenergy to the World's Future Energy Demand, IEA Bioenergy Strategic Position Paper, IEA Bioenergy:ExCo:2007:02.

FAO (United Nations Food and Agriculture Organisation) (2003), World Agriculture: Towards 2015/2030. An FAO perspective, Earthscan Publications Ltd., London.

FAO (2008a), The State of Food and Agriculture. Biofuels: Prospects, Risks and Opportunities, FAO, Rome.

FAO (2008b), Gender and Equity Issues in Liquid Biofuels Production: Minimizing the Risks to Maximize the Opportunities, www.fao.org/docrep/010/ai503e/ai503e00.HTM

FAO (2008c), The State of Food Insecurity in the World. High Food Prices and Food Security - Threats and Opportunities, $\mathrm{ftp}: / / \mathrm{ftp} . f a o . o r g / d o c r e p / f a o / 011 / \mathrm{i0291e/i0291e00.pdf}$

FAO (2009a), Women and Rural Employment. Fighting Poverty by Redefining Gender Roles, Economic and Social perspectives - Policy Brief No. 5, FAO, Rome.

FAO (2009b), Forest Facts by Country, http://www.fao.org/forestry/country/en/

FAO (2009c), State of the World's Forests 2009, FAO, Rome.

FAO Aquastat (2009), Countries and regions. http://www.fao.org/hr/water/aquastat/countries/index.stm

FAOStat (2009), http://faostat.fao.org

Fargione, J., J. Hill, D. Tilman, S. Polasky and P. Hawthorne (2008), "Land Clearing and the Biofuel Carbon Debt", Science, Vol. 319, pp. 1235-1238

Brazilian Government (2009), About Brazil - Indicators, http://www.brasil.gov.br/ingles/about brazil/indicators/

Fehrenbach, H., U.R. Fritsche and J. Giegrich (2008), “Greenhouse Gas Balances for Biomass: Issues for Further Discussion". Issue paper for the informal workshop, January 25 2008, Brussels.

Fiscal Policy Office Thailand (2009), http://www.fpo.go.th/eng/index2.php

Fischer, G. and L. Schrattenholzer (2001), "Global Bioenergy Potentials Through 2050," Biomass and Bioenergy, Vol. 20, pp. 151-159.

Fischer, G., E. Hizsnyik, S. Prieler, H. van Velthuizen (2007), Assessment of Biomass Potentials for Bio-Fuel Feedstock Production in Europe: Methodology and Results, www.refuel.eu/uploads/media/Refuel-D6Jul2007-final6.pdf

FIVIMS (The Thai Food Insecurity and Vulnerability Information Mapping System) (2005), The Results of the Thailand Analysis, www.asiafivims.net/thailand/fivims/analysis.htm

F.O. Licht (2009), World Ethanol and Biofuels Report, Vol. 2009/7, No. 13.

Forestry South Africa (2007), Industry Statistics Report ex Forestry South Africa: Theoretical Roundwood Supply Situation 2004/05, www.forestry.co.za

Forestry South Africa (2008), Industry Statistics Report ex Forestry South Africa: Forestry and FP Industry Facts 2006/07, www.forestry.co.za 
Fresh Plaza (2008), Thailand: Agricultural research and development need a boost, www.freshplaza.com/news detail.asp?id=24698

GCIS (Government Communication and Information System) (2009), South African Year Book 2008/09, Agriculture and Land Affairs, GCIS, Pretoria, South Africa, pp. 49-79, http://www.gcis.gov.za/resource centre/sa info/yearbook/2008-09.htm

Geoportal (2009), India Land use and Land Cover Map of India . http://www.geoportal.org

GNESD (Global Network on Energy for Sustainable Development) (2006), Urban and Peri-Urban Energy Access in Brazil. www.gnesd.org

Goldemberg, J. and P. Guardabassi (2008), “Are Biofuels a Feasible Option?”, Energy Policy, Vol. 37, pp. 10 - 14.

Gonsalves, J.H. (2006), An Assessment of the Biofuels Industry in India. A United Nations Conference on Trade and Development. UNCTAD/DIT/TED/2006/6, http://www.unctad.org/en/docs/ditcted20066 en.pdf

Gordon, H. (2009): "Agricultural Productivity and Shared Growth", Sustaining and Sharing Economic Growth in Tanzania, The World Bank, Washington, D.C.

Grasoline South Africa (2009), "Pumping Fuel out of Johnson Grass”, Farmer's Weekly, No. 4, April 2009, pp 26-27.

GTZ (Deutsche Gesellschaft für Technische Zusammenarbeit) (German Technical Cooperation) (2005), Liquid Biofuels for Transportation in Tanzania, Potential and Implications for Sustainable Agriculture and Energy in the 21st Century, Study commissioned by the GTZ, Eschborn.

Hall, R. (2004), "Land and Agrarian Reform in South Africa: A Status Report 2004", Programme for Land and Agrarian Studies, Research report, No. 20, University of the Western Cape, Cape Town.

Hargrove, W.L. (2007), Environmental Impacts of Biofuel Production and Processing, http://www.kwo.org/bacs/pp Ethanol Plant Envi Impacts Hargrove Dec2007.ppt

Hassuani, S. J., M. R. Lima Verde Leal and I. de Carvalho Macedo (2005), Biomass Power Generation: Sugar Cane Bagasse and Trash, Piracicaba.

Hoogwijk, M.M., A. Faaij, R. van den Broek, G. Berndes, D. Gielen and W. Turkenburg (2003), “Exploration of the Ranges of the Global Potential of Biomass for Energy", Biomass and Bioenergy, Vol. 25, pp. 119-133.

Hoogwijk, M.M. (2004), On the Global and Regional Potential of Renewable Energy Sources, University Utrecht, Utrecht.

Hoogwijk, M., A. Faaij, B. Eickhout, B. de Vries and W. Turkenburg (2005), “Potential of Biomass Out to 2100, for Four IPCC SRES Land-use Scenarios", Biomass and Bioenergy, Vol. 29, pp. 225-257.

Hönicke, M. and T. Meischner (2009), Landwirtschaft für Tank, Teller, oder Trog - Der Anbau von Agrarkraftstoffen und die Folgen für die Ernährungssicherung in Brasilien und Tansania (Agriculture for tank, plate or trough - Production of agrofuels and the consequences on food security for Brazil and Tanzania), BUKO Agrar Koordination, www.bukoagrar.de/fileadmin/dateiupload/Bilder/ Bildungsmaterial/Buko Agrar Studie FIA e.V. ES-1.pdf

Hurly, K.M., R.J. Lynsky and R.A. Stranack (2003), "Protecting the Privilege of Burning Sugar Cane at Harvest", 4th International Farm Management Congress, Western Australia, Burswood Convention Centre, Perth 10-15 August, 2003.

Ibarra, E. (2007), Improved Energy Crops and Agroforestry Systems in Mexico including cost benefit analysis and best practices, www.competebioafrica.net/publications/publ/COMPETE\%20MEXICO\%20Task\%204.2,\%204.3,\%204.4.pdf

IBGE (Instituto Brasileiro de Geografia e Estatistica) (2008), Social indicators 2008, http://www.ibge.gov.br/home/geociencias/recursosnaturais/levantamento/default.shtm

IBGE (2007), Agricultural database, www.ibge.gov.br 
IEA (International Energy Agency) (2006), World Energy Outlook 2006, OECD/IEA, Paris.

IEA (2007), Good Practice Guidelines: Bioenergy Project Development and Biomass Supply, OECD/IEA, Paris.

IEA (2008a), From 1st- to second-generation Biofuel Technologies: An Overview of Current Industry and RD\&D activities, OECD/IEA, Paris. http://www.iea.org/textbase/papers/2008/2nd_Biofuel_Gen.pdf

IEA (2008b), Energy Technology Perspectives 2008: Scenarios and Strategies to 2050, OECD/IEA, Paris.

IEA (2008c), "Biofuel performance with respect to environmental and other criteria", In: Biofuel Support Policies: An Economic Assessment, OECD, Paris.

IEA (2008d) World Energy Outlook 2008, OECD/IEA, Paris.

IEA (2009a), World Energy Outlook 2009, OECD/IEA, Paris.

IEA (2009b), Medium Term Oil Market Report, OECD/IEA, Paris.

IEA (2009c), Transport, Energy and $\mathrm{CO}_{2}$. Moving Toward Sustainability, OECD/IEA, Paris.

IEA Mobility Model (2009), Internal database, ETP Division, IEA, Paris.

IEA Statistics (2009), IEA statistical database, Energy Statistics Division, IEA, Paris.

IEA Bioenergy Task 39 (2009), Commercializing 1st- and 2nd-generation Liquid Biofuels: Definitions, www.task39.org/About/Definitions/tabid/1761/language/en-US/Default.aspx

IFPRI (International Food Policy Research Institute) (2001), Global food projections to 2020. Emerging Trends and Alternative Futures, IFPRI, Washington D.C.

IFPRI (2009), "Land Grabbing" by Foreign Investors in Developing Countries: Risks and Opportunities, IFPRI Policy Brief, No. 13, IFPRI, Washington, D.C.

Institute for Agriculture and Trade Policy (2006), Water Use by Ethanol Plants. Potential Challenges, www.agobservatory.org/index.cfm?refid $=89449$

Financial Express (2009), India Crosses \$100-bn FDI Mark amid Crisis, http://www.financialexpress.com/news/india-crosses-100bn-fdi-mark-amid-crisis/525005/

International Road Federation (2006), The IRF World Road Statistics 2006, www.irfnet.org/filesupload/statistics-gallery/Samples/2007/Sample_WRS\%20(2).pdf

ISO (International Sugar Organization) (2009), "Outlook on Brazil's Competitiveness in Sugar and Ethanol", International sugar journal, Vol. 111, No. 1327, pp 422-427.

ISTA Mielke GmbH (2008), Oil World Annual Report, ISTA Mielke GmbH, Hamburg.

ISTA Mielke GmbH (2009), Oil World Monthly, Vol. 2009/52, No. 13, ISTA Mielke GmbH Hamburg.

ITC (International Trade Centre) (2009), Tanzania's country profile, www.intracen.org/appli1/TradeCom/TP IP Cl.aspx?RP=834\&YR=2006

ITTO (International Tropical Timber Organisation) (2005), Status of Tropical Forest Management 2005: Mexico, www.itto.int/en/sfm detail/id=12540000

IUCN (International Union for the Conservation of Nature) (2007), "Gender and Bioenergy", Factsheet presented at the COP 13 of the UNFCCC, Bali, December 2007, http://www.genderandenvironment.org/biblioteca/buscador.php

Jagger, A. (2009), "Brazil Invests in Second-Generation Biofuels", Biofuels, Bioproducts and Biorefining, Vol. 3, No. 1 , pp. $8-10$.

Janssen, R. (2006), "Opportunities for Biofuels in Tanzania", presentation in Global Forum on Sustainable Energy, $6^{\text {th }}$ Meeting "Africa is Energizing Itself", 29 Nov-1 Dec, Vienna, Austria. 
JGSEE (The Joint Graduate School of Energy and Environment) (2009), Expert opinion based on delivered questionnaire, April 2009.

John, G.R. and Mhilu C. (2009), Expert opinion based on delivered questionnaire, April 2009.

Kluyts, J.F., F.W.C. Neser and M.J. Bradfield (2007), "Derivation of Economic Values for the Simmentaler Breed in South Africa", South African Journal of Animal Science, Vol. 37, No. 2.

Koopmans, A., and Koppejan, J. (1997), "Agricultural and Forest Residues - Generation, Utilization and Availability", paper presented at the Regional Consultation on Modern Applications of Biomass Energy, Kuala Lumpur, 6 January.

Kline, K.L., G.A. Oladosu, R.D. Perlack, V.H. Dale and M. McMahon (2008), Biofuel Feedstock Assessment for Selected Countries: To Support the DOE study of Worldwide Potential to Produce Biofuels with a Focus on U.S. Imports, ORNL (Oak Ridge National Laboratory), Oak Ridge.

Kraxner, F. (2008), "Resources and Competition between Different Uses", Presentation at IEA Bioenergy ExCo61, Oslo, 14 May.

Krukanont, P. and S. Prasertsan (2005), "Geographical Distribution of Biomass and Potential Sites of Rubber Wood Fired Power Plants in Southern Thailand", Biomass and Bioenergy, Vol. 26, Issue 1, pp. 47-59.

Laohalidanond, K., J. Heil and C. Wirtgen (2006), "The Production of Synthetic Diesel from Biomass", KMITL Science and Technology Journal, Vol. 6, Issue 1, pp. 35-45.

LARRRI (Land Rights Research and Resources Institute) (2008), "Biofuel Development in Africa: Opportunities, Threats and Challenges for Rural Small Holders in Tanzania", report of the forum held at Landmark Hotel, 12 January 2008, Dar es Salaam, Tanzania.

Lattimore, B., C.T. Smith, B.D. Titus, I. Stupak, I. And G. Egnell (2009), "Environmental Factors in Woodfuel Production: Opportunities, Risks, and Criteria and Indicators for Sustainable Practices", Biomass \& Bioenergy, Vol. 33, pp. 1321-1342.

Libert (2007), "Utilisation de I'huile de palme brute dans un groupe électrogène" (Utilisation of palm oil in an electricity generator), presented at the International Conference "Enjeux et Perspectives des Biocarburants pour I' Afrique", Ouagadougou, Burkina Faso, 27-29 November 2007.

Liu X. (1993), Cropping System Zoning in China, Agricultural Press, Beijing.

Macedo, I.C. and L.A.B. Cortez (2000). "Sugar-Cane Industrial Processing in Brazil", in Rosillo-Calle, F.; Bajay, S. V.; Rothman, H. (ed.). Industrial Uses of Biomass Energy. London: Taylor- Francis, p.140-154, 2000.

Macedo, I.C., J.E.A. Seabra and J.E.A.R. Silvac (2008), "Green House Gases Emissions in the Production and Use of Ethanol from Sugar Cane in Brazil: The 2005/2006 Averages and a Prediction for 2020", Biomass and Bioenergy, Vol. 32, pp. $582-595$.

MAFD (Ministry of Agriculture and Food Security) (2009), "Tanzania Government Perspectives on Biofuels", paper presented to the Roundtable Sustainable Biofuels in Nairobi, Kenya, 23-24 March 2009, http://cgse.epfl.ch/page79684.html

Makenete, A., W. Lemmer and J. Kupka, (2007), "The Impact of Biofuel Production on Food Security. A Briefing Paper with a Particular Emphasis on Maize-to-Ethanol Production", Southern African Biofuels Association, 17 September.

Martinez, L. (2006), "Task 3: Overview of Agricultural Aspects", in Sener, BID \& GTZ, "Potenciales y Viabilidad del Uso de Bioetanol y Biodiesel para el Transporte en México" (Potential and fasibility of the use of bioethanol and biodiesel for transport in Mexico), México D.F.

Mathews, J.A. and H. Tan (2009), "Biofuels and Indirect Land Use Change Effects: The Debate Continues." Biofuels, Bioproducts and Biorefining, Vol. 3, No. 3, pp. 305-317. 
MEM (Ministry of Energy and Minerals) (2007), Biomass Energy Situation in Tanzania, www.tatedo.org/publications/reports/biomassenergy.pdf

Meyer, W. and G. Rusk (2003), Financial Analysis and Costs of Forestry Operations: South Africa and Regions, Forestry Economics and Services, Pietermaritzburg.

MIB (Ministry of Information and Broadcasting) (2009), India 2009, A Reference Annual, MIB, Government of India, New Dheli.

Milich L. (2009), "Criteria for a Viable Biofuel Industry in Africa", in ABF company documents, www.africabiofuel.com/Company Documents.aspx

MINEPN (Ministry of the Environment and Protection of Nature Cameroon) (2008), Cameroon Fourth National Report to the Convention on Biological Diversity, http://data.camerounforet.com/fr/system/files/11 03 433.pdf

Ministry of Agriculture, India (2008), Agricultural Statistics at a Glance, http://dacnet.nic.in/eands/latest 2006.htm

Ministry of Commerce and Industry (2009), Fact Sheet on Foreign Direct Investment (FDI) from August 1991 to July 2009, http://dipp.nic.in/fdi statistics/india fdi index.htm

Ministry of Railways (2009), China's railway infrastructure, www.china-mor.gov.cn

MME (Ministry of Mines and Energy, Brazil) (2009), Review comments received on initial draft.

MOA (Ministry of Agricultural of the People's Republic of China) (2007), Agricultural Biomass Energy Industry Development Plan (2007-2015), Beijing.

MOA (Ministry of Agricultural of the People's Republic of China) (2008), China Agricultural Development Report, http://www.agri.gov.cn/sjzl/baipsh/2007.htm

MOF (Ministry of Finance) (2006), On the development of bio-energy and bio-chemical and taxation advice to support the implementation of policies, http://iis.mof.gov.cn/iinjiijianshesi/zhengwuxinxi/zhengcefagui/200805/t20080523 34014.html

Molua, E.L. and C.M. Lambi (2007), "The Economic Impact of Climate Change on Agriculture in Cameroon", Policy Research Working Paper 4364, The World Bank, Washington D.C.

MOSPI (Indian Ministry of Statistics and Programme Implementation) (2007), National Sample Survey Reports 2007, www.mospi.gov.in/mospi nsso rept pubn.htm

MPNG (Ministry of Petroleum and Natural Gas) (2004), Notification of 27th October 2004 to be published in the Gazette of Inida, http://petroleum.nic.in/gaznew.pdf

Mucina, L. and M.C. Rutherford (2006), The Vegetation of South Africa, Lesotho and Swaziland. Strelitzia 19, South African National Biodiversity Institute, Pretoria, South Africa.

Muller, J.L., R.J. Scholes, C.M. Shackleton and D.H.K. Fairbanks (1999), "Chapter 1: Modelling Biomass Potential", in J. Muller (ed.), South African Renewable Energy Resource Database, CSIR Report No. ENV-P-C 98161, Pretoria

NATS (North American Transportation Statistics) (2009), Transportation Infrastructure, http://nats.sct.gob.mx/nats/sys/tables.jsp?i=3\&id=24

NBST (National Bureau of Statistics Tanzania) (2004), Tanzania Agriculture Sample Census 2003, www.nbs.go.tz/

NBTT (National Biofuels Task Team) (2006), National Biofuels Study: An Investigation into the Feasibility of Establishing a Biofuels Industry in the Republic of South Africa, www.dme.gov.za/energy/documents.stm

NDRC (National Development and Reform Commission of the People's Republic of China) (2007a), Renewable Energy Medium and Long-Term Development Plan in China. 
NDRC (2007b), Industrial Catalogue for Foreign Investment, http://www.gov.cn/ziliao/flfg/200711/07/content 798572.htm.

NDT (National Department of Transport) (2001), Road Infrastructure Strategic Framework for South Africa a Discussion Document, www.transport.gov.za/library/docs/rifsa/intro.html

Ndlovu, Z. (2007), "Port Infrastructure and Operational Efficiency, and Port Productivity Management", Presentation held at the PMAESA Maritime Conference, Mahe, Seyshelles. 11-14 December.

NIA (National Innovation Agency) (2009), "Status and Perspective for Second-Generation Biofuels in Thailand", presentation held on the workshop "Potential for Sustainable Production of Second Generation Biofuels", IEA Headquarters, Paris, 9-10 February 2009.

NIS (National Institute of Statistics) (2006), Annuaire Statistique du Cameroun 2006, http://www.statisticscameroon.org/pdf/Yearbook2006/3 part.pdf

Novozymes (2009), Novozymes and Sinopec sign a new second-generation framework agreement in China, www.novozymes.com/en/MainStructure/PressAndPublications/PressRelease/2009/sinopecnovozymes.htm

OECD (Organisation for Economic Co-operation and Development) (2004),Biomass and Agriculture: Sustainability, Markets and Policies, OECD, Paris.

OECD (2008a), "A Review of Policy Measures Supporting Production and Use of bioenergy", www.oecd.org/dataoecd/37/43/41037609.pdf

OECD (2008b), "Producer Support Estimate and related indicators by country", http://stats.oecd.org/WBOS/Index.aspx?QueryName=426\&QueryType=View\&Lang=en

OECD (2008c), "Development in Bioenergy Production Across the World - Electricity, Heat and Second Generation Biofuels", working party on agricultural policies and markets, OECD, Paris.

OECD (2008d), Biofuel Support Policies: An Economic Assessment, OECD, Paris.

OECD (2008e), African Economic Outlook 2008, OECD, Paris.

OECD (2008f), Stat-Extracts. Producer Support Estimate and Related Indicators By Country, http://stats.oecd.org/WBOS/Index.aspx?QueryName=426\&QueryType=View\&Lang=en

OECD and FAO (2009), Agricultural Outtlook 2009-2018, OECD Publishing, Paris.

Oeko-Institut and UNEP (United Nations Environment Programme) (2009), $2^{\text {nd }}$ Joint International Workshop on Bioenergy, Biodiversity Mapping and Degraded Lands. Report on the Workshop Outcomes. http://www.bioenergywiki.net/images/1/15/2nd Paris WS Report.pdf

PEMEX (Petróleos Mexicanos) (2008), 2008 Statistical Yearbook, www.ri.pemex.com/files/content/ING040708.pdf

PEMEX (2009), "Valor del Comercio Exterior de Hidrocarburos y sus Derivados" (Export Value of Hydrocarbons and their Derivates), www.ri.pemex.com/files/dcpe/petro/evolexporta esp.pdf

Petrobras (2009), Petrobras research center, http://www2.petrobras.com.br

Planning Commission (2003), Report of the Committee on Development of Biofuels, http://planningcommission.nic.in/reports/genrep/cmtt bio.pdf

PNUD (Programa de las Naciones Unidas para el Desarrollo) (2007), "Informe sobre desarrollo humano: Mexico 2006-2007. Migración y desarrollo humano" (Human Development Report: Mexico 2006-2007. Migration and human development), Mexico D.F.

Practical Action Consulting (2009), Small-Scale Bioenergy Initiatives: Brief Description and Preliminary Lessons on Livelihood Impacts from Case Studies in Asia, Latin America and Africa. Prepared for PISCES and FAO, FAO, Rome. http://www.fao.org/bioenergy/home/en/ 
Prasertsan, S. and B. Sajjakulnukit (2006), "Biomass and Biogas Bioenergy in Thailand: Potential, Opportunity and Barriers", Renewable Energy, Vol. 31, Issue 5, pp. 599-610.

Presidencia (2008), “México iniciará la producción de etanol en 2010" (Mexico will start producing ethanol in 2010), www.presidencia.gob.mx/prensa/sagarpa/?contenido=38107

Page | $214 \quad$ Exhibition, Brussels, 16 March.

Pordesimo, L. O., S. Sokhansanj and W. C. Edens (2004), "Moisture and Yield of Corn Stover Fractions Before and After Grain Maturity", Transactions of the ASAE, Vol. 47, Iss. 5, pp. 1597-1603.

Qiu, H., J. Huang, J. Yuang, S. Rozelle, Y. Zhang, Y. Zhang, Y. Zhang (2009), "Bioethanol development in China and the potential impacts on its agricultural economy", Applied Energy, Vol 87, No. 1, pp. 76-83.

RAWG (Research and Analysis Working Group of the United Republic of Tanzania) (2007), Poverty and Human Development Report 2007, Published by REPOA (Research on poverty alleviation) for RAWG, Dar es Salaam, Tanzania.

Reinhardt, G. (2006), An Assessment of Energy and Greenhouse Gases of NExBTL. Institute for Energy and Environmental Research GmbH by order of the Neste Oil Corporation, Porvoo, Finland, Heidelberg, June 2006.

Rembio (2009), Expert opinion based on delivered questionnaire, April 2009.

Reuters (2009), Thai Govt Keeps Rice Subsidies but at Cost of Exports, www.flex-newsfood.com/pages/22230/rice/Thailand/thai-govt-keeps-rice-subsidies-cost-exports.html

Department of Resources, Energy and Tourism, Australian Government (2009), Second Generation Biofuels Research and Development Program (Gen2), http://www.ret.gov.au/resources/resources programs/

Rosillo-Calle, F., P. de Groot, S.L. Hemstock and J. Woods (eds.) (2006), The Biomass Assessment Handbook: Bioenergy for a Sustainable Environment, Earthscan Publications Ltd., London.

Rothkopf, G. (2007), A Blueprint for Green Energy in the Americas. Strategic Analysis of Opportunities for Brazil and the Hemisphere, Inter-American Development Bank, Washington D.C.

Rutherford. M. C., G.F. Midgeley, W.J. Bond, L.W. Powrie, R. Roberts, R. and L. Allsopp (1999), "Plant Biodiversity: Vulnerability and Adaptation Assessment", South African Country Study on Climate Change. National Botanical Institute, Cape Town.

SAGARPA (Secretaría de Agricultura, Ganadería, Desarrollo Rural, Pesca y Alimentación) (2009), Caña de Azúcar (Sugar Cane), www.azucar.gob.mx

Sajjakulnukit, B., R. Yingyuad, V. Maneekhao, V. Pongnarintasut, S.C Bhattacharya and P. Abdul Salam (2005), "Assessment of Sustainable Energy Potential of Non-Plantation Biomass Resources in Thailand", Biomass and Bioenergy, Vol. 29, Issue 3, pp. 214-224.

Sassner, P. and G. Zacchi (2008), "Integration Options for High Energy Efficiency and Improved Economics in a Wood-To-Ethanol Process", Biotechnology for Biofuels, Vol. 1. http://www.biotechnologyforbiofuels.com/content/pdf/1754-6834-1-4.pdf

SDTC (Sustainable Development Technology Canada) (2008), NextGen Biofuels Fund, http://www.sdtc.ca/en/funding/index.htm

Seabra, J.E.A. (2008), "Análise de opções tecnológicas para uso integral da biomassa no setor de cana-deaçúcar e suas implicações" (Analysis of technology options for integrated use of biomass in the sugarcane sector and its implications), PhD Tehsis, University of Campinas.

Searchinger, T., R. Heimlich, R.A. Houghton, F. Donng, A. Elobeid, J. Fabiosa, S. Tokgoz, D. Hayes, and T.-H. Yu (2008), "Use of U.S. Croplands for Biofuels Increases Greenhouse Gases through Emissions from Land Use Change", Scienceexpress, 7 February 2008. 
Seeking Alpha, 2009, "Mexico's Credit Rating: Still Investment Grade", http://seekingalpha.com/article/127837-mexico-s-credit-rating-still-investment-grade

Sethi, M. (2006), "Land Reform in India: Issues and Challenges", in Rosset, P., R. Patel and M. Courville (eds.): Promised Land, Competing Visions of Agrarian Reform, Food First, Oakland CA, USA., pp 73-92.

Sezela Cane Grower's Association (n.d.), Statistics and Information, www.scga.co.za/stats.htm

SFA (State Forestry Administration of P. R. China) (2005), Report of Forest Resources in China, China Forestry Publishing Press.

SFA (2007), China Forestry Statistical Yearbook 2007, China Forestry Publishing Press.

Shelton, H. M., and C. Phaikaew (2006), Country pasture / Forage resource profiles Thailand, FAO, www.fao.org/ag/AGP/AGPC/doc/Counprof/Thailand/Thailand.htm

SIAP (Servicio de Información Agroalimentaria y Pesquera) (2009), "Producción Annual“ (Annual Production), www.siap.gob.mx/index.php?idCat=159\&idSegCat $=1$

Smeets, E. and A. Faaij (2007), "Bioenergy Potentials from Forestry in 2050", Climatic Change, Vol. 81, pp. 353-390.

Smeets, E., A. Faaij, I. Lewandowski, W. Turkenburg (2007), “A Bottom-Up Assessment and Review of Global Bioenergy Potentials to 2050", Energy and Combustion Science, Vol. 33, p. 56-106.

SNI (Société Nationale d' Investissement du Cameroun) (2008), "Rapport national d'investissement" (National report of investment), presentation at the conference "L'eau pour l'agriculture et l'énergie en Afrique - les défis du changement climatique", Syrte, Jamahiriya Arabe Libyenne, 15-17 Décembre 2008.

STATS (National Bureau of Statistics of China) (2008a), The Status Quo of China's Population, http://www.gov.cn/test/2005-07/26/content 17363.htm

STATS (2008b), China Statistical Yearbook, China Statistics Press.

STATS (2008c), People's Republic of China 2007 National Economic and Social Development Statistical Bulletin, http://www.stats.gov.cn/tjgb/ndtjgb/qgndtjgb/t20080228 402464933.htm

STATS SA (Statistics South Africa), (2008), Mid Year Population Estimates 2008, Statistical Release P0302, www.statssa.gov.za

Sukumaran, R.K. and A. Pandey (2009), "Bioethanol - Ethanol from Biomass", in Biswas, S., P.R. Basak and N. Kaushik, (eds.), Bioprocesses and Bioproducts: Emerging Trends, Technology Information Forecasting \& Assessment Council (TIFAC), DST, New Delhi, pp. 11-36.

Soumonni, O. and Cozzens, S. (2008), "The Potential for Biofuel Production and Use in Africa: An Adaptive Management Approach", paper presented in the VI Globelics Conference, September 22-24 2008, Mexico City.

TAB (Büro für Technikfolgen-Abschätzung beim Deutschen Bundestag) (2001), Bioenergy sources and developing countries, http://www.tab.fzk.de/en/projekt/zusammenfassung/ab73.htm

Tanzania Invest (2008), Improvements to Tanzania Investment Climate planned, http://www.tanzaniainvest.com/tanzania-economy/news/35-news/136-improvements-to-tanzaniainvestment-climate-planned

TATEDO (Tanzania Traditional Energy Development and Environment Organisation) (2009), Biomass Energy, www.tatedo.org/index.htm

Thaienvimonitor (2009), Water Resources, http://www.thaienvimonitor.net/Database/water.htm

Thai Ministry of Energy, Department of Alternative Energy Development and Efficiency (2008), Alternative Energy Promotion Measures, www.dede.go.th/dede/fileadmin/upload/pictures eng/pdffile/ AE Promotion Measures.pdf 
Thai Ministry of Energy, Department of Alternative Energy Development and Efficiency (2009), Update on biodiesel, www.dede.go.th

The East African (2009), Rice Farmers May Be Evicted by New Biofuel Companies, http://www.theeastafrican.co.ke/news/-/2558/663988/-/item/0/-/nkndig/-/index.html

Tian Y. (2008). Report on biomass resources in China. Chinese Agricultural Academy of Engineering.

TNSO (National Statistical Office of Thailand) (2008), The 2003 Agricultural Census, http://web.nso.go.th/eng/en/agriculture/agr00.htm

Top News (2009), Fitch downgrades Thailand's credit rating after unrest, http://www.topnews.in/fitchdowngrades-thailands-credit-rating-after-unrest-2152319

Transparencia Mexicana (2008), "México, estancado en sus niveles de corrupción Mexicana” (Mexico mired in corruption levels), www.transparenciamexicana.org.mx/documentos/INCBG/2007/Comunicado de prensa INCBG.pdf

Transparency International (2008), 2008 Corruption Perceptions Index, www.transparency.org/news room/in focus/2008/cpi2008/cpi 2008 table

Tyson, P.D. (1986), Climatic Change and Variability Over Southern Africa. Oxford University Press, Cape Town.

Uhlig, A. (2008), "Lenha e carvão vegetal no Brasil: balanço oferta-demanda e métodos para a estimação do consumo" (Firewood and charcoal in Brazil: supply-demand balance and methods for the estimation of consumption). Doctoral Thesis. University of São Paulo.

UCSUSA (Union of Concerned Scientists USA) (2008), Carbon Counts in the 2007 Renewable Fuel Standard, www.ucsusa.org/clean vehicles/solutions/advanced vehicles and fuels/2007-renewable-fuel.html

UNCTAD (United Nations Conference on Trade and Development) (2008), Making Certification Work for Sustainable Development: The Case of Biofuels, UNCTAD, New York and Geneva.

UNDP (United Nations Development Programme) (2007), Human Development Report 2007/2008, Fighting Climate Change: Human Solidarity in a Divided World, published for the UNDP, Palgrave Macmillan Ltd., New York.

UN Energy (United Nations Energy) (2007), Sustainable Bioenergy: A Framework for Decision Makers, http://esa.un.org/un-energy/pdf/susdev.Biofuels.FAO.pdf

UNEP (United Nations Environment Programme) (2009), Towards sustainable production and use of resources: Assessing biofuels, UNEP, Nairobi

UNFCCC (United Nations Framework Convention on Climate Change) (2009), CDM Project Activities, http://cdm.unfccc.int/Projects/registered.html

USDA-FAS (US Department of Agriculture-Foreign Agricultural Service) (2007), Mexico: Bio-Fuels Annual Report 2007, http://www.fas.usda.gov/gainfiles/200706/146291366.pdf

USDA-FAS (2008), GAIN Report N TH8083: Thailand. Bio-Fuels Annual 2008, USDA Foreign Agricultural Service, Bangkok.

USDA-FAS (2009), GAIN Report N TH9047: Thailand. Bio-Fuels. Biofuel's Impact on Food Crops 2009, USDA Foreign Agricultural Service, Bangkok.

USDC (United States Department of Commerce) (2009), India Energy Market, http://www.buyusa.gov/kern/indiaenergyreport.html

USDOE (2008a), World Biofuel Production Potential: Understanding the Challenges to Meeting the U.S. Renewable Fuel Standard, U.S. DOE, Washington, D.C.

USDOE (2008b), DOE Announces Funding Opportunity of up to \$200 Million for Pilot and Demonstration Scale Projects, http://www.energy.gov/news/6817.htm 
Utz, R. (2008), Sustaining and Sharing Economic Growth in Tanzania, The international Bank for Reconstruction and Development / The World Bank, Washington.

Virtual-Brazil.com (2009), Transportation in Brazil, www.v-brazil.com/business/transportation.html

VTT (2007), Bioenergy Technology Review, Vtt, Espoo, Finland.

Wilson, L. (1997), Factors Influencing Energy Use in Urban Transport Sector, A Case study of Dar es Salaam City, University of Dar es Salaam, Dar es Salaam.

Winkler, H. (2006), Energy Policies for Sustainable Development in South Africa. Options for the Future, Energy Research Centre. University of Cape Town. Cape Town.

Wit, M. de (2009), "Costing the Integrated Waste Management Bylaw", keynote address at City of Cape Town Waste Minimisation Summit, The River Club, Observatory, 11 March 2009.

World Bank (2005), Mexico Infrastructure Public Expenditure Review (IPER), World Bank, Washington D.C.

World Bank (2006), The Investment Climate in Brazil, India, and South Africa: A Contribution to the IBSA Debate. World Bank, Washington.

World Bank (2007), Word Development Indicators 2007, World Bank, Washington D.C.

World Bank (2008a), Doing Business 2009. Country Profile for Thailand, www.doingbusiness.org/Documents/CountryProfiles/THA.pdf

World Bank (2008b), Doing Business 2009. Country Profile for Mexico, www.doingbusiness.org/Documents/CountryProfiles/MEX.pdf

World Bank (2008c), Thailand Infrastructure Annual Report 2008, http://siteresources.worldbank.org/INTTHAILAND/Resources/333200-1177475763598/37142751234408023295/5826366-1234408105311/full-report.pdf

World Bank (2009), India Country Overview 2009, http://go.worldbank.org/ZUIBUQT360

World Nuclear Association (2009), Nuclear Power in Brazil, http://www.world-nuclear.org/info/inf95.html Xiao, X. (2005), National Forest Inventory of China, China Forestry Publishing Press.

Xinhua News Agency (2008), People's Republic of China Yearbook, People's Republic of China Yearbook Press. Xinhuanet (2009), China's population, http://news.xinhuanet.com/ziliao/2003-01/18/content 695553.htm.

Zah, R., H. Böni, M. Gauch, R. Hischier, M. Lehmann and P. Wäger (2007), Ökobilanz von Energieprodukten: Ökologische Bewertung von Biotreibstoffen, (Eco-balance of energy products: Ecological evaluation of biofuels), study on behalf of the Swiss Federal Office of Energy and the Federal Office of Agriculture, Bern. 


\section{iea}

\section{International Energy Agency}
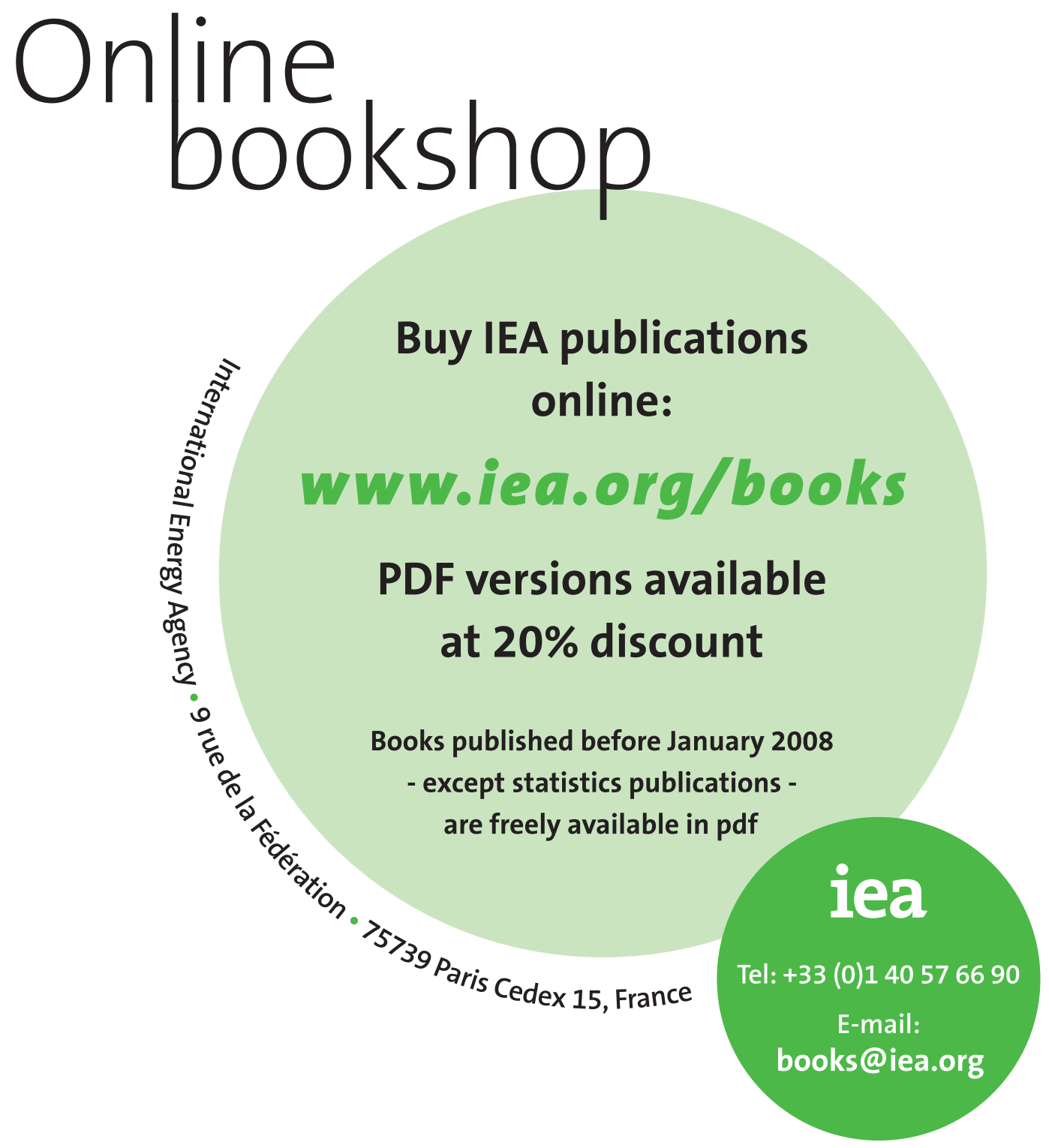


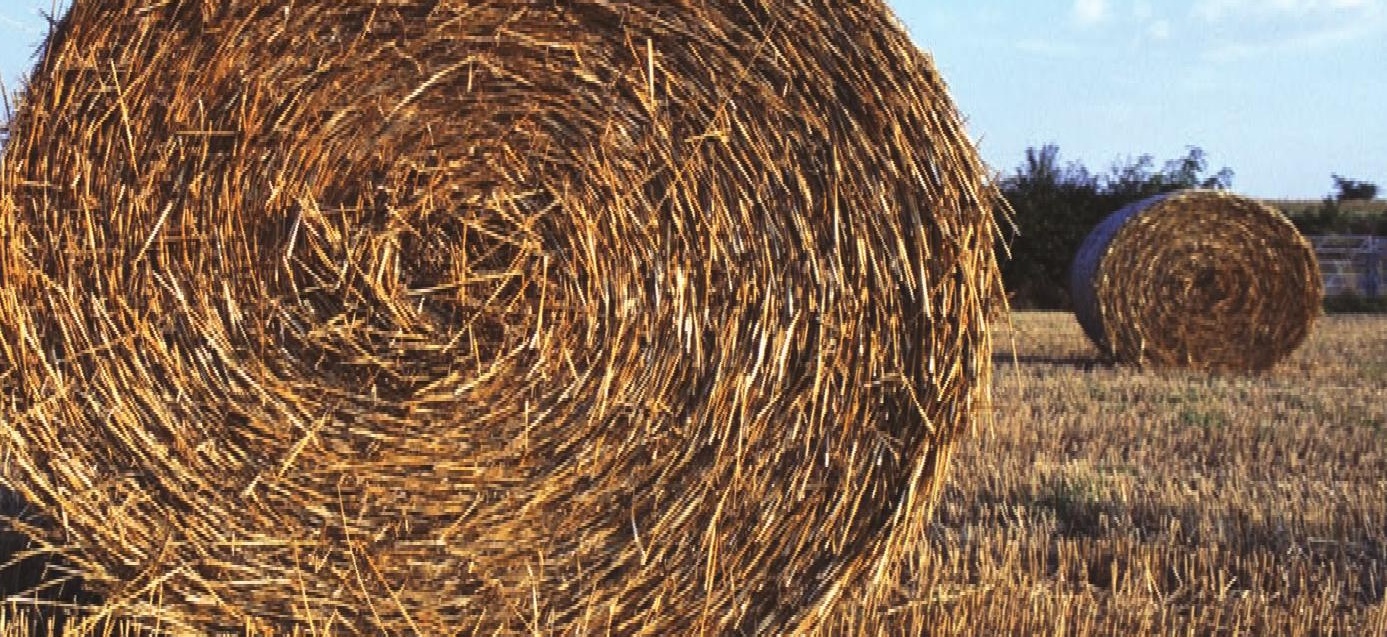

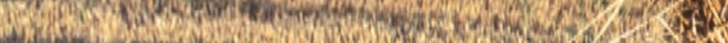

19w

International

Energy Agency

iea

(1) 